\title{
The role of technological advances in sodium prescription and adequacy assessment during hemodialysis
}

Citation for published version (APA):

Moret, K. E. (2011). The role of technological advances in sodium prescription and adequacy assessment during hemodialysis. [Doctoral Thesis, Maastricht University]. Maastricht University.

https://doi.org/10.26481/dis.20110121km

Document status and date:

Published: 01/01/2011

DOI:

10.26481/dis.20110121km

Document Version:

Publisher's PDF, also known as Version of record

Please check the document version of this publication:

- A submitted manuscript is the version of the article upon submission and before peer-review. There can be important differences between the submitted version and the official published version of record.

People interested in the research are advised to contact the author for the final version of the publication, or visit the DOI to the publisher's website.

- The final author version and the galley proof are versions of the publication after peer review.

- The final published version features the final layout of the paper including the volume, issue and page numbers.

Link to publication

\footnotetext{
General rights rights.

- You may freely distribute the URL identifying the publication in the public portal. please follow below link for the End User Agreement:

www.umlib.nl/taverne-license

Take down policy

If you believe that this document breaches copyright please contact us at:

repository@maastrichtuniversity.nl

providing details and we will investigate your claim.
}

Copyright and moral rights for the publications made accessible in the public portal are retained by the authors and/or other copyright owners and it is a condition of accessing publications that users recognise and abide by the legal requirements associated with these

- Users may download and print one copy of any publication from the public portal for the purpose of private study or research.

- You may not further distribute the material or use it for any profit-making activity or commercial gain

If the publication is distributed under the terms of Article 25fa of the Dutch Copyright Act, indicated by the "Taverne" license above, 
The role of technological advances in sodium prescription and adequacy assessment during hemodialysis 
(C) Marcella van Leeuwen, Maastricht

Layout: Tiny Wouters

Production: Datawyse | Universitaire Pers Maastricht

ISBN: 978-94-6159-029-9

The financial support for the printing of this thesis, received from the following companies, is gratefully acknowledged: Abbott BV, Amgen BV, Baxter BV, Cair Nederland BV, Esaote-Pie Medical BV, Fresenius Medical Care BV, Gambro-Hospal BV, Roche Nederland BV, Shire, Transonic Systems Europe BV. 


\title{
The role of technological advances in sodium prescription and adequacy assessment during hemodialysis
}

\author{
PROEFSCHRIFT \\ Ter verkrijging van de graad van doctor \\ aan de universiteit van Maastricht, \\ op gezag van de Rector Magnificus, \\ Prof. mr. G.P.M.F. Mols, \\ volgens het besluit van het College van Decanen, \\ in het openbaar te verdedigen \\ op vrijdag 21 januari 2011 om 16.00 uur \\ door \\ Karin Elisabeth Maria Moret \\ Geboren op 21 april 1968 in Eindhoven
}

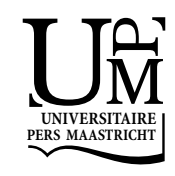




\section{Promotor:}

Prof. dr. K.M.L. Leunissen

\section{Copromotores:}

Dr. J.P. Kooman

Dr. C.H. Beerenhout, Maxima Medisch Centrum, Veldhoven

\section{Beoordelingscommissie:}

Prof. dr. A.P.G. Hoeks (voorzitter)

Dr. P.J. Blankestijn, UMC Utrecht

Prof. dr. J.P. van Hooff

Prof. dr. R.P. Koopmans

Dr. P. Kotanko, Renal Research Institute, New York 
Voor Papa 



\section{Contents}

Chapter 1 Introduction 9

Chapter 2 Aim and outline of the thesis $\quad 35$

Chapter 3 Ionic mass balance and blood volume preservation during a high, $\quad 39$ standard, and individualized dialysate sodium concentration

Chapter $4 \quad$ Variations in pre-dialytic plasma conductivity in dialysis patients: $\quad 53$ effect on ionic mass balance, blood pressure and interdialytic weight gain

Chapter 5 The effect of sodium profiling and feedback technologies on plasma conductivity and ionic mass balance: a study in hypotension-prone dialysis patients

Chapter 6 Conductivitypulses needed for Diascan ${ }^{\circledR}$ measurements: Does it cause sodium burden?

Chapter 7 Agreement between different parameters of dialysis dose in achieving treatment targets: results from the NECOSAD study.

Chapter 8 Ionic dialysance and the assessment of Kt/V: the influence of different estimates of $\mathrm{V}$ on method agreement

Chapter 9 Summary and discussion

Samenvatting en conclusies

Dankwoord

Curriculum Vitae 



\section{Chapter 1}

Introduction

The role of technological advances in sodium prescription and adequacy assessment during hemodialysis 
Chapter 1 


\section{Introduction}

\section{The role of technological advances in sodium balance and urea removal during hemodialysis}

Regulation of water and electrolyte balance and excretion of uremic waste products belong to the predominant functions of the kidney. In patients with end-stage renal failure, dialysis has to substitute for these functions.

The most frequently used method for chronic dialysis treatment is hemodialysis. During hemodialysis, blood is separated from dialysis fluid, a highly purified solution with a mix of electrolytes and bicarbonate, by a semi permeable membrane (the dialyzer). During hemodialysis, uremic waste products and excess electrolytes, such as potassium, are removed by diffusion form the blood to the dialysis fluid, whereas water is removed by ultrafiltration (which occurs by application of a hydrostatic pressure gradient over the dialyzer). Hemodialysis is generally performed for a minimum of 3 times per week, 4-5 hours per treatment. During this treatment blood flows at a rate of $300 \mathrm{ml} / \mathrm{min}$, whereas dialysis fluid flows, counter currently, at a rate of $500 \mathrm{ml} / \mathrm{min}$ or higher.

This thesis focuses on these two major issues which, even after nearly 50 years of chronic dialysis therapy, still remain a subject of controversy in the literature, i.e. the regulation of sodium balance as well as the monitoring of dialysis adequacy in terms of urea removal.

Especially, the role of recent technological advances in monitoring and prescribing

1. sodium balance during hemodialysis, as well as

2. dialysis adequacy will be the scope of investigation. 


\section{Sodium balance during hemodialysis}

\section{Sodium and water loading in dialysis patients}

One of the main tasks of the kidney is to regulate sodium and water homeostasis, which it performs by a fine-tuned balance between filtration, reabsorption and secretion. In patients with end stage renal failure treated with hemodialysis, this complex role of the kidney is substituted by an artificial extracorporeal system. This is not an easy task given the fact that the normal kidney is working continuously (168 hours per week). The artificial system has to equalise this task in 12-15 hours per week. The removal of relatively large amounts of water and sodium in such a short period of time may contribute to intra-dialytic hypotensive episodes, which is a serious limitation in the realization of "dry weight". Moreover, adherence to a sodium restricted diet, which might aid in reducing inter-dialytic weight gain, is often difficult for dialysis patients to maintain, also given the fact that sodium is present in many prefabricated foods ${ }^{1}$.

It is therefore not surprising that volume overload is very common in hemodialysis patients ${ }^{2}$. This chronic volume overload plays a major role in the pathogenesis of hypertension and subsequently left ventricular hypertrophy in dialysis patients ${ }^{3}$. Recently, overhydration was shown to be directly related to mortality in dialysis patients ${ }^{4}$.

The main effect of a high dietary salt intake on blood pressure and volume control in dialysis patients may be mediated by an increase in plasma osmolality and thirst, leading to increased fluid intake. However, there are also arguments for an independent effect of sodium on blood pressure control and cardiovascular structure and functioning in patients with end stage renal failure. This may be related to disturbances in activity and or response to various neurohumoral changes, such as the renin-angiotensin and sympathetic nervous systems, Na-K-ATP-ase inhibitors, and the nitric oxide system in patients with end-stage renal failure ${ }^{5,6}$.

The presence of an "osmotically inactive" sodium pool has recently been the focus of interest, although these observations have not yet been extrapolated to clinical practice $^{7}$. Also, the relative importance of the volume independent pressor effects of sodium in patients with end stage renal disease is still not yet completely elucidated ${ }^{6,7}$. Nevertheless, it is well known that a sodium restricted diet is of great importance in the treatment of hypertension and may finally result in reduction of left ventricular hypertrophy in dialysis patients ${ }^{8}$. However, the dialysis treatment itself plays also a very important role in sodium balance during dialysis.

\section{Sodium removal during dialysis: theoretical considerations}

During dialysis, sodium transport over the dialyzer occurs both by convection as well as by diffusion. The relative magnitude of convection is, in general, higher as compared to diffusion, although data on this subject are limited in the literature. 
Given the high importance of volume and sodium homeostasis in hemodialysis patients, there are surprisingly few data on sodium balance during dialysis. This might be partly due to the complexity of the subject. Sodium flux across the dialyzer is dependent on various factors, such as the rate and amount of ultrafiltration, the difference between the ionized sodium concentration in plasma water and dialysate, the concentration of sodium in dialysate and the Donnan factor (the attractive force for positive ions by the negative loading of plasma proteins which cannot pass the dialysis membrane) ${ }^{9}$.

Sodium concentrations may be measured either in plasma or in plasma water, by different methods such as flame photometry, indirect ionometry and direct ionometry. The use of these different measure methods makes it difficult to compare studies. Additionally there is no consensus in what the preferred measuring method of sodium in plasma is, which makes the literature on this subject somewhat complicated.

The amount of sodium removed by convection is related to the volume of water removed during ultrafiltration, i.e. more or less equal to the product of the ultrafiltration volume and plasma sodium concentration. Due to the Donnan effect, the sodium concentration in the ultrafiltrate may be somewhat lower than the sodium concentration in plasma water ${ }^{9,10,11}$, although large ultrafiltration volumes do not necessarily change the so-called "hydrosodium balance" (the relation between sodium and water in the body) ${ }^{10}$.

The principle of sodium removal by diffusion is more complicated. Diffusion of sodium between blood and dialysate is dependent on the sodium concentration in plasma water and in dialysate. Under normal circumstances, sodium concentration in plasma water is approximately 7\% (approximately $10 \mathrm{mmol} / \mathrm{l}$ ) higher as compared to the concentration in plasma, due to the fact that the volume of plasma is higher than the volume of plasma water. This is caused by the fact that $\pm 7 \%$ of plasma consists of plasma proteins. As proteins are not present in dialysate, a relatively large diffusion of sodium from patient to dialysate would be expected if sodium concentration in dialysate would equal plasma sodium concentration ${ }^{9,10}$. However, diffusion of sodium from patient to dialysate is hampered by the Donnan effect, i.e. the attraction of positively loaded ions by the negatively charged plasma proteins. The extent of the Donnan effect has been estimated around 5-10 $\mathrm{mmol} / \mathrm{I}^{11}$. Also the binding of sodium with anions which might reduce the sodium "activity" available for diffusion ${ }^{10}$, may be somewhat higher in plasma as compared to dialysate. In plasma water, it is assumed that $\pm 7 \mathrm{mmol} / \mathrm{l}$ of the total sodium concentration of $\pm 150 \mathrm{mmol} / \mathrm{l}$ sodium is in a bound form versus $\pm 4 \mathrm{mmol} / \mathrm{l}$ in dialysate ${ }^{9,10}$.

Locatelli et al. showed that no net diffusive sodium transport between blood and dialysis fluid occurs when sodium concentration in plasma, as measured by flame photometry, is $\pm 2 \mathrm{mmol} / \mathrm{l}$ lower than sodium concentration of dialysate. This roughly corresponds to a difference in sodium activity between plasma water and dialysate of $4 \mathrm{mEq} / \mathrm{l}$ and to a Donnan effect in hemodialysis of $0.97^{9}$. These findings are in 
agreement with those of van Stone et al, who observed "isonatremic" dialysis treatments (i.e. no change in the hydrosodium balance) when the sodium concentration in the dialysate was $2 \%$ higher as compared to the plasma sodium concentration $^{12,13}$.

On the other hand, Flanigan showed net sodium gain when a patient with a plasma sodium concentration of $138 \mathrm{mmol} / \mathrm{l}$ was dialyzed against a dialysate sodium concentration of $140 \mathrm{mmol} / \mathrm{l}$. The different findings between these studies might be due to the fact that the Donnan effect is not completely predictable due to coating of proteins of the dialysis membrane ${ }^{11,12}$. It can be expected that diffusive influx of sodium might occur with supraphysiologic dialysate sodium concentrations and in patients with low predialytic plasma sodium concentrations ${ }^{13,14}$. However, exact data on sodium balance during dialysis are surprisingly scarce in the literature.

\section{How can sodium balance be measured during dialysis?}

Sodium removal during dialysis therapy can be assessed by measuring sodium concentration in the fresh dialysis fluid and the spent dialysate (direct dialysis quantification) by the following formula:

$\mathrm{V}_{\text {out }} \times \mathrm{C}_{\text {out }}-\mathrm{V}_{\text {in }} \times \mathrm{C}_{\text {in, }}$ in which

$\mathrm{V}_{\text {out }}=$ volume of spent dialysate,

$\mathrm{C}_{\text {out }}=$ concentration of solute in spent dialysate,

$\mathrm{V}_{\text {in }}=$ volume of fresh dialysate,

$C_{\text {in }}=$ concentration of solute in fresh dialysate ${ }^{14,15}$.

This impractical approach is only feasible for research purposes (collection of \pm 120 litres of dialysate per treatment in a container at the dialysis unit) and not useful for daily clinical practice. Sodium removal (or intake) may also be reflected by changes in body weight and intradialytic (or, respectively, interdialytic) changes in plasma water sodium concentration by the following formula ${ }^{17,18}$ :

$=$ predialysis total body sodium - postdialysis total body sodium

$=$ predialysis plasma sodium $\times((0.58 \times$ target weight $)+$ ultrafiltration volume $)$

- postdialysis plasma sodium $\times(0.58 \times$ target weight $)$

However, this formula assumes that total body water is $58 \%$ of body weight in dialysis patients, which is not necessarily correct in (all) dialysis patients ${ }^{19}$.

Additionally, although both methods are basically physiologically sound, it is hampered by the variability of the different sodium measurements. It has been stated that an acceptable level for the variation coefficient of flame photometry and ionselective electrodes is 1.0 and $1.4 \%$, respectively ${ }^{20,21}$. Although this is quite acceptable for clinical purposes, a difference of $2.8 \mathrm{mmol} / \mathrm{l}$ between pre- and post plasma sodium concentration might reflect a major change in the hydrosodium balance, but might also be entirely explained by a variation in the methodology. Sodium removal during hemodialysis can also be estimated with single-pool kinetics, for which successful 
models have been developed ${ }^{22-24}$. Although not easily applied to daily clinical practice due to their complexity, these models played an important role in the development of measurement and feedback systems which are able to measure and model plasma conductivity, and assess ionic mass balance during hemodialysis (see below).

\section{How to measure sodium in plasma and dialysate?}

When discussing sodium concentration in plasma and dialysate, it is important to reflect shortly on the different methods available to measure sodium. It is important to distinguish between sodium concentration and sodium activity. Whereas the sodium concentration reflects the total amount of sodium divided by the distribution volume, sodium activity refers to ionic activity, which is the relevant fraction for diffusion ${ }^{2,7,10}$.

Flame photometry is based on the principle that each element has its own specific spectrum of emission. After excitation, by an increase in temperature, electrons are transferred from a lower to a higher energy state. After returning to the lower energy state, the electrons emits a photon with a characteristic wavelength, which may correspond to a colour in the visible spectrum (e.g. yellow in case of sodium). Using flame photometry to detect plasma sodium, the change in intensity of a flame color after introduction of a plasma sample is assessed. Flame photometry measures total sodium concentration (i.e. the ionic concentration plus the amount bound with anions) in a plasma sample with a known volume. Normally plasma consists for $93 \%$ of water and for $7 \%$ of proteins and lipids. Thus, as flame photometry measures sodium in a sample of plasma (and not of plasma water), spuriously low plasma levels may be reported if the concentration of proteins or lipids in plasma increases (pseudohyponatremia). In dialysate, the flame photometry measures total sodium concentration, and due to the absence of significant proteins, pseudohyponatremia is not a concern.

In contrast to flame photometry, direct ionometry measures sodium activity in plasma water, irrespectively of the volume in which sodium is dissolved. The sodium activity is converted into sodium concentration using the activity coefficient of the solution ${ }^{11}$. Due to the fact that $6-7 \%$ of the volume in plasma is taken by lipids and proteins (see above), the concentration of sodium in plasma water is 6-7\% higher as compared to the concentration in plasma (i.e. $\pm 149-150 \mathrm{mmol} / \mathrm{l}$ as compared to $140 \mathrm{mmol} / \mathrm{l}$ ). Sodium activity may be lower than the actual concentration due to the bonding of sodium with anions such as bicarbonate. Also in dialysate, sodium activity is lower ( $\pm 4 \mathrm{mmol} / \mathrm{l}$ ) as compared to the sodium concentrations due to bonding of sodium with anions such as bicarbonate. Therefore, sodium concentration values reported in dialysate by direct ionometry may be lower as compared to the values of flame photometry ${ }^{25}$.

Many laboratories use indirect ionometry to measure sodium in plasma and dialysate. Using indirect ionometry, a sample of plasma (not plasma water) is diluted and all 
sodium present in the sample is ionized due to addition of a buffer, which brings the activity coefficient nearly to 1.0. Therefore indirect ionometry reflects the total sodium concentration in plasma and dialysate, and its values are comparable to those of flame photometry ${ }^{25,26}$. The fact that the concentration is expressed in a known sample of plasma (instead of in plasma water, as with direct ionometry) also means that with indirect ionometry, pseudohyponatremia can occur, a phenomenon that is not observed with direct ionometry.

The use of different measurements of sodium concentration may thus have an effect on the assessment of sodium removal during dialysis, when using dialysate collections. In peritoneal dialysis, it has been shown that due to the bonding of sodium with anions in the dialysate in the course of a dwell (again: the complex is not measured), direct ionometry may underestimate sodium removal during dialysis as compared with flame photometry, whereas indirect ionometry yields results comparable to flame photometry ${ }^{25}$. The different methods to estimate sodium removal have not been compared yet during hemodialysis. However, as the concentration of e.g. bicarbonate in the dialysate may change during the course of the dialysis treatment, it is likely that the use of direct ionometry to assess sodium balance by direct dialysis quantification would also lead to different values as compared to flame photometry or indirect ionometry.

In order to gain more insight into sodium balance during hemodialysis, frequent assessment of plasma sodium is mandatory. However, this is complicated by the need for blood sampling. Therefore, there is a need for reliable, non-invasive methodology by which plasma sodium and sodium balance can be assessed on a treatment-totreatment basis.

\section{Conductivity and ionic mass balance measurements in the assessment of sodium balance}

Conductivity of a solution is the ability to conduct an electrical current. In a watery solution, conductivity is related to ion content. It has been shown that a linear relation exists between the sodium content and conductivity of dialysate and plasma (water) $^{27,28,29}$. Therefore, it has been postulated that conductivity can substitute for sodium concentration in plasma and dialysate ${ }^{27}$. Plasma conductivity (PC) can be assessed non invasively by measurement of ionic dialysance (D). In turn, ionic dialysance is assessed by measurement of dialysate conductivity at the dialyzer inlet $\left(\mathrm{Cd}_{\text {in }}\right)$ and outlet $\left(\mathrm{Cd}_{\text {out }}\right)$ after changing the dialysate inlet concentration (i.e. the smaller the change in conductivity at the dialysate outlet after changing the dialysate inlet concentration, the higher the ionic dialysance, due to transport over the dialyzer). 


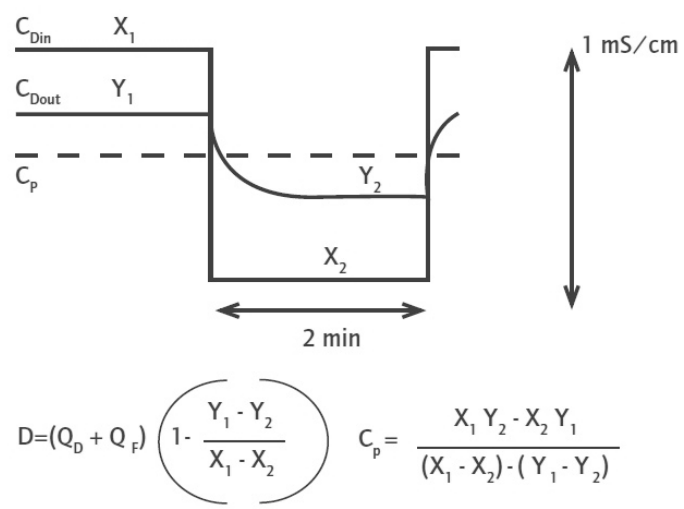

Figure 1.1 Scheme of the record of the inlet and outlet dialysate conductivity during a measurement of ionic dialysance where $X_{1}$ and $X_{2}$ are the two given values of inlet dialysate conductivity, $Y_{1}$ and $Y_{2}$ the two measured values of outlet dialysate conductivity and $C_{p}$ the representation of the patient's plasma conductivity. $Q_{D}$ is dialysateflow, $Q_{F}$ ultrafiltration rate.

The conductivity model does not need to take the Donnan effect into account, because conductivity is determined by both positive and negative ions in the solution $^{25}$. As will be discussed later, the conductivity kinetic model can substitute for the sodium kinetic model in predicting post-dialytic plasma conductivity (as a substitute for sodium).

With the Diascan module in the Hospal Integra device, plasma conductivity (PC) is calculated by measuring ionic dialysance (D) in combination with dialysate flow (Qd) and dialysate conductivity measurements at the dialyzer inlet $\left(\mathrm{Cd}_{\text {in }}\right)$ and outlet $\left(\mathrm{Cd}_{\text {out }}\right)$, according to the formula:

$$
P C=\left[C_{\text {out }}-\left(1-D / Q d_{\text {in }}\right) \times C d_{\text {in }}\right] /\left(D / Q d_{\text {in }}\right) \text {. }
$$

$D$ is assessed every 30 min during dialysis treatment by measuring the increase in $\mathrm{Cd}_{\text {out }}$ after a temporary increase in $\mathrm{Cd}_{\text {in }}$ by $1 \mathrm{mS} / \mathrm{cm}$ according to the formula:

$$
D=\left(Q d_{\text {in }}+Q f\right) \times\left[1-\left(C d_{\text {out }} 1-C d_{\text {out }} 2\right) /\left(C d_{\text {in }} 1-C d_{\text {in }} 2\right)\right]^{27,28,30} \text {. }
$$

1 and 2 indicate, respectively measurements before and after the temporary increase in $\mathrm{Cd}_{\text {in }}$ respectively, $Q \mathrm{~d}_{\text {in }}$ is dialysate flow at inlet and $\mathrm{Qf}$ is ultrafiltration rate.

Empirically, plasma sodium was shown to be approximately $4 \mathrm{mmol} / \mathrm{l}$ lower than PC multiplied by $10^{27}$, whereas sodium concentration in plasma water is slightly higher than PC $\times 10^{28}$. As will be discussed later, ionic dialysance is strongly related to urea clearance, and therefore this method has also been introduced for assessment of dialysis adequacy. 
In addition, sodium balance can be approximated by assessing ionic mass balance (IMB) by constant measurement of the conductivity in the dialysis outlet and inlet according to the formula:

$$
\text { IMB }=\left[\left(Q_{d_{\text {out }}} \times C_{d_{\text {out }}}\right)-\left(Q d_{\text {in }} \times C d_{\text {in }}\right)\right] \times 10 \times \text { time }(\mathrm{min})
$$

$\mathrm{Qd}_{\text {out }}=$ dialysate flow at outlet

$\mathrm{Cd}_{\text {out }}=$ dialysate conductivity at outlet

$\mathrm{Qd}_{\text {in }}=$ dialysate flow at inlet

$\mathrm{Cd}_{\text {in }}=$ dialysate conductivity at outlet

Although the sodium concentration is by far the greatest determinant of dialysate conductivity $^{29}$ the transfer of other ions such as potassium or bicarbonate might also influence ionic mass removal during dialysis.

The relation between sodium removal (estimated from pre- and postdialytic plasma sodium measurements, using the formula described above) and ionic mass balance was assessed by Lambie et al. The $r^{2}$ between both methods was 0.66 whereas IMB underestimated sodium loss by $14.8 \pm 3.3 \%$ compared to the reference method. Still, also the inherent variation in plasma sodium measurements (see above) should be taken into account when assessing sodium balance by means of pre- and post-dialytic plasma sodium concentrations. Until now, IMB has not yet been validated using direct dialysis quantification.

\section{The use of dialysate sodium in clinical practice}

During dialysis, water and sodium are removed by controlled ultrafiltration resulting from the application of a hydrostatic gradient over the dialyzer. In contrast, due to their structure (the small surface area and the lack of permeability of the membrane), early dialysis systems were incapable of controlled ultrafiltration ${ }^{31}$. Water and sodium were removed by osmotic ultrafiltration, by using a high concentration of glucose in the dialysate (comparable to the ultrafiltration mechanism of peritoneal dialysis), in combination with a low sodium concentration of the dialysate $(126 \mathrm{mmol} / \mathrm{l})$. Dialysis treatment time in the earlier days of dialysis was much longer compared to the current policy of time (often $>8$ hours/treatment versus 3 to 4 hours/treatment). The improved design of the dialyzer, blood pumps, and negative pressure dialysis modules, made removal of sodium and water by controlled ultrafiltration possible. Solute clearance was increased by using larger dialyzer surface areas, which permitted shortened dialysis times. The high clearance of uremic solutes resulted in rapid changes in plasma osmolality. This provoked the so-called dialysis disequilibrium syndrome, characterized by fatigue, nausea, muscle cramps and, in severe cases, brain oedema due to water transport from extracellular to intracellular compartment. In order to prevent the disequilibrium syndrome, and because low sodium dialysate was no longer necessary for sodium and water removal, dialysate sodium concentration was increased gradually to $130-135 \mathrm{mmol} / \mathrm{l}$ in the early eighties ${ }^{10}$, which reduced the 
osmotic shift of water from the extracellular to the intracellular compartments. However, due to the decrease in dialysis time to approximately 4 hours, water and sodium had to be removed in a shorter time period, resulting in an increased risk of episodes of intra-dialytic hypotension.

A decline in blood volume during hemodialysis plays an important role in the pathogenesis of intra-dialytic hypotension. The decline in blood volume during dialysis is a resultant of the ultrafiltrated volume and refill from the interstitial compartments. With increased dialysate sodium concentrations, fluid shifts from the intracellular compartments to the extracellular and intravascular compartments is increased. This has led to the prescription of higher dialysate sodium concentrations. In a recent survey of Davenport et al. in 439 chronic dialysis patients, 251 were treated with a dialysate sodium concentration of $140 \mathrm{mmol} / \mathrm{l}, 132$ with a concentration of $137-139 \mathrm{mmol} / \mathrm{l}$, and 52 with a concentration of $136 \mathrm{mmol} / \mathrm{I}^{32}$. In the Netherlands* also different dialysate sodium concentrations are used in clinical practice:

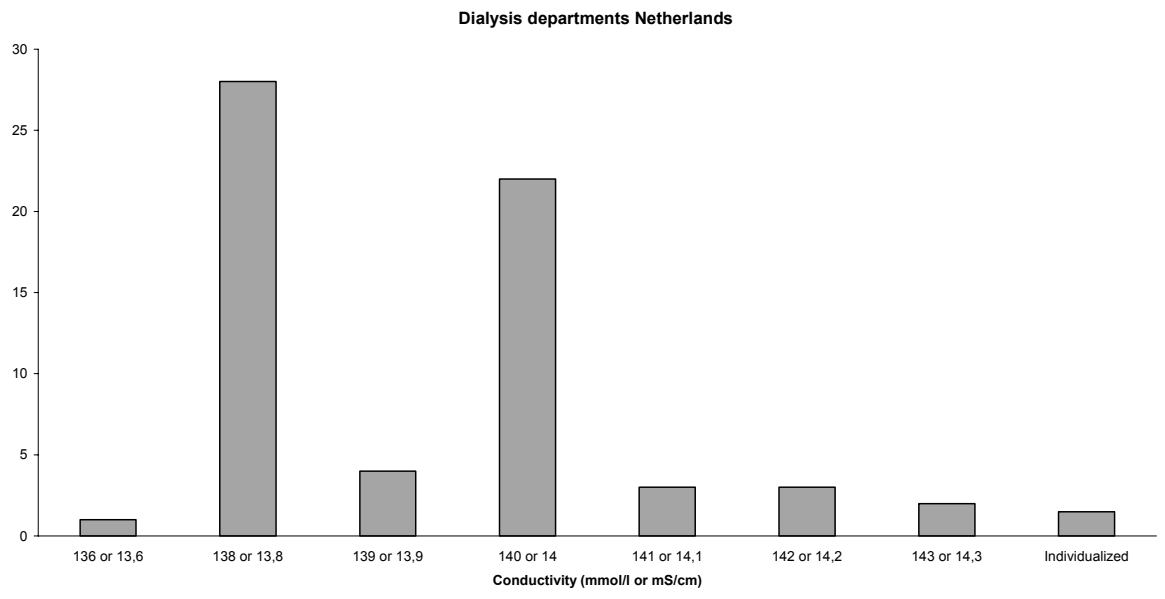

* In general, dialysate conductivity of $14.0 \mathrm{~ms} / \mathrm{cm}$ corresponds approximately to dialysate sodium concentration of $140 \mathrm{mmol} / \mathrm{l}$ with standard dialysate bicarbonate concentration of $34 \mathrm{mmol} / \mathrm{l}$. In case of higher or lower dialysate bicarbonate concentration the conductivity will slightly differ

\section{Dialysate sodium as a tool to prevent intra-dialytic hypotension}

Despite changes in dialysis prescription, such as the use of lower dialysate temperatures, the appearance of intra-dialytic hypotensive episodes in dialysis patients is still regularly. Intra-dialytic hypotension not only results in patient discomfort but also may increase the risk of myocardial and cerebral ischemia ${ }^{33}$. Probably due to an improved refill of plasma volume by increasing tonicity of the extracellular compartment, the use of high dialysate sodium concentrations $(>144 \mathrm{mmol} / \mathrm{l})$ resulted in a reduction in intra-dialytic hypotension in some ${ }^{34,35}$, but 
not in all studies ${ }^{36}$. A beneficial effect on hemodynamic stability during dialysis was also observed for sodium profiles, in which dialysate sodium is modelled (most often from values up to $150 \mathrm{mmol} / \mathrm{l}$ at the start of dialysis to $140 \mathrm{mmol} / \mathrm{l}$ at the end of dialysis) ${ }^{34,37}$. Various studies found a reduction in intra-dialytic hypotension with the use of sodium profiles ${ }^{34,37,38}$ which are also mentioned as a therapeutic option by K-DOQI guidelines ${ }^{39}$.

However, sodium profiles may not be effective in all patients with frequent intradialytic hypotension ${ }^{40}$. Unfortunately the use of both, high sodium dialysate and sodium profiles may lead to increased thirst, inter-dialytic weight gain, and hypertension $^{36,38,40,41}$. Few studies have addressed this long term effect of sodium profiles on sodium balance and plasma sodium concentration in dialysis patients. Therefore, the use of sodium profiles in the prevention of intra-dialytic hypotension is still a matter of controversy ${ }^{33}$.

\section{Individualization of dialysate sodium, variation in plasma sodium concentration}

In order to prevent possible patient discomfort due to either diffusive sodium loading from dialysate to patient (cellular overhydration) or excessive diffusive sodium loss (intradialytic hypotension), individualization of the dialysate sodium might be a solution. This so-called zero hydrosodium balance causes removal of the exact quantity of sodium that has accumulated in the inter-dialysis period to reach a zero balance $^{42}$. Prescribing dialysate sodium as the plasma sodium concentration was found to improve both hemodynamic stability during dialysis as well as inter-dialytic blood pressure control ${ }^{43}$. For the prescription of individualized sodium dialysis, the pre-dialytic plasma concentration has to be known ${ }^{40}$. Therefore the use of individualized sodium prescription would be facilitated if pre-dialytic plasma sodium was found to be a stable entity.

Indeed, a fixed sodium set point is assumed by various authors ${ }^{11,44,45}$. Although predialytic plasma sodium appeared to be relatively stable in a small study of Flanigan et al., the coefficient of variation in a cohort of non-diabetic dialysis patients during 12 consecutive months was $2 \%$. Whereas this appears small, it corresponds to a range of $137-143 \mathrm{mmol} / \mathrm{l}$ in a patient with a mean pre-dialytic plasma sodium concentration of $140 \mathrm{mmol} / \mathrm{l}$, which may have a major effect on diffusive sodium balance during dialysis, as discussed previously. At this moment, few studies assessed the variability of pre-dialytic plasma sodium concentrations in dialysis patients. Also, the relation between variations in plasma sodium and clinical parameters, such as inter-dialytic weight gain and blood pressure, has not been assessed. 


\section{On-line feedback models to control plasma conductivity and blood volume}

In 1980, Gotch ${ }^{23}$ developed a single-pool sodium kinetic model for hemodialysis (HD) in order to obtain a zero sodium balance over the treatment cycle (intra-HD sodium removal = inter-HD sodium accumulation). Using flame photometry to determine total sodium concentrations, this early analytical single-pool kinetic model showed a degree of imprecision of $\sim 2.8 \mathrm{mmol} / \mathrm{l}$ in predicting end-dialysis plasma water sodium concentration. This means, for a final total body water volume of 40 litres (58\% for $70 \mathrm{~kg}$ body weight), an imprecision of $\sim 112 \mathrm{mmol}$ in predicting sodium removal with dialysis. However, on the basis of Gotch's theoretical premises, Di Filippo ${ }^{46}$ demonstrated more recently, using direct ionometry, a level of imprecision in the prediction of sodium balance of less then $34 \mathrm{mmol}$. Unfortunately, these models are unsuitable for routine clinical use because of the need for blood sampling and laboratory determinations at each dialysis session.

Recently, it has become possible to model the decline in blood volume and changes in plasma conductivity (PC), as a surrogate of plasma sodium, by means of feedback technologies. Following the theoretical premises of conductivity monitoring; i.e. dialysate and plasma sodium are linearly related to conductivity, a conductivity kinetic model can be used instead of a sodium kinetic model, which can be achieved by a dialysis module which is able to measure dialysis conductivity and ionic dialysance online, by which plasma conductivity can be assessed and modelled ${ }^{47,48}$.

In the case of PC-controlled feedback, a target for end-dialytic PC is set, which is achieved by frequent adjustments of dialysate conductivity during the dialysis sessions, in response to on-line measured changes in $\mathrm{PC}^{29,49,50}$. With $\mathrm{PC}$-controlled feedback (Diacontrol ${ }^{\circledR}$; Hospal-Gambro, Mirandola, Italy), PC is modelled automatically during dialysis by adjustment of DC using single-pool kinetic modelling. With PC-controlled feedback, it is possible to achieve these targets with a high level of precision. Post-dialytic plasma conductivity can be assessed with a precision of $<0.14 \mathrm{mS} / \mathrm{cm}(\sim 1.4 \mathrm{mmol} / \mathrm{l})^{47}$. Unfortunately, clinical experience with conductivitycontrolled feedback in particular is still limited ${ }^{50,51}$. In one study in patients treated with paired filtration dialysis (a modification of haemodiafiltration in which convection and diffusion take place separately) conductivity controlled feedback resulted in a decline in incidence in intra-HD hypotension ${ }^{51}$. Comparable results were reported in patients treated with hemodialysis, although these studies have only been published in abstract form ${ }^{52,53}$. These results are nevertheless promising, but the effect of conductivity controlled feedback has not been compared yet with other strategies in the prevention of intra-dialytic hypotension. Moreover, the use of a preset postdialytic plasma conductivity target in the "physiologic range" ${ }^{54}$ (i.e. 14.0-14.2 mS/cm, roughly corresponding to a plasma sodium concentration of $138-140 \mathrm{mmol} / \mathrm{l}$ ) might possibly lead to reduced sodium loading in patients with low pre-dialytic plasma sodium levels ${ }^{28,29,49}$. The effect of conductivity controlled feedback, which is only 
available on a single dialysis module (Diacontrol ${ }^{\circledR}$ ), on sodium balance in comparison with other treatment strategies has also not been studied.

Another, more used, feedback method in the prevention of hemodynamic instability is blood-volume controlled feedback systems. Blood volume controlled feedback prevents a decline in blood volume below an individually set threshold by continuous adjustments of the ultrafiltration rate and dialysate conductivity in response to measured changes in relative blood volume. This threshold is based on an empirically determined relative blood volume below which the patient is known to develop complaints. Relative blood volume can be assessed during dialysis by measuring the change in hematocrit or protein content by optical methods or ultrasound ${ }^{55}$.

The biofeedback system used in this thesis (Hemocontrol ${ }^{\circledR}$; Hospal-Gambro, Mirandola, Italy) is based on a closed-loop automatic control system using three controlled variables and two control variables. These controlled variables are total weight loss, change in relative blood volume, and equivalent conductivity. Equivalent conductivity is a value which is defined as the mean dialysate conductivity value required to achieve the same sodium mass balance compared to standard hemodialysis with a fixed conductivity. The control variables consist of the ultrafiltration rate and the delivered dialysate conductivity. Discrepancies between ideal and achieved controlled variable values are processed by a multi-input/multioutput controller that in turn effectuates a response through the two actuators, the control variables ultrafiltration rate and dialysate conductivity. Changes in blood volume are determined by continuous relative blood volume monitoring. Total weight loss is measured volumetrically.

Although the mean dialysate conductivity is usually set at a "physiologic" level $(14.0-14.2 \mathrm{mS} / \mathrm{cm}(\sim 140-142 \mathrm{mmol} / \mathrm{l})$, the effect of these rapid fluctuations of dialysate conductivity on ionic removal has not yet been studied. Most studies, however, have not reported important changes in plasma sodium levels during biofeedback treatment. Blood volume controlled feedback, though shown to be effective in reducing intra-dialytic hypotension, has not been compared with other methods in the prevention of intra-dialytic hypotension. Also, the effect of blood volume controlled feedback on sodium balance has not been assessed in detail ${ }^{56-59}$. The discussion above shows that many issues regarding sodium balance in hemodialysis therapy still remain unanswered. 


\section{Dialysis adequacy}

\section{Dialysis adequacy estimated by urea removal}

The second part of the thesis focuses on the monitoring of dialysis adequacy.

Next to restoration of the water, electrolyte, and acid-base balance of the body, the removal of uremic toxins is the main goal of dialysis therapy. Although many uremic toxins are responsible for the uremic syndrome ${ }^{60,61}$ (only the removal of urea is used as a marker of dialysis adequacy, although urea per se does not appear to be highly toxic. However, urea removal indices were found to be related to outcome (ref. NCDS) and plasma urea is easy to measure, whereas the kinetic modelling of urea during dialysis is relatively straightforward ${ }^{62}$. Other relevant uremic toxins, such as phosphate or $\beta-2$ microglobulin, have different kinetics compared to urea ${ }^{63}$.

\section{Urea reduction ratio (URR)}

The most simple method to express dialysis adequacy in terms of urea removal is the urea reduction ratio (URR), for which only pre- and post-dialytic plasma urea concentration is needed. It can be expressed as:

$$
\left(1-C_{\text {end }} / C_{0}\right) \times 100
$$

$\mathrm{C}_{\text {end }}=$ urea concentration at the end of dialysis

$\mathrm{C}_{0}=$ urea concentration at the start of dialysis.

URR is easy to calculate and is therefore widely used in clinical practice ${ }^{64}$. However, a serious drawback of the use of URR resides in the fact that urea removal by ultrafiltration is not taken into account, nor the urea generation during dialysis. Thus, its application in individual therapy quantification introduces significant errors. It has been suggested that due to these limitations, the use of URR as index of dialysis dose might have a negative effect on treatment outcome and should not be used, although some studies showed a good correlation between URR and survival ${ }^{65,66,67}$

Neither European Best Practice Guidelines (EBPG) nor Kidney Disease Outcomes Quality Initiative (K-DOQI) advocate URR as an appropriate method for assessing dialysis adequacy ${ }^{68,69,70}$. In the 2007 EBPG on dialysis strategies it has been suggested that URR should be used as an approximation for practical purposes, but not as a substitute for formal urea kinetic modelling ${ }^{69}$.

\section{Single pool Kt/Vurea (spKt/V)}

spKt/V is the most commonly used marker to express dialysis dose, and its use is advocated by both K-DOQI and EBPG guidelines. Kt stands for dialyzer clearance (K) $\mathrm{x}$ dialysis time $(\mathrm{t})$, which can be considered as the amount of blood which is cleared of urea during a dialysis treatment. $V$ stands for the amount of urea distribution volume of the patient. Therefore, spKt/ $\mathrm{V}$ is a dimensionless unit. With a spKt/V of 1.0, basically a volume of blood equal to the urea distribution volume has been totally 
cleared of urea. With spKt/ $\mathrm{V}$, urea generation during dialysis, as well as urea removal during ultrafiltration is taken into account.

The following formula for spKt/V is advocated in K-DOQI guidelines ${ }^{70}$ :

$$
\text { spKt/V }=-\mathrm{LN}\left(\left(\frac{\mathrm{Cend}}{\mathrm{C} 0}\right)-0.008 \cdot \mathrm{t}\right)+\left(4-3.5 \cdot\left(\frac{\mathrm{Cend}}{\mathrm{C} 0}\right)\right) \cdot \frac{\mathrm{Uf}}{\mathrm{Wt}}
$$

$\begin{array}{ll}\mathrm{CO}, \text { Cend }= & \text { urea concentration at start and end-session } \\ \mathrm{Uf}= & \text { ultrafiltration volume } \\ \mathrm{Wt}= & \text { post-dialytic body weight }(\mathrm{kg}) \\ \mathrm{t}= & \text { treatment time in hours }\end{array}$

With this formula, urea removal during dialysis is calculated according to single-pool kinetics. However, after dialysis, significant rebound of urea is observed, showing that urea kinetics do not follow a single pool model.

\section{Which types of rebound can be distinguished?}

There are three main causes of rebound after dialysis. The first type of rebound, occurring within 15-20 seconds after the end of dialysis is a result of access recirculation, if present. The effect of access recirculation can be circumvented by the methodology of post-dialytic blood sampling. The most used method is the "slowflow" method, by which the speed of the dialyzer blood pump is reduced 15 seconds before the termination of dialysis. Immediate stopping of the blood pump may lead to 'freezing' of the blood sample and therefore to underestimation of the actual plasma urea concentration when access recirculation is present ${ }^{70}$.

The second type of rebound is a result of cardiopulmonary recirculation, which takes place until 1-2 minutes after the end of dialysis. Cardiopulmonary recirculation occurs because a part of the purified blood, which returns to the heart, flows immediately back to the fistula without passing the tissues. Cardiopulmonary recirculation is inherently present in every haemodialysis treatment, except in patients with central venous catheters ${ }^{71}$. However, the effect of cardiopulmonary recirculation on urea rebound does not appear to be very large ${ }^{72}$. The effect of cardiopulmonary recirculation can be circumvented by taking the blood sample 3 minutes after the end of dialysis ${ }^{70}$.

The third type of rebound, which appears to be a result of a disequilibrium of urea distribution within different body pools, and is lasting until 30-60 minutes after the end of dialysis, depending on the intensity of dialysis. It has been shown that $99 \%$ of the post-dialytic urea rebound was complete at 48 minutes and $94 \%$ at 30 minutes $^{73}$ after haemodialysis treatment. The cause of this phenomenon is still subject of debate and different hypotheses. A first hypothesis assumes that during dialysis, a concentration gradient exists between the intracellular and extracellular spaces, 
because of resistance of the cell membrane to urea transport, which leads to rebound of urea from the intracellular space after the end of dialysis. A second hypothesis (regional flow model) assumes that this phenomenon is caused by the differences in perfusion of various tissues, which may lead to rebound of urea from the less well perfused regions of the body ${ }^{70,74,75}$.

\section{Equilibrated double pool Kt/Vurea (eKt/V)}

The best way to compensate for rebound due to urea redistribution is to measure blood urea 30-60 minutes after the end of dialysis. Despite the fact that rebound may not be entirely complete, the eKt/ $\mathrm{V}$, which takes the 30-minutes post-dialytic sample into account, is often used in the literature as the reference method ${ }^{76}$. However, this approach is cumbersome in clinical practice, both for hospital staff and patients. Therefore, several formulae have been developed in order to compensate for urea disequilibrium. One of the most frequently used formulae is the empirically derived Daugirdas-Schneditz formula, which corrects the single-pool Kt/ $\mathrm{V}$ for treatment time $^{77}$. The derived values were found to be well related to the actual equilibrated $\mathrm{Kt} / \mathrm{V}$, and seem to be as reliable as values based on dialysate collection techniques ${ }^{76}$.

The most commonly used formula for eKt/V, based on the regional blood flow twopool urea kinetic model is:

$$
\mathrm{eKt} / \mathrm{V}=\frac{\mathrm{spKt} / \mathrm{V}-(0.6 \times \mathrm{spKt} / \mathrm{V})}{\mathrm{t}}+0.03
$$

$\mathrm{t}=\quad$ treatment time in hours

spKt $/ \mathrm{V}=\quad$ singlepool Kt/ $/ \mathrm{V}_{\text {urea }}$

In general, also depending on the duration of dialysis, eKt/ $\mathrm{V}$ is $0.15-0.20$ lower than spKt/V.

In contrast to K-DOQI, the eKt/V is advocated by the EBPG guidelines as the preferred tool to assess dialysis adequacy. Reasons for K-DOQI not to prescribe eKt/ $\mathrm{V}$ as benchmark for dialysis adequacy are its mathematical relation to spKt/ $\mathrm{V}$, and the fact that shortened dialysis time (which increase the discrepancy between spKt/ $\mathrm{V}$ and eKt/V) are disallowed by K-DOQI guidelines. In general, K-DOQI did not consider the evidence for the use of eKt/ $\mathrm{V}$ instead of spKt/V of sufficient strength to justify the additional effort and target range ${ }^{70}$.

As reaching the target levels of $\mathrm{Kt} / \mathrm{V}_{\text {urea }}$ is associated with improved survival and decreased incidence and duration of hospitalization ${ }^{78,79}$, the discussion whether URR, eKt/V or spKt/V should be the preferred parameter in the assessment of dialysis adequacy remains. 


\section{Dialysis adequacy estimated from ionic dialysance}

Current guidelines advocate to assess $\mathrm{Kt} / \mathrm{V}_{\text {urea }}$ at least at a monthly basis. However, considerable variation in delivered dialysis dose has been observed between individual dialysis sessions ${ }^{80}$. This would, given the relation between $\mathrm{Kt} / \mathrm{V}_{\text {urea }}$ and clinical outcomes $^{78,79}$ justify more frequent assessment of dialysis dose. However, for assessment of Kt/V by formal urea kinetic modelling pre- and post-dialysis blood sampling is needed, which makes more frequent assessment of $\mathrm{Kt} / \mathrm{V}_{\text {urea }}$ by the standard approach, impractical. Therefore, reliable non-invasive assessment of dialysis dose would be a great asset for clinical practice.

An increasingly used method is the estimation of $\mathrm{Kt} / \mathrm{V}_{\text {urea }}$ from ionic dialysance $\left(\mathrm{Kt} / \mathrm{V}_{\mathrm{id}}\right)$. As discussed in the previous section, ionic dialysance can be assessed during the dialysis session by temporarily increasing dialysate conductivity ( equivalent to the dialysate sodium concentration) in the inlet port of the dialyzer and measuring the change in conductivity at the dialysate outlet ${ }^{81,86}$. The effective ionic dialysance and the plasma conductivity of the patient are measured in an automated and noninvasive way. The underlying assumption is that plasma conductivity does not change during temporary changes in dialysate conductivity because of the large sodium distribution pool ${ }^{82}$, although this assumption has been questioned ${ }^{83}$. Urea clearance can be assessed from ionic dialysance because sodium and urea have comparable molecular weights. This technique has already been integrated on some commercially available dialysis modules. Its great advantage would be the presence of an inexpensive, readily available on-line estimation of dialysis adequacy and sodium removal, which can be assessed at every dialysis treatment. In several studies, $\mathrm{Kt} / \mathrm{V}_{\mathrm{id}}$ appeared to be well related to $\mathrm{Kt} / \mathrm{V}_{\text {urea }}{ }^{84}$, although in some studies ${ }^{85}$, an underestimation of $\mathrm{Kt} / \mathrm{V}_{\text {id }}$ was observed as compared to $\mathrm{Kt} / \mathrm{V}_{\text {urea. }}$. This was explained by the effects of cardiopulmonary recirculation, which would tend to overestimate "true" urea removal ${ }^{86,87,88}$. Indeed, Mercadal et al. observed that after correction for recirculation, urea clearance and ionic dialysance were equivalent ${ }^{88}$. Other authors ${ }^{83}$ though attributed differences between ionic dialysance and urea removal to changes in the total body sodium pool due to the effect of conductivity pulses themselves. In addition, also the dialyser clearance and the charge of the dialysis membrane may influence the relation between ionic dialysance and urea clearance.

\section{The influence of the estimation of urea distribution volume on $\mathrm{Kt} / \mathrm{V}_{\text {id }}$}

Also the estimate of urea distribution volume deserves attention in the assessment of $\mathrm{Kt} / \mathrm{V}_{\mathrm{id}}$. The ionic dialysance method only takes clearance and treatment time into account $(\mathrm{Kt})$, whereas the $\mathrm{V}$ component has to be derived from anthropometric formulae or kinetic modelling. Nevertheless, several studies questioned the reliability of these anthropometry-based equations ${ }^{89,90}$. In general, anthropometry-derived equations appear to underestimate the true urea distribution volume, which would partly offset the effect of underestimation urea clearance by ionic dialysance ${ }^{86}$. 
Assessment of $\mathrm{V}$ by urea kinetic modelling $\left(\mathrm{V}_{\mathrm{ukm}}\right)$ may be more reliable than anthropometric derived $\mathrm{V}^{91}$. Recently, an estimate of $\mathrm{V}$ which was calculated with the use of ionic dialysance measurements $\left(\mathrm{V}_{\mathrm{IOD}}\right)$ themselves has been proposed $\left(\mathrm{V}_{\mathrm{IOD}}\right)$, which correlated very well with $\mathrm{V}$ obtained by direct dialysis quantification and bioimpedance measurements ${ }^{92,93}$. A comparison of $V_{I O D}$ with other estimates of $V$ regarding the agreement between $\mathrm{Kt} / \mathrm{V}$, assessed by eKt/ $\mathrm{V}$ and $\mathrm{Kt} / \mathrm{V}_{\text {id }}$ was only assessed in relatively small patient groups. 


\section{Appendix Mathematical definitions}

1. Sodium balance: $\mathrm{V}_{\text {out }} \times \mathrm{C}_{\text {out }}-\mathrm{V}_{\text {in }} \times \mathrm{C}_{\text {in }}$

2. Sodium balance:

= predialysis total body sodium-postdialysis total body sodium

$=$ predialysis plasma sodium $\times((0.58 \times$ target weight $)+$ ultrafiltration volume $)$

- postdialysis plasma sodium $\times(0.58 \times$ target weight $)$

3. $P C=\left[C d_{\text {out }}-\left(1-D / Q d_{\text {in }}\right) \times C d_{\text {in }}\right] /\left(D / Q d_{\text {in }}\right)$

4. $\quad D=\left(Q d_{\text {in }}+Q f\right) \times\left[1-\left(C d_{\text {out }} 1-C d_{\text {out }} 2\right) /\left(C d_{\text {in }} 1-C d_{\text {in }} 2\right)\right]$

5. $\quad I M B=\left[\left(Q d_{\text {out }} \times C d_{\text {out }}\right)-\left(Q d_{\text {in }} \times C d_{\text {in }}\right)\right] \times 10 \times$ time $(\min )$

6. $\quad$ URR $=(1-$ Cend $/ C 0) \times 100$

7. $\mathrm{spKt} / \mathrm{V}=$ $-\mathrm{LN}\left(\left(\frac{\mathrm{Cend}}{\mathrm{C} 0}\right)-0.008 \cdot \mathrm{t}\right)+\left(4-3.5 \cdot\left(\frac{\mathrm{Cend}}{\mathrm{C} 0}\right)\right) \cdot \frac{\mathrm{Uf}}{\mathrm{Wt}}$

8. $\mathrm{eKt} / \mathrm{V}=$ $\frac{\mathrm{spKt} / \mathrm{V}-(0.6 \times \mathrm{spKt} / \mathrm{V})}{\mathrm{t}}+0.03$

9. $\quad \mathrm{V}$ (Watson):

males: $2,447-0,09516 \cdot A+0,1074 \cdot H t+0,3362 \cdot W t$ females: $-2,097+0,1069 \cdot H t+0,2466 \cdot W t$

$\mathrm{V}_{\text {out }}=$ volume of spent dialysate,

$\mathrm{C}_{\text {out }}=$ concentration of solute in spent dialysate

$\mathrm{V}_{\text {in }}=$ volume of fresh dialysate,

$\mathrm{C}_{\text {in }}=$ concentration of solute in fresh dialysate

$\mathrm{PC}=$ plasma conductivity

$\mathrm{Qf}=$ ultrafiltration rate

$D=\quad$ ionic dialysance

$\mathrm{Qd}_{\text {out }}=$ dialysate flow at outlet

$\mathrm{Cd}_{\text {out }}=$ dialysate conductivity at outlet

$\mathrm{Qd}_{\text {in }}=$ dialysate flow at inlet

$\mathrm{Cd}_{\text {in }}=$ dialysate conductivity at inlet

$\mathrm{CO}=$ urea concentration at start session 
Cend $=$ urea concentration at end-session

$\mathrm{Uf}=\quad$ ultrafiltration volume (in liters)

$\mathrm{Wt}=$ post-dialytic body weight (in kilograms)

$\mathrm{Ht}=\quad$ length (in centimetres)

$A=\quad$ age (in years)

$\mathrm{t}=$ treatment time (in hours)

spKt $/ \mathrm{V}=$ singlepool Kt/ $\mathrm{V}$

eKt/V = equilibrated, double pool Kt/V

URR = Urea Reduction Rate

$\mathrm{V}_{\text {watson }}=$ urea distribution volume calculated by the Watson formula

$V_{I O D}=$ urea distribution volume calculated by the ionic dialysance formula

$\mathrm{V}_{\mathrm{UKM}}=$ urea distribution volume calculated by the urea kinetic modelling formula 


\section{References}

1. MacGregor GA, de Wardener HE. Salt, diet and health: Neptune's poisoned chalice; the origins of high blood pressure. New York: Cambridge University Press; 1998.

2. Wabel P, Moissl U, Chamney P, Jirka T, Machek P, Ponce P, Taborsky P, Tetta C, Velasco N, Vlasak J, Zaluska W, Wizemann V. Towards improved cardiovascular management: the necessity of combining blood pressure and fluid overload. Nephrol Dial Transplant. 2008;23:2965-71.

3. Kooman JP, van der Sande F, Leunissen K, Locatelli F. Sodium balance in hemodialysis therapy. Semin Dial. 2003;16:351-5.

4. Wizemann V, Wabel P, Chamney P, Zaluska W, MoissI U, Rode C, Malecka-Masalska T, Marcelli D. The mortality risk of overhydration in haemodialysis patients. Nephrol Dial Transplant. 2009;24:1574-9.

5. Kooman JP, van der Sande FM, Leunissen KM. Sodium, blood pressure and cardiovascular pathology: is it all volaemia? Nephrol Dial Transplant. 2004;19:1046-9.

6. Ritz E, Dikow R, Morath C, Schwenger V. Salt--a potential 'uremic toxin'? Blood Purif. 2006;24:63-6.

7. Titze J, Ritz E: Salt and its effect on blood pressure and target organ damage: new pieces in an old puzzle. J Nephrol. 2009;22:177-89.

8. Ozkahya M, Toz H, Qzerkan F, Duman S, Ok E, Basci A, Mees EJ. Impact of volume control on left ventricular hypertrophy in dialysis patients. J Nephrol. 2002;15:655-60.

9. Locatelli F, Ponti R, Pedrini L, Di Filippo S. Sodium and dialysis: a deeper insight. Int J Artif Organs 1999;12: 71-74.

10. Locatelli F, Di Filippo S, Manzoni C. Relevance of the conductivity kinetic model in the control of sodium pool. Kidney Int 2000;Suppl 76: S89-S95.

11. Flanigan MJ. Role of sodium in hemodialysis. Kidney Int Suppl. 2000;76:S72-8.

12. Stiller S, Bonnie-Schorn E, Grassmann A, Uhlenbusch-Körwer I, Mann H. A critical review of sodium profiling for hemodialysis. Semin Dial. 2001;14:337-47.

13. Van Stone JC. Individualization of the dialysate prescription in chronic hemodialysis. Dial Transplant 1994;23:624-35.

14. Gelens M, Luik AJ, Kleffens M, van der Sande FM, Kooman JP. A dialysate sodium concentration of $140 \mathrm{mmol} / \mathrm{I}$ may lead to net diffusive sodium gain. Blood Purif 2002;20: 190.

15. Locatelli F, Di Filippo S, Manzoni C. Removal of small and middle molecules by convective techniques. Nephrol Dial Transplant 2000;15 (S2):37-44.

16. Panzetta G, Bianco F, lanche M, Vianello S, Vidi E, Savoldi S, Galli G, Dal Moro A, Klein P, Zanchi R, Cicinato $P$. Validation of a simple method for assessing sodium intake in dialysis patients. Blood Purif 2001;19:15-20.

17. Ramdeen G, Tzamaloukas AH, Malhotra D, Leger A, Murata GH. Estimates of interdialytic sodium and water intake based on the balance principle: differences between nondiabetic and diabetic subjects on hemodialysis. ASAIO J 1998;44:812-7.

18. Lambie SH, Taal MW, Fluck RJ, Mclntyre CW. Online conductivity monitoring: validation and usefulness in a clinical trial of reduced dialysate conductivity. ASAIO J. 2005;51:70-6.

19. Kloppenburg WD, Stegeman CA, de Jong PE, Huisman RM. Anthropometry-based equations overestimate the urea distribution volume in hemodialysis patients. Kidney Int. 2001;59:1165-74

20. Baadenhuijsen H, Bayer PM, Keller H, Knedel M, Montalbetti N, Brenna S, Prencipe L, Vassault A, Bailly M, Phung HT, et al. Multicentre evaluation of the Boehringer Mannheim/Hitachi 717 analysis system. J Clin Chem Clin Biochem 1990;28:261-9.

21. Burnett RW, Covington AK, Fogh-Andersen N, Külpmann WR, Lewenstam A, Maas AH, Müller-Plathe $O$, Sachs C, Siggaard-Andersen O, VanKessel AL, Zijlstra WG. Recommendations for measurement of and conventions for reporting sodium and potassium by ion-selective electrodes in undiluted serum, plasma or whole blood. International Federation of Clinical Chemistry and Laboratory Medicine (IFCC). IFCC Scientific Division Working Group on Selective Electrodes. Clin Chem Lab Med 2000;38: 1065-71.

22. Di Filippo S, Corti M, Andrulli S, Manzoni C, Locatelli F. Determining the adequacy of sodium balance in hemodialysis using a kinetic model. Blood Purif 1996;14: 431-6.

23. Gotch FA, Lam MA, Prowitt M, Keen M. Preliminary clinical results with sodium-volume modeling of hemodialysis therapy. Proc Clin Dial Transplant Forum 1980;10:12-7. 
24. Pozzoni P, DI Filippo S, Pontoriero G, Locatelli F. Effectiveness of sodium and conductivity kinetic models in predicting end-dialysis plasma water sodium concentration: preliminary results of a singlecenter experience. Hemodial Int. 2007;11:169-77.

25. La Milia V, Di Filippo S, Crepaldi M, Andrulli S, Del Vecchio L, Scaravilli P, Virga G, Locatelli F. Sodium removal and sodium concentration during peritoneal dialysis: effects of three methods of sodium measurement. Nephrol Dial Transplant. 2004;19:1849-55.

26. Maas AH, Siggaard-Andersen O, Weisberg HF, Zijlstra WG. Ion-selective electrodes for sodium and potassium: a new problem of what is measured and what should be reported. Clin Chem 1985;31: 482-5.

27. Locatelli F, Di Filippo S, Manzoni C. Relevance of the conductivity kinetic model in the control of sodium pool. Kidney Int Suppl. 2000;76:S89-95.

28. Locatelli F, Di Filippo S, Manzoni C, Corti M, Andrulli S, Pontoriero G. Monitoring sodium removal and delivered dialysis by conductivity. Int J Artif Organs. 1995;18:716-21

29. Bosetto A, Bene B, Petitclerc T. Sodium management in dialysis by conductivity Adv Ren Replace Ther 1999;6: 243-54.

30. Petitclerc T, Bene B, Goux N, Saudon MC, Jacobs C. Non invasive monitoring of effective dialysis dose delivered to the hemodialysis patient. Nephrol Dial Transplant 1995;10:212-6.

31. J Stewart Cameron: A History of dialysis, Oxford University Press, USA ISBN: 0198515472.

32. Davenport A. Audit of the effect of dialysate sodium concentration on inter-dialytic weight gains and blood pressure control in chronic haemodialysis patients. Nephron Clin Pract. 2006;104:c120-5.

33. Kooman J, Basci A, Pizzarelli F, Canaud B, Haage P, Fouque D, Konner K, Martin-Malo A, Pedrini L, Tattersall J, Tordoir J, Vennegoor M, Wanner C, ter Wee P, Vanholder R. EBPG guideline on haemodynamic instability. Nephrol Dial Transplant. 2007;22 Suppl 2:ii22-44.

34: Dheenan S, Henrich WL. Preventing dialysis hypotension: a comparison of usual protective maneuvers. Kidney Int 2001;59:1175-81.

35: Cybulsky AV, Matni A, Hollomby DJ. Effects of high sodium dialysate during maintenance hemodialysis. Nephron 1985;41:57-61.

36. Barre $P E$, Brunelle G, Gascon-Barre M. A randomized double blind trial of dialysate sodiums of 145 $\mathrm{mEq} / \mathrm{L}, 150 \mathrm{mEq} / \mathrm{L}$, and $155 \mathrm{mEq} / \mathrm{L}$. ASAIO Transactions 1988;34:338-41.

37. Oliver MJ, Edwards LJ, Churchill DN. Impact of sodium and ultrafiltration profiling on hemodialysisrelated symptoms. J Am Soc Nephrol 2001;12:151-6.

38. Song JH, Park GH, Lee SY, Lee SW, Lee SW, Kim MJ. Effect of Sodium Balance and the Combination of Ultrafiltration Profile during Sodium Profiling Hemodialysis on the Maintenance of the Quality of Dialysis and Sodium and Fluid Balances. J Am Soc Nephrol 2005;16:237-46.

39. K/DOQI Workgroup: K/DOQI clinical practice guidelines for cardiovascular disease in dialysis patients. Am J Kidney Dis 2005;45(4 Suppl. 3):S1-S153.

40. Sang GL, Kovithevongs C, Ulan R, Kjellstrand CM. Sodium ramping in hemodialysis: a study of beneficial and adverse effects. Am J Kidney Dis 1997;29:669-77.

41. Song JH, Lee SW, Suh CK, Kim MJ. Time-averaged concentration of dialysate sodium relates with sodium load and interdialytic weight gain during sodium-profiling hemodialysis.[erratum appears in Am J Kidney Dis 2002;40:1357]. Am J Kidney Dis 2002;40:291-301.

42. Locatelli F, Covic A, Chazot C, Leunissen K, Luño J, Yaqoob M. Optimal composition of the dialysate, with emphasis on its influence on blood pressure. Nephrol Dial Transplant. 2004;19:785-96.

43. de Paula FM, Peixoto AJ, Pinto LV, Dorigo D, Patricio PJ, Santos SF. Clinical consequences of an individualized dialysate sodium prescription in hemodialysis patients. Kidney Int 2004;66:1232-8.

44. Santos SF, Peixoto AJ. Revisiting the dialysate sodium prescription as a tool for better blood pressure and interdialytic weight gain management in hemodialysis patients. Clin J Am Soc Nephrol. 2008;3:522-30

45. Keen ML, Gotch FA. The association of the sodium "setpoint" to interdialytic weight gain and blood pressure in hemodialysis patients. Int J Artif Organs. 2007;30:971-9.

46. Di Filippo S, Corti M, Andrulli S, Manzoni C, Locatelli F. Determining the adequacy of sodium balance in hemodialysis using a kinetic model. Blood Purif 1996;14:431-6.

47. Polaschegg HD. Automatic non-invasive intradialytic clearance measurements. Int J Artif Organs 1993; 16:185-91. 
48. Petitclerc T, Goux N, Reynier AL, Bene B. A model for non-invasive estimation of in vivo dialyzer performances and patient's conductivity during hemodialysis. Int J Artif Organs 1993;16:585-91.

49. Locatelli F, Di Filippo S, Manzoni C. Relevance of the conductivity kinetic model in the control of sodium pool. Kidney Int Suppl 2000;76:S89-S95.

50. Di Giulio S, Meschini L, Friggi A, Stortoni F, Cherubini C, de Paolis P, Rosa M. Sodium transport with different dialysis ultrafiltration schedules using a bio-feedback module (BFB). Nephrol Dial Transplant. 1998;13 Suppl 6:39-42.

51. Locatelli F, Andrulli S, Di Filippo S, Redaelli B, Mangano S, Navino C, Ariano R, Tagliaferri M, Fidelio T, Corti M, Civardi S, Tetta C. Effect of on-line conductivity plasma ultrafiltrate kinetic modeling on cardiovascular stability of hemodialysis patients. Kidney Int 1998;53:1052-60.

52. Sanz-Moreno C, Sanchez-Sobrino B, Botella J. The Diascan: a biofeedback module with automatic variation of dialysate conductivity to obtain the best clinical tolerance and target plasma conductivity. Nephrol Dial Transplant 1995;10:1023.

53. Di Giulio S, Meschini L, de Paolis P, Cherubini C, Friggi A, Rosa M, Stortoni F. Improved cardiovascular stability with biofeedback module for automatic prescription of electrolyte transport during hemodialysis. Blood Purif 1994;12:174-5.

54. Hernández-Jaras J, García-Pérez H, Torregrosa E, Calvo C, Cerrillo V. Usefulness of the Biofeedback Diacontrol module in the automatic programming of plasmatic conductivity and ionic mass transfer. Nefrologia. 2003;23:62-70.

55. Dasselaar JJ, Huisman RM, de Jong PE, Franssen CF. Measurement of relative blood volume changes during haemodialysis: merits and limitations. Nephrol Dial Transplant 2005;20:2043-9.

56. Wolkotte C, Hassell DR, Moret K, Gerlag PG, van den Wall Bake AW, van der Sande FM, Kooman JP. Blood volume control by biofeedback and dialysis-induced symptomatology. A short-term clinical study. Nephron. 2002;92:605-9.

57. Santoro A, Mancini E, Paolini F, Cavicchioli G, Bosetto A, Zucchelli P. Blood volume regulation during hemodialysis. Am J Kidney Dis 1998;32:739-48.

58. Basile C, Giordano R, Vernaglione L, Montanaro A, De Maio P, De Padova F, Marangi AL, Di Marco L, Santese D, Semeraro A, Ligorio VA. Efficacy and safety of haemodialysis treatment with the Hemocontrol biofeedback system: A prospective medium-term study. Nephrol Dial Transplant 2001;16:328-34.

59. Ronco C, Brendolan A, Milan M, Rodeghiero MP, Zanella M, La Greca G. Impact of biofeedbackinduced cardiovascular stability on hemodialysis tolerance and efficiency. Kidney Int 2000;58:800-8.

60. Vanholder R, Baurmeister U, Brunet P, Cohen G, Glorieux G, Jankowski J. European Uremic Toxin Work Group. A bench to bedside view of uremic toxins. J Am Soc Nephrol. 2008;19:863-70.

61. Johnson WJ, Hagge WW, Wagoner RD, Dinapoli RP, Rosevear JW. Effects of urea loading in patients with far-advanced renal failure". Mayo Clinic Proc. 1972;47:21-9.

62. Gotch FA, Sargent JA. A mechanistic analysis of the National Cooperative Dialysis Study (NCDS)". Kidney int. 1985;28: 526-34.

63. Leypoldt JK. Kinetics of beta2-microglobulin and phosphate during hemodialysis: effects of treatment frequency and duration. Semin Dial. 2005;18:401-8.

64. Couchoud C, Jager KJ, Tomson C, Cabanne JF, Collart F, Finne P, de Francisco A, Frimat L, Garneata L, Leivestad $T$, Lemaitre V, Limido A, Ots $M$, Resic $H$, Stojceva-Taneva O, Kooman J; QUEST working group on dialysis adequacy. QUEST working group on dialysis adequacy. Assessment of urea removal in haemodialysis and the impact of the European Best Practice Guidelines Nephrol Dial Transplant. 2009;24:1267-74.

65. Sherman RA, Cody RP, Rogers ME, Solanchick JC. Accuracy of the urea reduction ratio in predicting dialysis delivery. Kidney Int 1995;47:319-21.

66 Owen WF, Lew NL, Liu Y, Lowrie EG, Lazarus JM. The urea reduction ratio and serum albumin concentration as predictors of mortality in patients undergoing hemodialysis. N Engl J Med 1993;329:1001-6.

67. Held PJ, Port FK, Wolfe RA, Stannard DC, Carroll CE, Daugirdas JT, Bloembergen WE, Greer JW, Hakim RM. The dose of hemodialysis and patient mortality. Kidney Int 1996; 50:550-6.

68. European Best Practice Guidelines Expert Group on Haemodialysis. Nephrol Dial Transplant 2002; 17(Suppl 7):S16-S31. 
69. Tattersall J, Martin-Malo A, Pedrini L, Basci A, Canaud B, Fouque D, Haage P, Konner K, Kooman J, Pizzarelli F, Tordoir J, Vennegoor M, Wanner C, ter Wee P, Vanholder R. EBPG guideline on dialysis strategies. Nephrol Dial Transplant 2007;22(Suppl 2):ii5-21.

70. NKF-KDOQI clinical practice guidelines; update 2006. Am J Kidney Dis 2006;48(Suppl 1):S2-S90.

71. Schneditz D. Theoretical and practical issues in recirculation; assessment of vascular access. EDTNA ERCA J. 1998;24:3-6.

72. Daugirdas JT, Greene T, Depner TA, Leypoldt J, Gotch F, Schulman G, Star R; Hemodialysis Study Group. Factors that affect postdialysis rebound in serum urea concentration, including the rate of dialysis: Results from the HEMO Study. J Am Soc Nephrol 2004;15:194-203.

73. Pedrini LA, Zereik S, Rasmy S. Causes, kinetics and clinical implications of post-hemodialysis urea rebound. Kidney Int 1988;34:817-24.

74. George TO, Priester-Coary A, Dunea G, Schneditz D, Tarif N, Daugirdas JT. Cardiac output and urea kinetics in dialysis patients: evidence supporting the regional blood flow model. Kidney Int1996;50: 1273-7.

75. Kooman JP, van der Sande FM, Leunissen KML. Kt/V: finding tree within the woods. Nephrol Dial Transpl 2001;16:1749-52.

76. Daugirdas JT, Depner TA, Gotch FA, Greene T, Keshaviah P, Levin NW, Schulman G. Comparison of methods to predict equilibrated Kt/V in the HEMO Pilot Study. Kidney Int1997;52:1395-405.

77. Daugirdas JT, Schneditz D. Overestimation of hemodialysis dose depends on dialysis efficiency by regional blood flow but not by conventional two pool urea kinetic analysis. ASAIO J1995;41:M719-24.

78. Tentori F, Hunt WC, Rohrscheib M, Zhu M, Stidley CA, Servilla K, Miskulin D, Meyer KB, Bedrick EJ, Johnson HK, Zager PG. Which targets in clinical practice guidelines are associated with improved survival in a large dialysis organization? J Am Soc Nephrol 2007;18:2377-84.

79. Plantinga LC, Fink NE, Jaar BG, Sadler JH, Levin NW, Coresh J, Klag MJ, Powe NR. Attainment of clinical performance targets and improvement in clinical outcomes and resource use in hemodialysis care: a prospective cohort study. BMC Health Serv Res 2007;7:5.

80. Mclntyre CW, Lambie SH, Taal MW, Fluck RJ. Assessment of haemodialysis adequacy by ionic dialysance: intra-patient variability of delivered treatment. Nephrol Dial Transplant 2003;18:559-63.

81. Petitclerc T, Ben B, Jacobs C, Jaudon MC, Goux N. Non-invasive monitoring of effective dialysis dose delivered to the haemodialysis patient. Nephrol Dial Transplant 1995;10:212-6.

82. Di Filippo S, Manzoni C, Andrulli S, Pontoriero G, Dell'Oro C, La Milia V, Bacchini G, Crepaldi M, Bigi MC, Locatelli F. How to determine ionic dialysance for the online assessment of delivered dialysis dose. Kidney Int2001;59:774-82

83. Gotch FA, Panlilio FM, Buyaki RA, Wang EX, Folden TI, Levin NW. Mechanisms determining the ratio of conductivity clearance to urea clearance. Kidney Int Suppl 2004;;89:S3-24.

84. di Filippo S, Andrulli S, Manzoni C, Corti M, Locatelli F. On-line assessment of delivered dialysis dose. Kidney Int1998;54:263-7.

85. Manzoni Manzoni C, Di Filippo S, Corti M, Locatelli F. Ionic dialysance as a method for the on-line monitoring of delivered dialysis without blood sampling. Nephrol Dial Transplant 1996;11:2023-30.

86. Haemodialysis with on-line monitoring equipment: tools or toys? Francesco Locatelli, Umberto Buoncristiani, Bernard Canaud, Hans Kohler,Thierry Petitclerc and Pietro Zucchelli Nephrol Dial Transplant 2005;20:22-33.

87. Lindsay RM, Béne B, Goux N, Heidenheim P, Landgren C, Sternby J. Relationship between effective ionic dialysance and in vivo urea clearance during hemodialysis. Am J Kidney Dis 2001;38:565-74.

88. Mercadal L, Du Montcel ST, Jaudon MC, Hamani A, Izzedine H, Deray G, Béné B, Petitclerc T. Ionic dialysance vs urea clearance in the absence of cardiopulmonary recirculation. Nephrol Dial Transplant 2002;17:106-11.

89. Mercadal L, Petitclerc T, Jaudon MC, Bene B, Goux N, Jacobs C. Is ionic dialysance a valid parameter for quantification of dialysis efficiency. Artif Organs1998;22:1005-09.

90. Kloppenburg W, Stegeman C, Hooyschuur M, van der Ven J, de Jong PE, Huisman RM. Assessing dialysis adequacy and dietary intake in the individual hemodialysis patient. Kidney Int 1999;55: 1961-9.

91. Daugirdas JT, Greene T, Depner TA, Chumlea C, Rocco MJ, Chertow GM, Hemodialysis (HEMO) Study Group. Anthropometrically estimated total body water volumes are larger than modeled urea volume in chronic hemodialysis patients: effects of age, race, and gender. Kidney Int 2003;64:1108-19. 
92. Di Filippo S, Manzoni C, Andrulli S, Pontoriero G, Dell'Oro C, La Milia V, Tentori F, Crepaldi M, Bigi MC, Locatelli F. Ionic dialysance allows an adequate estimate of urea distribution volume in hemodialysis patients. Kidney Int 2004;66:786-91.

93. Wuepper A, Tattersall J, Kraemer M, Wilkie M, Edwards L. Determination of urea distribution volume for Kt/V assessed by conductivity monitoring. Kidney Int 2003;64:2262-71. 


\section{Chapter 2}

Aim and outline of the thesis

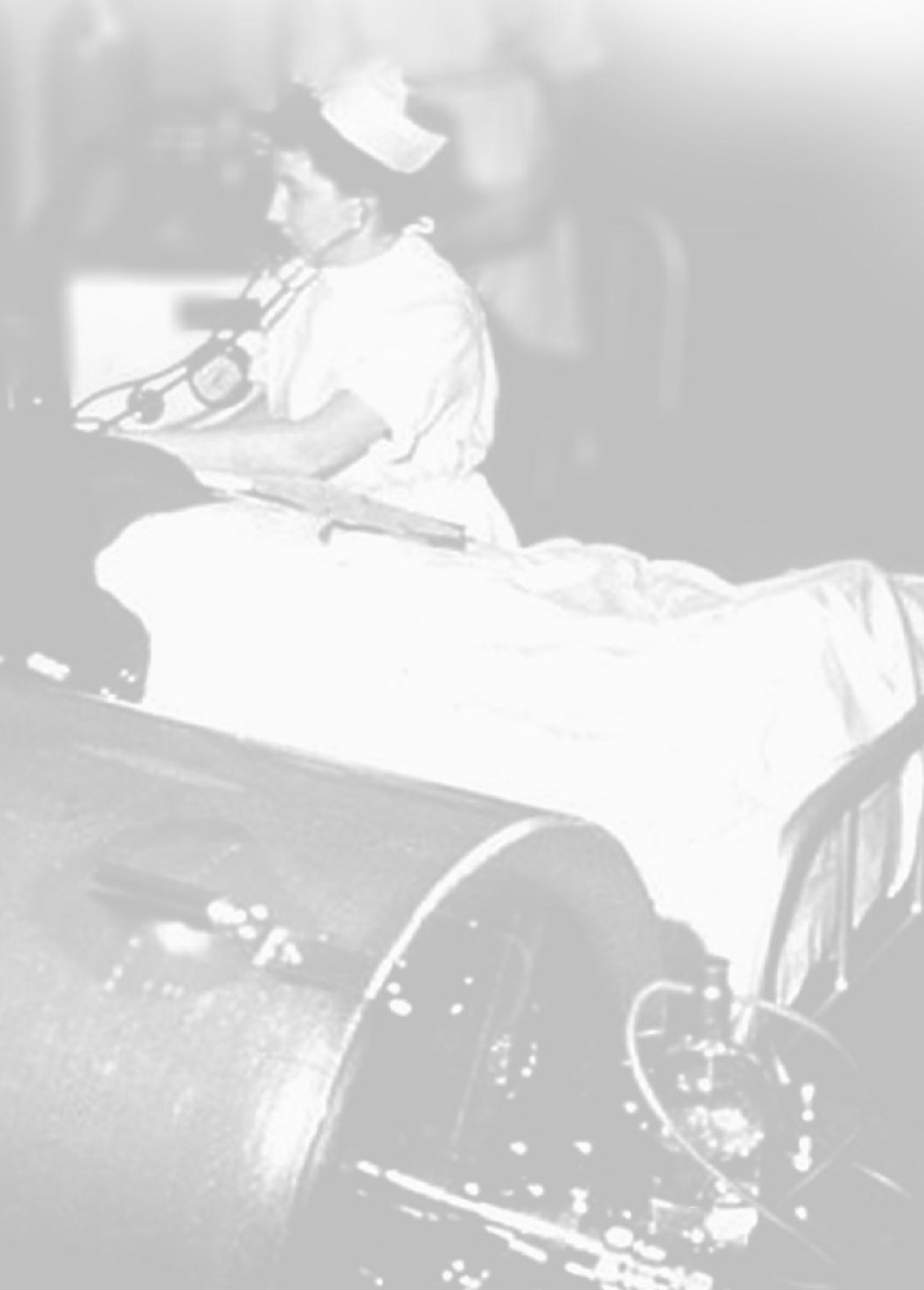


Chapter 2 


\section{Aim and outline of the thesis}

The objective of this thesis is to study the added value in clinical practice of technological advances during hemodialysis by examining the influence of the following issues.

\section{Variations in pre-dialytic plasma conductivity and the effect on ionic mass balance}

In Chapter 3 we describe how differences in dialysis sodium prescription affect diffusive ionic mass balance during a single dialysis session. Moreover, ionic mass balance by on-line conductivity measurements is validated against conductivity measurements in spent dialysate collections. In Chapter $\mathbf{4}$ the long term variation in pre-dialytic plasma conductivity in hemodialysis patients treated with a fixed dialysate sodium concentration is addressed. In addition, the relation between variations in plasma conductivity and clinical parameters, such as inter-dialytic weight gain and blood pressure is studied. Furthermore, it is studied to which extent differences in pre-dialytic plasma conductivity result in differences in (diffusive) ionic mass balance. In this chapter, ionic mass balance is validated using sodium balance measurements by direct dialysate quantification. In Chapter $\mathbf{5}$ the influence of sodium profiling as well as blood volume controlled feedback and conductivity controlled feedback on ionic mass balance is addressed. Additionally, the effects on hemodynamic stability of these different treatment modalities is studied. The effect of the imposed rapid fluctuations of dialysate conductivity during the assessment of plasma conductivity and ionic dialysance has not yet been studied. In Chapter 6 the effect of ionic dialysance measurements on sodium load is assessed.

\section{The different parameters for estimating dialysis adequacy and the effect on outcome}

Chapter 7 studies the effects of treatment monitoring with different parameters of dialysis adequacy based on urea kinetic modelling, i.e. the urea reduction rate, eKt/ $\mathrm{V}$ and spKt/V. This study was carried out in the NECOSAD cohort and addresses which percentage of patients would be classified as receiving an "adequate" or "inadequate" treatment dose based on target and minimally adequate levels of these different parameters. In addition also the prognostic significance of the different adequacy parameters will be discussed. In Chapter $\mathbf{8}$ the agreement between Kt/V assessed by ionic dialysance and by formal urea kinetic modelling is assessed. Furthermore the effect of different estimates of urea distribution volume on dialysis adequacy on dialysis adequacy estimation is discussed. The mechanisms between the intertreatment variability of Kt/ $\mathrm{V}$ by ionic dialysance are also studied. 
In Chapter 9, the results of the studies in the thesis are summarized and their implications are addressed. 


\section{Chapter 3}

Ionic mass balance and blood volume preservation during a high, standard, and individualized dialysate

\section{sodium concentration}

Karin EM Moret, Daxenos Hassell, Jeroen P Kooman, Frank van der Sande,

Paul GG Gerlag, A Warmold L van den Wall Bake, Jarno van den Bogaart, Karel ML Leunissen

Nephrol Dial Transplant 2002;17:1463-1469 


\section{Abstract}

\section{Background}

Although a higher dialysate sodium concentration (DNa) is frequently used to improve hemodynamic stability during haemodialysis, few studies have compared ionic mass balance (IMB) during different DNa. Moreover, DNa is usually a standard prescription, whereas inter-individual pre-dialytic serum sodium levels may differ widely. The aims of the study were to assess IMB and the decline in blood volume $(\triangle \mathrm{BV})$ during isovolaemic HD as well as during HD combined with ultrafiltration (UF) during DNa [140], DNa [144], and an individualized DNa [ind], in which DNa is equal to pre-HD plasma conductivity $\times 10$.

\section{Methods}

IMB and plasma conductivity were assessed by on-line conductivity measurements (Diascan ${ }^{\circledR}$; Hospal ${ }^{\circledR}$ ) in $13 \mathrm{HD}$ patients. After one hour of isovolaemic HD, measurements were continued during UF+HD until dry weight. $\triangle \mathrm{BV}$ was assessed by an optical method (Hemoscan ").

\section{Results}

During isovolaemic HD with DNa [140] and [144], Pre-Na was significantly related to IMB ( $r=0.83$ and $r=0.61$; $P<0.05)$. Diffusive ionic mass influx from dialysate to patient occurred when the difference between $D N a$ and pre-dialytic plasma sodium was larger than $5 \mathrm{mmol} / \mathrm{l}$. During UF+HD, IMB was $318 \pm 166 \mathrm{mmol}$ during $\mathrm{DNa}$ [140], 277 $\pm 116 \mathrm{mmol}$ during DNa [ind], and 239 \pm 111 during DNa [144] (mean $\pm \mathrm{SD} ; P<0.05$ compared with the other treatment modalities) whereas $\triangle \mathrm{BV}$ did not differ significantly. In the five patients with a predialytic sodium concentration below $140 \mathrm{mmol} / \mathrm{l}$, ionic removal was significantly higher during DNa [ind] $(324 \pm 87)$ compared with DNa [140] $(228 \pm 127 \mathrm{mmol} ; P<0.05)$ without a significant difference in BV $(-9.7 \pm 1.6$ vs $-7.8 \pm 2.3 \%)$.

\section{Conclusion}

A large difference in IMB was observed between DNa 144 and DNa 140, without a significant difference in $\triangle B V$. In patients with low pre-dialytic serum sodium levels, diffusive ionic influx from the dialysate into the patient may occur. In patients with low pre-dialytic sodium levels, DNa [ind] leads to an enhanced ionic removal compared with $\mathrm{DNa}[140]$ without large differences in $\triangle \mathrm{BV}$. 


\section{Introduction}

The dialysate sodium concentration is a two-edged sword. Whereas a low dialysate sodium concentration may lead to large removal of sodium but also to an impaired preservation of blood volume provoking intra-dialytic hypotension, a high dialysate sodium concentration may improve hemodynamic stability during dialysis, although possibly at the cost of increased inter-dialytic weight gain and hypertension. In general, an optimal dialysate sodium concentration would find a balance between both an adequate blood volume preservation and sodium removal ${ }^{1}$. In earlier studies, but also more recently ${ }^{2,3}$, several authors recommended higher dialysate sodium concentrations in order to prevent intra-dialytic hemodynamic instability in hypotension-prone dialysis patients ${ }^{2,3}$. Few data are, however, available on ionic mass balance (IMB) during dialysis with different dialysate sodium concentrations, although such data are of pivotal importance in view of the relation between sodium, hypertension, and left ventricular abnormalities in dialysis patients ${ }^{4-6}$.

In most of the literature, the dialysate sodium concentration is seen as a standard prescription, whereas the pre-dialytic plasma sodium concentration may differ between dialysis patients. The fact that this phenomenon may lead to large interindividual differences in diffusive ionic transfer suggests that individualization of dialysate, i.e. based on pre-dialytic plasma conductivity or sodium measurements or effected by biofeedback modules, would seem judicious. Nevertheless, although the use of individualization of the dialysate sodium concentration may be appealing in the sense of a more physiologic and patient-based dialysis prescription, it is not known whether such an approach actually improves the dialysis treatment in terms of the balance between blood volume preservation and ionic removal.

New techniques based on conductivity measurements enable the physician to assess IMB during dialysis, which is likely to be representative of sodium balance, due to the quantitative predominance of sodium ions in both plasma and dialysate. In this aspect, however, it is of great importance to distinguish between convective transport evoked by ultrafiltration and purely diffusive ionic transport. The aims of the present study were to first assess IMB in vivo both during isovolaemic dialysis as well as during haemodialysis combined with ultrafiltration using different dialysate sodium concentrations, and secondly to compare standard and individualized dialysate sodium concentrations in terms of blood volume preservation and IMB. 


\section{Subjects and methods}

\section{Study protocol}

\section{Validation study}

During nine treatment sessions, IMB was assessed both by Diascan ${ }^{\circledR}$ (vide infra) and by direct dialysis quantification. Using direct dialysis quantification, the total amount of spent dialysate was collected in a box. Conductivity measurements were performed in a sample of spent dialysate taken from the box, as well as in a sample of incoming dialysate. IMB by direct dialysis quantification was assessed according to the formula:

$\left(\mathrm{Cd}_{\text {in }} \times \mathrm{Qd} \mathrm{x}\right.$ dialysis time $)-\left(\mathrm{Vd}_{\text {out }} \times \mathrm{Cd}_{\text {out }}\right)$, in which

Qd is dialysate flow,

$\mathrm{Cd}_{\text {in }}$ is dialysate conductivity of incoming dialysate,

$\mathrm{Vd}_{\text {out }}$ is volume of spent dialysate, and

$\mathrm{Cd}_{\text {out }}$ is the conductivity of spent dialysate. Conductivity of incoming and spent dialysate was measured with a conductivity meter (IBP HDN-90, Hannover, Germany). Moreover, sodium concentration of incoming dialysate was assessed by ionometry (Vitros $950^{\circledR}$; Johnson and Johnson).

\section{Clinical study}

Patients were studied during three dialysis sessions with dialysate sodium concentrations of, respectively, $140 \mathrm{mmol} / \mathrm{I}(14 \mathrm{~ms} / \mathrm{cm})\{\mathrm{DNa}[140]\}$, and $144 \mathrm{mmol} / \mathrm{I}$ $(14.4 \mathrm{mS} / \mathrm{cm})\{\mathrm{DNa}[144]\}$, and an individualized sodium concentration \{DNa [ind]\}. Dialysate sodium was individualized according to pre-dialytic plasma conductivity (dialysate sodium is equal to pre-dialytic plasma conductivityx10), as measured by Diascan $^{\circledR}\left(\right.$ Hospal $\left.^{\circledR}\right)$ (vide infra). Three different dialysis sessions with, respectively, DNa [140], DNa [144], and DNa [ind] were compared, in randomized order. Sessions were performed at exact intervals of one week, in order to prevent large differences in ultrafiltration volume and also to prevent an effect of a previous modification of dialysate sodium on the subsequent study sessions. In the other dialysis treatments, during which no measurements were performed, a dialysate sodium concentration of $140 \mathrm{mmol} / \mathrm{l}$ was used, as was standard policy in our clinic at the time of the investigation.

During each session, patients were first studied during one hour of isovolaemic dialysis, followed by combined ultrafiltration and haemodialysis until clinical dry weight, using the same dialysate sodium concentration. Parameters assessed were $\mathrm{IMB}$, relative blood volume, serum sodium, and plasma conductivity, which were measured at the start of the study, after one hour of isovolaemic dialysis, and at the end of the dialysis session (after combined haemodialysis and ultrafiltration). 


\section{Patients}

Thirteen patients were included in the study (eight male; five female). Mean $\pm S D$ age of the patients was $65.5 \pm 16.0$ years (range 26-81). Patients with acute renal insufficiency with severe hypotensive episodes were excluded. Mean dry body weight was $66.8 \pm 12.2 \mathrm{~kg}$ (range 43-92). Seven patients still had residual renal function. Mean urine volume in the patient group was $770 \pm 91 \mathrm{ml} /$ day (range $0-2.25 \mathrm{l}$ ). All patients gave informed consent for participation in the study.

\section{Dialysis schedule}

The dialysis schedule of the patients was twice weekly in five patients and three times a week in eight patients. Mean treatment time was $231 \pm 23$ min (range 180-270). Polysulfone (F8HPS; Fresenius ${ }^{\circ}$ ) dialysis membranes were used. Composition of the dialysate was: potassium $2.0 \mathrm{mmol} / \mathrm{l}$, calcium $1.5 \mathrm{mmol} / \mathrm{l}$, magnesium $0.5 \mathrm{mmol} / \mathrm{l}$, bicarbonate $32 \mathrm{mmol} / \mathrm{l}$, acetate $3.0 \mathrm{mmol} / \mathrm{l}$, and glucose $1 \mathrm{~g} / \mathrm{l}$. Temperature of the dialysate was $36^{\circ} \mathrm{C}$. Patients were ultrafiltered until their clinically determined dry weight.

\section{Study parameters}

\section{Ionic mass balance}

IMB was estimated by Diascan ${ }^{\circledR}\left(\text { Hospal }^{\circledR}\right)^{7,8}$. In short, Diascan ${ }^{\circledR}$ measures IMB by constant measurement of the conductivity in the dialysis outlet and inlet according to the formula:

$$
I M B=\left[\left(Q d_{\text {out }} \times C d_{\text {out }}\right)-\left(Q d_{\text {in }} \times C d_{\text {in }}\right)\right] \times 10 \times \text { time }(\mathrm{min}) .
$$

$\mathrm{Qd}_{\text {out }}$ and $\mathrm{Qd}_{\text {in }}$ are dialysate flow at, respectively, outlet and inlet; $\mathrm{Cd}_{\text {out }}$ and $\mathrm{Cd}_{\text {in }}$ are dialysate conductivity at, respectively, outlet and inlet. A positive IMB means sodium removal from the patient, a negative IMB means sodium transport to the patient.

\section{Plasma conductivity}

Plasma conductivity $\left(P_{c}\right)$ is measured by Diascan ${ }^{\circledR}$ by measuring dialysance (D) in combination with measurements of $\mathrm{Cd}_{\text {out }}$ and $\mathrm{Cd}_{\text {in }}$ according to the formula:

$$
\mathrm{P}_{\mathrm{c}}=\left[\mathrm{Cd}_{\text {out }}-\left(1-\mathrm{D} / \mathrm{Qd}_{\mathrm{in}}\right) \times \mathrm{Cd}_{\text {in }}\right] /\left(\mathrm{D} / \mathrm{Qd}_{\mathrm{in}}\right) \text {. }
$$

$D$ is assessed every 30 min by measuring the increase in $\mathrm{Cd}_{\text {out }}$ after a temporary increase in $\mathrm{Cd}_{\text {in }}$ by $1 \mathrm{~ms} / \mathrm{cm}$ according to the formula:

$$
D=\left(Q d_{\text {in }}+Q f\right) \times\left[1-\left(C d_{\text {out }} 1-C d_{\text {out }} 2\right) /\left(C d_{\text {in }} 1-C d_{\text {in }} 2\right)\right] \text {, }
$$

where 1 and 2 indicate, the measurements before and after the temporary increase in $\mathrm{Cd}_{\text {in }}{ }^{7,8}$ respectively, $\mathrm{Qd}$ in is dialysate flow at inlet and $\mathrm{Qf}$ is ultrafiltration rate. 


\section{Relative blood volume}

Blood volume was measured continuously by continuous optical assessment of changes in hemoglobin during the dialysis session $\left(\text { Hemoscan }^{\circledR}\right)^{9}$.

\section{Serum sodium}

Serum sodium was assessed by ionometry (Vitros 950 ${ }^{\circledR}$ ), which assesses sodium activity in the serum. Sodium activity is automatically converted to the molar ionized sodium concentration. Obtained values were corrected by converting the molar concentration to flame photometer values by a standard correction factor $(0.93)^{10}$. The coefficient of variation for this method, as given by the manufacturer, is $0.4 \%$.

\section{Statistical analysis}

Results obtained at the different treatment sessions were compared using Friedman's ANOVA and, if significant, further analysed by a Wilcoxon test. Correlations between variables were assessed by Pearson's $r$. $P$ values $<0.05$ were considered significant. Statistical analysis was performed using a SPSS 10.0 software package.

\section{Results}

\section{Validation study}

IMB assessed by Diascan ${ }^{\circledR}$ and direct dialysis quantification were highly significantly related $(r=0.94 ; P<0.05$; Figure 3.1). Dialysate conductivity of incoming dialysate assessed by the Integra ${ }^{\circledR}$ monitor was highly significantly related to dialysate conductivity assessed by the independent method $(r=0.99 ; P<0.05)$. Moreover, dialysate sodium concentration and dialysate conductivity were highly significantly related $(r=0.96 ; P<0.05)$.

\section{Isovolaemic dialysis}

All measurements were successful, except for one initial plasma conductivity measurement during DNa [140]. Pre-dialytic plasma conductivity and serum sodium concentrations are displayed in Tables 3.1 and 3.2. Pre-dialytic plasma conductivity was significantly related to pre-dialytic serum sodium $(r=0.80 ; P<0.05)$. 


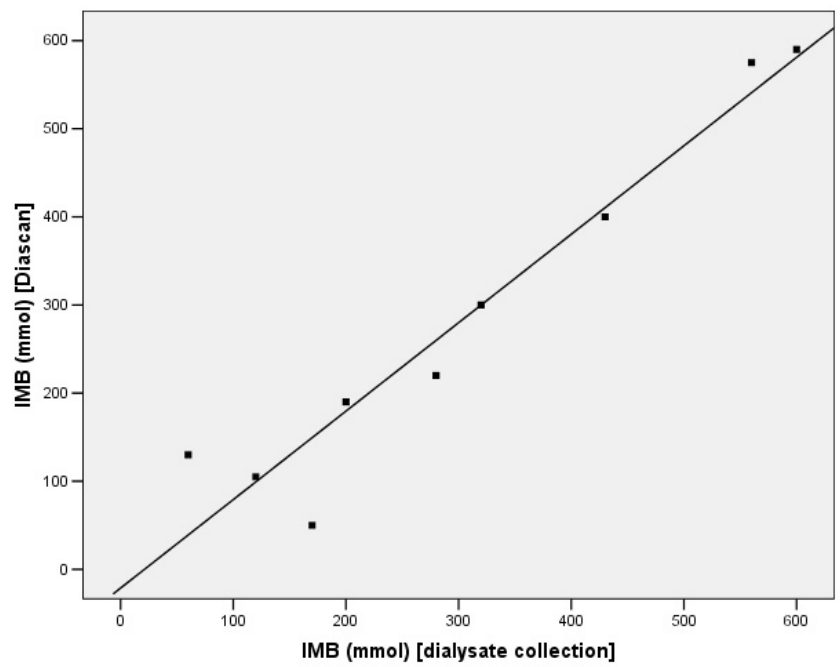

Figure 3.1 Relation between IMB assessed by dialysate collection and Diascan ${ }^{\circledR}$.

Table 3.1 Plasma conductivity and ionic mass balance during isovolaemic dialysis, followed by haemodialysis combined with ultrafiltration.

\begin{tabular}{lccccc}
\hline & \multicolumn{3}{c}{ Plasma conductivity $(\mathrm{ms} / \mathrm{cm})$} & \multicolumn{2}{c}{ IMB (mmol) } \\
& A & B & C & B & C \\
\hline $\mathrm{DNa}[140]$ & $14.21 \pm 0.31$ & $14.18 \pm 0.22$ & $14.11 \pm 0.16$ & $33.6 \pm 31.5^{*}$ & $317.7 \pm 166.0$ \\
$\mathrm{DNa}[144]$ & $14.26 \pm 0.20$ & $14.26 \pm 0.16$ & $14.32 \pm 0.10^{\#}$ & $11.3 \pm 26.0$ & $238.7 \pm 116.4^{*}$ \\
$\mathrm{DNa}$ [ind] & $14.24 \pm 0.22$ & $14.22 \pm 0.21$ & $14.24 \pm 0.24$ & $24.8 \pm 21.7$ & $276.9 \pm 116.2$ \\
\hline
\end{tabular}

* $\mathrm{P}<0.05$ compared with $\mathrm{DNa}[140]$ and $\mathrm{DNa}[$ ind]; \# $P<0.05$ comparedwith pre-HD. Values as mean $\pm \mathrm{SD}$. IMB, ionic mass balance; $A$, start dialysis; $B$, end isovolaemic dialysis ( $t=1 \mathrm{~h}$ ); $C$, end dialysis combined with ultrafiltration. NB: a more positive IMB corresponds to a larger ionic removal.

Table 3.2 Serum sodium, decline in blood volume, and ultrafiltration volume during isovolaemic dialysis followed by haemodialysis combined with ultrafiltration.

\begin{tabular}{lcccccc}
\hline & \multicolumn{3}{c}{ Serum sodium (mmol/l) } & \multicolumn{2}{c}{ BV (\%) } & UF-vol (I) \\
& $\mathrm{A}$ & $\mathrm{B}$ & $\mathrm{C}$ & $\mathrm{B}$ & $\mathrm{C}$ & \\
\hline $\mathrm{DNa}[140]$ & $139.1 \pm 2.0$ & $139.5 \pm 2.8$ & $139.4 \pm 1.3$ & $-1.8 \pm 1.3$ & $-8.6 \pm 4.6$ & $1.5 \pm 1.0$ \\
$\mathrm{DNa}[144]$ & $139.2 \pm 1.9$ & $138.6 \pm 2.5$ & $140.2 \pm 1.5^{\#}$ & $-1.5 \pm 1.3$ & $-7.4 \pm 3.7$ & $1.4 \pm 0.9$ \\
$\mathrm{DNa}$ [ind] & $140.0 \pm 2.1$ & $140.1 \pm 2.1$ & $140.3 \pm 2.0$ & $-1.9 \pm 1.3$ & $-8.4 \pm 2.2$ & $1.4 \pm 0.73$ \\
\hline
\end{tabular}

Plasma conductivity and plasma sodium did not change significantly during isovolaemic dialysis (Tables 3.1 and 3.2). Although precision of the measurements was not formerly tested in this study, we got an impression on the precision. Plasma sodium levels at the start and after the end of isovolaemic dialysis were correlated, as were plasma conductivity measurements. The correlation coefficient was $r=0.92$ for 
plasma conductivity but only $r=0.70$ for plasma sodium levels $(P<0.015)$, suggesting, but not proving, a higher precision of plasma conductivity measurements.

Mean dialysate conductivity during $\mathrm{DNa}$ [ind] was $143 \pm 2.1 \mathrm{mmol} / \mathrm{l}$. IMB differed significantly between the session with DNa [144] on the one hand and DNa [140] and $\mathrm{DNa}$ [ind] on the other, whereas $\mathrm{DNa}$ [140] and DNa [ind] were not significantly different (Table 3.1). IMB during isovolaemic dialysis with DNa [144] and DNa [140] was significantly related to the pre-dialytic plasma conductivity $(r=0.97$ and $r=0.81$; $P<0.05$ ) (Figures $3.2 \mathrm{~A}$ and $3.3 \mathrm{~A}$ ), and to a somewhat lesser degree, to the pre-dialytic serum sodium concentration ( $r=0.83$ and $r=0.61 ; P<0.05)$ (Figures $3.2 \mathrm{~B}$ and 3.3B). A negative IMB, indicating net ionic influx from dialysate to patient, occurred when the pre-dialytic serum sodium concentration was more than $5 \mathrm{mmol} / \mathrm{l}$ below the dialysate sodium concentration (Figures $3.2 \mathrm{~B}$ and $3.3 \mathrm{~B}$ ). The relative blood volume declined slightly during all treatment sessions without significant differences between the sessions (Table 3.1). There was no significant relation between the change in blood volume and IMB during isovolaemic dialysis with either treatment session.

A

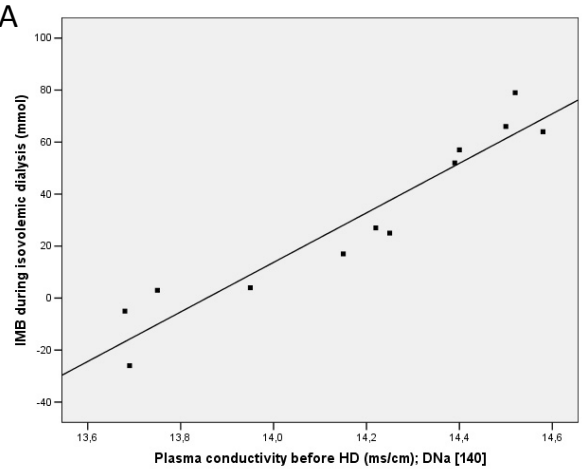

B

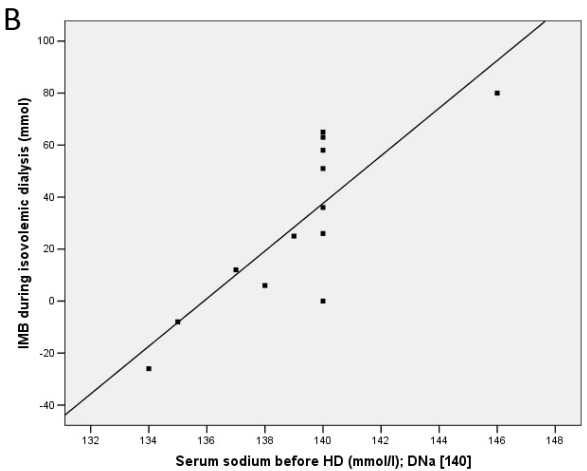

Figure 3.2 (A) Relation between pre-dialytic plasma conductivity and IMB during isovolaemic dialysis (HD) with a dialysate sodium concentration of $140 \mathrm{mmol} / \mathrm{I}$ (DNa [140]). (B) Relation between pre-dialytic serum sodium and IMB during isovolaemic dialysis (HD) with a dialysate sodium concentration of $140 \mathrm{mmol} / \mathrm{l}$ (DNa [140]).

\section{Ultrafiltration combined with haemodialysis}

The mean ultrafiltration volume was comparable between the three treatment sessions (Table 3.2).

Serum sodium increased significantly during DNa [144] but not during the other treatment modalities (Table 3.2). Moreover, IMB was significantly less positive during DNa [144], indicating less ionic removal, compared with DNa [140] and DNa [ind] $(P<0.05)$ (Table 3.2 and Figure 3.4). IMB was significantly related to ultrafiltration volume during both DNa [140] $(r=0.87)$, DNa [144] $(r=0.81)$, and DNa [ind] $(r=0.64$; all 
$P<0.05)$. During DNa [140], but not during the other treatment sessions, IMB was significantly related to pre-dialytic plasma conductivity $(r=0.59 ; P<0.05)$.

A

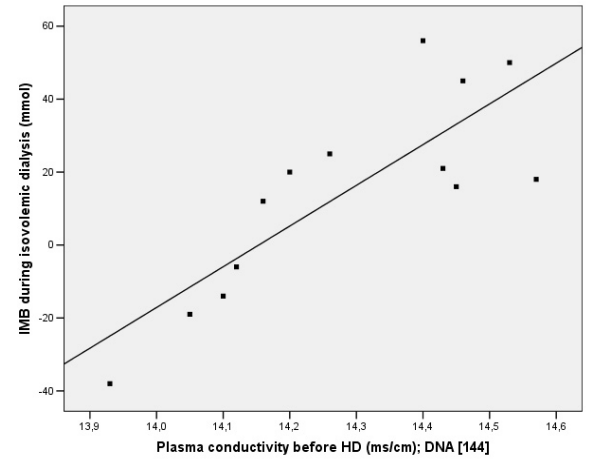

B

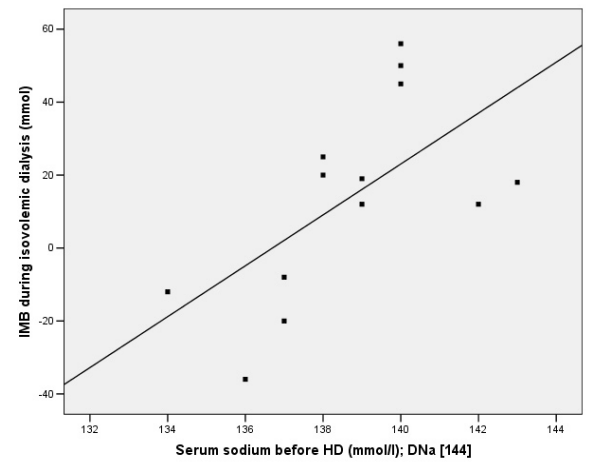

Figure 3.3 (A) Relation between pre-dialytic plasma conductivity and IMB during isovolaemic dialysis (HD) with a dialysate sodium concentration of $144 \mathrm{mmol} / \mathrm{l}$ (DNa [144]). (B) Relation between pre-dialytic serum sodium and IMB during isovolemic dialysis (HD) with a dialysate sodium concentration of $144 \mathrm{mmol} / \mathrm{l}$ (DNa [144]).

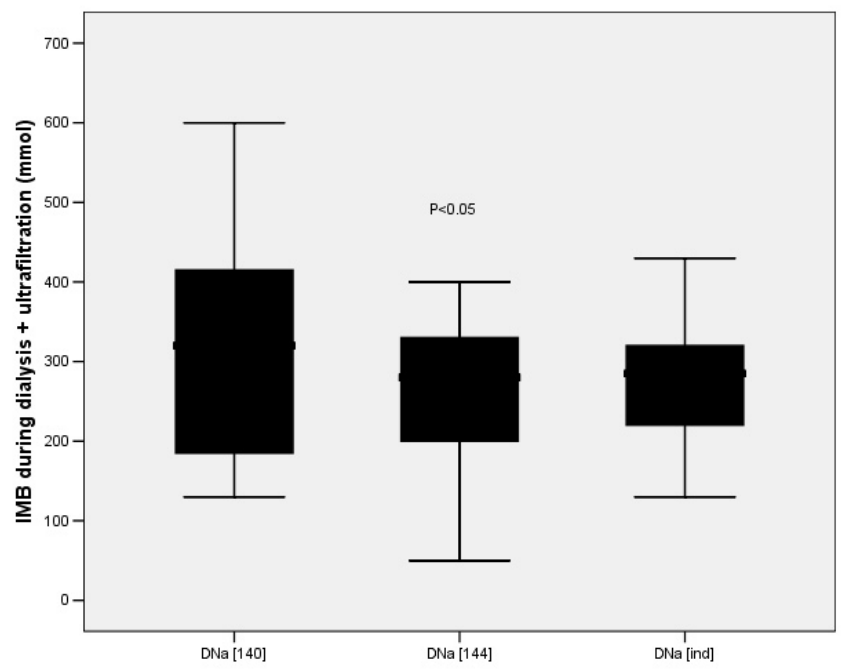

Figure 3.4 IMB during ultrafiltration combined with haemodialysis (UF+HD) with different dialysate sodium concentrations. DNa [140], dialysate sodium $140 \mathrm{mmol} /$; DNa [144], dialysate sodium $144 \mathrm{mmol} / \mathrm{l} ; \mathrm{DNa}$ [ind], individualized dialysate sodium. Box indicates the 25th-75th percentile range (line in box, median). Capped bars indicate the 10th-90th percentile range. 
The decline in relative blood volume (Table 3.2 and Figure 3.5) did not differ between the three treatment sessions. However, daily inter-dialytic weight gain following the treatment session was significantly higher after DNa [144] $(0.66 \pm 0.33 \mathrm{~kg} /$ day) compared with DNa [140] $(0.57 \pm 0.33 \mathrm{~kg} /$ day; $P<0.05)$, whereas the difference with $\mathrm{DNa}$ [ind] $(0.58 \pm 0.30)$ did not reach significance.

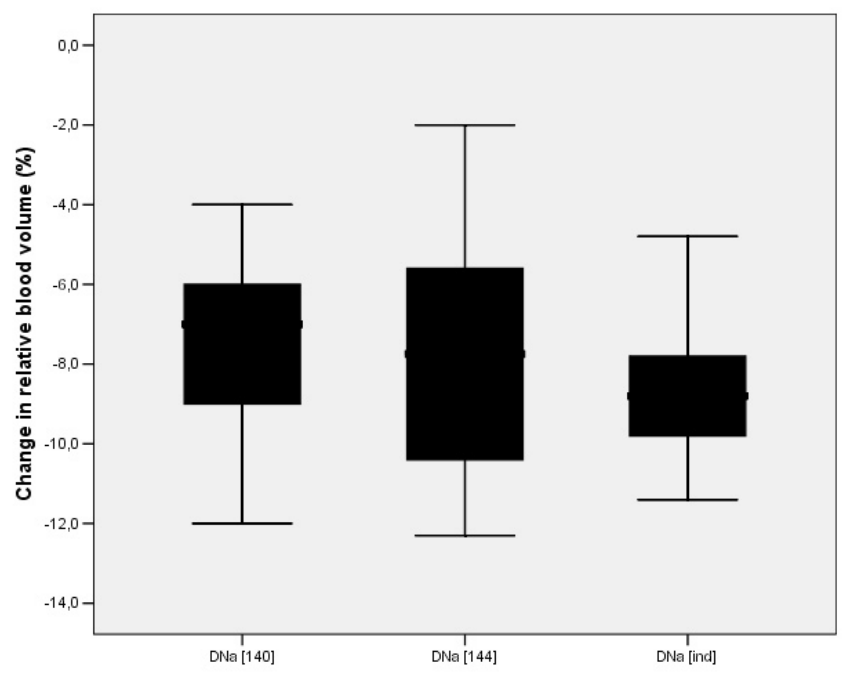

Figure 3.5 Decline in blood volume (BV) during ultrafiltration combined with haemodialysis (UF+HD) with different dialysate sodium concentrations. DNa [140], dialysate sodium $140 \mathrm{mmol} / \mathrm{l} ; \mathrm{DNa}$ [144], dialysate sodium $144 \mathrm{mmol} / \mathrm{l}$; DNa [ind], individualized dialysate sodium. Box indicates the 25th-75th percentile range (line in box, median). Capped bars indicate the 10th-90th percentile range.

The change in systolic blood pressure during the entire dialysis session (which was 12.7 $\pm 21.0 \mathrm{mmHg}$ during DNa [140], $0.0 \pm 15.3 \mathrm{mmHg}$ during DNa [144], and 5.9 \pm 17.4 $\mathrm{mmHg}$ during $\mathrm{DNa}$ [ind]) did not differ significantly between the different dialysis sessions, although it tended to be higher during DNa [140] compared with DNa [ind] $(P=0.08)$. Also, the decline in diastolic blood pressure (which was $-5.6 \pm 12.6 \mathrm{mmHg}$ during DNa [140], $-7.5 \pm 14 \mathrm{mmHg}$ during DNa [144], and $-2.4 \pm 9.4 \mathrm{mmHg}$ during $\mathrm{DNa}$ [ind]) did not differ significantly between the different dialysis sessions.

When patients with a pre-dialytic serum sodium concentration below $140 \mathrm{mmol} / \mathrm{l}$ or higher or equal to $140 \mathrm{mmol} / \mathrm{l}$ were analysed separately $(n=5)$, IMB was significantly higher during $\mathrm{DNa}$ [ind] compared with $\mathrm{DNa}$ [140] in patients with a pre-dialytic serum sodium concentration below $140 \mathrm{mmol} / \mathrm{l}$ (Figure 3.6) (324 \pm 87 vs $228 \pm 127 \mathrm{mmol}$; $P<0.05)$ whereas the decline in relative blood volume did not differ significantly $(-9.8 \pm 1.6$ vs $-7.8 \pm 2.3 \%$; $P=N S)$. In contrast, in patients with a pre-dialytic serum sodium 
concentration higher or equal to $140 \mathrm{mmol} / \mathrm{I}(n=8)$, IMB was significantly lower during DNa [ind] compared with DNa [140] (254 \pm 123 vs $350 \pm 178 \mathrm{mmol} ; P<0.05)$ (Figure 3.5) whereas also in these patients, the decline in relative blood volume did not differ significantly $(-7.1 \pm 1.8$ vs $-8.1 \pm 3.11 \%)$.

A

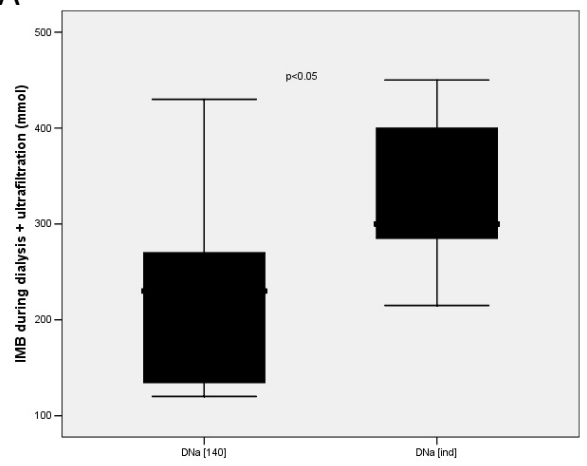

B

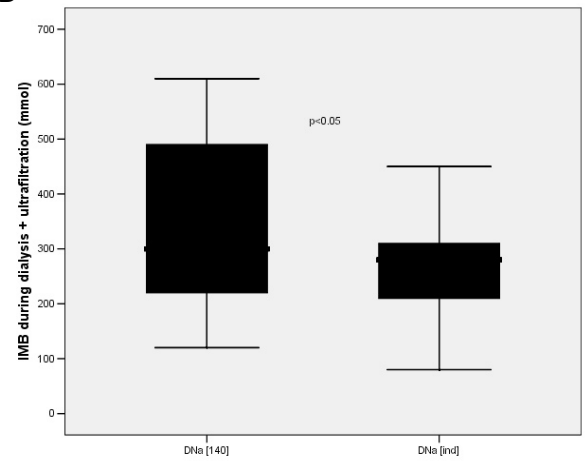

Figure 3.6 IMB during ultrafiltration combined with haemodialysis during dialysis with dialysate sodium concentrations of $140 \mathrm{mmol} / \mathrm{l}$ (DNa [140]) and individualized dialysate sodium (DNa [ind]) in patients with a pre-dialytic serum sodium concentration $<140$ (left) and $\geq 140 \mathrm{mmol} / \mathrm{l}$ (right). Box indicates the 25th-75th percentile range (line in box, median). Capped bars indicate the 10th-90th percentile range.

\section{Discussion}

The main findings of the present study are first, the large difference in ionic mass balance between haemodialysis with DNa [140] and DNa [ind] on the one hand and DNa [144] on the other, in combination with the small and non-significant difference in blood volume preservation between these modalities; secondly, the strong relation between pre-dialytic plasma sodium and plasma conductivity with ionic mass balance, which explains the diffusive ionic influx during isovolaemic dialysis in patients with low pre-dialytic plasma sodium levels; thirdly, the increased ionic removal during DNa [ind] in patients with low pre-dialytic plasma sodium levels and reduced ionic removal in patients with high pre-dialytic plasma sodium levels despite the absence of differences in blood volume preservation compared with DNa [140].

Ionic mass balance measurements by Diascan ${ }^{\circledR}$ appears to be suitable in detecting ionic changes during dialysis, as shown by the good agreement between Diascan ${ }^{\circledR}$ measurements and conductivity measurements in spent dialysate obtained during an entire dialysis session. As a result of the abundance of sodium ions in both dialysate and plasma, it is likely that IMB reflects predominately sodium balance during dialysis. It should, however, be mentioned that due to rapid changes in $\mathrm{pH}$, chloride, and 
bicarbonate, the relation of conductivity measurements to sodium balance may deviate slightly during dialysis. Moreover, in the present study, the relation between both plasma sodium and plasma conductivity levels was not completely linear. We believe, however, that this phenomenon might be due to a lack of precision of sodium measurements, as shown by the greater reproducibility of plasma conductivity measurements compared with plasma sodium levels, presented in the results section on isovolaemic dialysis. Moreover, the relation between pre-dialytic plasma conductivity measurements and IMB in the present study was far stronger than that obtained using plasma sodium measurements. The possible lack of preciseness of plasma sodium determination raises some doubt on the usefulness of monitoring plasma sodium levels in order to detect differences in ionic removal between various treatment modalities ${ }^{11}$.

Both during isovolaemic dialysis, as well as during haemodialysis combined with ultrafiltration, a significant difference in ionic mass balance was observed between DNa [144] compared with DNa [140] and DNa [ind], indicating less ionic removal during DNa [144]. Moreover, plasma sodium levels increased significantly during DNa [144], but not during the other treatment modalities. The mean difference in measured ionic mass balance between high and standard sodium dialysate was approximately $90 \mathrm{mmol}$ during an entire dialysis session, in theory corresponding to $2000 \mathrm{mg}$ of sodium, thus the entire recommended daily sodium intake of a dialysis patient. The long-term clinical significance of this phenomenon cannot be elucidated from the present study but may not be negligible in view of the strong arguments for a relation between sodium, hypertension, and cardiac abnormalities in dialysis patients ${ }^{4,5}$. Indeed, even inter-dialytic weight gain was higher after treatment with DNa [144]. However, only three single treatments were compared in this study and effects of different dialysate sodium prescription on ionic mass balance need to be repeated in more long term studies. Remarkable was the small and non-significant difference in blood volume preservation between the three treatment modalities. Nevertheless, in this stable group of dialysis patients, the decline in systolic blood pressure tended to be somewhat higher during DNa [140] compared with DNa [144]. The net diffusive ionic influx during DNa [140] in patients with low pre-dialytic plasma sodium levels is a phenomenon not often described in the literature, but is in line with earlier experimental data and theoretical considerations ${ }^{11-13}$. In the present study, diffusive ionic influx was observed when the plasma sodium concentration was approximately $2 \mathrm{mmol} / \mathrm{l}$ lower than the dialysate sodium concentration. Factors influencing diffusion between dialysate and plasma are complex and include the sodium concentration in plasma water, the Donnan effect, and the formation of complexes of sodium ions with anions in plasma water and dialysate ${ }^{11-13}$, as described in the Introduction.

Individualization of the dialysate in the present study was achieved by adjusting dialysate conductivity (which corresponds to $\mathrm{DNa}^{7}$ ) to the pre-dialytic plasma conductivity of the patient. This approach was performed because (effective) plasma 
conductivity measured by Diascan ${ }^{\circledR}$ is only related to the concentration of sodium ions which are free to diffuse and not trapped by the Donnan effect ${ }^{7}$. Individualization of DNa appeared predominantly relevant in patients with low pre-dialytic sodium levels, because in these patients, an increased ionic removal was achieved compared with DNa [140] whereas the decline in blood volume did not differ significantly. Nevertheless, the mean observed difference of approximately $2 \%$ might again be relevant in some patients. Therefore, it would certainly seem judicious to apply blood volume measurements if individualization of $\mathrm{DNa}$ is to be applied in hypotensiveprone dialysis patients with low pre-dialytic plasma sodium levels.

In the patients with higher pre-dialytic sodium levels, ionic removal was actually less during $\mathrm{DNa}$ [140] compared with $\mathrm{DNa}$ [ind] whereas again the decline in blood volume was not apparently different from DNa [140].

Drawbacks of the study are first the relatively small number of included patients, although this does not appear to have influenced the primary goal of the study, i.e. to assess IMB during different dialysate [Na] concentrations. Moreover, because the main objection was to study IMB and blood volume preservation during different dialysate sodium concentrations, stable haemodialysis patients were included. Further studies should also address the feasibility of individualized sodium concentrations of the dialysate in hypotension-prone dialysis patients.

Moreover, several patients still have residual renal function, which might have interfered with the influence of dialysate sodium prescription on inter-dialytic weight gain.

In conclusion, comparing three single sessions differing in dialysate sodium concentration, a relatively large difference in IMB, which may amount to the entire recommended daily sodium intake of a dialysis patient, was observed between DNa [144] on the one hand and $\mathrm{DNa}$ [140] and $\mathrm{DNa}$ [ind] on the other despite a nearly comparable blood volume preservation. In patients with a low pre-dialytic plasma sodium concentration, net diffusive ionic influx from the dialysate to the patient may occur during a fixed DNa. In patients with a low pre-dialytic plasma sodium concentration, individualization of dialysate sodium led to an improved ionic removal in patients, apparently without large implications for blood volume preservation during dialysis. 


\section{References}

1. Locatelli F, di Filippo S, Manzoni C. Relevance of the conductivity kinetic model in the control of sodium pool. Kidney Int 2000;58 [Suppl 76]:S89-S95.

2. Dheenan S, Henrich WL. Preventing dialysis hypotension: a comparison of usual protective maneuvers. Kidney Int 2001;59:1175-81.

3. Meers C, Toffelmire EB, McMurray M, Hopman W. Reducing complications during hemodialysis using gradient ultrafiltration with gradient sodium dialysate. ANNA J 1999;26:495-500.

4. Kooman JP, Leunissen KM, Luik AJ. Salt and hypertension in end-stage renal disease. Blood Purif1998; 16:301-11.

5. Ozkahya M, Ok E, Cirit M, Aydin S, Akçiçek F, Başçi A, Dorhout Mees EJ. Regression of left ventricular hypertrophy in haemodialysis patients by ultrafiltration and reduced salt intake without antihypertensive drugs. Nephrol Dial Transplant 1998; 13:1489-93.

6. Krautzig S, Janssen U, Koch KM, Granolleras C, Shaldon S. Dietary salt restriction and reduction of dialysate sodium to control hypertension in maintenance haemodialysis patients. Nephrol Dial Transplant 1998;13:552-3.

7. Bosetto A, Bene B, Petitclerc T. Sodium management in dialysis by conductivity. Adv Ren Replace Ther 1999;6:243-54.

8. Petitclerc T, Bene B, Goux N, Saudon MC, Jacobs C. Non invasive monitoring of effective dialysis dose delivered to the hemodialysis patient. Nephrol Dial Transplant 1995;10:212-6.

9. Paolini F, Mancini E, Bosetto A, Santoro A. Hemoscan: a dialysis machine-integrated blood volume monitor. Int J Artif Organs 1995;18:487-94.

10. Maas AHJ, Siggaard-Andersen O, Weisberg HF, Zijlstra WG. Ion-selective electrodes for sodium and potassium: a new problem of what is measured and what should be reported. Newslett Int Fed Clin Chem 1982;31:2-5.

11. Locatelli F, Ponti R, Pedrini L, Costanzo R, Di Filippo S, Marai P, Pozzi C. Sodium kinetics across dialysis membranes. Nephron 1984;38:174-7.

12. Flanigan MJ. Sodium flux and dialysate sodium in hemodialysis. Semin Dial 1998;11:298-304.

13. Locatelli F, di Filippo S, Manzoni C. Sodium kinetics during dialysis. Semin Dial 1999;12 [Suppl 1]: S41-4. 


\section{Chapter 4}

Variations in pre-dialytic plasma conductivity in dialysis patients: effect on ionic mass balance, blood pressure and interdialytic weight gain

Karin Moret, Charles Beerenhout, Jeroen Kooman ASAIO in press 


\section{Abstract}

\section{Background}

In this study, variations in plasma conductivity (PC), as a surrogate marker of plasma sodium, as well as its relation with intra-dialytic ionic mass balance (IMB) and blood pressure were assessed in 73 patients. PC and IMB were retrieved on a treatment-to-treatment basis during a 6-months period. Dialysate sodium was $140 \mathrm{mmol} / \mathrm{l} .4070$ treatments were analyzed.

\section{Methods and Results}

Mean coefficient of variation for pre-dialytic PC was $1.3 \%$, and mean intra-individual range in pre-dialytic PC measurements during the six months follow-up period was $0.9 \mathrm{mS} / \mathrm{cm}$ [ plasma sodium $9 \mathrm{mmol} / \mathrm{l}]$. Predialytic PC was related to both diffusive and total IMB ( $r=0.91 ; P<0.001$ and $r=0.35 ; P<0.01)$. The average diffusive IMB over a six-month period was negative in $33 \%$ of patients, and the average $\mathrm{PC}$ increased during dialysis in $14 \%$ of patients. Averaged pre-dialytic PC was significantly related to systolic blood pressure $(r=0.35 ; P<0.01)$, whereas within patients, pre-dialytic systolic blood pressure was significantly different between treatments with the lowest and highest pre-dialytic PC $(139 \pm 24$ versus $147 \pm 21 \mathrm{mmHg} ; P<0.05)$.

\section{Conclusion}

Concluding, depending on PC, diffusive ionic transfer from dialysate to patient may occur in a significant percentage of patients using a dialysate sodium concentration of $140 \mathrm{mmol} / \mathrm{I}$. Variations in PC are related to blood pressure, which might suggest a volume-independent effect of sodium. 


\section{Introduction}

Volume and sodium overload in dialysis patients are related to hypertension, edema and left ventricular dilatation ${ }^{1}$. Preliminary data suggest that, apart from volume, sodium might also have an independent effect on blood pressure regulation in dialysis patients ${ }^{2,3}$.

During dialysis, the main determinant of sodium removal during dialysis is the ultrafiltration volume (convective mass transfer). However, also the contribution of diffusive mass transfer of sodium may be significant ${ }^{4}$. As such, the prescription of the dialysate sodium concentration has an important effect on sodium balance during dialysis. With the advent of dialysate conductivity monitoring, it has become possible to approximate sodium fluxes during dialysis by means of the assessment of intradialytic ionic mass balance (IMB), as well as plasma conductivity (PC) as a surrogate of plasma sodium ${ }^{4-8}$. These developments offer the opportunity to study sodium balance in more detail. The main advantage of PC is, that it can be used on a treatment-totreatment basis without need for blood sampling.

Whereas previous studies have focused on the effect of modifications of dialysis treatment, such as sodium profiling ${ }^{4,5,9,10}$ in relatively small groups of patients, little is known about sodium balance on a treatment to treatment basis during dialysis with standard sodium concentrations (e.g. $140 \mathrm{mmol} / \mathrm{l}$ ) at facility level. One study showed an increase in plasma sodium during dialysis in a significant subset of patients with the use of a dialysate sodium concentration of $140 \mathrm{mmol} / \mathrm{I}^{11}$. Pre-dialytic plasma sodium levels are generally considered to be stable in dialysis patients, assuming a fixed sodium set-point in dialysis patients ${ }^{12,13}$, which may be of importance when dialysate sodium prescriptions are individualized. However, long term studies on sodium balance and variations in plasma sodium are scarce.

The aim of the present study was to assess variations in PC, as a surrogate marker of plasma sodium on a treatment to treatment basis at facility level. Moreover, the relation of inter and intra-individual changes in $\mathrm{PC}$ with $\mathrm{IMB}$, blood pressure, relative blood volume (RBV) and inter-dialytic weight gain was assessed.

\section{Methods}

\section{Study protocol}

In the dialysis centre of Maxima Medical Centre Veldhoven, The Netherlands, treatment data on PC, IMB, and changes in RBV are automatically stored in a database on a treatment to treatment basis. Data were retrieved from this database for a consecutive period of 6 months in each patient, and were randomly collected in the period between august 2006 and November 2007. Moreover, in this database, preand post-dialytic BP and body weight are recorded. The study was carried out 
according to the declaration of Helsinki and approved by the local institutional review board.

Data from 73 chronic dialysis patients were recorded. Patient characteristics are displayed in Table 4.1. All patients were on thrice-weekly hemodialysis, except for two patients, who were treated with twice-weekly dialysis sessions. All patients were treated with Integra (Hospal-Gambro, Mirandola, Italy) device, by which PC, IMB and changes in relative blood volume are automatically assessed and recorded. Polysulfone, low flux dialysis membranes (F8HPS ${ }^{\circ}$, Fresenius, Bad Homburg, Germany) were used. At the time of the study, prescription of the dialysate was: sodium 140 $\mathrm{mmol} / \mathrm{l}$ (conductivity $14.0 \mathrm{mS} / \mathrm{cm}$ ), potassium $2.0 \mathrm{mmol} / \mathrm{l}$, calcium $1.5 \mathrm{mmol} / \mathrm{l}$, magnesium $0.5 \mathrm{mmol} / \mathrm{l}$, bicarbonate $32 \mathrm{mmol} / \mathrm{l}$, acetate $3.0 \mathrm{mmol} / \mathrm{l}$ and glucose $1 \mathrm{~g} / \mathrm{l}$. Setting of the dialysate conductivity of the dialysis machine was $14 \mathrm{mS} / \mathrm{cm}$. Temperature of the dialysate was $36^{\circ} \mathrm{C}$. Patients were ultrafiltrated until their clinically determined dry weight. Fifteen patients were treated with the Hemocontrol (HospalGambro) biofeedback module, for which also an equivalent dialysate conductivity of $14.0 \mathrm{mS} / \mathrm{cm}$ was prescribed.

Table 4.1 Patient characteristics.

\begin{tabular}{lc}
\hline Age (years) & $67 \pm 16$ \\
Male/Female & $42 / 31$ \\
Dry weight (kg) & $70.2 \pm 14$ \\
Dialysis duration (hours) & $3.9 \pm 0.38$ \\
Dialysis frequency (per week) & $2.9 \pm 0.3$ \\
Residual Glomerular filtration rate (ml/min) & $1.1 \pm 1.8$ \\
\hline
\end{tabular}

\section{Ionic mass balance}

Intra-dialytic IMB was estimated by Diascan $^{\circledR}$ (Hospal-Gambro) integrated in the Integra $^{\circledR}$ dialysis module ${ }^{8,14}$. In short, Diascan ${ }^{\circledR}$ measures IMB by constant measurement of the conductivity in the dialysis outlet $\left(C d_{\text {out }}\right)$ and inlet $\left(C d_{\text {in }}\right)$. IMB is reported directly by the dialysis module. By convention, and also as such reported by the Integra ${ }^{\circledR}$ device, a positive IMB reflects net ionic removal from the patient, a negative IMB means net ionic transfer from dialysate to the patient ${ }^{6}$. Diffusive IMB was assessed by the following formula:

diffusive IMB = total IMB $-[($ mean PC $\times 10.4)-9.57] \times$ UF volume ${ }^{6}$.

\section{Validation of IMB measurements}

In 22 patients, direct dialysis quantification by Quantiscan ${ }^{\circledR}$ was performed during a single dialysis session. Quantiscan ${ }^{\circledR}$ continuously samples a small amount of the spent dialysis fluid. Electrolytes were assessed in duplicate in the spent dialysis fluid: sodium 
(flame photometry and indirect ionometry), potassium, calcium, phosphate, bicarbonate and chloride. Sodium balance was assessed as follows:

$$
\left[\mathrm{C}_{\text {out }} \times \mathrm{V}_{\text {out }}\right]-\left[\mathrm{C}_{\text {in }} \times \mathrm{V}_{\text {in }}\right]
$$

$C_{\text {out }}$ and $C_{\text {in }}$ are the sodium concentration in spent and fresh dialysate, respectively.

$\mathrm{V}_{\text {out }}$ and $\mathrm{V}_{\text {in }}$ are the volume of spent and incoming dialysate.

$V_{\text {out }}$ is calculated as (dialysate flow rate $(\mathrm{ml} / \mathrm{min})+$ ultrafiltration rate $\left.(\mathrm{ml} / \mathrm{min})\right) \mathrm{x}$ dialysis time ( $\mathrm{min})$

and $\mathrm{V}_{\text {in }}$ as dialysate flow rate $(\mathrm{ml} / \mathrm{min}) \mathrm{x}$ dialysis time $(\mathrm{min})$. The same procedure was followed for the other ions.

\section{Plasma conductivity}

PC was measured and reported directly by Diascan by measuring dialysance (D) in combination with measurements of $C d_{\text {out }}$ and $C d_{\text {in }}$ according to the formula:

$$
P C=\left[C_{d_{\text {out }}}-\left(1-D / Q d_{\text {in }}\right) \times C d_{\text {in }}\right] /\left(D / Q d_{\text {in }}\right)
$$

$D$ is assessed every $30 \mathrm{~min}$ by measuring the increase in $\mathrm{Cd}_{\text {out }}$ after a temporary increase in $\mathrm{Cd}_{\text {in }}$ by $1 \mathrm{mS} / \mathrm{cm}$ according to the formula:

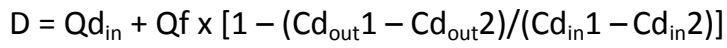

1 and 2 indicate, respectively, the measurements before and after the temporary increase in $\mathrm{Cd}_{\text {in }}{ }^{4,14}, \mathrm{Qd}_{\text {in }}=$ dialysate flow at inlet, $\mathrm{Qf}=$ ultrafiltration rate

\section{Plasma sodium}

Plasma sodium levels were assessed before dialysis, approximately once monthly, by indirect ionometry (Vitros 950'). Plasma sodium levels were available in 332 treatments. The relation between PC and plasma sodium given in the literature is:

$$
\text { Plasma sodium }=(P C \times 10.4)-9.57^{6,7} .
$$

\section{Relative blood volume, blood pressure and residual GFR}

Changes in relative blood volume were measured continuously by continuous optical assessment of changes in haemoglobin during the dialysis session (Hemoscan ${ }^{\circledR}$, Hospal-Gambro). Blood pressure was taken as part of the clinical routine in sitting position just prior to the start of dialysis treatment. Body weight was measured, as part of the clinical routine, on a gravimetric scale. Residual GFR was assessed by interdialytic urine collections as the mean of urea and creatinine clearance.

\section{Data analysis}

Intra- and inter-individual variations in PC are reported by means of the range, standard deviation, and coefficient of variation. The relation between pre-dialytic PC, $\mathrm{IMB}$, relative blood volume, interdialytic weight gain and blood pressure was assessed by correlation analysis (Pearson's $r$ ). Measurements during the 6 months period were 
also pooled for each patient, and the mean of these data was used for analysis. Multiregression analysis was used where necessary. Regarding intra-individual variations, pre-dialytic blood pressure and interdialytic weight gain were compared between the session with the highest and lowest value of PC and analyzed using a paired student-t test. Correction for ultrafiltration volume and timing of the dialysis shift (after longest or short dialysis interval) was performed using univariate analysis with lowest or highest plasma conductivity as fixed factor and timing of dialysis shift and ultrafiltration volume as covariates.

\section{Results}

In total, 4070 measurements were retrieved in 73 patients. The mean number of treatment analysed was 56 [range 45 to 63 treatments]. Missing data were amongst others, the result of technical problems with the data management tool. The mean of the pooled data collected during the 6 months period for the patient is summarized in Table 4.2, separately presented for patients on Hemocontrol and standard dialysis treatment.

Table 4.2 Summary of parameters (6 months data pooled for each patient).

\begin{tabular}{lcc}
\hline & Standard dialysis $(\mathrm{n}=58)$ & Hemocontrol $(\mathrm{n}=15)$ \\
\hline Pre-dialytic PC (mS/cm) & $14.19 \pm 0.22$ & $14.39 \pm 0.14$ \\
Post-dialytic PC (mS/cm) & $14.06 \pm 0.09$ & $14.07 \pm 0.06$ \\
Total IMB (mmol/treatment) & $342.8 \pm 140.8$ & $463.8 \pm 57.6$ \\
Diffusive IMB (mmol/treatment) & $26.8 \pm 64.5$ & $95.6 \pm 35.8$ \\
Inter-dialytic weight gain (kg) & $2.5 \pm 1.0$ & $2.7 \pm 0.5$ \\
Decline in relative blood volume (\%) & $-7.9 \pm 2.7$ & $-7.9 \pm 2.3$ \\
Pre-dialytic systolic BP (mmHg) & $143.2 \pm 18.4$ & $153.2 \pm 15.3$ \\
Pre-dialytic diastolic BP (mmHg) & $78.6 \pm 11.3$ & $81.0 \pm 0.9$ \\
\% patients with negative IMB & 32.9 & 0 \\
\% patients with increasing PC & 13.7 & 0 \\
\hline
\end{tabular}

$\mathrm{PC}=$ plasma conductivity $(\mathrm{mS} / \mathrm{cm}) ; \mathrm{IMB}=$ ionic mass balance $(\mathrm{mmol} /$ treatment$) ; \mathrm{BP}=$ blood pressure $(\mathrm{mmHg})$

Diffusive mass balance was $18.3 \pm 16.7 \%$ of convective mass balance. Whereas total IMB was positive (indicating net ionic transfer from the patient to the dialysate) in all patients using the pooled data, the averaged diffusive IMB was negative (indicating diffusive ionic transfer from dialysate to patient) in 33\% of patients. In $14 \%$ of patients, the averaged PC increased during dialysis. As shown in Table 4.3, the only parameter which distinguished between patients with respective negative or positive diffusive IMB, or an increase or decrease in PC during dialysis, was the pre-dialytic PC. For intra-individual variations in pre-dialytic $\mathrm{PC}$, the coefficient of variation during the 6 months follow-up period was $1.3 \%$. For post-diaytic PC, the coefficient of variation was $1.0 \%$. The mean $(14.31 \pm 0.19$ versus $14.21 \pm 0.23)$ and coefficient of variation $[1.2$ 
vs $1.3 \%$ ] of pre-dialytic PC was not significantly different between patients with $(n=15)$ or without diabetes mellitus $(n=58)$

Table 4.3 Differences between patients with a (mean averaged) negative of positive diffusive IMB and increase or decrease in PC during dialysis.

\begin{tabular}{lcccccc}
\hline & $\mathrm{IMB}<0$ & $\mathrm{IMB} \geq 0$ & & $\mathrm{PC} \uparrow$ & $\mathrm{PC} \downarrow$ & \\
& Mean $\pm \mathrm{SD}$ & $\mathrm{Mean} \pm \mathrm{SD}$ & $P$ value & Mean $\pm \mathrm{SD}$ & Mean $\pm \mathrm{SD}$ & $P$ value \\
\hline & 24 & 49 & & 10 & 63 & \\
Age & $70.7 \pm 13.6$ & $66.7 \pm 16.9$ & $\mathrm{NS}$ & $69.0 \pm 15.5$ & $67.1 \pm 16.2$ & $\mathrm{NS}$ \\
Diabetes Mellitus & $\mathrm{n}=4(17 \%)$ & $\mathrm{n}=11(22 \%)$ & $\mathrm{NS}$ & $\mathrm{n}=0$ & $\mathrm{n}=15(24 \%)$ & 0.08 \\
Pre-dialytic PC (mS/cm) & $14.00 \pm 0.18$ & $14.34 \pm 0.14$ & $<0.001$ & $13.83 \pm 0.11$ & $14.29 \pm 0.15$ & $<0.001^{*}$ \\
Inter-dialytic weight gain $(\mathrm{kg})$ & $2.6 \pm 1.0$ & $2.5 \pm 0.8$ & $\mathrm{NS}$ & $2.8 \pm 1.0$ & $2.5 \pm 0.9$ & $\mathrm{NS}$ \\
\hline
\end{tabular}

Mean values (SD) are presented for continues variables. Significant, $P<0.05$.

$\mathrm{IMB}<0$ means net diffusive ionic transport from dialysate to patient. $P C=$ plasma conductivity $(\mathrm{mS} / \mathrm{cm})$; $\mathrm{IMB}=$ ionic mass balance ( $\mathrm{mmol} /$ treatment).

Within patients, pre-dialytic PC was $13.78 \mathrm{mS} / \mathrm{cm} \pm 0.29$ before the treatment with the lowest pre-dialytic PC and $14.65 \mathrm{mS} / \mathrm{cm} \pm 0.25$ before the treatment in which the highest pre-dialytic PC was recorded. The intra- and inter-patient variations in predialytic PC can also be observed in Figure 4.1A and 4.1B. The variation in the CV of pre-dialytic PC is shown in Figure 4.1C.

Although the observation period was not designed to assess seasonal variations in detail, we observed a significantly difference between the various seasons with the lowest values in autumn $(14.21 \pm 0.28 \mathrm{mS} / \mathrm{cm})$, followed by summer $(14.22 \pm 0.28$ $\mathrm{mS} / \mathrm{cm})$, winter $(14.25 \pm 0.30)$ and spring $(14.27 \pm 0.28 \mathrm{mS} / \mathrm{cm})(\mathrm{p}<0.001)$. Regarding the timing of the dialysis shift, we also compared pre-dialytic PC between treatments after the longest shift, and the other treatments. No significant difference in PC was observed: $14.24 \pm 0.29$ before the longest shifts and $14.25 \pm 0.29$ before the other shifts. The variation in post-dialytic PC was less as compared to pre-dialytic PC . Mean SD for post-dialytic PC was $0.09 \mathrm{mS} / \mathrm{cm}$. Post-dialytic PC was $13.85 \mathrm{mS} / \mathrm{cm} \pm 0.19$ after the treatment with the lowest pre-dialytic $P C$ and $14.30 \mathrm{mS} / \mathrm{cm} \pm 0.20$ after the treatment in which the highest pre-dialytic PC was recorded (Table 4.4). 


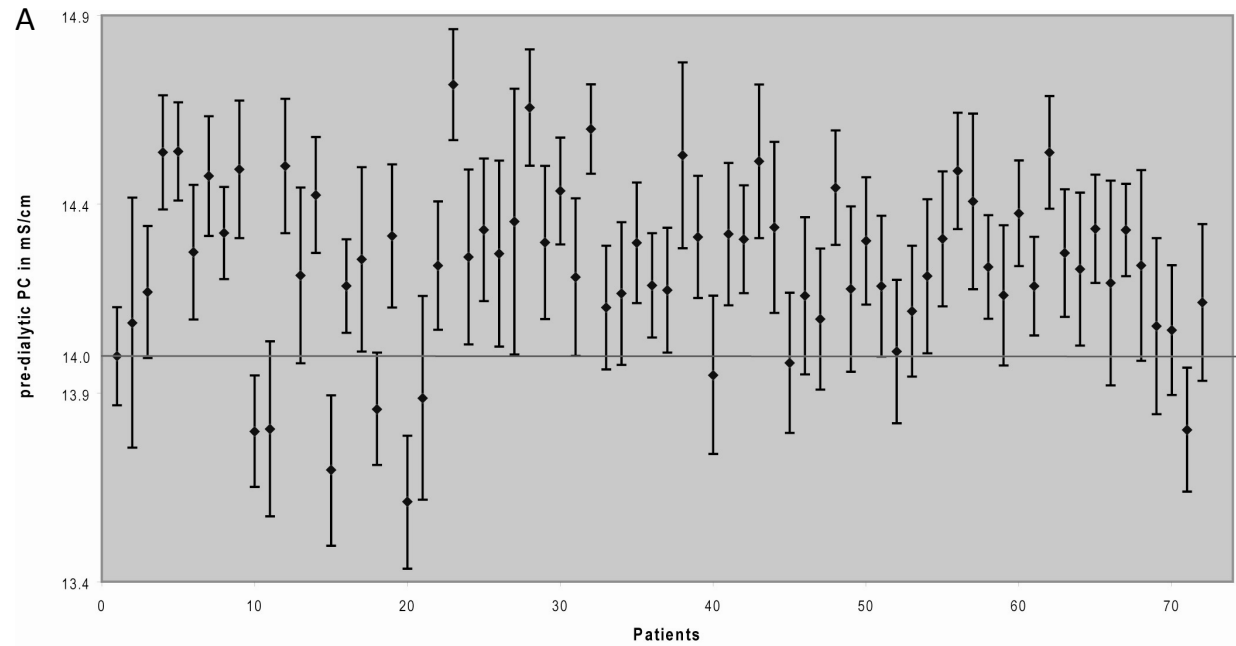

Figure 4.1A Inter and intra-dialytic variation in pre-dialytic plasma conductivity (mean $\pm \mathrm{SD}$ ). The horizontal line depicts a PC of $14.0 \mathrm{mS} / \mathrm{cm}$. PC=plasma conductivity $(\mathrm{mS} / \mathrm{cm})$

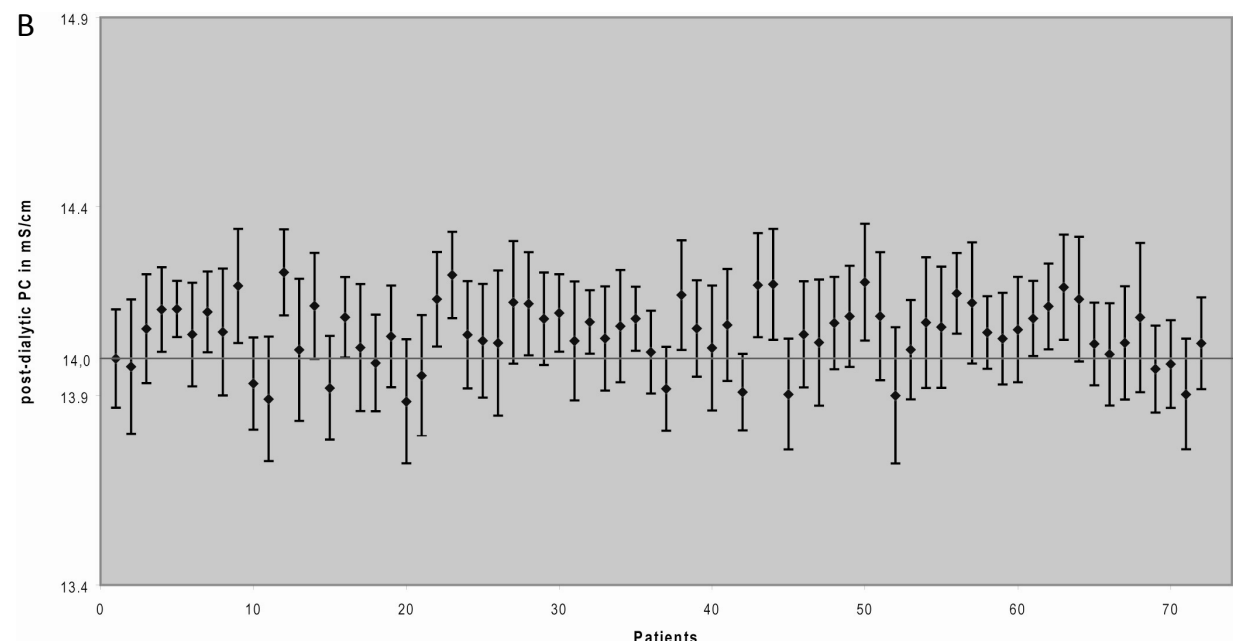

Figure 4.1B Inter and intra-dialytic variation in post-dialytic plasma conductivity (mean $\pm \mathrm{SD})$. The horizontal line depicts a $\mathrm{PC}$ of $14.0 \mathrm{mS} / \mathrm{cm}$. PC=plasma conductivity $(\mathrm{mS} / \mathrm{cm})$ 


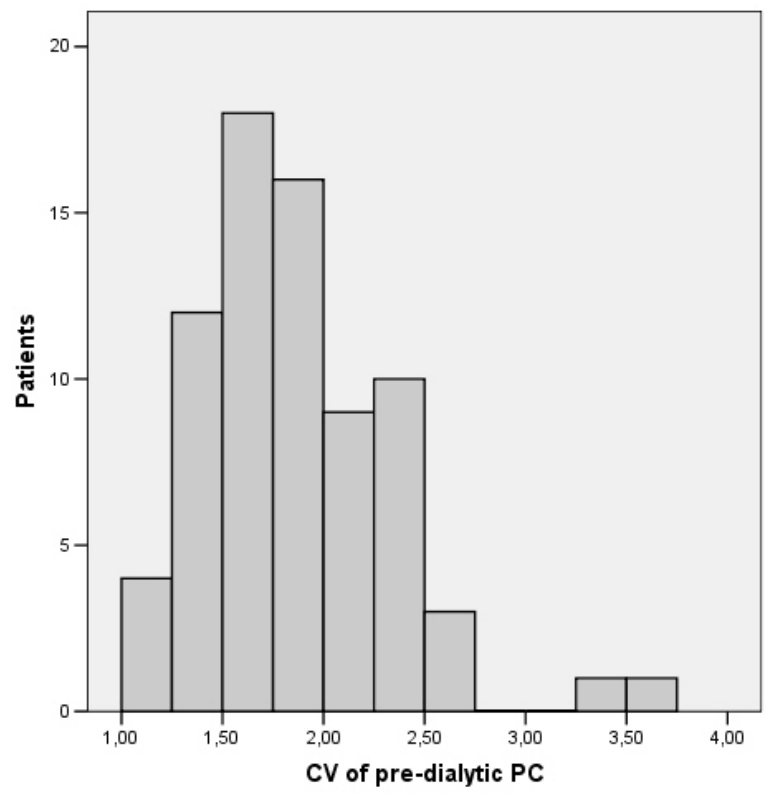

Figure 4.1C Coefficient of variation for plasma conductivity: frequency and distribution in patients $\mathrm{PC}=$ plasma conductivity $(\mathrm{mS} / \mathrm{cm})$

\section{Relation between PC, IMB and hemodynamic parameters}

In the 4070 measurements, pre-dialytic PC was significantly related to diffusive IMB $(r=0.82 ; P<0.001)$ (Figure 4.2). The same held true for diabetic patients $(n=15)$, which were analyzed in a subgroup $(r=0.86 ; P<0.001)$. Total and diffusive IMB, as well as inter-dialytic weight gain were not significantly different between patients with or without diabetes mellitus.

The mean averaged PC during the 6 months period in the 73 patients was significantly related to total $(r=0.37 ; P<0.01)$ and diffusive IMB $(r=0.91 ; P<0.001)$, as well as to the change in $P C$ during dialysis $(r=-0.85 ; P<0.001)$. Total IMB was strongly related to ultrafiltration volume $(r=0.88)$. Pre-dialytic $P C$ was significantly related to pre-dialytic systolic blood pressure $(r=0.35 ; P<0.01)$ [Figure $4.3 \mathrm{~A}$ ], but not to diastolic blood pressure $(r=0.1 ; P=N S)$ or interdialytic weight gain in the period before $(r=-0.09$; $P=N S)$. Using multiregression analysis, the relation between pre-dialytic systolic BP and pre-dialytic PC ( $\beta=0.37 ; P=0.002)$ was independent of inter-dialytic weight gain, and the number of antihypertensive agents used $(\beta=0.14 ; P=N S)$. Although the relation between pre-dialytic PC and diffusive IMB was comparable $(r=0.84 ; P<0.001)$ in the subgroup of patients on Hemocontrol ${ }^{\circledR}$, diffusive IMB was positive in all patients whereas no rise in PC was observed. 


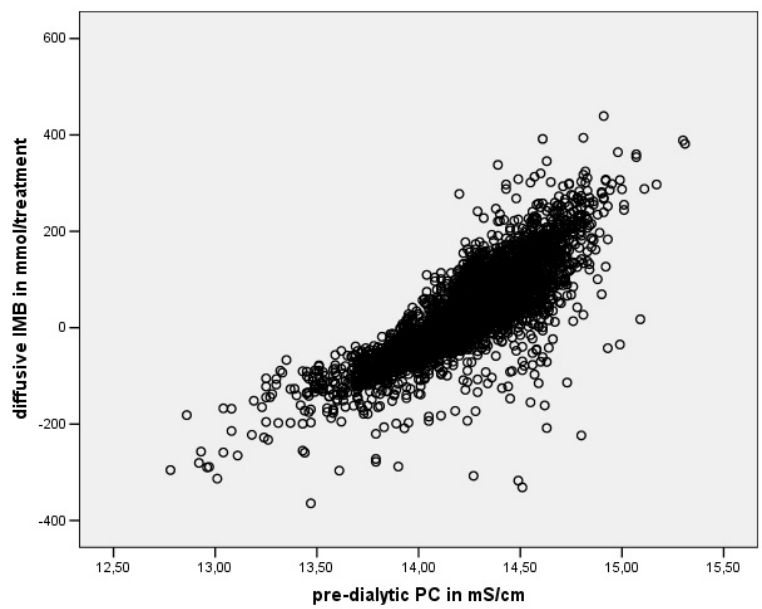

Figure 4.2 Relation between pre-dialytic PC and diffusive IMB $\mathrm{PC}=$ plasma conductivity $(\mathrm{mS} / \mathrm{cm})$; $\mathrm{IMB}=$ ionic mass balance ( $\mathrm{mmol} /$ treatment)

\section{Intra-patient variations in pre-dialytic PC}

When analyzing the effect of intra-patient variations of PC, significant differences in $\mathrm{IMB}$, pre-dialytic systolic (Figure 4.3B) and diastolic blood pressure were observed between the treatments with the lowest and highest pre-dialytic $\mathrm{PC}$, whereas interdialytic weight gain (in the period before the highest and lowest PC) were not significantly different (Table 4.4). There was no significant relation between the absolute difference in blood pressure and the corresponding difference in PC between both treatments.

Table 4.4 Intra-patient differences between treatments with the highest and lowest pre-dialytic PC.

\begin{tabular}{lccc}
\hline & Lowest PC & Highest PC & \\
\hline Pre-dialytic PC (mS/cm) & $13.78 \pm 0.29$ & $14.65 \pm 0.25$ & $<0.001$ \\
Post-dialytic PC (mS/cm) & $13.85 \pm 0.19$ & $14.30 \pm 0.20$ & $<0.001$ \\
Total IMB (mmol/treatment) & $237.3 \pm 163.8$ & $511 \pm 165.9$ & $<0.001$ \\
Diffusive IMB (mmol/treatment) & $-84.7 \pm 66.7$ & $132.4 \pm 98.3$ & $<0.001$ \\
Inter-dialytic weight gain (kg) & $2.4 \pm 1.1$ & $2.7 \pm 1.0$ & NS \\
Decline in relative blood volume (\%) & $-8.1 \pm 3.5$ & $-7.7 \pm 3.6$ & NS \\
Pre-dialytic systolic BP (mmHg) & $138.6 \pm 23.8$ & $147.4 \pm 21.2$ & $<0.05$ \\
Pre-dialytic diastolic BP (mmHg) & $75.2 \pm 13.3$ & $81.0 \pm 13.6$ & $<0.01$ \\
\hline
\end{tabular}

$\mathrm{PC}=$ plasma conductivity $(\mathrm{mS} / \mathrm{cm}) ; \mathrm{IMB}=$ ionic mass balance $(\mathrm{mmol} /$ treatment $) ; \mathrm{BP}=$ blood pressure $(\mathrm{mmHg})$ 
There were no significant differences in inter-dialytic weight gain $(2.6 \pm 1.0$ versus $2.5 \pm 1.0 \mathrm{I})$, systolic $(148.6 \pm 25.1$ versus $145.5 \pm 24.3 \mathrm{mmHg}$ ) or diastolic blood pressure $(80.5 \pm 13.5$ versus $79.6 \pm 14.4 \mathrm{mmHg})$ in the period after the highest and lowest predialytic PC.

When using univariate analysis with correction for covariates, the difference between the treatments with lowest or highest pre-dialytic PC value and pre-dialytic systolic blood pressure remained significant $(F=5.9 ; P<0.05)$ independent of the season ( $\mathrm{F}=8.38 ; P<0.01)$, timing of the dialysis shift [after long or short interval] $(\mathrm{F}=0.27 ; P=\mathrm{NS})$ and interdialytic weight gain (in the period before the lowest or highest $P C)(F=3.03$; $P=0.08)$. The same held true for the difference in pre-dialytic diastolic blood pressure between the treatments with the highest and lowest pre-dialytic $P C(F=6.91 ; P=0.01)$ when corrected for inter-dialytic weight gain $(F=4.13 ; P<0.05)$, timing of dialysis shift ( $\mathrm{F}=0.86 ; P=\mathrm{NS})$ or season $(\mathrm{F}=2.91 ; P=0.09)$.

\section{Plasma sodium: variation and relation with PC and IMB}

Mean pre-diaytic plasma sodium was $140.0 \pm 3.4 \mathrm{mmol} / \mathrm{l}$. Mean intra-individual coefficient of variation was $1.4 \%$. The mean difference between the lowest and highest plasma sodium concentration was $4.6 \mathrm{mmol} / \mathrm{l}$.

In the present study, the relation between pre-dialytic plasma sodium and PC was highly significant $(r=0.77 ; P<0.001)$ [Figure 4.4A]. The regression equation between plasma sodium and PC was as follows:

plasma sodium $=26.98+7.94 * P C$

(in which a PC of $14.0 \mathrm{mS} / \mathrm{cm}$ would correspond to a plasma sodium of $138.1 \mathrm{mmol} / \mathrm{l}$. Using the data of the 332 treatments for which plasma sodium was available, predialytic plasma sodium was significantly related to diffusive IMB $(r=0.57 ; P<0.001)$ and total IMB ( $r=0.26 ; P<0.001$ ) (Figure 4.4B).

\section{Validation study: relation between IMB and sodium balance}

As displayed in Figure 4.5A a highly significant relation was observed between IMB and sodium balance (using flame photometry) based on direct dialysis quantification $(r 2=0.98)$. The disagreement in absolute values appeared to increase at higher levels of $\mathrm{IMB}$, as shown in Figure 4.5B However, the F-vale for the regression equation between sodium balance and IMB was very high $(F=307.6)$, with the following equation:

Sodium balance $(\mathrm{mmol})=57+1.29 \times \mathrm{IMB}$.

Using indirect ionometry to determine sodium, the correlation became somewhat less strong $(r=0.91)$, but the mean difference between both methods was also somewhat less as compared to the flame photometry measurements ( $76 \pm 202 \mathrm{mmol}$ ). Whereas in multiregression analysis, the relation between IMB and sodium balance was highly 
significant, the balance of the other ions such as potassium, chloride, bicarbonate and calcium was not significantly related to IMB.

A

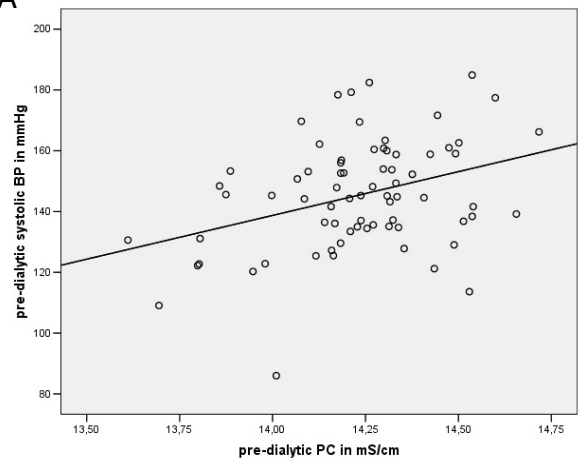

B

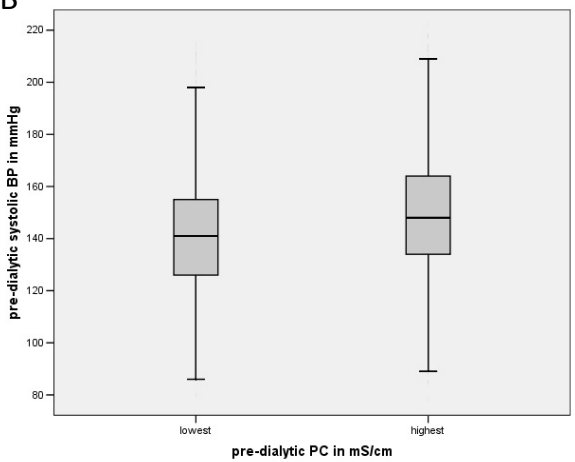

Figure 4.3 A: Relation between pre-dialytic PC and pre-dialytic systolic BP (mean of pooled data) $B$ : Intra-patient difference in systolic BP between treatments with the lowest and highest PC before dialysis. $\mathrm{PC}=$ plasma conductivity $(\mathrm{mS} / \mathrm{cm}) ; \mathrm{BP}=\mathrm{Blood}$ Pressure $(\mathrm{mmHg})$.

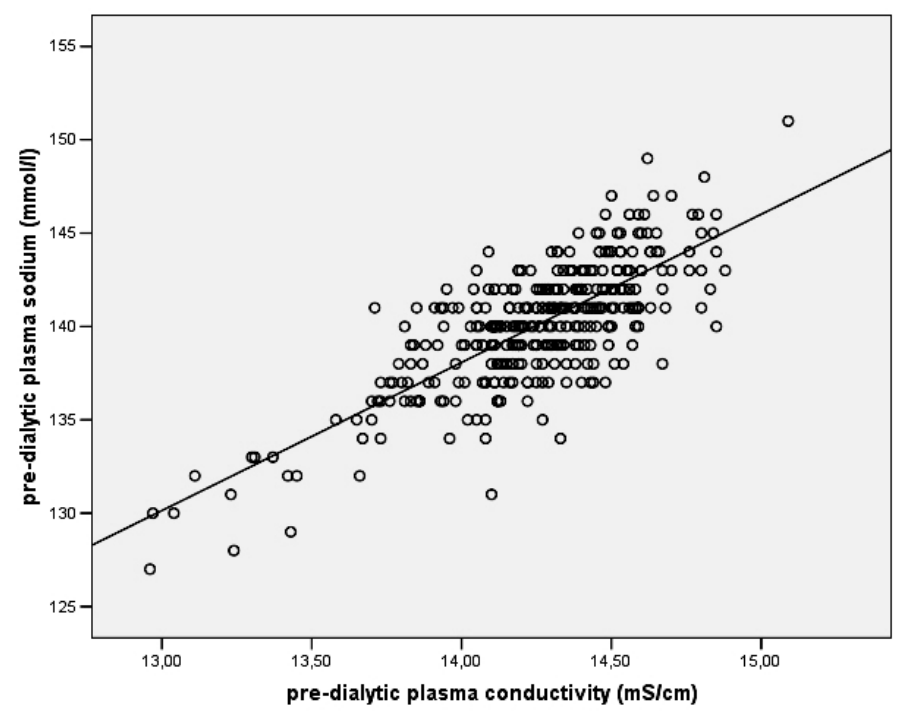

Figure 4.4A Relation between pre-dialytic plasma sodium and plasma conductivity $\mathrm{PC}=$ plasma conductivity $(\mathrm{mS} / \mathrm{cm})$ 


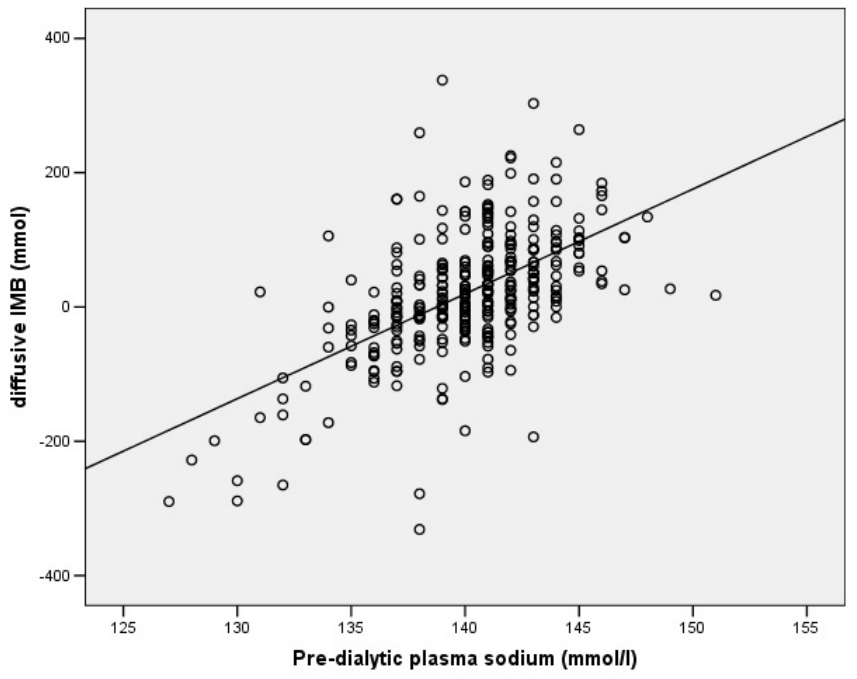

Figure 4.4B

Relation between pre-dialytic plasma sodium and diffusive ionic mass balance. $\mathrm{IMB}=$ ionic mass balance (mmol/treatment)

A

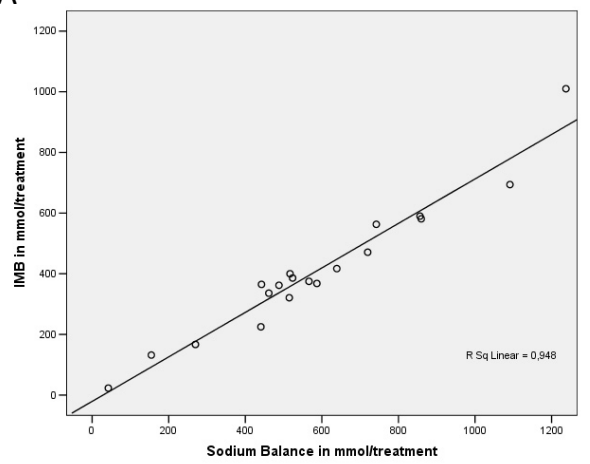

B

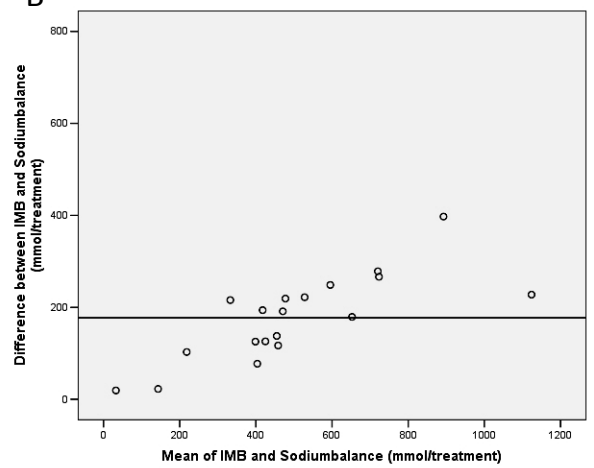

Figure 4.5 A: Relation between IMB by Diascan ${ }^{\circledR}$ and sodium balance by flame photometry in direct dialysis quantification.

B: Agreement between IMB by Diascan ${ }^{\circledast}$ and sodium balance by flame photometry in direct dialysis quantification.

$\mathrm{IMB}=$ Ionic mass balance (mmol/treatment); Sodium balance (difference between dialysate inlet sodium and dialysate outlet sodium). 


\section{Discussion}

This study shows that both intra- and inter-individual variations in PC, which was used as a surrogate for plasma sodium, have a significant effect on IMB (as a surrogate marker for sodium balance) during dialysis. With a dialysate sodium concentration of $140 \mathrm{mmol} / \mathrm{l}$, in a significant percentage of patients diffusive ionic mass transfer from dialysate to patient was observed, whereas PC increased during dialysis in a lesser percentage of patients. Both inter- and intra-individual variations in pre-dialytic PC were related to pre-dialytic blood pressure, independent of interdialytic weight gain and thus appear to be of physiologic relevance.

In agreement with earlier studies in dialysis patients, we observed a significant interindividual variation in pre-dialytic PC, as a surrogate for plasma sodium. Moreover, also significant intra-individual variations in PC were observed. In 10 nondiabetic dialysis patients whom were followed for 12 months, Flanigan observed a variation in plasma sodium concentrations of approximately $2 \%{ }^{11}$. This would appear in agreement with the mean coefficient of variation of $1.3 \%$ of PC in the present study, which is in agreement with data from the normal population in the literature and likely reflects for the largest part "real" intra-individual and not method variation ${ }^{15}$. However, the mean intra-individual difference in PC measurements between the lowest and highest PC measurements during the 6 months follow-up period was $0.9 \mathrm{mS} / \mathrm{cm}$, corresponding to a plasma sodium concentration of $\pm 9 \mathrm{mmol} / \mathrm{l}$. This observation shows that during a follow-up period of 6 months, relatively large intrapatient variations in PC may occur. Although some of these values may be outliers, they still might have pathophysiologic relevance due to the relation with blood pressure and IMB. We were not able to provide a definite explanation for the variations in PC. He et al. showed an effect of dietary sodium intake on plasma sodium levels $^{16}$. We also noted some seasonal variation in PC, although the study was not specifically designed for this purpose. The seasonal variation in PC is in agreement with the data of Chen ${ }^{17}$ in peritoneal dialysis patients.

The variation in PC is in agreement with earlier observations on plasma sodium. In the study of Flanigan, the variation in pre-dialytic plasma sodium concentrations was often in the order of $5 \mathrm{mmol} / \mathrm{l}$ during the 12 month follow-up period. In the present study, the mean range in plasma sodium levels, which were however only available on a monthly basis, was $4.6 \mathrm{mmol} / \mathrm{l}$.

Various authors suggested the presence of an individual sodium setpoint in dialysis patients, which may be used as a tool for individualized sodium prescription ${ }^{6,13,18}$. Data on the presence of a fixed sodium setpoint in individual dialysis patients are somewhat conflicting. Whereas some authors did not observe change in pre-dialytic plasma sodium concentration after changing dialysate sodium prescription ${ }^{18-20}$, we and others observed a change in pre-dialytic PC or plasma sodium after a change in 
dialysate sodium prescription ${ }^{5,9,21}$. The reason for this discrepancy is not clear, but it might also be hypothesized that the patients who experience an increase in plasma sodium level after an increase in dialysate sodium, managed to comply with the habitual fluid restriction, at the cost of increased thirst. The results of the present study suggest that plasma sodium levels, when used as a guide for individualisation of dialysate sodium prescription, should be examined on a regular basis. However, it cannot be excluded that variations in other ions, such as potassium and bicarbonate, also play a role in the observed variations in PC, although e.g. potassium in a concentration of $2 \mathrm{mmol} / \mathrm{l}$ contributes only for $0.5 \%$ to dialysate conductivity ${ }^{8}$.

Pre dialytic PC was a strong determinant of diffusive IMB, and in a lesser degree to total IMB, during dialysis. Using the mean of 6 months, diffusive IMB was negative in nearly $33 \%$ of dialysis patients, suggesting diffusive ionic influx from dialysate to the patient. Due to the strong correlation between IMB and sodium balance ${ }^{6}$ this might suggest net diffusive sodium influx from dialysate to the patient. However, these results should be interpreted with some caution given the fact that sodium removal may be somewhat underestimated by $\mathrm{IMB}^{6}$. Surprisingly, we did not observe a mean diffusive ionic influx in the patients treated with Hemocontrol ${ }^{\circledR}$, which is likely due to the fact that mean PC was higher in these patients. For this observation, we do not have a good explanation. In an earlier randomized crossover study, we observed no difference in IMB of PC when patients were treated with either Hemocontrol ${ }^{\circledR}$ or standard dialysis ${ }^{5}$.

In the present study, we compared IMB measurements to sodium balance using direct dialysis quantification. A highly significant relation was observed between IMB and direct dialysis quantification with sodium measurements assessed by flame photometry.

However, also in our study, some underestimation of sodium removal by IMB was observed. Mass balances of other ions, such as potassium or bicarbonate, were not significantly related to IMB. Access recirculation, which theoretically could also affect IMB measurements was not assessed in the study. However, given the highly significant regression model between IMB and sodium balance, we believe IMB might be used as a indicative marker for sodium balance, taking the caveats into account. In an earlier study, large differences in IMB were observed between treatments which only differed in dialysate sodium prescription ${ }^{4}$.

Averaged over the 6-months period, PC increased during dialysis in $14 \%$ of patients, which is an additional argument for diffusive sodium influx in a significant minority of dialysis patients. In general, diffusive ionic influx appeared to occur when pre-dialytic PC was below $14.25 \mathrm{~ms} / \mathrm{cm}$ (roughly corresponding to a plasma sodium concentration of $140 \mathrm{mmol} / \mathrm{l})^{22,23}$. However, given the slight underestimation of sodium removal by $\mathrm{IMB}$ and the possible effect of other ions on $\mathrm{IMB}$, the extrapolation of these findings 
should be interpreted with some caution. Interestingly, the number of patients in which PC increased during dialysis was less compared to the number of patients with diffusive ionic influx. Although the reason for this observation is not entirely clear, this might be due to the fact that to decrease in PC may to some degree, also be due to lowered plasma levels of other ions.

Although far less treatments in which pre-dialytic plasma sodium levels were observed were available for analysis, diffusive ionic influx (negative IMB) from dialysate to patient appeared to occur when plasma sodium concentration was below $140 \mathrm{mmol} / \mathrm{l}$, which would appear in basic agreement with the relation between PC and diffusive IMB discussed above.

Due to the strong influence of ultrafiltration on ionic mass removal, net ionic mass removal was observed in nearly all patients. Admittedly, the clinical importance of the diffusive ionic mass transfer cannot be elucidated from the present study. Lowering of dialysate sodium from 141 to $138 \mathrm{mmol} / \mathrm{l}$ at a facility level resulted in a small improvement in BP control without an increase in hypotensive episodes ${ }^{24}$. Individualisation of dialysate sodium concentration in patients with lower pre-dialytic plasma sodium concentrations was shown to have additive value in terms of blood pressure control $^{18}$.

Apart from the effects on diffusive IMB, intra-individual differences in PC might be of physiologic relevance, given the significant relation with pre-dialytic systolic BP. This relation was independent from interdialytic weight gain, suggesting an independent pressor effect of plasma sodium, although these observations should be confirmed in future studies as a causal relationship cannot be deduced from the present observational data. Proposed pathophysiological mechanisms for this relation remain hypothetical, and include, among others, an effect of sodium on sympathetic activity, nitric oxide metabolism, or digoxin-like factors ${ }^{24,25}$. The effect of seasonal variations, which also might influence blood pressure levels, did not explain the relation between PC and blood pressure in our study. As plasma sodium may be decreased in patients with heart failure, one could argue however that also differences in cardiac function, leading to low pre-dialytic systolic BP, could also provide an explanation of these findings. We are not able to provide echocardiographic examinations for all patients during the study period. However, differences in cardiac function are unlikely to explain the effect of intra-individual differences in PC on blood pressure: both predialytic systolic BP and diastolic BP were significantly different between treatments with the highest and lowest pre-dialytic PC.

An important advantage of the present study is that it comprises a large group of unselected patients, in which measurements of PC, IMB, and relative blood volume were available for every treatment within a 6 months observation interval. A major limitation is the observational nature of the study. Another drawback of the study is 
the fact that PC, and not plasma sodium measurements were used. The use of PC as a surrogate for plasma sodium appears justified in view of the strong relation between PC and plasma sodium ${ }^{7}$, and due to the fact that measurements can be obtained automatically from the software of the dialysis module without the need for blood sampling during every dialysis treatment. From a theoretical point of view, both plasma sodium and PC are surrogate markers of plasma osmolality, which is the driving force for thirst. In the present study, plasma sodium and PC were also highly significantly related. However, in view of the possible (minor) contributions of other ions to PC, our findings should be interpreted with caution.

Another drawback of the study is the absence of detailed information on volume status of the patient, alimentary intake, and the absence of ambulatory blood pressure measurements.

Concluding, diffusive ionic mass transfer is strongly dependent upon pre-dialytic PC. A dialysate sodium concentration of $140 \mathrm{mmol} / \mathrm{I}$ was associated with diffusive mass transfer from dialysate to patient, and a rise in PC in a significant percentage of patients. Both intra- and inter-patient variations in PC are significantly related to predialytic systolic blood pressure, independent of interdialytic weight gain, which might suggest a volume-independent effect of sodium. The results of this study may provide additional support for the use of dialysate sodium levels at the lower physiologic range and, where necessary, individualization of dialysate sodium levels.. 


\section{References}

1. Regulation of arterial pressure in the anephric state. Coleman TG, Bower JD, Langford HG, Guyton AC. Circulation 1970;42:509-14.

2. Krautzig S, Janssen U, Koch KM, Granolleras C, Shaldon S. Dietary salt restriction and reduction of dialysate sodium to control hypertension in maintenance haemodialysis patients. Nephrol Dial Transpl 1998;13:552-3.

3. Kooman JP, Leunissen KM, Luik AJ. Role of sodium and volume in the pathogenesis of hypertension in dialysis patients. Reflections on pathophysiological mechanisms. Blood Purif 2004;22:55-9.

4. Moret K, Hassell D, Kooman JP, van der Sande F, Gerlag PG, van den Wall Bake AW, van de Bogaart J, Leunissen KM. Ionic mass balance and blood volume preservation during a high, standard, and individualized dialysate sodium concentration. Nephrol Dial Transplant 2002;17: 1463-9.

5. Moret K, Aalten J, van den Wall Bake W, Gerlag P, Beerenhout C, van der Sande F, Leunissen K, Kooman J. The effect of sodium profiling and feedback technologies on plasma conductivity and ionic mass balance: a study in hypotension-prone dialysis patients. Nephrol Dial Transplant 2006;21: 138-44.

6. Lambie SH, Taal MW, Fluck RJ, Mclntyre CW. Online conductivity monitoring: validation and usefulness in a clinical trial of reduced dialysate conductivity. ASAIO J 2005;51:70-6.

7. Locatelli F, Di Filippo S, Manzoni C, Corti M, Andrulli S, Pontoriero G. Monitoring sodium removal and delivered dialysis by conductivity. Int J Artif Organs 1995;18:716-21.

8. Bosetto A, Bene B, Petitclerc T. Sodium management in dialysis by conductivity Adv Ren Replace Ther 1999;6:243-54.

9. Song JH, Park GH, Lee SY, Lee SW, Lee SW, Kim MJ. Effect of sodium balance and the combination of ultrafiltration profile during sodium profiling hemodialysis on the maintenance of the quality of dialysis and sodium and fluid balances. J Am Soc Nephrol 2005;16:237-46.

10. Mann H, Stiller S. Sodium modeling. Kidney Int Suppl 2000;76:S79-S88.

11. Flanigan MJ. Role of sodium in hemodialysis. Kidney Int Suppl 2000 Aug;76:S72-8.

12. Santos SF, Peixoto AJ. Revisiting the dialysate sodium prescription as a tool for better blood pressure and interdialytic weight gain management in hemodialysis patients. Clin J Am Soc Nephrol 2008;3:522-30.

13. Keen ML, Gotch FA. The association of the sodium "setpoint" to interdialytic weight gain and blood pressure in hemodialysis patients. Int J Artif Organs 2007;30:971-9.

14. Petitclerc T, Béné B, Jacobs C, Jaudon MC, Goux N. Non invasive monitoring of effective dialysis dose delivered to the hemodialysis patient. Nephrol Dial Transplant 1995;10:212-6.

15. Lacher DA, Hughes JP, and Carroll MD. Estimate of Biological Variation of Laboratory Analytes Based on the Third National Health and Nutrition Examination Survey. Clin Chem 2005; 51: 450 - 452

16. He F, Markandu ND, Sagnella GA, de Wardener HE, MacGregor GA. Plasma sodium: ignored and underestimated. Hypertension 2005;45:98-102

17. Li SY, Chen JY, Chuang CL, Chen TW. Seasonal variations in serum sodium levels and other biochemical parameters among peritoneal dialysis patients. Nephrol Dial Transplant. 2008;23:687-92

18. de Paula FM, Peixoto AJ, Pinto LV, Dorigo D, Patricio PJ, Santos SF. Clinical consequences of an individualized dialysate sodium prescription in hemodialysis patients. Kidney Int 2004;66:1232-8.

19. Flanigan MJ, Khairullah QT, Lim VS. Dialysate sodium delivery can alter chronic blood pressure management. Am J Kidney Dis 1997;29:383-91.

20. Barré PE, Brunelle G, Gascon-Barré M.. A randomized double blind trial of dialysate sodiums of 145 $\mathrm{mEq} / \mathrm{L}, 150 \mathrm{mEq} / \mathrm{L}$, and $155 \mathrm{mEq} / \mathrm{L}$. ASAIO Trans 1988;34:338-41.

21. Levin A, Goldstein MB. The benefits and side effects of ramped hypertonic sodium dialysis. J Am Soc Nephrol 1996;7:242-6.

22. Locatelli F, Di Filippo S, Manzoni C, Corti M, Andrulli S, Pontoriero G. Monitoring sodium removal and delivered dialysis by conductivity. Int J Artif Organs 1995;18: 716-21.

23. Kooman JP, van der Sande FM, Leunissen K et al. Sodium balance in hemodialysis therapy. Semin Dial 2003;16:351-3. 
24. Thein H, Haloob I, Marshall MR. Associations of a facility level decrease in dialysate sodium concentration with blood pressure and interdialytic weight gain. Nephrol Dial Transplant 2007 ;22:2630-9.

25. Kooman JP, van der Sande FM, Leunissen KM. Role of sodium and volume in the pathogenesis of hypertension in dialysis patients. Reflections on pathophysiological mechanisms. Blood Purif 2004;22:55-9.

26. Ritz E, Dikow R, Morath C, Schwenger V. Salt--a potential 'uremic toxin'? Blood Purif 2006;24:63-6. 



\section{Chapter 5}

The effect of sodium profiling and

feedback technologies on plasma conductivity and ionic mass balance: a study in hypotension-prone dialysis patients

Karin Moret, Jeroen Aalten, Warmold van den Wall Bake, Paul Gerlag, Charles Beerenhout, Frank van der Sande, Karel Leunissen, Jeroen Kooman 


\section{Abstract}

\section{Background}

Sodium profiling improves hemodynamic tolerance in haemodialysis (HD) patients but may also influence sodium homeostasis. Changes in blood volume and plasma conductivity (PC) during HD can be modelled by feedback technology, but their effects on sodium homeostasis are not widely studied.

\section{Methods}

This randomized crossover study compared PC and ionic mass balance (IMB) as surrogate markers of sodium balance between standard HD [dialysate conductivity (DC) $14.0 \mathrm{mS} / \mathrm{cm}$ ], sodium profiling (DC 15.0 $14.0 \mathrm{mS} / \mathrm{cm}$ ), blood volume (BV)-controlled and PC-controlled feedback (target: post-HD PC: $14.0 \mathrm{mS} / \mathrm{cm}$ ) in $10 \mathrm{HD}$ patients with frequent hypotension.

\section{Results}

440 treatments were studied. Pre-dialytic PC was significantly higher during sodium profile $(14.4 \pm 0.2 \mathrm{mS} / \mathrm{cm})$ compared to standard HD $(14.2 \pm 0.3 \mathrm{mS} / \mathrm{cm})$, and was not different between the other manoeuvres: PC-controlled $(14.1 \pm 0.3 \mathrm{mS} / \mathrm{cm})$, and BV-controlled feedback $(14.2 \pm 0.2 \mathrm{mS} / \mathrm{cm})$. Except for the first treatment, during which IMB was lower during the sodium profile, IMB did not differ significantly between the various manoeuvres and was strongly dependent upon ultrafiltration volume and the difference between pre-dialytic PC and DC.

Symptomatic hypotensive episodes occurred least frequently during BV-controlled feedback (8\%) compared to the other manoeuvres (standard HD, 16\%; sodium profile, 14\%; PC-controlled feedback, 17\%), but differences were not significant. Inter-dialytic weight gain and pre-dialytic systolic blood pressure did not differ.

\section{Conclusions}

Pre-dialytic PC increased during the sodium profile, and did not differ between BV- or PC-controlled feedback compared to standard HD. Thus, it appears that both BV- and PC-controlled feedback can be safely prescribed without substantial salt- and water-loading, at least in the short term. Analysis of IMB is useful to assess differences in sodium balance between single treatment sessions but appears of less value in a steady-state situation. 


\section{Introduction}

Sodium profiling with a high dialysate sodium concentration is an effective method for the prevention of intra-dialytic hypotension, but also has possible drawbacks such as increased thirst, inter-dialytic weight gain and hypertension ${ }^{1,2}$. Recently, it has become possible to model the decline in blood volume and changes in plasma conductivity (PC), as a surrogate of plasma sodium, by means of feedback technologies. With blood volume (BV)-controlled feedback technologies, a target for a maximal decline in BV is set, which is achieved by continuous adjustments of ultrafiltration rate and (when using the Hemocontrol ${ }^{\circledR}$ module) continuous adjustments of dialysate conductivity in response to measured changes in $\mathrm{BV}^{2}$. In the case of PC-controlled feedback, a target for end-dialytic PC is set, and achieved by frequent adjustments of dialysate conductivity during the dialysis sessions, in response to on-line measured changes in $\mathrm{PC}^{3-5}$. With both BV- and PC-controlled feedback, it is possible to achieve these targets with a high level of precision. Both modalities are theoretically appealing and were shown to be successful in clinical studies ${ }^{3-10}$, although clinical experience with conductivity-controlled feedback in particular is still limited ${ }^{5,10}$. Both modalities, however, also have potential caveats. From a theoretical point of view, the frequent adjustments of dialysate conductivity (DC) during BV-controlled feedback may lead to alterations in sodium removal compared to standard dialysis sessions. PC-controlled feedback treatments with generalized pre-set targets (such as a post-dialytic PC of $14.0 \mathrm{mS} / \mathrm{cm}$ ) may lead to reduced sodium removal in those patients with low predialytic plasma sodium levels. Little data on sodium balance during these different manoeuvres are available in the literature and are, in most cases, based on a limited number of measurements during the study period ${ }^{6-9}$. By means of assessment of ionic mass balance (IMB) and changes in pre-dialytic PC, it is possible to assess sodium balance during dialysis therapy in a non-invasive way during every dialysis treatment ${ }^{3,4,11}$. However, although IMB was able to detect differences in sodium transfer during a single treatment session ${ }^{11}$, its value in assessing chronic changes in sodium balance is not well established. The aim of the present study was to compare the effects of standard dialysis, a sodium with a mean dialysate sodium concentration, and PC- and BV-controlled feedback treatments on PC and IMB, as surrogate parameters for sodium balance.

\section{Subjects and methods}

Twelve patients with frequent symptomatic (see definition below) or asymptomatic hypotensive episodes (decline in systolic blood pressure below $100 \mathrm{mmHg}$ ) during dialysis (i.e. $>2$ during 3 weeks before the start of the study) were included in the study. One patient withdrew from the study because of mitral valve surgery, and one patient died from a cardiac arrest. Data from these patients were excluded from the 
analysis. All patients had a residual glomerular filtration rate $<2 \mathrm{ml} / \mathrm{min}$. The origin of renal failure in the 10 patients who completed the study was diabetes mellitus $(n=4)$, cholesterol emboli $(n=1)$, chronic glomerulonephritis $(n=3)$, hypertensive nephrosclerosis $(n=1)$ and chronic interstitial nephritis $(n=1)$. Other characteristics of the patients who completed the study are shown in Table 5.1. The study was approved by the Ethics committee of the Maxima Medical Centre. All patients gave written informed consent.

Table 5.1 Patient characteristics.

\begin{tabular}{lc}
\hline Age & $71 \pm 11$ \\
Sex (M/F) & $6 / 4$ \\
Time on dialysis (months) & $24.1 \pm 17.7$ \\
Duration of dialysis (hours) & $3.9 \pm 0.5$ \\
Diabetes mellitus & $6(60 \%)$ \\
Congestive heart failure (NYHA33) & $4(40 \%)$ \\
Use of ACE inhibitors & $4(40 \%)$ \\
Kt/V (single pool) & $1.5 \pm 0.2$ \\
Serum albumin (g/l) & $38.2 \pm 3.8$ \\
\hline
\end{tabular}

\section{Design}

All patients were treated with standard HD treatment (DC $14.0 \mathrm{~ms} / \mathrm{cm}$ ), a linear decreasing sodium profile (DC $15.0-14.0 \mathrm{mS} / \mathrm{cm}$ ), BV-controlled feedback (mean DC $14.0 \mathrm{~ms} / \mathrm{cm}$ ) and PC-controlled feedback (target: post-dialytic PC $14.0 \mathrm{~ms} / \mathrm{cm}$ ). The treatment order was prescribed en blocs using a four-treatments, four-period randomized cross-over design. Patients were randomized into one of the following treatment blocks:

I standard dialysis - sodium profile - BV-controlled feedback - PC-controlled feedback;

II sodium profile - BV-controlled feedback - PC-controlled feedback - standard dialysis;

III BV-controlled feedback - PC-controlled feedback - standard dialysis - sodium profile; or

IV PC-controlled feedback - standard dialysis - sodium profile - BV-controlled feedback.

During each block, patients received 11 consecutive treatments of this modality, followed by 1 week's treatment with standard dialysis in order to prevent possible carry-over effects, after which 11 treatments with the following modality were started, etc. Total duration of the study was 4 months.

\section{Dialysis schedule}

The dialysis schedule of the patients was 3 times weekly in all patients. Dialysis time is mentioned in Table 5.1. Polysulfone (F8HPS; Fresenius ${ }^{\circledR}$ ) low flux dialysis membranes 
were used. Composition of the dialysate was: potassium $2.0 \mathrm{mmol} / \mathrm{l}$, calcium $1.5 \mathrm{mmol} / \mathrm{l}$, magnesium $0.5 \mathrm{mmol} / \mathrm{l}$, bicarbonate $32 \mathrm{mmol} / \mathrm{l}$, acetate $3.0 \mathrm{mmol} / \mathrm{l}$ and glucose $1 \mathrm{~g} / \mathrm{l}$. Temperature of the dialysate was $36^{\circ} \mathrm{C}$. Patients were ultrafiltered until their clinically determined dry weight.

\section{Ionic mass balance}

IMB was estimated by Diascan ${ }^{\circledR}$ (Hospal-Gambro ${ }^{\circledR}$, Lyon, France $)^{4,11,12}$. In short, Diascan $^{\circledR}$ measures IMB by constant measurement of the conductivity in the dialysis outlet and inlet according to the formula IMB $=\left[\left(Q d_{\text {out }} \times C d_{\text {out }}-\left(Q d_{\text {in }} \times C d_{\text {in }}\right)\right] \times 10 \times\right.$ time (min). $Q d_{\text {out }}$ and $Q d_{\text {in }}$ are dialysate flow at, respectively, outlet and inlet; $C d_{\text {out }}$ and $C d_{\text {in }}$ are dialysate conductivity at, respectively, outlet and inlet. A positive IMB reflects net sodium removal from the patient, a negative IMB means net sodium transfer from dialysate to the patient.

\section{Plasma conductivity}

PC was measured by Diascan ${ }^{\circledR}$ by measuring dialysance $(D)$ in combination with measurements of $C d_{\text {out }}$ and $C d_{\text {in }}$ according to the formula:

$$
P C=\left[C d_{\text {out }}-\left(1-D / Q d_{\text {in }}\right) \times C d_{\text {in }}\right] /\left(D / Q d_{\text {in }}\right) \text {. }
$$

$D$ is assessed every 30 min by measuring the increase in $C d_{\text {out }}$ after a temporary increase in $C d_{\text {in }}$ by $1 \mathrm{mS} / \mathrm{cm}$ according to the formula:

$$
D=\left(Q d_{\text {in }}+Q f\right) \times\left[1-\left(C d_{\text {out }} 1-C d_{\text {out }} 2\right) /\left(C d_{\text {in }} 1-C d_{\text {in }} 2\right)\right] .
$$

1 and 2 indicate, respectively, the measurements before and after the temporary increase in $C d_{\text {in }}{ }^{4,11,12}$.

\section{Relative blood volume}

BV was measured continuously by continuous optical assessment of changes in hemoglobin during the dialysis session (Hemoscan ${ }^{\circledR}$; Hospal-Gambro) ${ }^{13}$.

\section{Description of the feedback modules}

BV-controlled feedback (Hemocontrol ${ }^{\circledR} ;$ Hospal-Gambro), described in detail elsewhere ${ }^{6}$, is achieved with a closed-loop automatic control system using three controlled variables and two control variables. The three controlled variables are total weight loss (TWL), BV change (determined by hematocrit measurements), and equivalent conductivity, a value derived from the DC which is defined as the conductivity value required to achieve the same sodium mass balance compared to standard $\mathrm{HD}^{6}$. The control variables consist of the set ultrafiltration rate (UFR) and the delivered DC. Discrepancies between ideal and achieved controlled variable values are processed by a multi-input/multi-output controller that in turn effectuates a response through the two actuators, the control variables UFR and DC. Changes in BV are 
determined by Hemoscan ${ }^{\circledR}$ (see above). TWL is measured volumetrically. Before the start of the study, the patient underwent 10 regular treatments. During this period, the mean BV change at which hypotension occurred was recorded. The target BV:TWL ratio during BV-controlled feedback was $20 \%$ higher than this value.

With PC-controlled feedback (Diacontrol ${ }^{\circledR}$; Hospal-Gambro), PC is modelled automatically during dialysis by adjustment of DC using single-pool kinetic modelling ${ }^{4,5}$. PC is measured throughout the HD session by Diascan ${ }^{\circledR}$ as described above. The target post-dialytic PC was $14.0 \mathrm{mS} / \mathrm{cm}$ during all treatment sessions.

\section{Plasma sodium}

Plasma sodium was assessed by indirect ionometry (Vitros $950^{\circledR}$ ), which assesses sodium activity in the plasma. Sodium activity is automatically converted to the molar ionized sodium concentration. Obtained values were corrected by converting the molar concentration to flame photometer values by a standard correction factor $(0.93)^{10}$. The coefficient of variation for this method, as given by the manufacturer, is $0.4 \%$.

\section{Blood pressure measurements}

Blood pressure was assessed every 30 min with an oscillometric device (HDBPM 4; Hospal-Gambro). Also during each symptomatic event, blood pressure was measured.

\section{Definition of intra-dialytic hypotension}

Symptomatic hypotension was defined as a decline in systolic blood pressure to $<100$ $\mathrm{mmHg}$ (in patients with pre-dialytic systolic blood pressure $<110 \mathrm{mmHg}$ ), or a decline in systolic blood pressure larger than $30 \mathrm{mmHg}$ together with typical symptoms, necessitating nursing interventions. Also all intra-dialytic morbid events (cramps, nausea, headache, abdominal pain, with or without hypotension) were recorded. Also all episodes with a decline in systolic pressure below $100 \mathrm{mmHg}$ were recorded.

\section{Power analysis}

Primary outcome parameter was the difference in pre-dialytic PC between the various modalities. Assuming an SD of $0.2 \mathrm{mS} / \mathrm{cm}^{11}$, eight patients would be needed to show a mean difference of $0.2 \mathrm{mS} / \mathrm{cm}$ between two different treatment modalities with a level below 0.05 and a power of 0.80 . Assuming an SD of $110 \mathrm{mmol}$ for $\mathrm{IMB}^{11}$, nine patients had to be included in order to show a difference of $100 \mathrm{mmol}$ with the same significance levels. In order to correct for multiple comparisons and drop-outs, 12 patients were included. 


\section{Statistics}

Repeated measurements ANOVA was used to compare the different parameters between the various modalities. The mean value of the 11 treatments for each modality was entered into the analysis. To assess the determinants of IMB, multiregression analysis was used. Fisher's exact-test was used to assess differences in frequency of hypotension between the different modalities. $P$-values $<0.05$ were considered significant. The SPSS 12.0 package was used for statistical analysis.

\section{Results}

Data for IMB and PC were available for all sessions. In total, data of 440 sessions were analyzed.

\section{Plasma conductivity}

Mean pre- and post-dialytic PC were increased during the sodium profile compared to standard HD. Pre-dialytic PC did not differ between BV- and PC-controlled feedback compared to standard HD (Figure 5.1 and Table 5.2). Post-dialytic PC was significantly lower during PC-controlled feedback compared to the other manoeuvres.

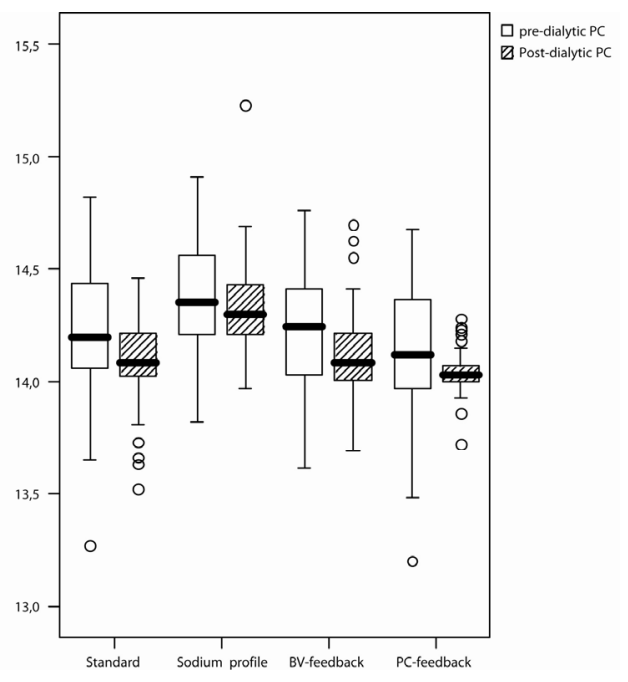

Figure 5.1 Pre- and post-dialytic PC levels during the different modalities. Covered boxes indicate 25$75 \%$ with median value; capped bars indicate the range of data. Dots indicate outliers. Both pre- and post-dialytic PC were significantly higher during the sodium profile compared to all other treatments $(P<0.05)$. Post-dialytic PC was significantly lower during PC-controlled feedback compared to the other manoeuvres. 
Table 5.2

\begin{tabular}{lcccc}
\hline & Standard & BV-feedback & PC-feedback & Sodium profile \\
\hline Pre-dialytic PC $(\mathrm{mS} / \mathrm{cm})^{\mathrm{a}}$ & $14.22 \pm 0.20$ & $14.22 \pm 0.17$ & $14.14 \pm 0.22$ & $14.37 \pm 0.14 \mathrm{~b}$ \\
${\text { Post-dialytic PC }(\mathrm{mS} / \mathrm{cm})^{\mathrm{a}}}^{\mathrm{a}}$ & $14.11 \pm 0.20 \mathrm{c}$ & $14.11 \pm 0.10 \mathrm{c}$ & $14.03 \pm 0.04 \mathrm{~b}, \mathrm{c}$ & $14.42 \pm 0.05 \mathrm{~b}$ \\
DC $(\mathrm{mS} / \mathrm{cm})^{\mathrm{a}}$ & $14.06 \pm 0.06$ & $14.23 \pm 0.04 \mathrm{~b}$ & $14.03 \pm 0.12$ & $14.42 \pm 0.05 \mathrm{~b}$ \\
Ionic mass removal (mmol) & $383 \pm 112$ & $432 \pm 80$ & $370 \pm 140$ & $414 \pm 106$ \\
IDWG & $2.0 \pm 1.0$ & $2.2 \pm 0.7$ & $2.0 \pm 0.9$ & $2.1 \pm 1.0$ \\
Decline in relative BV (\%) & $-6.1 \pm 2.4$ & $-6.6 \pm 2.3$ & $-6.4 \pm 3.1$ & $-7.4 \pm 2.1$ \\
Pre-dialytic SBP $(\mathrm{mmHg})$ & $146 \pm 26$ & $140 \pm 23$ & $145 \pm 19$ & $144 \pm 22$ \\
Nadir dialytic SBP $(\mathrm{mmHg})$ & $111 \pm 22$ & $108 \pm 19$ & $111 \pm 17$ & $112 \pm 18$ \\
Post-dialytic weight $(\mathrm{kg})$ & $76.8 \pm 14.2$ & $76.1 \pm 16.0$ & $76.1 \pm 14.8$ & $76.5 \pm 14.6$ \\
\hline
\end{tabular}

PC, plasma conductivity; DC, dialysate conductivity; IDWG, inter-dialytic weight gain; SBP, systolic blood pressure; BV, blood volume. ${ }^{a} P<0.05$ (ANOVA); ${ }^{b} P<0.001$ compared to all other treatments; ${ }^{c} P<0.001$ compared to pre-dialytic values.

PC-controlled feedback was able to reach target post-dialytic PC levels within narrow limits $(14.03 \pm 0.03 \mathrm{mS} / \mathrm{cm})$. In those sessions in which pre-dialytic plasma conductivity levels were $<14.0 \mathrm{mS} / \mathrm{cm}$, as expected, PC increased significantly $(+0.21 \pm 0.17$; $P<0.001)$ and declined during sessions when pre-dialytic PC was $>14.0 \mathrm{mS} / \mathrm{cm}$ $(-0.18 \pm 0.14 ; P<0.001)$. During $P C$-controlled feedback, the intra-individual coefficient of variation of pre-dialytic PC levels was $1.3 \%$. Pre-dialytic PC varied between values above and below $14.0 \mathrm{mS} / \mathrm{cm}$ in six of the patients during the period with PCcontrolled feedback.

Single measurements of pre-dialytic plasma sodium did not differ between the different modalities: $138 \pm 2 \mathrm{mmol} / \mathrm{I}$ during standard dialysis, $137 \pm 2 \mathrm{mmol} / \mathrm{l}$ during BVcontrolled feedback, $139 \pm 3 \mathrm{mmol} / \mathrm{l}$ during the sodium profile and $138 \pm 3 \mathrm{mmol} / \mathrm{l}$ during PC conductivity-controlled feedback.

\section{Ionic mass balance}

IMB during the first session was lowest during the sodium profile $(315 \pm 157 \mathrm{mmol}$; $P<0.05)$. Between the other manoeuvres, IMB during the first sessions did not differ: $423 \pm 166 \mathrm{mmol}$ during standard dialysis, $488 \pm 179 \mathrm{mmol}$ during BV-controlled feedback and $409 \pm 109 \mathrm{mmol}$ during PC-controlled feedback.

During the remainder of the sessions, IMB did not differ significantly between the different treatment modalities (Table 5.2).

However, during PC-controlled feedback, IMB was lower during the sessions when pre-dialytic PC was lower than $14.0 \mathrm{mS} / \mathrm{cm}(n=30)$ compared to sessions before which pre-dialytic PC was higher than $14.0 \mathrm{mS} / \mathrm{cm}(n=80)$. (248 \pm 98 vs $416 \pm 174 \mathrm{mmol} / \mathrm{l}$; $P<0.001)$ despite comparable ultrafiltration volume $(2.0 \pm 0.7$ vs $2.0 \pm 1.1 \mathrm{~kg})$.

Pooling all treatments, ionic mass removal was highly dependent upon both ultrafiltration volume $(ß=0.72 ; P<0.001)$ and the difference between pre-dialytic 
plasma conductivity and dialysate conductivity ( $(=0.72 ; P<0.001)$ (Figure 5.2$)$, but not on the treatment modality.

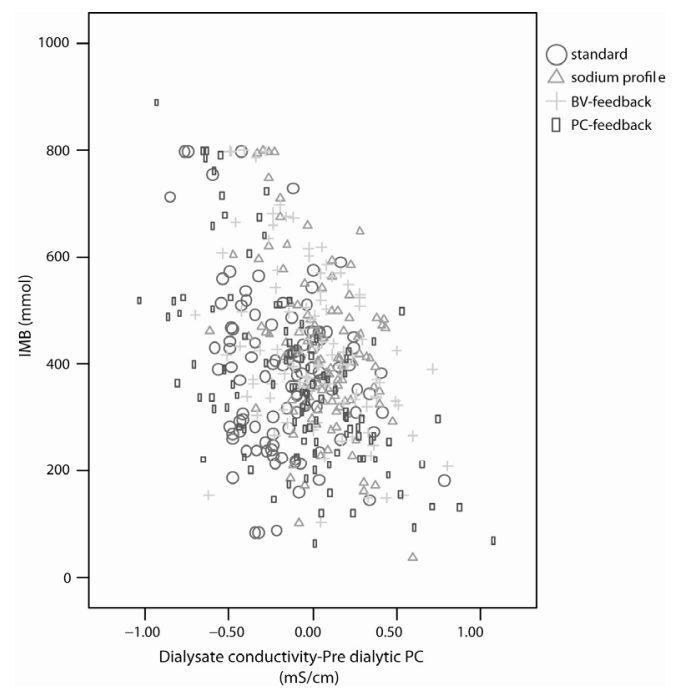

Figure 5.2 Relation between ionic mass balance and pre-dialytic and dialysate conductivity. $\left(r^{2}=-0.46\right.$; $P<0.001)$.

\section{Inter-dialytic weight gain and blood pressure and blood volume}

Neither inter-dialytic weight gain nor pre-dialytic blood pressure differed significantly between the various treatment modalities (Table 5.2). Also post-dialytic blood pressure and the maximal decline in blood pressure were not significantly different between the various treatment modalities. The decline in BV was comparable between the various treatment modalities (Table 5.2).

\section{Intra-dialytic hypotension}

Symptomatic hypotensive episodes occurred least frequently during BV-controlled feedback ( $8 \%$ ) compared to the other manoeuvres (standard HD, 16\%; sodium profile, $14 \%$; PC-controlled feedback, 17\%), but differences were not significant. The same held true for the total number of symptoms during dialysis (with or without hypotension): BV-controlled feedback, $n=22$; standard HD, $n=31$; sodium profile, $n=29$; PC-controlled feedback, $n=32(P=N S)$. The total number of sessions during which systolic BP declined to $<100 \mathrm{mmHg}$ did not differ significantly between the different manoeuvres: BV-controlled feedback, 26\%; standard HD, 35\%; sodium profile, $28 \%$; PC-controlled feedback, 26\% ( $P=N S)$. 
The peak systolic blood pressure did not differ between the various sessions (Table 5.2).

\section{Discussion}

In this randomized crossover study, we assessed the effect of a sodium profile and different feedback technologies on $P C, I M B$ and haemodynamic tolerance. $A$ significant increase in pre-dialytic PC was observed during the sodium profile, but not during BV-controlled feedback, whereas pre-dialytic PC was not different during PCcontrolled feedback compared to standard HD.

IMB was lowest during the sodium profile, but only during the first session, and not during the remainder of the dialysis sessions with the sodium profile. IMB during the other modalities was comparable. The increase in pre- and post-dialytic PC, as surrogate markers of plasma sodium, is in agreement with various, but not all, earlier studies towards the effect of profiles with high mean sodium concentrations ${ }^{1,2}$.

The effects of BV-controlled feedback on PC and IMB did not differ from standard dialysis. Data on the effects of BV-controlled feedback on sodium homeostasis are scarce, although earlier studies did not show a difference in plasma sodium levels compared to standard HD sessions. However, in these studies, serum sodium was only measured a few times during the study period, whereas in the present study, PC was assessed during all treatment sessions.

With PC-controlled feedback, mean pre-dialytic PC was not different compared to standard dialysis. However, mean post-dialytic PC was significantly lower compared to standard HD. The target post-dialytic PC was $14.0 \mathrm{~ms} / \mathrm{cm}$ in the present study. In agreement with earlier data from Locatelli et al. ${ }^{10}$, PC-controlled feedback was able to achieve this target within very narrow limits. However, caution should be applied with the use of PC-controlled feedback with generalized preset targets in patients with low pre-dialytic PC levels. An alternative approach given the intra-individual variation of predialytic PC or sodium levels may be the use of individualized targets for dialysate sodium or post-dialytic $P C^{10,11,14}$.

IMB was only significantly different between the first sessions of the different modalities, and not during the remaining sessions. This can be explained by the fact that, next to ultrafiltration volume, IMB is determined by the ratio between predialytic PC and dialysate conductivity ${ }^{11}$. Thus, as pre-dialytic PC increased during the sodium profile, the difference between $P C$ and $D C$ remained comparable to the other modalities, resulting in equal IMB. Therefore, the absence of differences in IMB between different dialysis modalities in a steady state does not imply that these do not differ in their effect on sodium balance. To estimate such an effect, measurement of plasma sodium or PC levels remains necessary.

However, during PC conductivity-controlled feedback, IMB was lower when predialytic PC was $<14.0 \mathrm{mS} / \mathrm{cm}$ compared with pre-dialytic PC levels $>14.0 \mathrm{mS} / \mathrm{cm}$. This is 
due to the strong relation between pre-dialytic PC and dialysate conductivity. As in the majority of patients, pre-dialytic PC levels varied between values above and below $14.0 \mathrm{mS} / \mathrm{cm}, \mathrm{IMB}$ may be unpredictable when using generalized pre-set targets, as discussed previously.

Despite differences in pre-dialytic PC, pre-dialytic blood pressure and inter-dialytic weight gain did not differ between the different treatment modalities. However, small effects on inter-dialytic blood pressure may have been missed in the present study, due to the absence of ambulatory blood pressure measurements.

The effect of sodium profiling on inter-dialytic weight gain and inter-dialytic blood pressure control is not consistent between different studies. Whereas some studies found an increase in inter-dialytic weight gain and/or an increase in pre-dialytic systolic or inter-dialytic blood pressure, other studies did not ${ }^{1,2}$.

A potential explanation for the absence of a difference in weight gain or blood pressure control between the various modalities may be strict adherence to fluid restriction by our patients. Regrettably, thirst sensation was not quantified in a structured way in the present study.

The incidence of symptomatic intra-dialytic hypotension was lowest during BVcontrolled feedback, but differences between the various manoeuvres did not reach significance, due to underpowering of the study for this parameter. Earlier studies with larger number of patients have demonstrated the effect of BV-controlled feedback on intra-dialytic complications ${ }^{6,7,15-17}$.

Except for the possible underpowering with respect to the secondary outcome parameter of intra-dialytic hypotension, some other drawbacks should also be mentioned. Firstly, PC and not plasma sodium was assessed in the present study, due to the fact that this parameter can be assessed on-line without need for blood sampling. Previous studies have shown a very close correlation between PC and plasma sodium levels ${ }^{11,18,19}$. However, PC is not equal to plasma sodium and, albeit to a much smaller degree, is also influenced by other electrolytes such as potassium. This might be reflected in the fact that post-dialytic PC was lower than pre-dialytic PC during all different modalities. From a theoretical point of view, differences in potassium and acid base balance are not to be expected between the different dialysis strategies studied in this paper. Indeed, frequent measurements of PC may be more sensitive in observing differences in sodium balance than single measurements of plasma sodium. In the present study, single measurements of plasma sodium did not differ between the various modalities.

Lastly, the sodium profile used in the present study is only an example of many different sodium profiles described in the literature ${ }^{2}$. However, in the majority of effective sodium profiles high dialysate sodium concentrations are used.

Summarizing, pre- and post-dialytic PC, as a surrogate marker of plasma sodium, increased during high-sodium profiling, but not during BV- or PC-controlled feedback treatments. Thus, it appears that both BV- and PC-controlled feedback can be safely prescribed without substantial salt- and water-loading, at least in the short term. 
Except for the first treatment, IMB did not differ between the various manoeuvres, due to the equilibration between pre-dialytic PC and DC. Therefore, IMB appears of limited value to assess differences in sodium balance between different manoeuvres in steady state. 


\section{References}

1. Song JH, Park GH, Lee SY, Lee SW, Lee SW, Kim MJ. Effect of sodium balance and the combination of ultrafiltration profile during sodium profiling hemodialysis on the maintenance of the quality of dialysis and sodium and fluid balances. J Am Soc Nephrol 2005;16:237-46.

2. Mann H, Stiller S. Sodium modeling. Kidney Int Suppl 2000;76:S79-S88.

3. Locatelli F, Di Filippo S, Manzoni C. Relevance of the conductivity kinetic model in the control of sodium pool. Kidney Int Suppl 2000;76:S89-S95.

4. Bosetto A, Bene B, Petitclerc T. Sodium management in dialysis by conductivity. Adv Ren Replace Ther 1999;6:243-54[Web of Science].

5. Di Giulio S, Meschini L, Friggi A, Stortoni F, Cherubini C, de Paolis P, Rosa M. Sodium transport with different dialysis ultrafiltration schedules using a bio-feedback module (BFB). Nephrol Dial Transplant 1998;13 [Suppl 6]:39-42.

6. Santoro A, Mancini E, Paolini F, Cavicchioli G, Bosetto A, Zucchelli P. Blood volume regulation during hemodialysis. Am J Kidney Dis 1998;32:739-48.

7. Wolkotte C, Hassell DR, Moret K, Gerlag PG, van den Wall Bake AW, van der Sande FM, Kooman JP. Blood volume control by biofeedback and dialysis-induced symptomatology. A short-term clinical study. Nephron 2002; 92: 605-9.

8. Basile C, Giordano R, Vernaglione L, Montanaro A, De Maio P, De Padova F, Marangi AL, Di Marco L, Santese D, Semeraro A, Ligorio VA. Efficacy and safety of haemodialysis treatment with the Hemocontrol biofeedback system: a prospective medium-term study. Nephrol Dial Transpl 2001;16: 328-34

9. Santoro A, Mancini E, Basile C, Amoroso L, Di Giulio S, Usberti M, Colasanti G, Verzetti G, Rocco A, Imbasciati E, Panzetta G, Bolzani R, Grandi F, Polacchini M. Blood volume controlled hemodialysis in hypotension-prone patients: a randomized, multicenter controlled trial. Kidney Int 2002;62:1034-45

10. Locatelli F, Andrulli S, Di Filippo S, Redaelli B, Mangano S, Navino C, Ariano R, Tagliaferri M, Fidelio T, Corti M, Civardi S, Tetta C. Effect of on-line conductivity plasma ultrafiltrate kinetic modeling on cardiovascular stability of hemodialysis patients. Kidney Int 1998;53:1052-60.

11. Moret K, Hassell D, Kooman JP, van der Sande F, Gerlag PG, van den Wall Bake AW, van de Bogaart J, Leunissen KM. Ionic mass balance and blood volume preservation during a high, standard, and individualized dialysate sodium concentration. Nephrol Dial Transplant 2002;17:1463-9

12. Petitclerc T, Bene B, Goux N, Saudon MC, Jacobs C. Non invasive monitoring of effective dialysis dose delivered to the hemodialysis patient. Nephrol Dial Transplant 1995;10:212-6.

13. Paolini F, Mancini E, Bosetto A, Santoro A. Hemoscan: a dialysis machine-integrated blood volume monitor. Int J Artif Organs 1995;18:487-94.

14. de Paula FM, Peixoto AJ, Pinto LV, Dorigo D, Patricio PJ, Santos SF. Clinical consequences of an individualized dialysate sodium prescription in hemodialysis patients. Kidney Int 2004;66:1232-8.

15. Ronco C, Brendolan A, Milan M, Rodeghiero MP, Zanella M, La Greca G. Impact of biofeedbackinduced cardiovascular stability on hemodialysis tolerance and efficiency. Kidney Int 2000;58:800-8.

16. Oliver MJ, Edwards $\amalg$, Churchill DN. Impact of sodium and ultrafiltration profiling on hemodialysisrelated symptoms. J Am Soc Nephrol 2001;12:151-6.

17. Dheenan S, Henrich WL. Preventing dialysis hypotension: a comparison of usual protective manoeuvers. Kidney Int 2001;59:1175-81.

18. Locatelli F, Di Filippo S, Manzoni C, Corti M, Andrulli S, Pontoriero G. Monitoring sodium removal and delivered dialysis by conductivity. Int J Artif Organs 1995;18:716-21.

19. Goureau Y, Petitclerc T, Man NK. Evaluation of plasma sodium concentration during hemodialysis by computerization of dialysate conductivity. ASAIO Trans 1990;36:M444-7 .

20. Petitclerc T. Estimation of mass transfer through a hemodialyzer: theoretical approach and clinical applications. Artif Organs 1998;22:601-7. 



\section{Chapter 6}

\section{Conductivitypulses needed for Diascan ${ }^{\circledR}$} measurements: Does it cause sodium burden?

Karin Moret, Diana C Grootendorst, Charles Beerenhout, Jeroen P Kooman NDT Plus 2009;2:334-5 
Recently, new techniques based on conductivity measurement enable the physician to evaluate the adequacy of hemodialysis dose (HDD) on all haemodialysis treatments by on-line monitoring of KT/V. Ionic dialysance (Diascan ${ }^{\circledR}$ Hospal $^{\circledR}$ ) is a parameter calculated from the dialysate conductivity at the dialyser inlet and outlet. Every half hour the inlet dialysate conductivity increases by $1 \mathrm{~ms} / \mathrm{cm}$ during 5 minutes while the outlet dialysate conductivity-cell measures the effect of this increase. The calculated ion transfer across the membrane (largely sodium) is almost equivalent to urea transfer and therefore ionic dialysance reflects the urea clearance. This method has a good correlation with $\mathrm{Kt} / \mathrm{V}$ measured by the mathematical urea equations in several studies $^{1,2,3,4}$.

However, some investigators suggest, that during the conductivity pulse of 5 minutes, significant amounts of sodium may be transferred into the patient ${ }^{5}$. In our centre we studied that effect. Diascan ${ }^{\circledR}$ also measures lonic Mass Balance (IMB) and plasma conductivity $(\mathrm{PC})$ which are likely to represent sodium balance and plasma sodium respectively (Plasma sodium in $\mathrm{mmol} / \mathrm{l} \approx$ plasma conductivity in $\mathrm{ms} / \mathrm{cm}^{*} 10$ ). This is performed by constant measurements of the conductivity in the dialysate inlet and outlet, according to the formulas:

$$
P C=\left[C_{\text {out }}-\left(1-D / Q d_{\text {in }}\right) \times C d_{\text {in }}\right] /\left(D / Q d_{\text {in }}\right)
$$

$Q d_{\text {in }}$ and $\mathrm{Qd}_{\text {out }}$ are dialysate flow at, respectively, inlet and outlet. $\mathrm{Cd}_{\text {in }}$ and $\mathrm{Cd}_{\text {out }}$ are dialysate conductivity at, respectively, inlet and outlet. $D$ is lonic Dialysance.

$$
I M B=\left[\left(Q d_{\text {out }} \times C d_{\text {out }}\right)-\left(Q d_{\text {in }} \times C d_{\text {in }}\right)\right] \times 10 \times \text { time }(\mathrm{min}) \text {. }
$$

A positive IMB means sodium removal from the patient. A negative IMB means sodium transport to the patient.

In patients with zero inter-diaytic weight gain, IMB was measured in 200 isovolemic hemodialysis sessions by $\operatorname{Diascan}^{\circledR}, 137$ sessions were performed with 4-8 conductivity pulses. 63 sessions were performed with only 1 conductivity pulse.

The results were that there was a highly significant correlation between pre-dialytic plasma conductivity and IMB (Spearman rank $r s=0.902, P<0.005$ ), in agreement with previous studies $^{6}$. There was no correlation between $\mathrm{IMB}$ and the number of conductivity pulses (Spearman rank $r_{s}=0.02, P=0.328$ )(Figure 6.1).

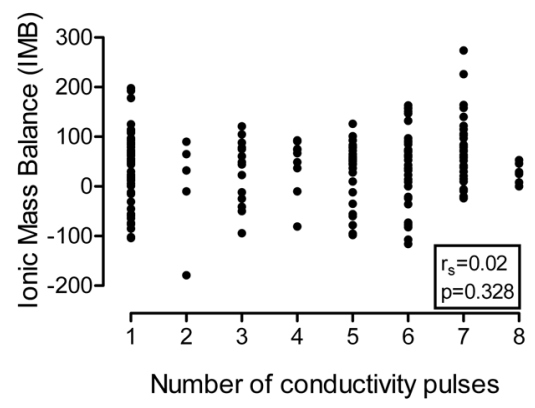

Figure 6.1 Correlation between IMB during isovolaemic haemodialysis and number of conductivity pulses. 
In conclusion, Diascan ${ }^{\circledR}$ is a useful tool to assess dialysis dose without evidence of an increased sodium load related to the conductivity pulses during hemodialysis treatment. 


\section{References}

1. Mercadal L, Petitclerc T, Jaudon MC, Béné B, Goux N, Jacobs C. Is Ionic dialysance a valid parameter for quantification of dialysis efficiency? Artif Organs1998; 22: 1005-9

2. Lindsay R, Bene B, Goux N, Heidenheim A, Landgren C, Sternby J. Relationship between effective ionic dialysance and in vivo urea clearance during haemodialysis. Am J Kidney Dis 2001; 38:565-74

3. McIntyre CW, Lambie SH, Taal MW, Fluck RJ. Assessment of haemodialysis adequacy by ionic dialysance: intra-patient variability of delivered treatment. Nephrol Dial Transplant 2003;18: 559-63

4. Moret K, Beerenhout CH, van den Wall Bake AWL, Gerlag PG, van der Sande FM, Leunissen KM, Kooman JP. Ionic dialysance and the assessment of Kt/V: the different estimates of $\mathrm{V}$ on method agreement, Nephrol Dial Transplant 2007 22:2276-82

5. Gotch FA, Panlilio FM, Buyaki RA, Wang EX, Folden TI, Levin NW. Mechanisms determining the ratio of conductivity clearance to urea clearance. Kidney Int Suppl 2004;(89):S3-24

6. Moret K, Hassell D, Kooman JP, van der Sande F, Gerlag PG, van den Wall Bake AW, van de Bogaart J, Leunissen KM. Ionic mass balance and blood volume preservation during a high, standard, and individualized dialysate sodium concentration. Nephrol Dial Transplant 2002; 17:1463-9 



\section{Chapter 7}

\section{Agreement between different parameters of dialysis} dose in achieving treatment targets: results from the NECOSAD study

Karin E Moret, Diana C Grootendorst, Friedo W Dekker, Elizabeth W Boeschoten, Raymond T Krediet, Saskia Houterman, Charles H Beerenhout, Jeroen P Kooman, the NECOSAD Study Group

Submitted 


\section{Abstract}

\section{Background}

The recommended parameter of dialysis dose differs between K-DOQI and EBPG guidelines. It is not well known to which extent agreement between the different parameters exists if target and delivered dialysis dose are prescribed according to urea reduction rate (URR), single pool Kt/V (spKt/V) or equilibrated double pool Kt/V (eKt/V), and which parameter is most strongly related to mortality.

\section{Methods}

In 830 hemodialysis patients from the NECOSAD cohort URR, spKt/V and eKt/V were calculated and compared according to classification regarding the recommended treatment targets $(70 \%, 1.4$ and 1.2 , respectively), as well as minimum delivered dialysis dose (65\%, 1.2 and 1.05, respectively). Moreover, the relation between treatment dose and survival was assessed using Cox regression analysis.

\section{Results}

A spKt/V of $\geq 1.4$ and URR $\geq 70 \%$ corresponded with eKt/V $\geq 1.20$ (as reference method) in respectively $98.0 \%$ and $90.6 \%$ of patients. spKt/V of $\geq 1.2$ and URR $\geq 65 \%$ corresponded with eKt/V $\geq 1.05$ in respectively $95.5 \%$ and $91.2 \%$ of patients. Deviations from the reference method were significantly related to differences in urea distribution volume (spKt/V), treatment time (URR) and ultrafiltration volume (URR). Adjusted HR $(95 \% \mathrm{Cl})$ was $0.98(0.96,0.99)$ for URR, $0.51(0.31,0.84)$ for spKt/V and $0.46(0.30,0.80)$ for eKt/V.

\section{Conclusion}

Use of URR leads to larger disagreement with the reference method (eKt/V) treatment target as compared to spKt/V. Low urea distribution volume, short treatment time, and low ultrafiltration volumes are predictive parameters for overestimation of dialysis dose when utilizing the alternative methods spKt/V and URR instead of eKt/V. Delivered eKt/V, spKt/V, and URR were all positively related to survival. However, only in case of eKt/V, the mimimum cut-off level was predictive of survival. 


\section{Introduction}

The delivered haemodialysis treatment dose is an important prognostic factor in patients treated with haemodialysis ${ }^{1}$. In addition, a survey of the medical literature reported an increase in the quality-adjusted life expectancy of haemodialysis patients with increasing dialysis adequacy ${ }^{2}$.

To determine dialysis adequacy, various methods are currently used. The most simple marker is the urea reduction rate (URR) for which only the pre- and post-dialytic blood urea concentrations are needed. However, the use of URR does not take the effects of ultrafiltration on urea removal into account, nor the effect of urea generation during dialysis. These factors are integrated when the formula of single pool Kt/ $\mathrm{V}_{\text {urea }}$ (spKt/V) is used to assess dialysis adequacy. The calculation of spKt/ $\mathrm{V}$ is somewhat more elaborate, as data of body weight, type of vascular access, treatment time and ultrafiltration volume are needed. However, with spKt/V, the effect of urea rebound from the peripheral tissues to the blood is neglected. For this purpose, the formula of equilibrated double pool Kt/V (eKt/V) was developed, which corresponds to spKt/ V with 30 minutes urea rebound. For computation of eKt/ $\mathrm{V}$, no additional parameters in addition to those needed for calculation of spKt/V) are required, although the formula is slightly more complicated compared to spKt/V.

Various guidelines groups have defined targets for dialysis dose prescription ${ }^{3,4}$. $\mathrm{K} / \mathrm{DOQ}$ guidelines recommend measurement of haemodialysis dose using spKt/V, whereas EBPG guidelines prefer using $\mathrm{eKt} / \mathrm{V}^{3,4}$. In addition, some national registries, such as the UK Renal Registry [6], advocate the use of URR to assess dialysis adequacy. However, despite the fact that the EBPG on dialysis adequacy have been published various years ago, a recent survey by the EDTA-QUEST [5] initiative showed that URR (46\%), followed by spKt/V (35\%), was used in a great majority of dialysis centers in daily practice. eKt/V was used by only $13 \%$ of respondents.

The primary aim of our study was to determine the agreement between URR, spKt/V and eKt/ $\mathrm{V}$ in the assessment of dialysis adequacy, taking the different cut-off values for these parameters into account. Second, to determine factors for disagreement, considering eKt/ $\mathrm{V}$ as gold standard. Third, the relation to survival in URR, spKt/V and eKt/ $\mathrm{V}$ was assessed.

\section{Subjects and Methods}

\section{Patients}

Patients with end stage renal disease starting dialysis treatment in 38 dialysis centres in The Netherlands were invited to participate in the Netherlands Cooperative Study on the Adequacy of Dialysis (NECOSAD) study. Recruitment of patients was between August 1996 and March 2007. Inclusion criteria were age $\geq 18$ years and starting renal 
replacement therapy for the first time. Additional criteria for the present analysis were treatment with haemodialysis at twelve months after the start of dialysis $(n=1122)$ and complete data for the measurement of dialysis adequacy $(n=830)$. The study was approved by the Medical Ethics Committees of all participating hospitals. All patients gave written informed consent.

\section{Design}

At start of dialysis, data regarding clinical and demographic characteristics, including gender, age, smoking status, primary kidney disease and co-morbidity, were collected. Patients were followed at three and six months after start of dialysis treatment, thereafter at 6-monthly intervals. Data for dialysis adequacy were collected at 12 months after the start of dialysis, because stability in haemodialysis treatment may be assumed (and the contribution of residual renal function may be less prominent as compared to the 3 and 6 months data). Body weight was measured before and after each haemodialysis session. Treatment characteristics collected were dialysis frequency, ultrafiltration volume and treatment time. Blood samples were drawn before and after a monitoring dialysis session and again before the following dialysis session. Urine was collected during the entire interdialytic interval. Follow-up was until time of death, transplantation, transfer to a non-participating hospital, recovery of renal function or end of study (20 August 2007). Follow-up was censored to a maximum of 5 years.

\section{Data collection}

Demographic and baseline data were obtained 0 to 4 weeks before the start of chronic dialysis treatment. Comorbidities were scored in case of presence of a doctors diagnosis. Co-morbidity risk score was assessed as recommended by Khan et al. ${ }^{7}$ Primary kidney disease and cause of death were classified according to the codes of the European Renal Association-Dialysis and Transplantation Association ${ }^{8}$.

\section{Dialysis dose/adequacy}

eKt/V was computed using the Daugirdas-Schneditz rate equation (Appendix 1) and considered as golden standard, while spKtV and URR were determined from the preen postdialysis blood urea nitrogen (BUN) using the two-BUN method (Appendix 2+3). Urea distribution volume (V) was calculated using Watson's formula (Appendix 4). rGFR was estimated according to the formula in Appendix 5. Since residual renal function may contribute significantly to final weekly $\mathrm{Kt} / \mathrm{V}$, the estimation of renal plus dialytic Kt/V allows better judgment of total adequacy. Therefore $\mathrm{rKt} / \mathrm{V}+\mathrm{eKt} / \mathrm{V}(\mathrm{wk})$ and $\mathrm{rKt} / \mathrm{V}+\mathrm{spKt} / \mathrm{V}(\mathrm{wk})$ were also assessed. eKtV and spKt/V including $\mathrm{rGFR}$ were expressed in weekly rKt/V+eKt/V(wk) and subsequently rKt/V+spKt/V(wk) (Appendix 6) to value total treatment dose. 
Minimal dialysis adequacy was compared between the minimum aims: eKt/ $\mathrm{V}>1.05$, which is the mimimum according to the HEMO study, ${ }^{9,10}$, and to spKt/V $>1.2$ and URR $>65 \%$ (mimimum according to K-DOQI) ${ }^{3}$.

Target dialysis adequacy was compared between the target levels of the different methods: eKt/V >1.20 (target EBPG 2001), spKt/V >1.40 and URR >70\% (target K-DOQI).

Dialysis adequacy was also categorized in order to enable comparison between the different adequacy formulas with different units. This was achieved by classifying into three categories. The middle category of each of the dialysis adequacy formulas, considered as sufficient dialysis dose and defined as the reference group, was compared to the lowest category (inadequate dialysis) and the highest category (above target dose).

\section{Statistical analysis}

Results are expressed as mean \pm SD. Differences in continuous variables were tested using the Students $t$ test if normally distributed or Wilcoxon rank-sum test if skewed. The agreement between the different methods was analyzed using linear regression models and descriptive statistics. Crude and adjusted hazard ratios for the different parameters were calculated using Cox proportional-hazards regression modeling. In analogy to the study of Termorshuizen et al. ${ }^{11}$ age, Khan comorbidity score, primary kidney disease and body mass index were used as covariates. The SPSS-13.0 package was used for statistical analysis. $\mathrm{P} \leq 0.05$ was regarded as statistically significant.

\section{Results}

A total of 2062 patients were included in the NECOSAD study. 1217 patients started with haemodialysis. In 830 of those, data for dialysis adequacy assessment at 12 months after the start of dialysis were available, and were included in the present analysis.

Baseline characteristics of these patients are listed in Table 7.1. At twelve months after start of dialysis mean age was $64,41 \%$ was female, $21 \%$ had diabetes and $74 \%$ of the haemodialysis patients were treated three times per week or more. Mean haemodialysis treatment time was $10.29 \pm 1.97$ hours/week. In Table 7.2 the characteristics of haemodialysis treatment, haemodialysis adequacy, and residual renal function (rGFR) are shown. Residual renal function was present in 522 patients. 
Table 7.1 Patient demographics at baseline.

\begin{tabular}{lc}
\hline Number of patients, $\mathrm{n}$ & 830 \\
\hline Age, years & $64(13)$ \\
Gender, \% male & 60 \\
Ethnicity, \% Caucasian & 92 \\
Weight, kg & $73.2(14.4)$ \\
Height, cm & $170.5(9.6)$ \\
BMl, kg/m2 & $25.2(4.5)$ \\
Primary kidney disease, \% & \\
Diabetes & 15 \\
Glomerulonephritis & 10 \\
Renal vascular disease & 21 \\
Other & 54 \\
Diabetes, \%* & 21 \\
Khan co-morbidity score, \% & \\
Low & 32 \\
Medium & 38 \\
High & 30 \\
\hline
\end{tabular}

Mean values (SD) are presented for continuous variables. * Patients with diabetes either as comorbid condition or primary kidney disease.

Table 7.2 Characteristics of haemodialysis treatment, adequacy and residual renal function.

\begin{tabular}{lc}
\hline Treatment time per week, hours & $10.29(1.97)$ \\
Dialysis frequency, per week & $2.76(0.48)$ \\
UF volume, millilitres & $1970(1184)$ \\
eKt/V & $1.02(0.23)$ \\
spKt/V & $1.18(0.26)$ \\
$\% U R R$ & $63(8)$ \\
rGFR, ml/min & $3.69(1.9)$ \\
rKt/V+eKt/V, per week & $3.56(0.86)$ \\
rKt/V+spKt/V, per week & $3.99(0.96)$ \\
V, litres & $37.2(6.29)$
\end{tabular}

* $n=522$. Mean values (SD) are presented for continuous variables.

\section{Adequacy of haemodialysis dose}

12 months after start of dialysis, mean delivered eKt/ $\mathrm{V}$ was $1.02 \pm 0.23$, spKtV $1.18 \pm 0.26$, and URR $63 \% \pm 8 \%$. Mean rGFR was $3.69 \pm 1.9 \mathrm{ml} / \mathrm{min} / 1.73 \mathrm{~m}^{2}$ and mean $\mathrm{V}$ was $37.2 \pm 6.3$ liters. Taking rGFR into account, total mean rKt/V+ eKt/V(wk) was $3.56 \pm$ 0.86 and mean rKt/V+spKt/V(wk) 3.99 \pm 0.96 (Table 7.2).

\section{Comparison of dialysis adequacy measures}

Correlation between spKt/ $\mathrm{V}$ and eKt/V (Pearson correlation $\mathrm{r}=0.99, \mathrm{P}<0.001$ ) and URR and eKt/V (Pearson correlation $r=0.95, P<0.001$ ) was highly significant (Figure 7.1). When spKt/ $V$ was used, 374 patients reached the minimal dose, whereas in 17 (4\%) of those minimal eKt/ $\mathrm{V}$ was not attained (Figure 7.1A). When using the URR equation, in 
352 patients dialysis dose attained the minimal criteria, whereas eKt/V showed in 31 (9\%) of these patients an inadequate dialysis dose (Figure 7.1B).

Using eKt/V $\geq 1.2$, spKt/V $\geq 1.4$ and $U R R \geq 70 \%$ as target aims for adequate haemodialysis dose, the three different parameters were analyzed. In 161 (19\%) of the patients spKt/V dialysis dose was at or above the target range, without residual renal function taking into account. However, three of these patients (2\%) did not reach the target level according to eKt/V (<1.2 but $>1.19)$ (Figure 7.1C). When URR was used in the cohort of 830 patients, 160 (19\%) patients had a dialysis dose at or above the target range. In fifteen of those $(9 \%)$, eKt/ $\mathrm{V}$ was below the target $(<1.2$ but 21.08) (Figure 7.1D).
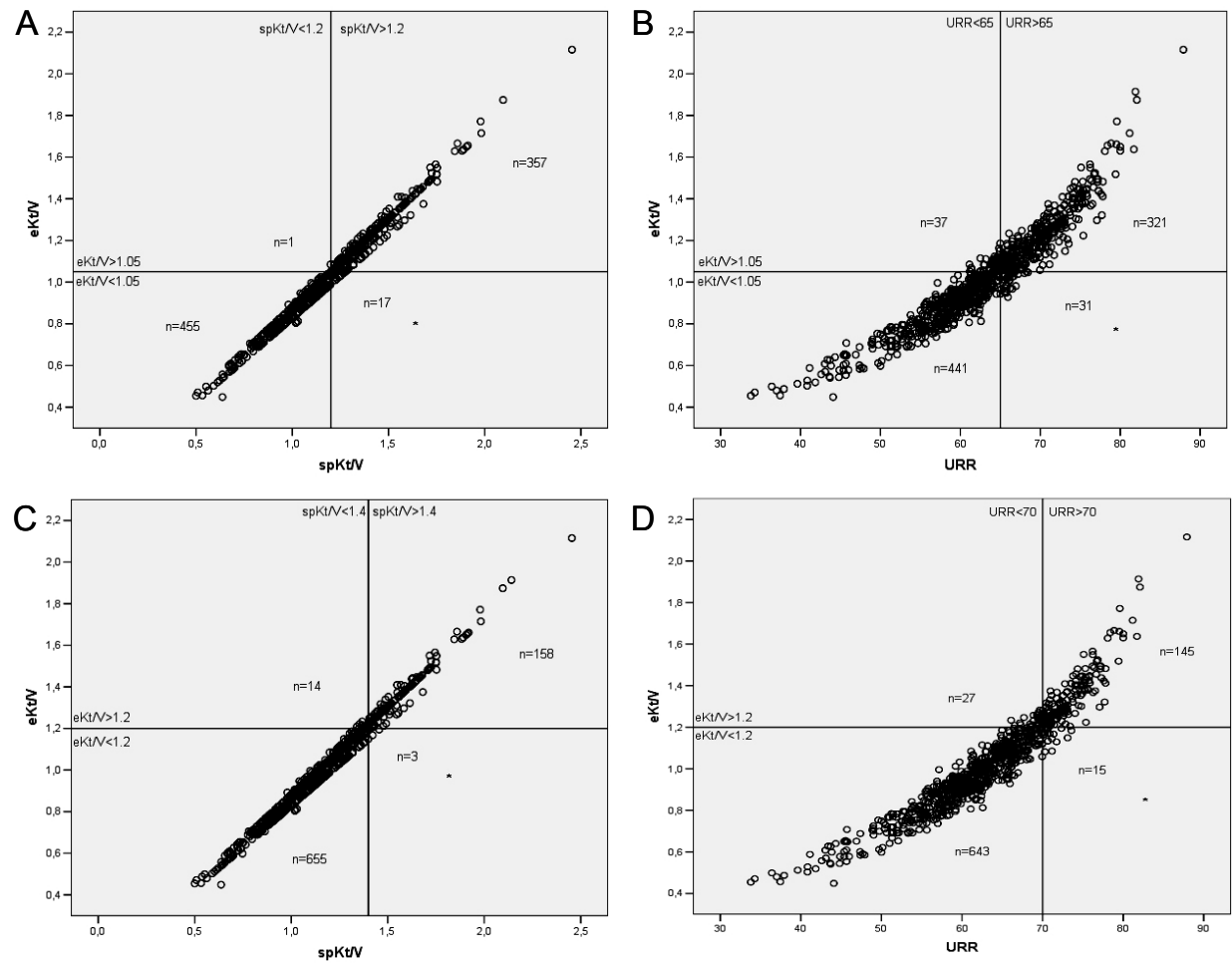

Figure 7.1 Correlation between single pool Kt/V and equilibrated double pool Kt/V $(r=0.994)$ and urea reduction rate and equilibrated double pool $\mathrm{Kt} / \mathrm{V}(\mathrm{r}=0.953)$. Panel $\mathrm{A}$ shows classified and misclassified cases between minimal dose of single pool $\mathrm{Kt} / \mathrm{V}$ and equilibrated double pool $\mathrm{Kt} / \mathrm{V}$, panel $\mathrm{B}$ shows classified and misclassified cases between minimal dose of urea reduction rate and equilibrated double pool Kt/V.

Panel $\mathrm{C}$ shows classified and misclassified cases between target dose of single pool Kt/ $\mathrm{V}$ and equilibrated double pool Kt/V, panel $\mathrm{D}$ shows classified and misclassified cases between target dose of urea reduction rate and equilibrated double pool Kt/V.

*The lower right quadrant are the misclassified patients in whom minimal dialysis adequacy is overestimated when making use of the alternative methods 
Table 7.3 summarizes differences in characteristics of patients in which dialysis adequacy would be overestimated when alternative methods for estimating dialysis adequacy were used instead of the gold standard. Treatment time and ultrafiltration volume were significantly different at the misclassification when minimum dose of URR was reached instead of eKt/V (8.8 vs 10.2 hrs/wk respectively 571 vs 1993 $\mathrm{ml} /$ treatment; $P<0.001)$. The misclassification using spKt/ $\mathrm{V}$ instead of eKt/V as minimal cut-off point showed significant differences in treatment time $(9.3 \mathrm{vs}$ $10.4 \mathrm{hrs} / \mathrm{wk}$ ) and urea distribution volume (31.1 vs $34.8 \mathrm{l} ; P=0.003$ ). The disagreement of reaching target dose by the alternative parameters compared to the golden standard showed the same significant characteristics. Treatment time and ultrafiltration volume were significantly different between the classified and misclassified patients when URR was used tot judge sufficient dialysis dose instead of eKt/V (8.2 vs $10.2 \mathrm{hrs} / \mathrm{wk}$ for treatment time and 330 vs $1916 \mathrm{ml} /$ treatment for ultrafiltration; $P<0.001)$. When using spKt/V instead of eKt/V only urea distribution volume obtained statistical significance while defining characteristics of misclassified patients (28.8 vs 33.3 I; $P<0.001$ ).

\section{Relation of the different treatment indices with mortality}

URR, spKt/V and eKt/V were each significantly related to survival, after correction for confounding factors. For each unit increase in dialysis adequacy, the adjusted HR $(95 \% \mathrm{Cl})$ was $0.98(0.96,0.99)$ for URR, $0.51(0.31,0.84)$ for spKt/V and $0.46(0.30$, 0.80 ) for eKt/V. When dividing the groups into three categories (below minimum, above target, and levels between minimum and target), with the latter as reference, the trends in survival between the different parameters remained, but only reached significance for eKt/V. Patients with eKt/V levels in the lowest category (below minimum) had the highest risk of mortality independent of other factors (Table 7.4). 


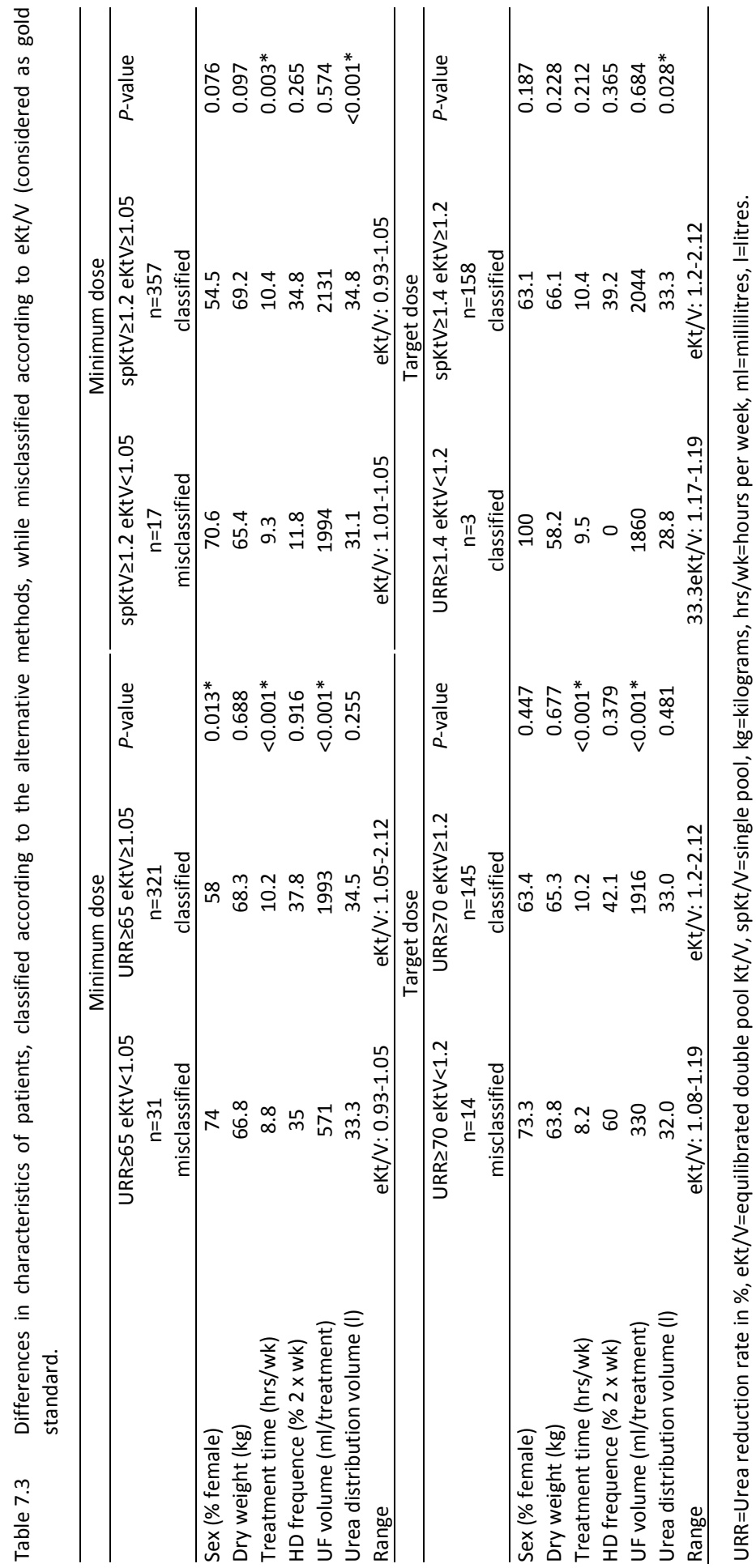


Table 7.4 Crude and adjusted mortality risk (hazard ratio [HR] with $95 \% \mathrm{Cl}$ ) for each of the formulas of dialysis adequacy / dose, $n=830$

\begin{tabular}{lcc}
\hline & Crude HR $(95 \% \mathrm{Cl})$ & Adjusted HR $(95 \% \mathrm{Cl})^{*}$ \\
\hline URR & $0.99(0.97,1.0)$ & $0.98(0.96,0.99)^{\#}$ \\
spKt/V & $0.72(0.49,1.07)$ & $0.51(0.31,0.84)^{\#}$ \\
eKt/V & $0.67(0.43,1.05)$ & $0.46(0.3,0.80)^{\#}$ \\
\hline
\end{tabular}

Adequacy formulas divided in categories, according to minimum and target value, with the recommended value as reference category

\begin{tabular}{lccc}
\hline Adjusted HR $(95 \% \mathrm{CI})^{*}$ & $\begin{array}{c}\text { Category 1 } \\
\text { (below minimum) }\end{array}$ & $\begin{array}{c}\text { Category 2 } \\
\text { (recommended) }\end{array}$ & $\begin{array}{c}\text { Category 3 } \\
\text { (above target) }\end{array}$ \\
\hline $\mathrm{URR}^{\mathrm{a}}$ & $1.08(0.82,1.43)$ & 1.00 & $0.73(0.51,1.04)$ \\
$\mathrm{spKt}^{\mathrm{b}} \mathrm{V}^{\mathrm{b}}$ & $1.29(0.98,1.69)$ & 1.00 & $0.86(0.61,1.20)$ \\
$\mathrm{eKt}^{\mathrm{c}}$ & $1.46(1.09,1.95)^{\#}$ & 1.00 & $1.07(0.75,1.52)$ \\
$\mathrm{rKt} / \mathrm{V}+\mathrm{spKt} / \mathrm{V}$, wk $^{\mathrm{b}}$ & $1.23(0.92,1.65)$ & 1.00 & $0.84(0.63,1.12)$ \\
$\mathrm{rKt} / \mathrm{V}+\mathrm{eKt} / \mathrm{V}$, wk $^{\mathrm{c}}$ & $1.12(0.83,1.51)$ & 1.00 & $0.77(0.58,1.02)$ \\
\hline
\end{tabular}

1: URR<65 $(n=478) \quad$ 2(reference): $65<\operatorname{URR}<70(n=194) \quad 3:$ URR $>70 \quad(n=158)$

b 1: spKt/V<1.2 $(n=456) \quad 2($ reference): $1.2<$ spKt/V<1.4 $(n=213) \quad 3:$ spKt $/ V>1.4(n=161)$

c1: eKt/V<1.05 ( $n=472) \quad 2$ (reference): $1.05<$ eKt $/ \mathrm{V}<1.2(n=172) \quad 3:$ eKt/V $>1.2(n=186)$

*HR adjusted for age, Khan co-morbidity score, BMI, primary kidney disease, nutritional status, duration of the dialysis session, and GFR (GFR not for spKt/V(wk) and eKt/V(wk). ${ }^{*}$ significant, $P<0.05$

\section{Discussion}

The results of the present study show that minimum dialysis dose will be satisfactory predicted by spKt/V and URR in a majority of patients ( $96 \%$ and $91 \%$ respectively), considering eKt/ $\mathrm{V}$ as gold standard. In a minority of patients, the adequacy minimum for eKt/V was not met, despite the fact that URR and/or spKt/V appeared to be in an acceptable range. The risk of misclassification was higher for URR (9\%) compared to spKt/V (4\%). All adequacy parameters were significantly related to mortality. However, after categorizing patients according to minimum and target values of the different adequacy parameters, only for eKt/V mortality rates were higher when minimum levels were not met.

There has been ample discussion about the recommended parameter for dialysis dose in various guidelines ${ }^{3,4}$. Whereas the EBPG recommends the use of eKt/V as the parameter of dialysis dose, spKt/V is advocated by K-DOQI. The rationale for the use of eKt/V by EBPG is based on the fact that urea rebound after dialysis is taken into account by adding a time-dependent factor to the equation ${ }^{12}$. Especially in patients treated with very short dialysis sessions, the difference between spKt/V and eKt/V increases, which might result in overestimating dialysis adequacy when dialysis dose is valued by spKt/ $\mathrm{V}^{2}$. In contrast, the K-DOQI group decided to maintain spKt/V as the recommended parameter of dialysis dose, as shortened dialysis treatment times are not allowed by both K-DOQI and EBPG guidelines, and because eKt/ $\mathrm{V}$ is a 
mathematical derivative of spKt/ $\mathrm{V}$, which cannot be adjusted directly by changing treatment parameters ${ }^{3}$.

In our study, in only $4 \%$ of patients with a spKt/V $\geq 1.2$, eKt/V was lower than 1.05 . Moreover, we see in this "misclassified" subgroup a mean eKt/ $V$ of 1.03 (<1.05 but $>1.01$ ), which is very close to minimum level. The notion that ultrashort dialysis neither was nor is current practice in the Netherlands ${ }^{13}$, explains our observation that the great majority of patients with spKt/V values above 1.2 had eKt/V levels above 1.05 , whereas in those patients who were "misclassified" according to spKt/V, the difference with the eKt/V target was very small.

For calculation of URR only pre- and post-dialytic urea measurements are needed. Therefore, it is a simple and time-saving calculated index ${ }^{18,22}$. However, weight of the patient, ultrafiltration volume and treatment time is not taking into account in this formula and therefore deviations with the gold standard parameter may be assumed. Especially at higher levels of URR, the discrepancy with Kt/V was found to increase in previous studies ${ }^{20,21}$. Nevertheless, in the present study, correlation was highly significant, but relationship became exponential for eKt/V $>1.3$. Nine $\%$ of patients with a URR above minimum (65\%) had eKt/V below $1.05(<1.05$ but $\geq 0.93)$. Mean eKt/V in these patients was 0.99 .

Differences in dialysis parameters which were related to misclassification when URR is used instead of eKt/ $\mathrm{V}$ to express target or minimum achieved dose were sex, treatment time and ultrafiltration volume. For the spKt/V formula, treatment time ( $<10$ hours a week) and urea distribution volume were lower in those patients who were above the minimal dose according to spKt/ $\mathrm{V}$, but below the minimal dose according to eKt/V. At low urea distribution volumes and short treatment time a larger rebound effect will be expected, which might explain the discrepancy between URR and spKt/V with eKt/V. The relation between misclassification according to URR and ultrafiltration volume can be explained by the notion that convective urea clearance, which is related to ultrafiltration volume, is not taken into account when using $\mathrm{URR}^{12}$.

In agreement with previous studies ${ }^{14-17,19,23,24}$, we found that eKt/V, spKt/V, and URR were significantly related to survival. However, when analyzing the minimum cut-off values, only eKt/ $\mathrm{V}$ below these values predicted mortality significantly, although the trend also suggested better survival with higher URR and spKt/V values. When taking residual renal urea clearance into account, the same predictions at the same cut-off values were observed.

A potential drawback of this study is the observation that a relatively small number of patients had an eKt/V above target, which could be attributed to the presence of residual renal function in a significant percentage of patients. Indeed, taking residual renal function into account, weekly Kt/V could be considered adequate in the majority of patients. Considering that the number of misclassified patients was relatively small, differences in outcome between patients of which adequacy was over-estimated due 
to URR- and spKt/V-targets, and patients who were correctly classified could not be assessed significantly.

Concluding, the results of our study show that treatment minimums according to eKt/V are overestimated by cut-off values of spKt/V and URR in respectively $4 \%$ and $9 \%$ of patients. The disagreement between the different formulas was related to a low urea distribution volume and dialysis treatment time, and, in case of URR, also to ultrafiltration volume.

Although all adequacy parameters were related to mortality, only in case of eKt/ $\mathrm{V}$, the cut-off value for minimum achieved dose predicted mortality. 


\section{References}

1. Held P, Levin N, Bovbjerg RR, Pauly MV, Diamond LH. Mortality and duration of haemodialysis treatment. J Am Med Assoc 1991;265:871-5 i:307-10

2. Hornberger JC. The haemodialysis prescription and quality adjusted life expectancy. Renal Physicians Association Working Committee on clinical guidelines. J Am Soc Nephrol 1993;4:1004-20

3. NKF-K/DOQI Clinical Practice Guidelines for Hemodialysis Adequacy: update 2000.Am J Kidney Dis. 2001;37 (1 Suppl 1):S7-S64

4. Tattersall J, Martin-Malo A, Pedrini L, Basci A, Canaud B, Fouque D, Haage P, Konner K, Kooman J, Pizzarelli F, Tordoir J, Vennegoor M, Wanner C, ter Wee P, Vanholder R. EBPG guideline on dialysis strategies. Nephrol Dial Transplant 2007;22 (Suppl 2):ii5-ii21

5. Couchoud C, Jager KJ, Tomson C, Cabanne JF, Collart F, Finne P, de Francisco A, Frimat L, Garneata L, Leivestad T, Lemaitre V, Limido A, Ots $M$, Resic $H$, Stojceva-Taneva O, Kooman J; QUEST working group on dialysis adequacy. Assessment of urea removal in haemodialysis and the impact of the European best practice guidelines. Nephrol Dial Transplant,2009;24:1267-74

6. Andrew J Williams ${ }^{a}$, Daniel Ford ${ }^{b}$, Anna Casula $^{b}$, Charles RV Tomson $^{\mathrm{b}}$ Nephron. UK Renal Registry 11th Annual Report (December 2008): Chapter 8 Adequacy of haemodialysis in UK renal centres in 2007: national and centre-specific analyses. Clin Pract 2009;111 (Suppl. 1):c141-c147

7. Khan IH, Catto GR, Edward N, Fleming LW, Henderson IS, MacLeod AM. Influence of coexisting disease on survival on renal-replacement therapy. Lancet 1993; 341: 415-8

8. van Dijk PC, Jager KJ, de Charro F, Collart F, Cornet R, Dekker FW, Grönhagen-Riska C, Kramar R, Leivestad T, Simpson K, Briggs JD; ERA-EDTA registry. Renal replacement therapy in Europe: the results of a collaborative effort by the ERA-EDTA registry and six national or regional registries. Nephrol Dial Transplant 2001;16:1120-9

9. Depner T, Daugirdas J, Greene T, Allon M, Beck G, Chumlea C, Delmez J, Gotch F, Kusek J, Levin N, Macon E, Milford E, Owen W, Star R, Toto R, Eknoyan G; Hemodialysis Study Group. Dialysis dose and the effect of gender and body size on outcome in the HEMO Study. Kidney Int. 2004; 65:1386-94

10. Greene T, Beck GJ, Gassman JJ, Gotch FA, Kusek JW, Levey AS, Levin NW, Schulman G, Eknoyan G. Design and statistical issues of the hemodialysis (HEMO) study. Control Clin Trials 2000; 21: 502-25

11. Termorshuizen F, Dekker FW, van Manen JG, Korevaar JC, Boeschoten EW, Krediet RT; NECOSAD Study Group. Relative contribution of residual renal function and different measures of adequacy to survival in hemodialysis patients: an analysis of the Netherlands Cooperative Study on the Adequacy of Dialysis (NECOSAD)-2. J Am Soc Nephrol 2004;15:1061-70

12. Daugirdas JT, Greene T, Depner TA, Leypoldt J, Gotch F, Schulman G, Star R; Hemodialysis Study Group. Factors that affect postdialysis rebound in serum urea concentration, including the rate of dialysis: results from the HEMO Study. J Am Soc Nephrol 2004; 15: 194-203

13. Harter HR. Review of significant findings from the National Cooperative dialysis study and recommendations. Kidney Int 1983; 23 Suppl 13: S107-12

14. Owen WF Jr, Chertow GM, Lazarus JM, Lowrie EG. Dose of haemodialysis and survival: differences by race and sex. J Am Med Assoc 1998; 280: 1764-1768

15. Chertow GM, Owen WF, Lazarus JM, Lew NL, Lowrie EG. Exploring the reverse J-shaped curve between urea reduction ratio and mortality. Kidney Int 1999; 56: 1872-1878 SECTION II. Haemodialysis adequacy

16. Gotch FA, Levin NW, Port FK, Wolfe RA, Uehlinger DE. Clinical outcome relative to the dose of dialysis is not what you think: the fallacy of the mean. Am J Kidney Dis 1997;30: 1-15

17. Charra B, Calemard E, Ruffet M, Chazot C, Terrat JC, Vanel T, Laurent G. Survival as an index of adequacy of dialysis. Kidney Int 1992; 41: 1286-91

18. Lowrie EG, Lew NL. The urea reducton ratio (URR): a simple method for evaluating haemodialysis treatment. Contemp Dial Nephrol 1991; 12: 11-20

19. Sherman RA, Cody RP, Rogers ME, Solanchick JC. Accuracy of the urea reduction ratio in predicting dialysis delivery. Kidney Int 1995; 47: 319-21

20. Kessler E, Ritchey NP, Castro F, Caccamo LP, Carter KJ, Erickson BA. Urea reduction ratio and urea kinetic modeling: a mathematical analysis of changing dialysis parameters. Am J Nephrol 1998; 18: $471-7$ 
21. De Oreo P, Hamburger R. Urea reduction ratio is not a consistent predictor of KtV. J Am Soc Nephrol 1995; 6: 597

22. Basile C, Casino F, Lopez T. Percent reduction in blood urea concentration during dialysis estimates KtV in a simple and accurate way. Am J Kidney Dis 1990; 15: 40-5

23. Lowrie EG, Chertow GM, Lew NL, Lazarus JM, Owen WF: The urea \{clearance $x$ dialysis time\} product (Kt) as an outcome based measure of dialysis dose. Kidney Int 1999;56:729-37.

24. Owen WF Jr, Lew NL, Liu Y, Lowrie EG, Lazarus JM. The urea reduction ratio and serum albumin concentration as predictors of mortality in patients undergoing hemodialysis. N Engl J Med 1993; 329:1001-6. 


\section{Appendix Mathematical definitions}

1. URR: $1-\frac{C 0-\text { Cend }}{C 0} \times 100 \%$

2. $\quad$ spKt/V: $\quad-L N\left(\left(\frac{C e n d}{C 0}\right)-0,008 \cdot t\right)+\left(4-3,5 \cdot\left(\frac{C e n d}{C 0}\right)\right) \cdot \frac{U f}{W t}$

3. $\mathrm{eKt} / \mathrm{V}: \quad \frac{s p K t / V-(0.6 \times s p K t / V)}{t}+0.03$

4. $\quad \mathrm{V}$ (Watson):

males: $\quad 2,447-0,09516 \cdot A+0,1074 \cdot H t+0,3362 \cdot W t$

females: $\quad-2,097+0,1069 \cdot H t+0,2466 \cdot W t$

5. rGFR: $\quad \frac{(U R E /(\text { Cend }+C))}{2} \times(1000 / 1440)$

6. $\quad \mathrm{rKt} / \mathrm{V}(\mathrm{wk}): \quad \frac{r G F R \times 1440 \times 7}{V \times 1000}$

7. eKt/V(wk): eKt $/ V \times H D$ frequency

8. $\quad \mathrm{spKt} / \mathrm{V}(\mathrm{wk}): \quad s p K t / V \times H D$ frequency

Cend: Plasma concentration of urea end session ( $\mathrm{mmol} / \mathrm{l})$

Co: $\quad$ Plasma concentration of urea before session ( $\mathrm{mmol} / \mathrm{l})$

C: $\quad$ Plasma concentration of urea after interdialytic interval, before next dialysis session ( $\mathrm{mmol} / \mathrm{l})$

$V: \quad$ urea distribution volume

URE: $\quad$ urea output in interdialytic urine collection $(\mathrm{mmol} / \mathrm{d})$

$t$ : treatment time( in hours)

A: age

Wt: $\quad$ weight after the haemodialysis session (in kilogram)

$H t: \quad$ length (in centimeters)

Uf: $\quad$ ultrafiltration (weight before dialysis session minus weight after dialysis session in litres)

rGFR: renal urea clearance (in $\mathrm{ml} / \mathrm{min}$ ) 



\section{Chapter 8

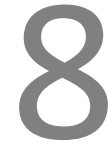

Ionic dialysance and the assessment of Kt/V: the influence of different estimates of $V$ on method agreement

Karin Moret, Charles H Beerenhout, A Warmold L van den Wall Bake, Paul G Gerlag, Frank M van der Sande, Karel M Leunissen, Jeroen P Kooman Nephrol Dial Transplant. 2007;22:2276-82 


\section{Abstract}

\section{Background}

Ionic dialysance was recently introduced as a means to assess dialysis adequacy $\left(\mathrm{K}_{\mathrm{ID}} \mathrm{t} / \mathrm{V}\right)$. With this method, urea distribution volume (V) has to be estimated. The primary aim of the present study was to assess the agreement between equilibrated $\mathrm{Kt} / \mathrm{V}$ assessed by urea kinetic modelling (eKt/V) and $\mathrm{K}_{\mathrm{ID}} \mathrm{t} / \mathrm{V}$ taking into account different estimates of $\mathrm{V}$, and to assess the monthly variation in $\mathrm{V}$. Secondly, the mechanisms behind the intra-treatment changes in ionic dialysance and inter-treatment variability of $K_{I D} t / V$ were assessed.

\section{Methods}

Sixty-six patients were included. eKt/V was estimated using 30 min post-treatment sampling in the second generation Daugirdas equation. $\mathrm{V}$ was assessed by the formulae of Watson and Chertow $\left(\mathrm{V}_{\text {Watson }} ; \mathrm{V}_{\text {Chertow }}\right)$ double-pool urea kinetic modelling $\left(\mathrm{V}_{\mathrm{UKM}}\right)$ and by ionic dialysance $\left(\mathrm{V}_{\mathrm{IOD}}\right)$ [Diascan; Hospal $\left.{ }^{\circledR}\right]$.

\section{Results}

The use of $\mathrm{V}_{\mathrm{UKM}}$ or $\mathrm{V}_{\mathrm{IOD}}$ instead of $\mathrm{V}_{\text {Watson }}$ or $\mathrm{V}_{\text {Chertow }}$ improved the relation between eKt/ $\mathrm{V}$ and $\mathrm{K}_{\mathrm{ID}} \mathrm{t} / \mathrm{V}$ (both $r=0.93 ; p<0.001$ vs $r=0.84$ and $r=0.81 ; p<0.001)$. Mean values of eKt/V $(1.19 \pm 0.21), K_{I D} t / V_{U K M}(1.19 \pm 0.30)$ and $\mathrm{K}_{\mathrm{ID}} \mathrm{t} / \mathrm{V}_{\mathrm{IOD}}(1.21 \pm 0.25)$ were comparable.

Intra-class correlation coefficient of $\mathrm{V}_{\mathrm{IOD}}$ was 0.87 with a 1-month interval and $<0.75$ after 2 and 3 months. Intra-class correlation coefficient of $V_{D P}$ was 0.79 with a 1-month interval and $<0.75$ after 2 and 3 months. Inter-treatment variation in $\mathrm{K}_{\mathrm{ID}} \mathrm{t} / \mathrm{V}$ during six consecutive dialysis sessions was $6.1 \% \pm 0.6 \%$. Changes in blood flow were the main determinant of variations in $\mathrm{K}_{\mathrm{ID}} \mathrm{t} / \mathrm{V}(\mathrm{p}<0.05)$. During treatment, ionic dialysance decreased by $12 \pm 13 \mathrm{ml} / \mathrm{min}(\mathrm{p}<0.001)$. The decline in blood volume was the major determinant of the intradialytic change in ionic dialysance $(p<0.05)$.

Conclusion The use of $\mathrm{V}_{\mathrm{IOD}}$ and $\mathrm{V}_{\mathrm{UKM}}$ results in better agreement between eKt/ $\mathrm{V}$ and $\mathrm{K}_{\mathrm{ID}} \mathrm{t} / \mathrm{V}$ compared with anthropometric formulae. $\mathrm{K}_{\mathrm{ID}} \mathrm{t} / \mathrm{V}$ was comparable with eKt/ $\mathrm{V}$ and thus lower than expected for a single-pool method. $V_{I O D}$ and $V_{U K M}$, should be assessed at least monthly. $K_{I D} t / V$ varies widely between consecutive dialysis sessions, mainly due to differences in blood flow. During treatment, ionic dialysance decreases, which is related to the relative decline in blood volume. 


\section{Introduction}

An adequate delivery of haemodialysis treatment dose is an important factor in the morbidity and mortality of patients treated with haemodialysis ${ }^{1}$. Regular evaluation of delivered treatment dose, commonly performed by measurement of $\mathrm{Kt} / \mathrm{V}$, is necessary to intervene when the delivered treatment is inadequate.

To assess Kt/V, the second generation Daugirdas formula is advocated by both K-DOQI and EDTA guidelines ${ }^{2,3}$. Both guidelines recommend measurement of haemodialysis dose at least once a month. Recent studies suggest that substantial variation in delivery of Kt/V occurs within intra-individual haemodialysis treatments on a sessionto-session basis ${ }^{4,5}$. Thus, a more frequent assessment of $\mathrm{Kt} / \mathrm{V}$ is desirable. However, the need for blood sampling makes more frequent assessment of $\mathrm{Kt} / \mathrm{V}$ by the standard approach, impractical.

Techniques based on measurement of ionic dialysance facilitate the evaluation of dialysis dose by online monitoring of the $\left.\mathrm{Kt} / \mathrm{V}\left(\mathrm{K}_{\mathrm{ID}} \mathrm{t} / \mathrm{V}\right)^{6-8}\right]$. Assessment of dialysis dose based on ionic dialysance was shown to correlate well with $\mathrm{Kt} / \mathrm{V}$ assessed by traditional urea kinetic modelling ${ }^{8,9}$. However, despite highly significant correlations, several studies showed either lower or higher values of $\mathrm{K}_{\mathrm{ID}} \mathrm{t} / \mathrm{V}$ compared with $\mathrm{Kt} / \mathrm{V}$ assessed by urea kinetic modelling. One reason for these differences is the fact that in some studies, $\mathrm{K}_{\mathrm{ID}} \mathrm{t} / \mathrm{V}$, which is a single-pool model, was compared with equilibrated $\mathrm{Kt} / \mathrm{V}(\mathrm{eKt} / \mathrm{V})^{5,8}$. However, another factor which is likely to play a major role in the disagreement between $\mathrm{K}_{\mathrm{ID}} \mathrm{t} / \mathrm{V}$ and $\mathrm{Kt} / \mathrm{V}$ assessed by traditional modelling is the estimation of urea distribution volume $(V)$. With the ionic dialysance method, $V$ has to be inserted in order to calculate the final $K_{I D} t / V$. So far, in the studies which addressed $\mathrm{K}_{\mathrm{ID}} \mathrm{t} / \mathrm{V}$, most commonly the Watson formula is used to assess $\mathrm{V}\left(\mathrm{V}_{\text {Watson }}\right)^{8}$. However, several studies questioned the reliability of these anthropometry-based equations ${ }^{4,11}$. Assessment of $\mathrm{V}$ by urea kinetic modelling $\left(\mathrm{V}_{\mathrm{UKM}}\right)$ may be more reliable in this aspect ${ }^{18}$. Recently, an estimate of $V$ with the use of ionic dialysance measurements has been proposed $\left(\mathrm{V}_{\mathrm{IOD}}\right)$, which correlated very well with $\mathrm{V}$ obtained by direct dialysis quantification and bio-impedance measurements ${ }^{12,13}$. However, a comparison of $V_{I O D}$ with other estimates of $\mathrm{V}$ regarding the agreement between $\mathrm{Kt} / \mathrm{V}$, assessed by urea kinetic modelling and $K_{I D} t / V$ was only assessed in one study in 10 patients ${ }^{13}$. Moreover, the frequency by which $\mathrm{V}_{\mathrm{IOD}}$ or $\mathrm{V}_{\mathrm{UKM}}$ would have to be assessed is not known.

Two previous studies showed substantial inter-treatment variations in $\mathrm{K}_{\mathrm{ID}} \mathrm{t} / \mathrm{V}^{5,14}$. Although the mechanisms behind these variations remain partly understood, intertreatment differences in dialysis time and blood flow rate appear to be major determinants ${ }^{5}$. However, until now, only one study has assessed determinants of inter-treatment variations in $\mathrm{K}_{\mathrm{ID}} \mathrm{t} / \mathrm{V}^{5}$. One recent study also made apparent that ionic dialysance might change during the dialysis therapy ${ }^{15}$. Although systemic salt loading due to the conductivity measurements might be partly responsible for this 
phenomenon, also a reduction in clearance per se, e.g. due to fouling of the membrane, might lead to a reduction in ionic dialysance.

The primary aim of the present study was, firstly, to assess the agreement between $\mathrm{K}_{\mathrm{ID}} \mathrm{t} / \mathrm{V}$ with eKt/V taking into account different estimates of $\mathrm{V}$.

Secondly, possible mechanisms behind the inter-treatment variability of $K_{I D} t / V$ and intra-treatment changes in ionic dialysance were assessed.

\section{Subjects and methods}

Of our HD patient population, we asked all patients who had been on dialysis for more than three months to participate in the present study. Three patients refused to participate. Sixty-six patients were included in the study.

No changes were made to the dialysis prescriptions over the study period. The study protocol was approved by the local medical ethical committee and informed consent was obtained from each patient. Patient characteristics are displayed in Table 8.1. In 13 patients, residual renal function was present. Mean GFR in these patients was $2.4 \pm 2.6 \mathrm{ml} / \mathrm{min}$. Three patients had a central venous catheter. The others were dialyzed by either forearm or upper arm fistula or PTFE grafts. Three patients were dialyzed two times weekly, the others three times weekly.

Table 8.1 Patient characteristics.

\begin{tabular}{lc}
\hline Age (years) & $63 \pm 17$ \\
Male/Female & $39 / 27$ \\
Weight (kg) & $71 \pm 11$ \\
Length (cm) & $168.5 \pm 10.9$ \\
Dialysis duration (hours) & $4 \pm 0.5$ \\
Time on haemodialysis (months) & $37.5 \pm 32.8$ \\
\hline
\end{tabular}

\section{Study protocol}

The agreement between eKt/ $\mathrm{V}$ and $\mathrm{K}_{\mathrm{ID}} \mathrm{t} / \mathrm{V}$ was assessed after the longest dialysis interval. The inter-treatment variation in $\mathrm{K}_{\mathrm{ID}} \mathrm{t} / \mathrm{V}$ (using $\mathrm{V}_{\text {Watson }}$ ) was assessed during six consecutive treatments, as was the intra-treatment variation in ionic dialysance. All treatments were monitored for changes in blood flow, relative blood volume, ultrafiltration volume, treatment time, venous pressure, arterial pressure and transmembrane pressure. 


\section{Dialysis strategy}

All but three patients (as mentioned earlier) were treated three times weekly with haemodialysis, using bicarbonate as buffer and a sodium dialysate concentration of $138 \mathrm{mmol} / \mathrm{l}$. Polysulfone (F8HPS; Fresenius ${ }^{\circledR}$ ) dialysis membranes were used. Target blood flow was $300 \mathrm{ml} / \mathrm{min}$, whereas reached blood flow was $275 \pm 40 \mathrm{ml} / \mathrm{min}$.

\section{Urea kinetic modeling}

Pre- and post-dialysis serum urea samples were taken to measure urea reduction at the dialysis session after the longest interval. Post-dialysis blood samples for assessment of eKt/ $\mathrm{V}$ were drawn by venipuncture $30 \mathrm{~min}$ after the end of dialysis. The eKt/ $\mathrm{V}$ was estimated using the second generation Daugirdas equation with the $30 \mathrm{~min}$ post-dialytic blood samples added $\mathrm{in}^{2,3}$. Also single-pool $\mathrm{Kt} / \mathrm{V}$ was assessed employing the second generation Daugirdas equation (appendix), using post-dialytic samples drawn 2 min after dialysis.

\section{Ionic dialysance}

$\mathrm{K}_{\mathrm{ID}} \mathrm{t} / \mathrm{V}$ was measured online by Diascan ${ }^{\circledR}$ (Hospal-Gambro $\left.{ }^{\circledR}\right)^{6,16}$. The calculation of the mean ionic dialysance is based on differences in inlet and outlet conductivity values after a conductivity pulse of $1 \mathrm{mS} / \mathrm{cm}$ every $30 \mathrm{~min}$. Mean ionic dialysance multiplied by the real duration of the session is used to calculate $K_{I D} t$. $K_{I D} t$ was divided by $V_{\text {Watson, }}$ $\left(V_{\text {Chertow }}\right), V_{U K M}$ and $V_{I O D}$, respectively, to assess agreement with eKt/V.

Determinants of inter-treatment changes in $\mathrm{K}_{\mathrm{ID}} \mathrm{t} / \mathrm{V}_{\text {watson }}$ were assessed during six consecutive treatments ( $n=396)$.

During the same treatments, determinants of intra-treatment variations in ionic dialysance were assessed.

\section{Urea distribution volume}

$\mathrm{V}$ was determined using anthropometrically derived $\mathrm{V}\left(\mathrm{V}_{\text {Watson }}\right)$, based on the Watson formula, taking into account post-dialysis weight, height, gender and $a e^{17} . \vee$ was also determined using the Chertow formula ${ }^{18}$ (appendix).

In addition, $\mathrm{V}$ was assessed based on the formula recently proposed by di Filippo et al. taking into account both plasma urea samples and ionic dialysance measurements $\left(\mathrm{V}_{\mathrm{IOD}}\right)$ (appendix) ${ }^{12}$. Post-dialysis blood samples for assessment of $\mathrm{V}_{\mathrm{IOD}}$ and $\mathrm{V}_{\mathrm{UKM}}$ were drawn 2 min after the end of dialysis using the slow flow technique ${ }^{11}$. $V_{\text {UKM }}$ was calculated using the calculator available on the HDCN page (http://www.hdcn.com/ calcf/dzer.htm). This calculator is based on the two-urea sampling approach as described $\mathrm{in}^{19}$. The single-pool volume is corrected by the programme to a doublepool volume as described in $^{20}$ (appendix). Variations in $\mathrm{V}_{\mathrm{IOD}}$ and $\mathrm{V}_{\mathrm{UKM}}$ were reported during the first dialysis session of the first week of four consecutive months. 


\section{Changes in relative blood volume}

Changes in relative blood volume are determined by an on-line optical method (Hemoscan ${ }^{\circledR}$; Hospal-Gambro ${ }^{\circledR}$ ), assessing relative blood volume changes from blood hemoglobin concentration changes.

\section{Statistical analysis}

The agreement between data was analyzed using pearson's $r$ and Bland-Altman analysis $^{21}$. Differences between eKt/ $\mathrm{V}$ and $\mathrm{K}_{\mathrm{ID}} \mathrm{t} / \mathrm{V}$ using the different estimates of $\mathrm{V}$ were assessed by the student t-test. The standard deviation in $\mathrm{K}_{\mathrm{ID}} \mathrm{t} / \mathrm{V}$ and ionic dialysance during the six different treatments were related to the standard deviation of various potential determinants. Multivariate analysis was used to assess determinants of inter-dialytic variation in $\mathrm{K}_{\mathrm{ID}} \mathrm{t} / \mathrm{V}$ and intra-treatment changes in ionic dialysance. $P$ values $<0.05$ were considered significant. The variations in $V_{\text {IOD }}$ and $V_{U K M}$ were also assessed using the coefficient of variation and the intra-class correlation coefficient. An intra-class correlation coefficient $<0.85$ was considered unacceptable for clinical purposes. The SPSS-12.0 package was used for statistical analysis.

\section{Results}

\section{Agreement between $\mathrm{K}_{\mathrm{ID}} \mathrm{t} / \mathrm{V}$ and eKt/V in relation to different estimates of $\mathrm{V}$}

In five patients with inter-dialytic weight gain $<0.1 \mathrm{~kg}$, the formula for $\mathrm{V}_{\mathrm{IOD}}$ yielded unreliable results (NB: in patients with inter-dialytic weight gain $>0.3 \mathrm{~kg}$, adequate values for VIOD could be calculated. No patient had inter-dialytic weight gains between 0.1 and $0.3 \mathrm{~kg}$ ). Therefore, data of 61 patients were analyzed.

The eKt/V was 1.19 $\pm 0.21 . K_{I D} t / V$ was $1.12 \pm 0.21$ when corrected for $V_{\text {Watson }}(p<0.001$ compared with eKt/V) $1.00 \pm 0.19$ when corrected for $V_{\text {Chertow }}(P<0.001) ; 1.19 \pm 0.30$ when corrected for $V_{U K M}(P=n s)$ and $1.21 \pm 0.25(P=n s)$ when corrected for $V_{I O D}$. Singlepool Kt/ $\mathrm{V}$, assessed by urea kinetic modeling, was $1.32 \pm 0.31(P<0.001)$.

The correlation between $K_{I D} t / V$ and eKt/ $V$ was highly significant $(r=0.84$ and $r=0.81$; $P<0.001$ ), both when using $V_{\text {Watson }}$ and $V_{\text {Chertow }}$ as an estimate of $V$, although $a$ significant difference between both methods was observed $[0.08 \pm 0.13 ; P<0.05]$ and $[0.20 \pm 0.13]$ with wide limits of agreement (Figure 8.1). Both when using $V_{U K M}$ and $V_{I O D}$ as estimates of $\mathrm{V}$, the correlation between $\mathrm{K}_{\mathrm{ID}} \mathrm{t} / \mathrm{V}$ and eKt/ $\mathrm{V}$ became stronger (both $r=0.93 P<0.001)$ and limits of agreement were narrower [0.00 \pm 0.09$]$ and $[-0.01 \pm 0.14]$ (Figures 8.2 and 8.3). 


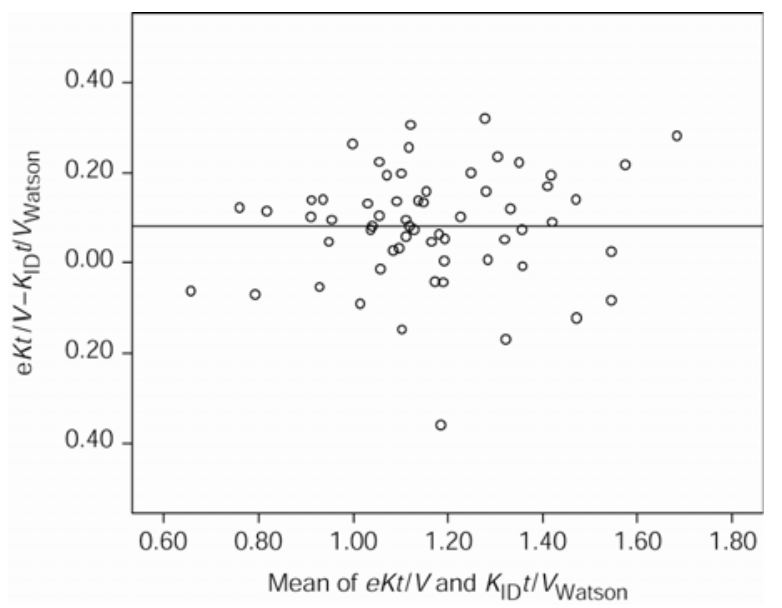

Figure 8.1 Agreement between eKt/V and $\mathrm{K}_{\mathrm{ID}} \mathrm{t} / \mathrm{V}$ using $\mathrm{V}_{\text {Watson }}$ as estimate of $\mathrm{V}$. eKt/V: Double-pool Kt/V according to second generation Daugirdas formula; $\mathrm{K}_{\mathrm{ID}} \mathrm{t} / \mathrm{V}: \mathrm{Kt} / \mathrm{V}$ assessed by ionic dialysance.

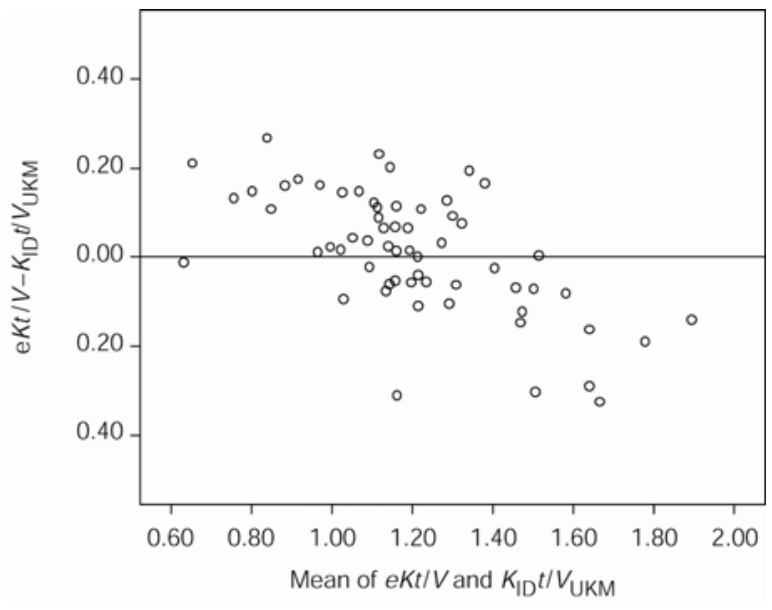

Figure 8.2 Agreement between eKt/V and $\mathrm{K}_{\mathrm{ID}} \mathrm{t} / \mathrm{V}$ using $\mathrm{V}_{\mathrm{UKM}}$ as estimate of $\mathrm{V}$. $\mathrm{V}_{\mathrm{UKM}}$ : Urea distribution volume assessed by double-pool urea kinetic modelling. 


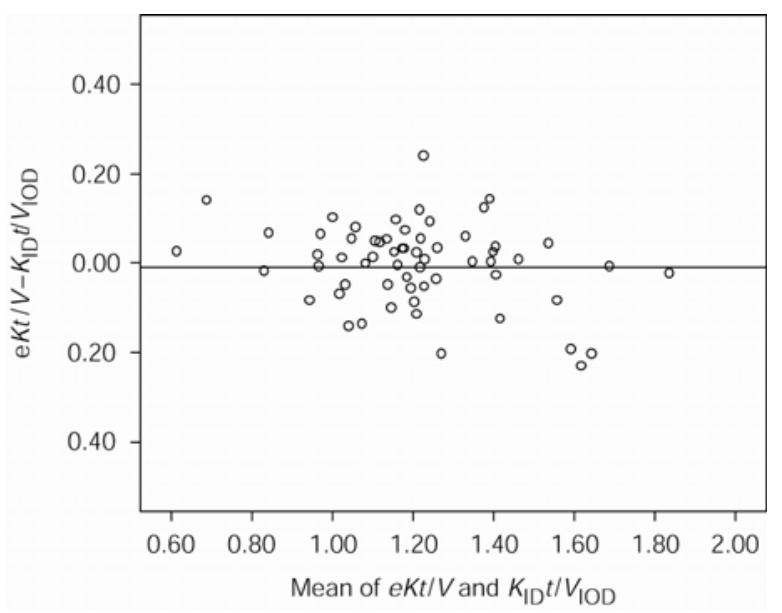

Figure 8.3 Agreement between eKt/V and $K_{I D} t / V$ using $V_{I O D}$ as estimate of $V . V_{I O D}$ : Urea distribution volume assessed by double-pool urea kinetic modelling with use of ionic dialysance.

\section{Monthly variation of $\mathrm{V}_{\mathrm{IOD}}$ and $\mathrm{V}_{\mathrm{UKM}}$}

Coefficient of variation of $\mathrm{V}_{\mathrm{IOD}}$ was $15.7 \%$ when $\mathrm{V}_{\mathrm{IOD}}$ measurements were compared with a one-month interval, $19.7 \%$ when $V_{I O D}$ was compared with a two-month, and $15.7 \%$ when $V_{\text {IOD }}$ was compared with a three-month interval.

Intra-class correlation coefficient of $V_{I O D}$ was 0.87 when $V_{I O D}$ measurements were compared with a one-month interval, 0.68 when $V_{I O D}$ was compared with a twomonth, and 0.74 when $V_{I O D}$ was compared with a three-monthly interval.

Coefficient of variation of $\mathrm{V}_{\mathrm{UKM}}$ was $9.5 \%$ when $\mathrm{V}_{\mathrm{UKM}}$ measurements were compared with a one-month interval, $16 \%$ when $V_{U K M}$ was compared with a two-monthly, and $11.7 \%$ when $V_{\text {UKM }}$ was compared with a three-monthly interval.

Intra-class correlation coefficient of $\mathrm{V}_{\mathrm{UKM}}$ varied from $0.79,0.73$ and 0.57 , respectively with a one-, two- and three-monthly interval.

\section{Inter-treatment variation in $\mathrm{K}_{\mathrm{ID}} \mathrm{t} / \mathrm{V}$ and intra-treatment variation in ionic dialysance}

Three hundred and ninety-six sessions were studied. Mean coefficient of variation of $\mathrm{K}_{\mathrm{ID}} \mathrm{t} / \mathrm{V}$ between the six measurements was $6.1 \pm 4.1 \%$ (range $\left.1.3-21.5 \%\right)$. The intertreatment variation in $\mathrm{K}_{\mathrm{ID}} \mathrm{t} / \mathrm{V}$ is displayed in Figure 8.4.

With multivariate analysis, the variation in blood flow appeared to be the independent parameter explaining the variation in $\mathrm{K}_{\mathrm{ID}} \mathrm{t} / \mathrm{V}$ (Table 8.2).

Mean ionic dialysance at the start of dialysance was $170 \pm 17 \mathrm{ml} / \mathrm{min}$. 
During treatment, ionic dialysance declined by a mean of $11.8 \pm 8.9 \mathrm{ml} / \mathrm{min}(P<0.001)$. With multivariate analysis, the intra-treatment change in ionic dialysance was significantly related to the decline in relative blood volume and blood flow rate (Table 8.3).

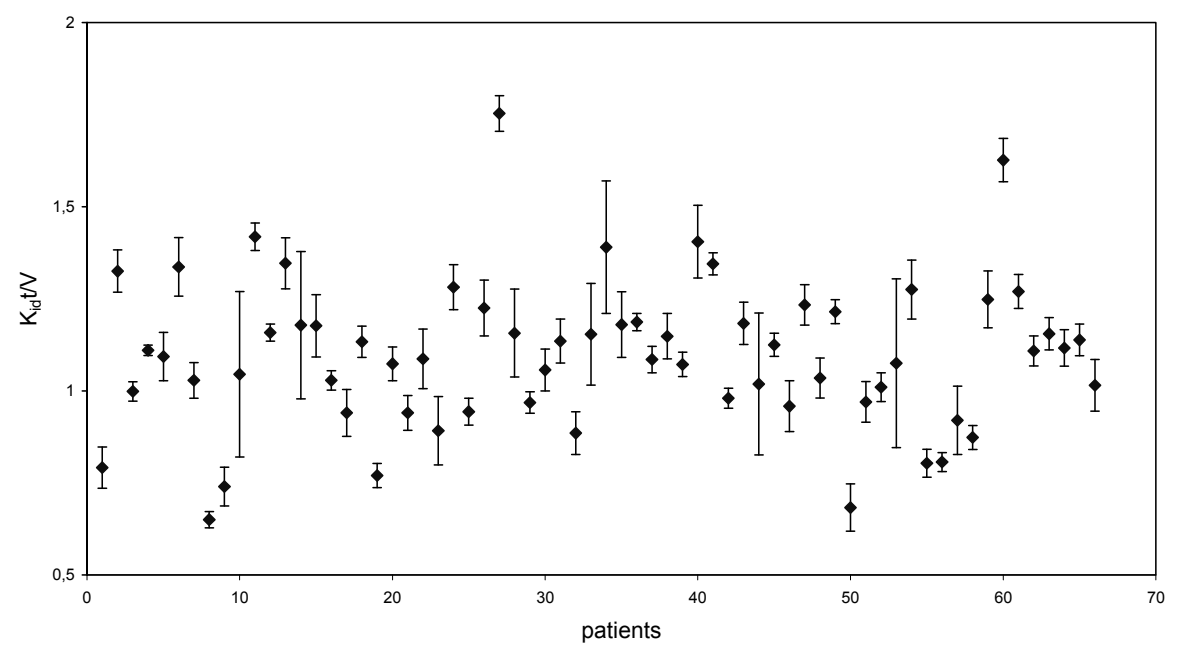

Figure 8.4 Inter-treatment variation in $\mathrm{K}_{\mathrm{ID}} \mathrm{t} / \mathrm{V}$ during six consecutive haemodialysis sessions. $\mathrm{V}_{\text {Watson: }}$ Urea distribution volume assessed by anthropometry (Watson formula).

Table 8.2 Multivariate analysis of determinants for inter-treatment variation in $\mathrm{Kt} / \mathrm{V}_{\mathrm{id}}$.

\begin{tabular}{lccc}
\hline & $\beta$ & $05 \% \mathrm{Cl}$ & $P$ \\
Venous pressure & 0.24 & {$[0.00-0.002]$} & 0.06 \\
Ultrafiltration volume & -0.19 & {$[-0.038$ to 0.014$]$} & $\mathrm{ns}$ \\
Blood flow & 0.30 & {$[0.00-0.002]$} & 0.016 \\
Dialysis time & 0.13 & {$[0.011$ to 0.043$]$} & $\mathrm{ns}$ \\
Decline in blood volume & 0.15 & {$[0.006$ to 0.022$]$} & $\mathrm{ns}$ \\
\hline
\end{tabular}

Table 8.3 Multivariate analysis of determinants for intra-treatment variation in ionic dialysance.

\begin{tabular}{lccc}
\hline & $\beta$ & $05 \% \mathrm{Cl}$ & $P$ \\
Venous pressure & -0.17 & {$[-0.28$ to 0.05$]$} & $\mathrm{ns}$ \\
Ultrafiltration volume & 0.09 & {$[-4.08$ to 8.1$]$} & $\mathrm{ns}$ \\
Blood flow & 0.15 & {$[-0.06$ to 0.23$]$} & $\mathrm{ns}$ \\
Dialysis time & 0.14 & {$[-1.3$ to 5.7$]$} & $\mathrm{ns}$ \\
Decline in blood volume & 0.39 & {$[0.85-4.60]$} & 0.005 \\
\hline
\end{tabular}




\section{Discussion}

Our study confirms previous findings $s^{5,6,8-11,22,23}$ of a good correlation between $\mathrm{K}_{\mathrm{ID}} \mathrm{t} / \mathrm{V}$ and $\mathrm{Kt} / \mathrm{V}$ assessed by urea kinetic modelling, but showed significant differences between both methods when anthropometric formulae were used to estimate $\mathrm{V}$. Compared with our study, Mclntyre et al. showed a better agreement between $\mathrm{K}_{\mathrm{ID}} \mathrm{t} / \mathrm{V}$ and eKt/ $\mathrm{V}$ with $\mathrm{V}_{\text {Watson }}$ as an estimate of $\mathrm{V}$, but studied a more homogeneous group of patients. We studied an unselected group of dialysis patients, nearly comprising the entire haemodialysis population of a single centre. Recent studies questioned the reliability of the anthropometry-based equations and suggested that assessment of $\mathrm{V}$ assessed by urea kinetic modelling might be more reliable in this aspect ${ }^{4,12}$.

When using $\mathrm{V}_{\mathrm{UKM}}$ or $\mathrm{V}_{\mathrm{IOD}}$ in the present study, the relation between eKt/ $\mathrm{V}$ and $\mathrm{K}_{\mathrm{ID}} \mathrm{t} / \mathrm{V}$ improved. Mean values of eKt/ $\mathrm{V}$ and $\mathrm{K}_{\mathrm{ID}} \mathrm{t} / \mathrm{V}$ were nearly comparable, despite the fact that $K_{I D} t / V$ is calculated according to a single-pool model. This is in agreement with the results of McIntyre et al. who also showed comparable values between eKt/ $\mathrm{V}$ and $\mathrm{K}_{\mathrm{ID}} \mathrm{t} / \mathrm{V}$, but in contrast to the data of Filippo et al. who showed higher values for $\mathrm{K}_{\mathrm{ID}} \mathrm{t} / \mathrm{V}$ compared with eKt/V, and to the study of Wuepper et al. where $K_{I D} t / V$ was comparable with single-pool $\mathrm{Kt} / \mathrm{V}^{5,12,13}$. It has been postulated that ionic dialysance may underestimate effective urea clearance due to the effects of systemic salt loading during the ionic dialysance measurements, resulting in a reduced conductivity diffusion gradient across the dialyser, especially when urea clearance is $>150$ $\mathrm{ml} / \mathrm{min}^{15}$. This might explain the fact that $\mathrm{K}_{\mathrm{ID}} \mathrm{t} / \mathrm{V}$, both in our study and in the study of McIntyre, was lower than expected for a single-pool model ${ }^{5}$. However, in chapter 6 , we found no evidence for systemic sodium loading during ionic dialysance measurements when assessed during an entire dialysis session. However, possible effects on short-term variations can not be refuted. Differences between the results obtained by Filippo et al. on one hand, and McIntyre and our study on the other hand, could theoretically be explained by lower levels of urea clearance in the former study ${ }^{5,12}$. However, this is unlikely in view of the fact that ionic dialysance in patients studied by Filippo was comparable with our patients ${ }^{12}$. In contrast to most other studies, Wuepper et al. used a model based on a two-step change in conductivity, which has different effects on systemic changes in sodium ${ }^{13,15}$.

However, even with a two-step change in conductivity, ionic dialysance may underestimate urea removal ${ }^{23}$, which may be related to the effects of cardiopulmonary recirculation ${ }^{24}$.

$\mathrm{V}_{\mathrm{IOD}}$, calculated according to single-pool kinetics, yielded comparable data to $\mathrm{V}_{\mathrm{UKM}}$, calculated according to double-pool kinetics. This is in agreement with the data of Filippo who showed comparable results between $\mathrm{V}$ assessed by direct dialysis quantification (a double pool $\mathrm{V}$ ) and $\mathrm{V}_{\mathrm{IOD}}{ }^{12}$. It has been shown that with haemodialysis with conventional dose prescriptions the ratio between $V$ assessed by single-pool and double-pool kinetics is nearly one to one ${ }^{25}$. A drawback of our study is the fact that we 
did not calculate $\mathrm{V}$ according to direct dialysis quantification or bio-impedance analysis.

In the small proportion of patients with inter-dialytic weight gain $<0.1 \mathrm{~kg}$, calculation of $V_{I O D}$ yielded unreliable values, which may possibly be due to the fact that $V_{I O D}$ was calculated according to single pool variable volume kinetics.

If $\mathrm{V}$ is to be assessed by $\mathrm{V}_{\mathrm{IOD}}$ or $\mathrm{V}_{\mathrm{UKM}}$, the question arises how often $\mathrm{V}$ should be measured. Kloppenburg et al. showed relatively large intra-patient variability in $\mathrm{V}$ assessed by urea kinetic modelling ${ }^{4}$. From the data in the present study, the variability in $\mathrm{V}_{\mathrm{IOD}}$ or $\mathrm{V}_{U K M}$ during a one-month period would appear acceptable for clinical purposes, but not when measurements of $\mathrm{V}$ are performed with longer time intervals. In agreement with earlier data of Lambie et al. ${ }^{14}$, a significant inter-treatment variation in $\mathrm{K}_{\mathrm{ID}} \mathrm{t} / \mathrm{V}$ was observed. In our study, this variation appeared to be mainly related to variations in blood flow rate. Although blood flow rate is routinely prescribed as $300 \mathrm{ml} / \mathrm{min}$ in our centre, sometimes the blood flow rate had to be decreased in response to changes in venous or arterial pressure, among other reasons, due to needle malpositions. The variations in blood flow rate between treatments are in agreement with the study of Lambie et al. ${ }^{14}$. In our study, changes in treatment time played less of a role compared with the findings of Stewart et al. because treatment time was basically kept unchanged.

In the present study, a decline in ionic dialysance during the dialysis session was observed, which also was described by Gotch et al. ${ }^{15}$. The change in ionic dialysance was related to the change in relative blood volume. The mechanism behind this phenomenon remains to be determined. However, it may be hypothesized that increased clotting of proteins to the dialyser membrane might be involved in less diffusive capacities. In addition, also systemic salt loading due to the conductivity measurements per se might affect measurements of ionic dialysance during dialysis ${ }^{15}$. This phenomenon is especially relevant above a urea clearance of $150 \mathrm{ml} / \mathrm{min}^{15}$ and therefore may also have played a role in the measured changes in the present study. Also, due to the hemoconcentration, the blood water flow rate decreases, resulting in a decline in urea clearance and ionic dialysance during the session.

Concluding, $\mathrm{K}_{\mathrm{ID}} \mathrm{t} / \mathrm{V}$ is a useful tool to assess dialysis dose. The use of $\mathrm{V}_{\mathrm{IOD}}$ and $\mathrm{V}_{\mathrm{UKM}}$ result in better agreement between eKt/ $\mathrm{V}$ and $\mathrm{K}_{\mathrm{ID}} \mathrm{t} / \mathrm{V}$ compared with anthropometric formulae. $\mathrm{K}_{\mathrm{ID}} \mathrm{t} / \mathrm{V}$ was comparable with eKt/V, and thus, lower than expected for a single-pool method. Due to the variability in $V_{\text {IOD }}$ and $V_{\text {UKM }}$ these parameters should be assessed at least monthly. $\mathrm{K}_{\mathrm{ID}} \mathrm{t} / \mathrm{V}$ varies widely between consecutive dialysis sessions, mainly due to differences in blood flow. During treatment, ionic dialysance decreases, which is related to the relative decline in blood volume. 


\section{References}

1. Held P, Levin N, Bovbjerg RR, Pauly MV, Diamond LH. Mortality and duration of hemodialysis treatment. J Am Med Assoc 1991; 265:871-5. i: 307-10.

2. NKF-K/DOQI Clinical Practice Guidelines for Hemodialysis Adequacy: update 2000. Am J Kidney Dis 2001;37(1 Suppl 1):S7-S64.

3. European Best Practice Guidelines Expert Group on Hemodialysis, European Renal Association. Section II. Haemodialysis adequacy. Nephrol Dial Transplant 2002;17(Suppl 7):16-31.

4. Kloppenburg W, Stegeman C, Hooyschuur M, van der Ven J, de Jong PE, Huisman RM. Assessing dialysis adequacy and dietary intake in the individual hemodialysis patient. Kidney Int 1999;55: 1961-9.

5. Mclntyre CW, Lambie SH, Taal MW, Fluck RJ. Assessment of haemodialysis adequacy by ionic dialysance: intra-patient variability of delivered treatment. Nephrol Dial Transplant 2003;18:559-63.

6. Petitclerc $T$, Béné $B$, Jacobs $C$, Jaudon MC, Goux N. Non-invasive monitoring of effective dialysis dose delivered to the dialysis patient. Nephrol Dial Transplant 1995;10:212-6.

7. Lindsay R, Bene B, Goux N, Heidenheim A, Landgren C, Sternby J. Relationship between effective ionic dialysance and in vivo urea clearance during haemodialysis. Am J Kidney Dis 2001;38:565-74.

8. Mercadal L, Ridel C, Petitclerc T. Ionic dialysance: principle and review of its clinical relevance for quantification of hemodialysis efficiency. Hemodial Int 2005;9:111-9.

9. Di Filippo S, Andrulli S, Manzoni C, Corti M, Locatelli F. On-line assessment of delivered dialysis dose. Kidney Int 1998;54:263-7.

10. Manzoni C, Di Filippo S, Corti M, Locatelli F. Ionic dialysance as a method for the on-line monitoring of delivered dialysis without blood sampling. Nephrol Dial Transplant 1996;11:2023-30.

11. Mercadal L, Petitclerc T, Jaudon MC, Béné B, Goux N, Jacobs C. Is Ionic dialysance a valid parameter for quantification of dialysis efficiency? Artif Organs 1998;22:1005-9.

12. Di Filippo S, Manzoni C, Andrulli S, Pontoriero G, Dell'Oro C, La Milia V, Tentori F, Crepaldi M, Bigi MC, Locatelli $\mathrm{F}$. Ionic dialysance allows an adequate estimate of urea distribution volume in hemodialysis patients. Kidney Int 2004;66:786-91.

13. Wuepper A, Tattersall J, Kraemer M, Wilkie M, Edwards L. Determination of urea distribution volume for Kt/V assessed by conductivity monitoring. Kidney Int 2003;64:2262-71.

14. Lambie SH, Taal MW, Fluck RJ, Mclntyre CW. Analysis of factors associated with variability in haemodialysis adequacy. Nephrol Dial Transplant 2004;19:406-12.

15. Gotch FA, Panlilio FM, Buyaki RA, Wang EX, Folden TI, Levin NW. Mechanisms determining the ratio of conductivity clearance to urea clearance. Kidney Int Suppl 2004;89:S3-24.

16. Bosetto A, Bene B, Petitclerc T. Sodium management in dialysis by conductivity. Adv Ren Replace Ther 1999;6:243-54.

17. Watson P, Watson I, Batt R. Total body water volumes for adult male and females estimated from simple anthropometric measurements. Am J Clin Nutr 1980;33:27-39.

18. Daugirdas JT, Greene T, Depner TA, Chumlea C, Rocco MJ, Chertow GM, Hemodialysis (HEMO) Study Group. Anthropometrically estimated total body water volumes are larger than modeled urea volume in chronic hemodialysis patients: effects of age, race, and gender. Kidney Int 2003;64:1108-19.

19. Depner TA. Prescribing Hemodialysis: A Guide to Urea Modeling. In: Appendix B. (1991) Boston: Kluwer Academic Publishers.

20. Daugirdas JT, Smye SW. Effect of a two compartment distribution on apparent urea distribution volume. Kidney Int 1997;51:1270-3.

21. Bland JM, Altman DG. Statistical methods for assessing agreement between two methods of clinical measurement. Lancet 1986; 307-310.

22. Kuhlmann U, Goldau R, Samadi N, Graf T, Gross M. Accuracy and safety of online clearance monitoring based on conductivity variation. Nephrol Dialysis Transplant 2001;16:1053-8.

23. Racki S, Zaputović L, Maleta I, Grzetić M, Mavrić Z, Devcić B, Vujicić B. Assessment of hemodialysis adequacy by ionic dialysance: comparison to standard method of urea removal. Ren Fail 2005;27:601-4.

24. Mercadal L, Montcel S, Jaudon $\mathrm{M}$, et al. Ionic dialysance vs. urea clearance in the absence of cardiopulmonary recirculation. Nephrol Dialysis Transplant 2002;17:106-11. 
25. Daugirdas JT, Greene T, Depner TA, Gotch FA, Star RA, and the Hemodialysis (HEMO) study group. Relation between apparent (single-pool) and true (double-pool) urea distribution volume. Kidney Int 1999;56:1928-33. 


\section{Glossary of terms}

$\alpha:$

A:

CO:

Cend:

Cend+30:

Cnext:

eKt/V:

spKt/V:

GFR:

G:

$\mathrm{Ht}$ :

ID:

$\mathrm{K}$ :

$\mathrm{K}_{\mathrm{ID}} \mathrm{t} / \mathrm{V}$ :

$\mathrm{K}_{\mathrm{ID}} \mathrm{t} / \mathrm{V}_{\text {chertow: }}$ :

$\mathrm{K}_{\mathrm{ID}} \mathrm{t} / \mathrm{V}_{\mathrm{IOD}}$

$\mathrm{K}_{\mathrm{ID}} \mathrm{t} / \mathrm{V}_{\text {UKM }}:$

$\mathrm{K}_{\mathrm{ID}} \mathrm{t} / \mathrm{V}_{\text {watson }}:$

Qf:

$\mathrm{t}$ :

Ti:

Uf:

URR:

$\mathrm{V}$ :

$\mathrm{V}_{\text {chertow: }}$

$\mathrm{V}_{\mathrm{UKM}}$ :

$\mathrm{V}_{\mathrm{IOD}}$ : rate of interdialytic weight gain $(\mathrm{ml} / \mathrm{min})$

age (years)

initial plasma water urea concentration $(\mathrm{mmol} / \mathrm{l})$

end-dialysis plasma water urea concentrations determined in blood samples taken at the end of the session with the blood pump speed reduced to $50 \mathrm{~mL} / \mathrm{min}$ for two minutes $(\mathrm{mmol} / \mathrm{l})$ end-dialysis plasma water urea concentrations determined in blood samples taken 30 minutes after the end of the session $(\mathrm{mmol} / \mathrm{l})$ plasma water urea concentration before the start of the subsequent dialytic treatment $(\mathrm{mmol} / \mathrm{l})$

double-pool (equillibrated) Kt/V according to the second generation Daugirdas formula

single-pool Kt/V according to the second generation Daugirdas formula

glomerular filtration rate

urea generation rate $(\mathrm{mg} / \mathrm{min})$

height $(\mathrm{cm})$

ionic dialysance $(\mathrm{mL} / \mathrm{min})$

dialyser clearance

$\mathrm{Kt} / \mathrm{V}$ according to ionic dialysance

$\mathrm{Kt} / \mathrm{V}$ according to ionic dialysance, with urea distribution volume assessed by the Chertow formula

$\mathrm{Kt} / \mathrm{V}$ according to ionic dialysance, with urea distribution volume assessed by single-pool urea kinetic modeling with use of ionic dialysance

$\mathrm{Kt} / \mathrm{V}$ according to ionic dialysance, with urea distribution volume assessed by double-pool urea kinetic modeling

$\mathrm{Kt} / \mathrm{V}$ according to ionic dialysance, with urea distribution volume assessed by the Watson formula

rate of ultrafiltration $(\mathrm{ml} / \mathrm{min})$

duration of treatment time (min)

interdialytic interval (min)

ultrafiltration ( $\mathrm{ml}$ )

urea reduction rate

urea distribution volume

urea distribution volume calculated by the Chertow formula urea distribution volume calculated by urea kinetic modeling urea distribution volume calculated by single-pool urea kinetic modeling with use of ionic dialysance 
$\mathrm{V}_{\text {watson }}$ : $\quad$ urea distribution volume calculated by the Watson formula

$\mathrm{V}_{\mathrm{sp}}$ :

Wt:

effective urea distribution volume given by the single pool model

Wp: postdialysis weight $(\mathrm{kg})$

predialysis weight $(\mathrm{kg})$ 


\section{Appendix Mathematical definitions}

1. URR:

$$
1-\frac{C 0-C e n d}{C 0} \times 100 \%
$$

2. spKt/V:

$$
-\ln \left(\left(\frac{C e n d}{C 0}\right)-0,008 \cdot t\right)+\left(4-3,5 \cdot\left(\frac{C e n d}{C 0}\right)\right) \cdot \frac{U f}{W t}
$$

3. eKt/V:

$$
\frac{s p K t / V-(0.6 \times s p K t / V)}{t}+0.03
$$

4. $\quad \mathrm{V}$ (Watson):

males:

$$
2,447-0,09516 \cdot A+0,1074 \cdot H t+0,3362 \cdot W t
$$

females: $\quad-2,097+0,1069 \cdot H t+0,2466 \cdot W t$

5. $\quad \mathrm{V}(\mathrm{IOD})$ :

$$
\left(Q_{f} \cdot t\right) \cdot\left[\left[1-\left(\frac{G-C e n d \cdot\left(I D-Q_{f}\right)}{G-C 0 \cdot\left(I D-Q_{f}\right)}\right)^{\frac{Q_{f}}{\left(I D-Q_{f}\right)}}\right]^{-1}-1\right]
$$

where 
$\mathrm{G}(\mathrm{mg} / \mathrm{min})$ :

$$
G=\alpha \cdot \frac{\text { Cnext }- \text { Cend } \cdot\left(\frac{(V+\alpha \cdot T i)}{V}\right)^{-1}}{1-\left(\frac{(V+\alpha \cdot T i)}{V}\right)^{-1}}
$$

6. $\quad \mathrm{V}$ (Chertow):

$-0.0749 \cdot A-1.0178 \cdot$ male $+0.127 \cdot H t-0.0401 \cdot W p+0.579$.

diabetes $-0.000672 \cdot W p^{2}-0.0349 \cdot(A \cdot$ male $)+0.1126 \cdot$

$($ male $\cdot W p)+0.00104 \cdot(A \cdot W p)+0.00186 \cdot(H t \cdot W p)$

\section{where}

male is equal to 1 for males and 0 for females and diabetes is 1 for diabetics and 0 for nondiabetics

7. $\mathrm{V}(\mathrm{UKM})$ :

$$
\frac{F K t}{L N \frac{F C 0}{C e n d}}
$$

where

$$
\mathrm{F}: \quad 1-0.44 \frac{K}{V_{S P}}
$$

and

$$
\mathrm{v}_{\mathrm{SP}}: \quad \frac{K t}{\ln \left(\frac{C 0}{\text { Cend }}\right)}
$$


8. rGFR:

$\frac{(U R E /(\text { Cend }+C))}{2} \times(1000 / 1440)$

9. $\quad r K t / V(w k)$ :

$\frac{r G F R \times 1440 \times 7}{V \times 1000}$

10. eKt/V(wk):

eKt / $V \times H D$ frequency

11. spKt/V(wk):

spKt / V $\times$ HDfrequency 


\section{Chapter 9}

Summary and discussion
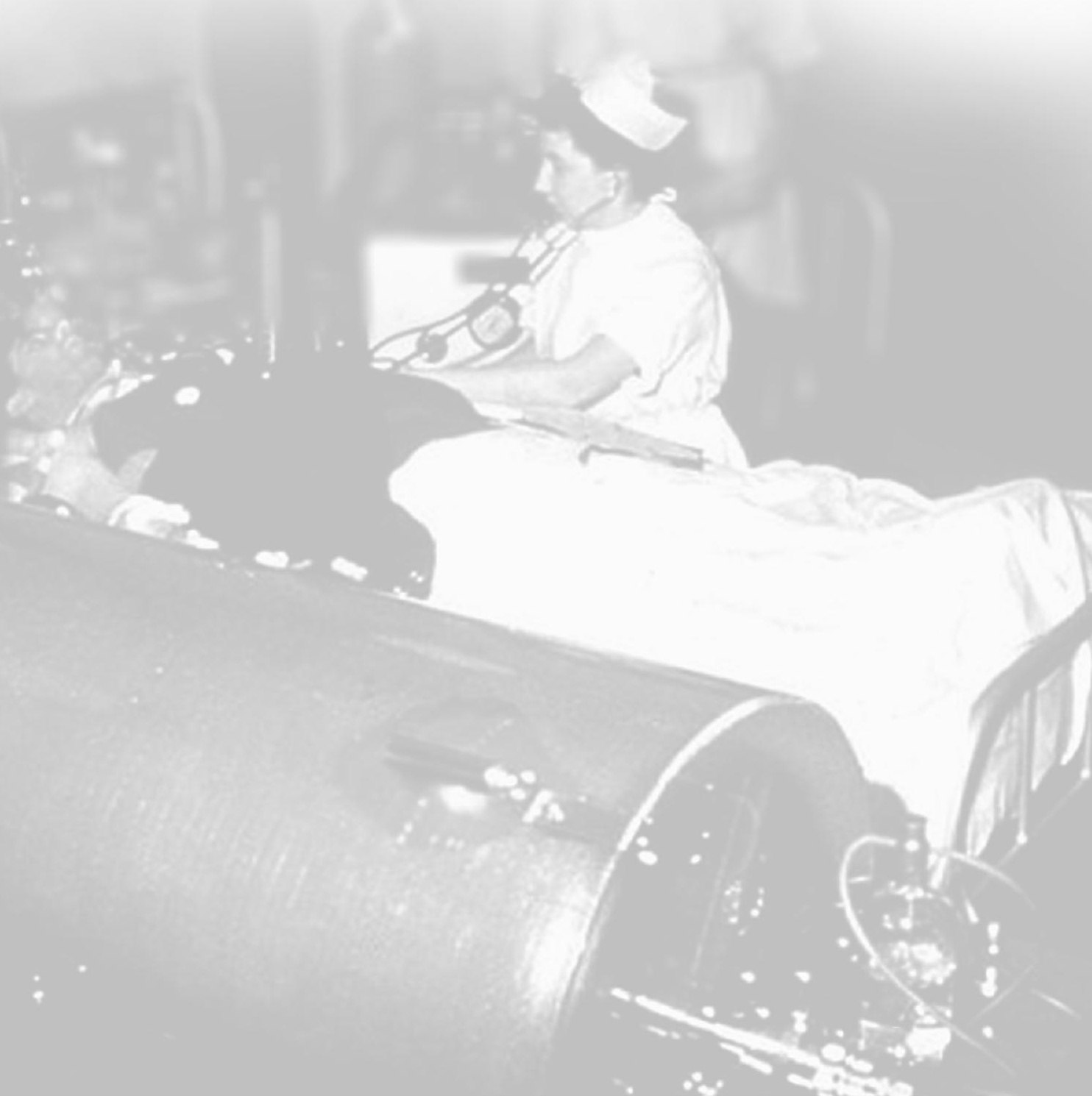
128 Chapter 9 


\section{Summary and discussion}

This thesis comprises two parts: the first part focuses on different aspects concerning the regulation of sodium balance during dialysis. These aspects were studied both during routinely described hemodialysis as well as during different modifications, such as feedback technologies and sodium profiles.

The second part focuses on the monitoring of dialysis efficacy. This was studied by conventional urea kinetic modeling and by the ionic dialysance method.

\section{First Part}

\section{Validation of plasma conductivity and ionic mass balance measurements}

In this thesis, plasma conductivity and ionic mass balance were used as a surrogate of respectively plasma sodium and sodium balance during dialysis.

The main advantages of plasma conductivity and ionic mass balance is that both can be studied without the need for blood sampling and are, with dedicated technology (Diascan ${ }^{\circledR}$; Hospal-Gambro), available during every dialysis treatment*:

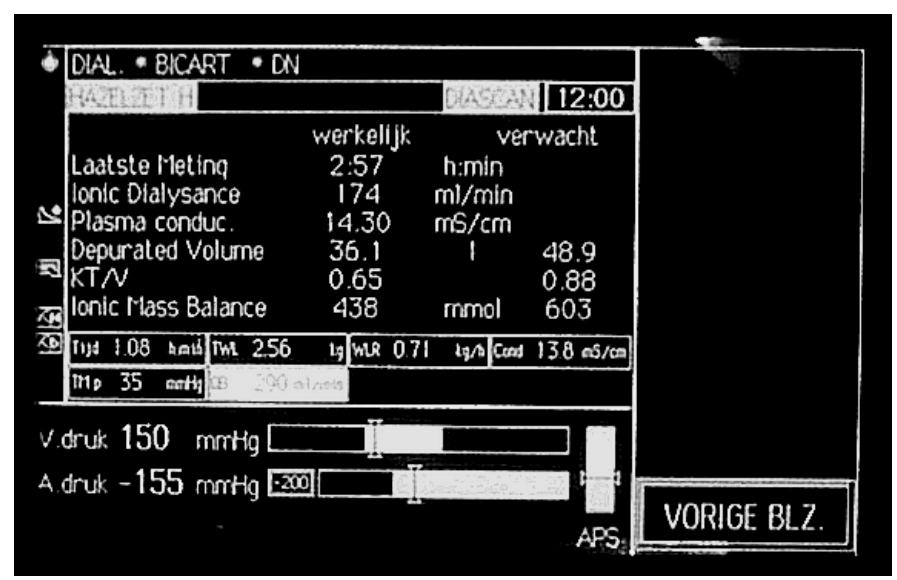

* in this thesis, for sake of simplicity and in agreement with terminology in the literature, the term plasma conductivity is used, whereas the Diascan ${ }^{\circledR}$ device actually calculates conductivity in plasma water 
As described in detail in Introduction of the thesis, conductivity of a solution is the ability to conduct an electrical current. Plasma conductivity is assessed by a simple mathematical formula which includes ionic dialysance and changes in outlet dialysate conductivity after a temporary increase in dialysate conductivity at the dialyzer inlet:

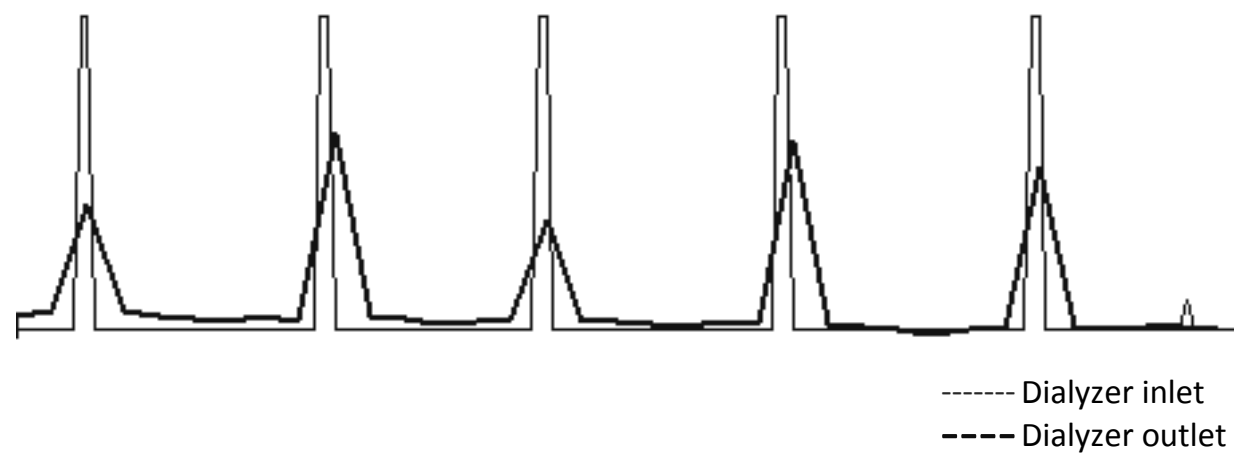

Earlier studies showed a near linear relation between plasma sodium and plasma conductivity. In these studies, plasma conductivity measured in $\mathrm{mS} / \mathrm{cm}$ was found to be $\pm 2 \mathrm{mmol} / \mathrm{l}$ lower as compared to plasma sodium measurements, in accordance to the formula:

Plasma sodium $=($ Plasma conductivity $\times 10.4)-9.57^{1}$. Based on results of different studies, plasma conductivity appears to be adequately validated as surrogate parameter of plasma sodium. Nevertheless it has to be considered that also other ions, although in a lesser degree, may influence plasma conductivity.

This affects also the relation between dialysate conductivity and dialysate sodium, as total conductivity can be influenced by other ions such as chloride and bicarbonate, which may change throughout the dialysis treatment. Although this was not described in full detail in chapters 3 and $\mathbf{4}$, with a dialysate conductivity prescription of 14.0 $\mathrm{mS} / \mathrm{cm}$, dialysate sodium measurements by flame photometry and indirect ionometry were comparable $(140.4 \pm 1.5$ and $139.9 \pm 0.7 \mathrm{mmol} / \mathrm{l})$, but lower when assessed by direct ionometry $(135.4 \pm 1.1 \mathrm{mmol} / \mathrm{l})$. As described in Introduction, this is likely due to formation of a complex with sodium and other ions in the dialysate, which is not measured by direct ionometry. Therefore, in agreement with la $\mathrm{Milia}^{3}$, the estimate of sodium removal in total dialysate collections is dependent on the methodology used, with indirect ionometry and flame photometry likely being the preferred approach.

As for the use of ionic mass balance (IMB) measurements as a surrogate for sodium balance, fewer validation data were available in the literature. Using a formula based on changes in plasma sodium during dialysis and ultrafiltration volume, Lambie observed a significant correlation between sodium balance assessed by this method and ionic mass balance measurements ${ }^{2}$. In chapter 4 , ionic mass balance was 
validated against sodium balance by dialysate collections (in which sodium was measured by flame photometry) and compared with the counted ions by the dialysis machine (Diascan ${ }^{\circledR}$ ). Also, in this study, a very strong relation was observed between sodium balance and ionic mass balance $\left[r^{2}=0.95\right]$, although in individual patients, some discrepancies between both methods were observed. Whether these are due to the inherent variation in sodium measurements, or to changes in other ions in dialysate during the course of dialysis treatment cannot be deduced from this study. In chapter 5, ionic mass balance measurements by Diascan ${ }^{\circledR}$ were shown to correlate highly significantly with conductivity measurements in dialysate collections.

Summarizing, with the limitations discussed above kept in mind, ionic mass balance measurements as a surrogate for sodium balance, plasma conductivity as a surrogate for plasma sodium and dialysate conductivity as a surrogate for dialysate sodium, were used in the remainder of the thesis.

\section{Relation between plasma conductivity and ionic mass balance}

Sodium balance during dialysis is mainly based on convection. However, also diffusion, due to a difference in plasma and dialysate sodium may play an important role. This was clearly shown in chapter $\mathbf{3}$ and $\mathbf{4}$, in which a very strong relation between predialytic plasma conductivity and diffusive ionic mass balance was observed. Both in a controlled study during isovolemic dialysis, and in a facility database in which treatments of all patients over a period of 6 months were analyzed.

In the study with isovolemic dialysis reported in chapter 3, which included 13 patients, ionic mass transfer from dialysate to patient was observed when plasma conductivity was $0.2-0.3 \mathrm{~ms} / \mathrm{cm}$ lower than dialysate conductivity, or when plasma sodium was $2 \mathrm{mmol}$ lower than dialysate sodium. In basic agreement, in the database study reported in chapter 4 , diffusive ionic influx appeared to occur when pre-dialytic PC was below $14.25 \mathrm{mS} / \mathrm{cm}$ (roughly corresponding to a plasma sodium concentration of $139 \mathrm{mmol} / \mathrm{l}$ ) when a dialysate sodium of $140 \mathrm{mmol} / \mathrm{l}$ was prescribed. The explanation for the discrepancies between both studies is not entirely clear. However, due to the effects of ultrafiltration, protein coating of the dialyzer membrane might influence the Donnan effect, and therefore diffusive ionic mass balance. In addition, also pH changes during dialysis may interfere with the Donnan effect ${ }^{4,5}$.

In the study reported in chapter 4 , diffusive mass balance accounted for $18.3 \pm 16.7 \%$ of total mass balance. However, the large range [0.4 - 75.3\%] shows that in individual patients, diffusive mass balance may contribute significantly to total IMB.

Several other studies also assessed the effects of dialysate sodium on sodium balance during dialysis. In the study of Song, diffusive sodium influx appeared to occur at dialysate sodium levels from $137.8 \mathrm{mmol} / \mathrm{l}^{6}$, whereas Flanigan observed an interdialytic increase in plasma sodium in a significant subset of patients when treated 
with a dialysate sodium concentration of $140 \mathrm{mmol} / \mathrm{I}^{7}$. Whether the (minor) differences between studies can be attributed to differences in dialyzer membrane characteristics (e.g. according to protein adsorption) or ultrafiltration rate is not definitely established.

Summarizing, the exact pre-dialytic plasma sodium concentration at which an inward direct diffusive transport occurs, cannot be definitely identified from the thesis, and is also likely dependent on dialysis-related factors such as ultrafiltration. According to the results reported in chapter 4, zero diffusive mass balance would be expected when dialysate sodium concentration approximates plasma sodium concentration.

An important extrapolation from chapter 3 and 4, and from studies of others, is that with frequently applied sodium concentrations of the dialysate $(140 \mathrm{mmol} / \mathrm{l})$, in patients with low pre-dialytic plasma sodium levels, diffusive influx of sodium from the dialysate to the patient may occur. Indeed, although ionic mass removal from patient to dialysate was observed in nearly all treatments, in nearly $33 \%$ of patients studied in chapter 4, diffusive ionic mass transfer from dialysate to patient and a rise in plasma conductivity was observed. From data in the literature, in general, a dialysate sodium concentration of around $137-138 \mathrm{mmol} / \mathrm{l}$ would appear to provide a reasonable balance between the prevention of inward diffusive sodium mass transfer and untoward effects of too low dialysate sodium levels on blood volume preservation $^{8,9}$. For instance, lowering of dialysate sodium from 141 to $138 \mathrm{mmol} / \mathrm{l}$ at a facility level resulted in a small improvement in BP control without an increase in hypotensive episodes ${ }^{8}$. In an audit of 2187 patients, the prescription of a dialysate sodium concentration of $140 \mathrm{mmol} / \mathrm{l}$ or higher was associated with higher interdialytic weight gains, pulse pressure, and even with a higher percentage of intradialytic hypotension as compared to patients whom were prescribed a dialysate sodium concentration of 136 or $137 \mathrm{mmol} / \mathrm{I}^{9}$.

Whether particularly patients with low pre-dialytic sodium levels and patients with difficult to-treat hypertension would benefit from further lowering of dialysate sodium (e.g. to $136 \mathrm{mmol} / \mathrm{l}$ ) is an interesting subject for future studies. In a recent trial, based on tolerability of the participating patients, a reduction of dialysate conductivity of up to $13.0 \mathrm{~ms} / \mathrm{cm}$ was achieved in some patients, with beneficial effects on hypertension control or inter-dialytic weight gain. Notably, patients with frequent intra-dialytic hypotensive episodes were not included in the trial ${ }^{2}$.

\section{Effects of modification of dialysis treatment on sodium balance and plasma conductivity}

Higher dialysate sodium concentrations and/or sodium profiles are frequently used as a method to prevent intra-dialytic hypotension ${ }^{10}$. The rationale behind the use of sodium profiles and increased dialysate sodium concentrations is the improvement of 
refill of blood volume from the interstitial tissues during ultrafiltration. However, the effect on sodium balance has not been widely studied.

Based on the results of chapter 3, ionic mass balance is well able to distinguish between treatments which differ in dialysate sodium prescription. Ionic mass removal was significantly lower in patients treated with a supraphysiologic dialysate sodium concentration of $144 \mathrm{mmol} / \mathrm{l}$ [80 mmol] as compared with a dialysate sodium concentration of $140 \mathrm{mmol} / \mathrm{l}$. In the study described in chapter 5, in which different maneuvers used to prevent intra-dialytic hypotension were compared (including sodium profiling), each during 11 consecutive treatments, difference in ionic mass balance was observed during the first treatment only, whereas pre-dialytic plasma conductivity increased during the period in which the sodium profile was prescribed. Thus, the absence of a lasting effect on ionic mass balance during sodium profiling is likely due to the strong relation between ionic mass balance and pre-dialytic plasma conductivity. During treatment with the sodium profile, due to the increase in predialytic plasma conductivity, the ratio between the dialysate conductivity and predialytic plasma conductivity remained unchanged. These results are in agreement with those of Lambie et al, in which a gradual reduction in dialysate conductivity resulted in a change in ionic mass balance mainly during the first session with the new dialysis prescription $^{2}$.

The increase in plasma conductivity is in some conflict with the paradigm of a pre-set individual plasma sodium setpoint ${ }^{4,7,11,12}$. According to this paradigm, sodium loading will lead to an increase in thirst and water intake, counteracting the effect of sodium loading on plasma sodium levels. In agreement with data from Thein ${ }^{8}$ but in disagreement with data from others ${ }^{2,6,12}$, changes in dialysate sodium prescription resulted in changes in plasma conductivity (and thus plasma sodium levels) but not in changes in inter-dialytic weight gain. Whether the lack of a change in inter-dialytic weight gain during the sodium profile in our study occurred at the expense at increased thirst cannot be deduced from the data.

Given the data in the literature, which show that sodium profiles may be associated with increased inter-dialytic weight, hypertension, as well as the effects on plasma conductivity observed in chapter $\mathbf{5}$ do not support the use of sodium profiles with supraphysiologic sodium concentrations as a preventive measure for intra-dialytic hypotension. Interestingly, although the number of included patients was small, in chapter 5, blood volume controlled feedback appeared to be an effective maneuver in the prevention of intra-dialytic hypotension without untoward effects on sodium balance. Blood volume controlled feedback is a concept at which ultrafiltration rate is adapted based on changes in relative blood volume in order to prevent dialysis hypotension. The efficacy of blood volume controlled feedback is in agreement with earlier studies from the literature, also from our own unit ${ }^{13,14}$. 
Also no difference on sodium balance was observed during plasma conductivity controlled feedback compared to standard dialysis. Plasma conductivity controlled feedback is a technology at which dialysate conductivity is adapted based on online measured plasma conductivity to reach a pre-set end-dialysis plasma conductivity goal. In this study, in agreement with the available literature at that time, we aimed for a post-dialytic plasma sodium concentration ${ }^{15,16,17}$ of $14.0 \mathrm{mS} / \mathrm{cm}$ was chosen as target (likely corresponding to a plasma sodium concentration of $\pm 138 \mathrm{mmol} / \mathrm{l}$ ). However, in some patients with low-predialytic plasma sodium concentrations diffusive sodium influx might have occurred. Thus, especially in those patients with lower plasma sodium levels, individualization of dialysate sodium would appear an attractive option.

\section{Individualization of dialysate sodium}

Data on individualization of dialysate sodium in the literature are scarce. In the study described in chapter 3, individualization of dialysate sodium resulted in an increase in sodium removal in those patients with low pre-dialytic PC level, but actually in a reduction in ionic mass removal in those patients with higher pre-dialytic PC. Therefore, at least from theoretical premises, especially those patients with low predialytic plasma sodium levels patients might benefit from individualized sodium prescription. Data in the literature regarding individualized dialysate sodium concentrations are scarce. In the study of de Paula ${ }^{18}$, individualization of dialysate sodium by manually setting dialysate sodium to equal patient pre-dialysis plasma water sodium concentration, with a correction factor for the Donnan effect, resulted in an improvement in hypertension control and a decrease in inter-dialytic weight gain. At the same time the incidence of intra-dialytic hypotension reduced according to treatments with a fixed dialysate sodium concentration of $138 \mathrm{mmol} / \mathrm{l}$. In this study, especially those patients with difficult-to-treat hypertension benefited from the lowering of dialysate sodium. Pre-dialytic plasma sodium concentrations before the intervention were already quite low $(134.0 \pm 1.4 \mathrm{mmol} / \mathrm{l})$, which was due to the fact that patients who had equal or higher plasma sodium concentrations were excluded from the study. A similar approach was followed by Sayarlioglu ${ }^{19}$, in which pre-dialytic blood pressure and inter-dialytic weight gain decreased if dialysate sodium was individualized in patients with pre-dialytic plasma sodium concentrations below the standard dialysis sodium concentration. Notably, in all these studies, only stable dialysis patients without frequent intra-dialytic hypotensive episodes were included. Thus, although more research is needed, individualization of dialysate sodium to predialytic plasma sodium concentration appears a promising tool, especially in those patients with low pre-dialytic plasma sodium levels, high inter-dialytic weight gains, and suboptimal hypertension control. However, for individualization of plasma sodium, also more information on variations in pre-dialytic plasma sodium (or plasma 
conductivity) would be interesting, given the controversial data in the literature on the presence of a fixed osmolar setpoint in dialysis patients.

\section{Variations in pre-dialytic PC}

In order to explore the concept of individual variations in pre-dialytic plasma conductivity, in chapter 4 a retrospective analysis of all treatments in the facility (4070 measurements in 73 patients) was performed during a period of 6 months, using plasma conductivity as a surrogate for plasma sodium. In this study, the mean coefficient of variation for pre-dialytic PC was $1.3 \%$. Still, the mean intra-individual difference between the lowest and highest pre-dialytic PC measurements during the 6 months follow-up period was $\pm 0.9 \mathrm{mS} / \mathrm{cm}$ [ plasma sodium $9 \mathrm{mmol} / \mathrm{l}$ ]. Interestingly, both inter- as well as intra-variations in pre-dialytic plasma conductivity were related to variations in pre-dialytic blood pressure, which might be a circumstantial argument for volume-independent effects of sodium on blood pressure. Clearly, more research is needed in this area.

Despite the fact that mean intra-patient variations as a whole were relatively minor, the results of the studies in chapter $\mathbf{4}$ and chapter $\mathbf{5}$ cast some doubt on the existence of a fixed osmolar setpoint in all patients. For individualization of treatment, frequent assessment of plasma sodium or plasma conductivity would appear a reasonable strategy. The on-line availability of plasma conductivity would appear to be a very practical tool to achieve individualization of dialysate sodium prescription without the need for blood sampling. This should be the focus of future studies.

\section{Second Part}

\section{Assessment of dialysis adequacy by urea kinetic modeling: is there a preferred method?}

$\mathrm{Kt} / \mathrm{V}_{\text {urea }}$ is widely used to assess dialysis adequacy. The output of this formula results in a number, which determines how many times $V$ (estimated urea distribution volume per individual dialysis patient) has to be purified of urea (and other small solutes) during the time of dialysis. In the assessment of dialysis adequacy, there is a discrepancy between the most influential guidelines on this topic, i.e. the European Best Practice Guidelines (EBPG) and Kidney Disease Outcomes Quality Initiative (KDOQI), regarding the assessment of $\mathrm{Kt} / \mathrm{V}$. Whereas $\mathrm{K}-\mathrm{DOQ}$ recommends the use of spKt/V measurements, EBPG endorses the use of eKt/ $\mathrm{V}$, which corrects for urea rebound due to urea compartmentalization after dialysis ${ }^{20,21}$. Notably, eKt/ $\mathrm{V}$ is a mathematical correction of spKt/ $\mathrm{V}$ for which no additional blood sampling is needed. Both guidelines advice to use the urea reduction rate (URR) only as an additional tool in the assessment of dialysis adequacy. 
It is not well known to which extent patients would be classified as receiving either an adequate or inadequate treatment when treatment is prescribed according to these different adequacy parameters. It is also not known whether the achievement of treatment targets between the different adequacy parameter has different prognostic power. In chapter 7, these questions were addressed in 830 patients of the NECOSAD database. eKt/V above 1.2, a spKt/V above 1.4 and URR above 70\% were used as targets for dialysis adequacy, and respectively 1.0, 1.2 and $65 \%$ as minimum levels.

Only $5 \%$ of patients with spKt/V above 1.4 had an eKt/V below 1.2. In these "misclassified" patients, the mean eKt/V was 1.19 , so very close to the treatment target. The percentage "misclassified" patients was somewhat higher when a URR $>70 \%$ was used as parameter for treatment targets. More or less the same percentage "misclassified" patients was observed when the minimum levels for dialysis adequacy were compared. In survival analysis, an eKtV, spKt/V and URR below the minimum levels were all associated with a higher risk of mortality, which provides support for the clinical usefulness of these adequacy parameters in dialysis monitoring.

Concluding, from the results in chapter 7 , the use of either spKt/ $\mathrm{V}$ or eKt/ $\mathrm{V}$ is not likely to have a major effect on the prescription of dialysis therapy, under the condition that appropriate cut-off levels are used. The risk of "misclassification" appears to be somewhat enhanced with the use of urea reduction rate as a parameter for dialysis adequacy. Whether this carries the risk of inferior patient outcomes cannot be deduced from this thesis .

\section{Assessment of dialysis adequacy by ionic dialysance}

For Kt/V measurements by urea kinetic modeling, blood sampling is needed. As described in the introduction of the thesis, Kt/ $\mathrm{V}$ assessment by ionic dialysance is a non-invasive method which allows to assess dialysis adequacy on a treatment-totreatment basis without the need for blood sampling. This is of special importance given the variety in intra-patient Kt/ $\mathrm{V}$ between treatments observed in chapter $\mathbf{8}$ and confirming the results of others ${ }^{22}$. Although dialysance (the diffusive transfer of a solute through the membrane) and clearance (the depuration of a solution from a given substance) are strictu sensu different concepts, ionic dialysance can be used to assess urea clearance during hemodialysis ${ }^{23}$.

In short, ionic dialysance is expected to be comparable to urea clearance based on the similar characteristics of transfer through the dialyser and the osmotic distribution volumes in the blood. As can be seen in the figure below, ionic dialysance (by Diascan ${ }^{\circledR}$ ) is measured by assessing changes in dialysate conductivity at the dialyser outlet after a change in inlet dialysate conductivity. The change in outlet conductivity can be used to calculate ionic dialysance, assuming that plasma conductivity does not change during the measurement ${ }^{24}$. A very strong relation between ionic dialysance 
and urea clearance has been observed. However, there appears to be a small underestimation of urea clearance by ionic dialysance, which may affect the relation between $\mathrm{Kt} / \mathrm{V}$ by urea kinetic modeling and ionic dialysance, as will be discussed below $^{24,25}$.
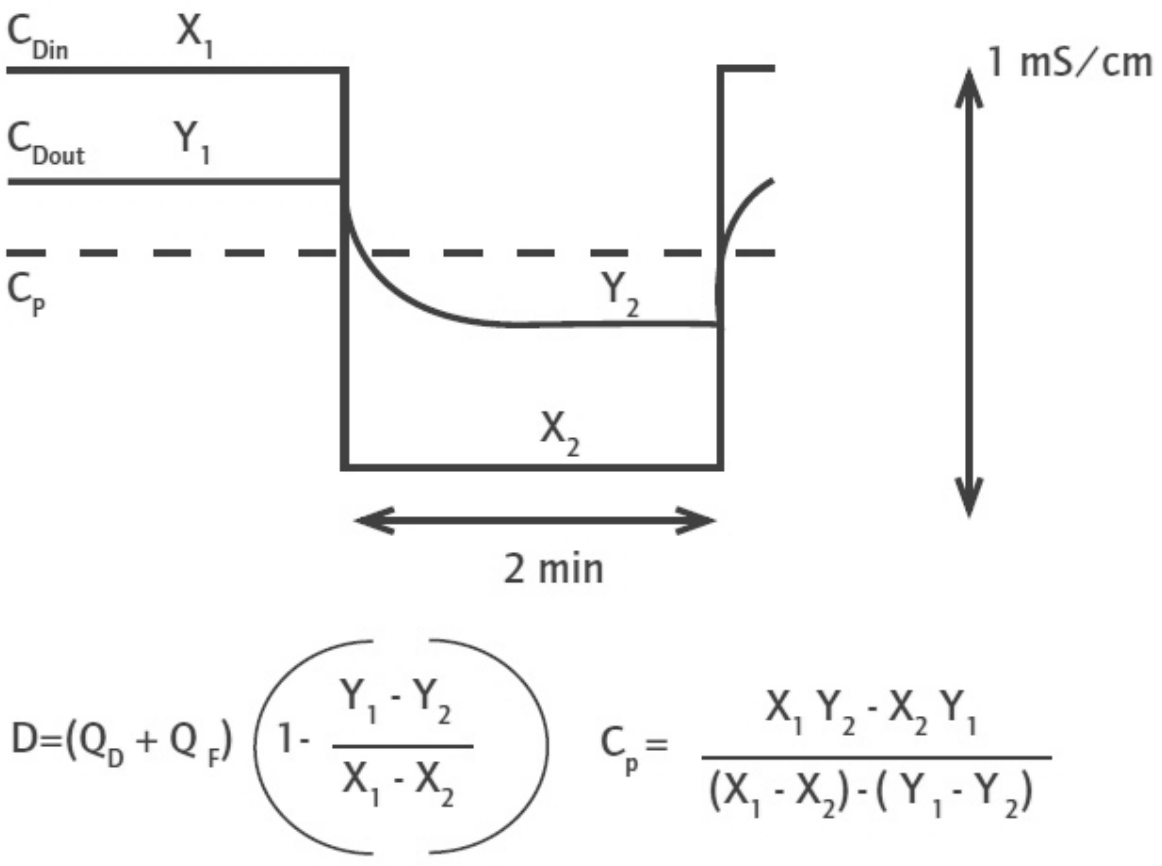

Figure 9.1 Scheme of the record of the inlet and outlet dialysate conductivity during a measurement of ionic dialysance where $X_{1}$ and $X_{2}$ are the two given values of inlet dialysate conductivity, $Y_{1}$ and $Y_{2}$ the two measured values of outlet dialysate conductivity and $C_{p}$ the representation of the patient's plasma conductivity. $Q_{D}$ is dialysateflow, $Q_{F}$ ultrafiltration rate

\section{Agreement between ionic dialysance and urea kinetic modeling in the assessment of $\mathrm{Kt} / \mathrm{V}$}

Although $\mathrm{Kt} / \mathrm{V}$ by ionic dialysance is a single pool method, both in the study described in chapter 8 and in various studies in the literature, Kt/V by ionic dialysance, when assessed by the Diascan ${ }^{\circledR}$ method, appears to be generally lower as compared to spKt/V by urea kinetic modelling ${ }^{24}$.

Besides this (small) underestimation of urea clearance by ionic dialysance, this is amongst others due to the method used to estimate urea distribution volume (V), as will be discussed in the following paragraph. The result has to be added in the 
calculation of Kt/V by ionic dialysance, in order that $\mathrm{V}$ gets a substantial influence on the final result. As the Watson formula, which is the most frequently used anthropometric formula, tends to overestimate urea distribution volume, this would result in a too low estimate of Kt/V. However, Kt/ $\mathrm{V}$ measured by Diascan ${ }^{\circledR}$ (a single pool method) showed better agreement with eKt/V as compared to spKt/V, even when this was calculated by $\mathrm{V}$ by urea kinetic modeling (chapter 8). The good agreement between eKt/ $\mathrm{V}$ and Kt/V by Diascan ${ }^{\circledR}$ is in agreement with the study of McIntyre et al. ${ }^{26}$.

Another factor which may be responsible for the lower estimate of $\mathrm{Kt} / \mathrm{V}$ by ionic dialysance as compared to urea kinetic modeling could be the effect of cardiopulmonary recirculation. Cardiopulmonary recirculation refers to the fact that part of the blood volume, which flows back from the arteriovenous fistula or graft to the heart is directly returned to the arterial part of the access without passing tissues. This phenomenon is inherently present during dialysis with an arteriovenous access but absent during dialysis with a central venous catheter.

Additionally, the underestimate of Kt/ $\mathrm{V}$ by ionic dialysance could be explained by the effect of the conductivity pulses on plasma conductivity. For calculation of ionic dialysance, it is assumed that plasma conductivity remains unaffected by the conductivity pulse itself. The stability of the plasma conductivity levels during ionic dialysance measurements has been questioned by Gotch, who hypothesized that the conductivity pulses may result in sodium loading and thus in an increase in plasma conductivity $^{28}$. In chapter 6 , the effect of conductivity pulses on ionic mass balance in patients treated with isovolemic dialysis was assessed. No difference in IMB was observed between treatments with and without Diascan ${ }^{\circledR}$ measurements. This is certainly no definite proof for the absence of a temporary effect of conductivity pulses on plasma conductivity. However, the findings of Mercadal discussed above argue for a more important role of cardiopulmonary recirculation in the disagreement between urea clearance and ionic dialysance ${ }^{27}$.

Interestingly, there appears to be a difference between the two most commonly used methods, i.e. the OCM monitor by Fresenius and Diascan by Gambro in the $\mathrm{Kt} / \mathrm{V}^{29}$. Both methods have slightly different ways to deliver conductivity pulses. The Diascan method delivers a conductivity step of $1 \mathrm{~ms} / \mathrm{cm}$ during a short time period, with a correction needed for the fact that outlet dialysate conductivity is not completely stabilized during this short time period, whereas the OCM monitor uses a triphasic approach with longer equilibration time ${ }^{24}$. Whether these methodological differences explain the difference between both methods deserves further investigation. 


\section{Urea distribution volume}

Differences between ionic dialysance and formal urea kinetic modeling are also dependent on the method used for the determination of urea distribution volume in the denominator. Next to the effects of cardiopulmonary recirculation on the assessment of ionic dialysance discussed above, another reason for the underestimation of spKt/ $\mathrm{V}$ by ionic dialysance is the fact that the most commonly used anthropometric formulas (e.g. Watson) overestimate urea distribution volume (V) as compared to urea kinetic modeling.

The lower urea distribution volume by urea kinetic modeling as compared to anthropometric formula can be explained either by the fact that anthropometric formula do not adequately reflect total body water in dialysis patients, e.g. by the reduction in skeletal muscle mass and a relative increase in visceral fat distribution in dialysis patients ${ }^{30}$. On the other hand, also a functional redistribution of the urea pool to central compartments, due to a reduction in perfusion of the peripheral compartments during dialysis might contribute to the overestimation of the effective urea distribution volume as compared to anthropometric formula.

As shown in chapter $\mathbf{8}$, and in agreement with data from di Filippo ${ }^{31}$, the use of kinetic modeling to calculate urea distribution volume resulted in an improved relation between Kt/ $\mathrm{V}$ assessed by ionic dialysance and by blood sampling methods. However, the calculation of urea distribution volume by kinetic models is relatively complex for busy clinical practice, even with the use of internet-based calculations, and there is need for blood sampling. This complexity especially appears to hold true if urea distribution volume is calculated by the ionic dialysance formula. Moreover, this formula did not appear to be reliable in patients with significant residual renal function, whereas urea distribution volume estimates by kinetic modeling and by ionic dialysance formula can also be unreliable in case of access recirculation

Therefore, the question remains whether other methods which are easy to apply in the clinic, could not aid in the estimate of the correct urea distribution volume. Bioimpedance, by which total body water is assessed by the impedance of the body to an alternating current, is easy to apply and non-invasive. In a recent study, Lindley et al. found, in agreement to the data in chapter $\mathbf{8}$, an underestimation of dialysis dose if anthropometric formula were used, whereas the use of bioimpedance resulted in comparable Kt/V results as compared to calculation of urea distribution volume by kinetic modeling ${ }^{32}$. Also, in a preliminary study performed in our unit, $\mathrm{V}$ by the new bioimpedance method $\mathrm{BCM}^{\circledR}$ (Fresenius) was significantly lower as compared to Watson V (32.4 liters \pm 7.2 vs. 34.9 liters \pm 6.1 ). The effect of the use of this new methodology on $\mathrm{Kt} / \mathrm{V}$ agreements between ionic dialysance and urea kinetic modeling is a focus for further studies.

Concluding, ionic dialysance has greatly facilitated the assessment of $\mathrm{Kt} / \mathrm{V}$, and appears to be relatively widely used in European centers according to a recent 
survey $^{33}$. However, still discrepancies between ionic dialysance and formal urea kinetic modeling are observed, which depend among others on the method used to assess ionic dialysance, on the methods of blood sampling, and on the methods used for determination of the urea distribution volume. In general, underestimation of spKt/V by Diascan ${ }^{\circledR}$ would have less serious consequences as compared to overestimation.

Due to the still existing controversies with regard to ionic dialysance, it appears prudent to assess $\mathrm{Kt} / \mathrm{V}$ by formal urea kinetic modeling once monthly in accordance with current guidelines. And moreover to use ionic dialysance as a tool to detect disturbances in delivery of dialysis dose, e.g. by access circulation or frequent treatment interruption, which would remain undetected if only assessed by oncemonthly adequacy monitoring. 


\section{References}

1. Locatelli F, Di Filippo S, Manzoni C, Corti M, Andrulli S, Pontoriero G. Monitoring sodium removal and delivered dialysis by conductivity.Int J Artif Organs. 1995;18:716-21

2. Lambie SH, Taal MW, Fluck RJ, Mclntyre CW. Online conductivity monitoring: validation and usefulness in a clinical trial of reduced dialysate conductivity. ASAIO J 2005;51:70-6

3. La Milia V, Di Filippo S, Crepaldi M, Andrulli S, Del Vecchio L, Scaravilli P, Virga G, Locatelli F. Sodium removal and sodium concentration during peritoneal dialysis: effects of three methods of sodium measurement. Nephrol Dial Transplant. 2004;19:1849-55

4. Flanigan MJ. Sodium flux and dialysate sodium in hemodialysis. Semin Dialysis 1998; 11:298-304

5. Vaussenat F, Bosc JY, LeBlanc M, Canaud B. Data acquisition system for dialysis machines. A model for membrane hydraulic permeability. ASAIO J. 1997 Nov-Dec;43(6):910-5

6. Song JH, Lee SW, Suh CK, Kim MJ. Time-averaged concentration of dialysate sodium relates with sodium load and interdialytic weight gain during sodium-profiling hemodialysis. Am J Kidney Dis. 2002;40:291-301.

7. Flanigan MJ. Role of sodium in hemodialysis. Kidney Int 2000; 76(Suppl):S72-S78

8. Thein H, Haloob I, Marshall MR. Associations of a facility level decrease in dialysate sodium concentration with blood pressure and interdialytic weight gain. Nephrol Dial Transplant 2007;22:2630-2639

9. Davenport A, Cox C, Thuraisingham R; PanThames Renal Audit Group.The importance of dialysate sodium concentration in determining interdialytic weight gains in chronic hemodialysis patients: the Pan Thames Renal Audit. Int J Artif Organs. 2008;31:411-7

10. Song JH, Park GH, Lee SY, Lee SW, Lee SW, Kim MJ. Effect of sodium balance and the combination of ultrafiltration profile during sodium profiling hemodialysis on the maintenance of the quality of dialysis and sodium and fluid balances. J Am Soc Nephrol 2005;16:237-246

11. Santos SF, Peixoto AJ. Revisiting the dialysate sodium prescription as a tool for better blood pressure and interdialytic weight gain management in hemodialysis patients. Clin J Am Soc Nephrol 2008;3:522-30

12. Keen ML, Gotch FA. The association of the sodium "setpoint" to interdialytic weight gain and blood pressure in hemodialysis patients. Int J Artif Organs. 2007;30:971-9.

13. Wolkotte C, Hassell DR, Moret K, Gerlag PG, van den Wall Bake AW, van der Sande FM, Kooman JP. Blood volume control by biofeedback and dialysis-induced symptomatology. A short-term clinical study. Nephron. 2002;92:605-9.

14. Santoro A, Mancini E, Paolini F, Cavicchioli G, Bosetto A, Zucchelli P: Blood volume regulation during hemodialysis. Am J Kidney Dis 1998;32:739-748.

15. Hernández-Jaras J, García-Pérez H, Torregrosa E, Calvo C, Cerrillo V. Usefulness of the Biofeedback Diacontrol module in the automatic programming of plasmatic conductivity and ionic mass transfer. Nefrologia. 2003;23:62-70

16. Petitclerc T, Hamani, Jacobs C. Optimization of sodium balance during hemodialysis by routine implementation of kinetic modeling. Blood Purif 1992; 309-

17. Jacobs C, Kjellstrand CM, Koch KM, eds. Replacement of renal function by dialysis. Winchester JF. 4th edition,1996

18. de Paula FM, Peixoto AJ, Pinto LV, Dorigo D, Patricio PJ, Santos SF. Clinical consequences of an individualized dialysate sodium prescription in hemodialysis patients. Kidney Int 2004;66:1232-1238

19. Sayarlioglu H, Erkoc R, Tuncer M, Soyoral Y, Esen R, Gumrukcuoglu HA, Dogan E, Sayarlioglu M: Effects of low sodium dialysate in chronic hemodialysis patients: an echocardiographic study. Ren Fail 29: 143-146, 2007

20. Tattersall J, Martin-Malo A, Pedrini L, Basci A, Canaud B, Fouque D, Haage P, Konner K, Kooman J, Pizzarelli F, Tordoir J, Vennegoor M, Wanner C, ter Wee P, Vanholder R. EBPG guideline on dialysis strategies. Nephrol Dial Transplant. 2007;22 Suppl 2:ii5-21

21. NKF-K/DOQI Clinical Practice Guidelines for Hemodialysis Adequacy: update 2000. Am J Kidney Dis 2001; 37:S7-S64.

22. Lambie SH, Taal MW, Fluck RJ, Mclntyre CW. Analysis of factors associated with variability in haemodialysis adequacy. Nephrol Dial Transplant 2004; 19:406-12 
23. Petitclerc T. Do dialysate conductivity measurements provide conductivity clearance or ionic dialysance? Kidney Int 2006;70:1682-1686.

24. Mercadal L, Ridel C, Petitclerc T. Ionic dialysance: principle and review of its clinical relevance for quantification of hemodialysis efficiency. Hemodial Int (2005) 9:111-9

25. Di Filippo S, Manzoni C, Andrulli S, Pontoriero G, Dell'Oro C, La Milia V, Bacchini G, Crepaldi M, Bigi MC, Locatelli F.How to determine ionic dialysance for the online assessment of delivered dialysis dose. Kidney Int. 2001;59:774-82.

26. Mclntyre CW, Lambie SH, Taal MW, Fluck RJ. Assessment of haemodialysis adequacy by ionic dialysance: intra-patient variability of delivered treatment. Nephrol Dial Transplant 2003; 18:559-63

27. Mercadal L, Du Montcel ST, Jaudon MC, Hamani A, Izzedine H, Deray G, Béné B, Petitclerc T. Ionic dialysance vs. urea clearance in the absence of cardiopulmonary recirculation. Nephrol Dialysis Transplant 2002; 17:106-11

28. Gotch FA, Panlilio FM, Buyaki RA, Wang EX, Folden TI, Levin NW. Mechanisms determining the ratio of conductivity clearance to urea clearance. Kidney Int Suppl. 2004:S3-S24

29. Maduell F, Vera M, Arias M, Serra N, Blasco M, Bergadá E, Fontsere N, Cases A, Campistol JM. Influence of the ionic dialysance monitor on Kt measurement in hemodialysis. Am J Kidney Dis. 2008;52:85-92

30. Woodrow G, Oldroyd B, Turney JH, Tompkins L, Brownjohn AM, Smith MA. Whole body and regional body composition in patients with chronic renal failure. Nephrol Dial Transplant 1996; 11: 1613-8

31. Di Filippo S, Manzoni C, Andrulli S, Pontoriero G, Dell'Oro C, La Milia V, Tentori F, Crepaldi M, Bigi MC, Locatelli $\mathrm{F}$. Ionic dialysance allows an adequate estimate of urea distribution volume in hemodialysis patients. Kidney Int 2004; 66:786-91

32. Lindley EJ, Chamney PW, Wuepper A, Ingles H, Tattersall JE, Will EJ. A comparison of methods for determining urea distribution volume for routine use in on-line monitoring of haemodialysis adequacy. Nephrol Dial Transplant. 2009;24:211-6

33. Couchoud C, Jager KJ, Tomson C, Cabanne JF, Collart F, Finne P, de Francisco A, Frimat L, Garneata L, Leivestad T, Lemaitre V, Limido A, Ots $M$, Resic $H$, Stojceva-Taneva O, Kooman J; QUEST working group on dialysis adequacy. Assessment of urea removal in haemodialysis and the impact of the European Best Practice Guidelines. Nephrol Dial Transplant 2009;24:1267-74 
Samenvatting en conclusies

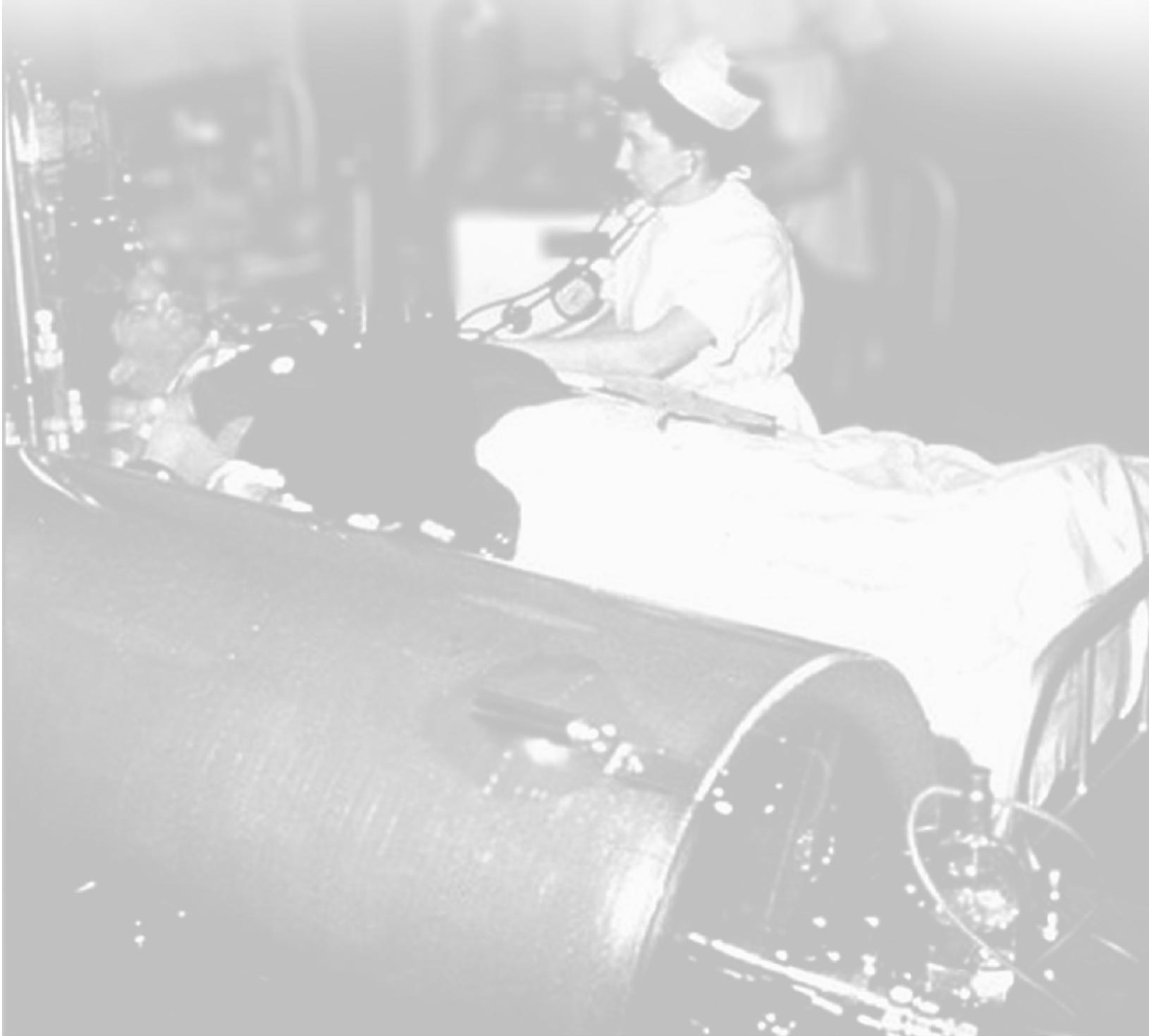




\section{Samenvatting}

Dit proefschrift bestaat uit twee delen: het eerste deel richt zich op verschillende aspecten met betrekking tot natriumbalans tijdens de hemodialyse behandeling. Deze werd onderzocht tijdens reguliere hemodialysebehandelingen, maar ook tijdens alternatieve hemodialysebehandelingen, zoals hemodialyse met behulp van biofeedback of natriumprofielen.

Het tweede deel richt zich op het monitoren van de effectiviteit van de dialyse behandeling. Dit werd onderzocht door middel van conventionele ureumkinetiek en door middel van ionische dialysance.

\section{Deel 1}

\section{Validatie van plasma/dialysaat geleidbaarheid en ionische massa balans metingen}

In dit proefschrift, worden de benamingen plasma natrium/plasma geleidbaarheid, dialysaat natrium/dialysaat geleidbaarheid en natriumbalans/ionische massa balans naast elkaar gebruikt met een overeenkomende betekenis.

Het belangrijkste voordeel van plasma geleidbaarheid en ionische massabalans is dat ze allebei non-invasief gemeten kunnen worden (zonder bloedafname) en zijn, met behulp van deze technologie (Diascan ${ }^{\circledR}$; Hospal-Gambro) elke dialysebehandeling beschikbaar*:

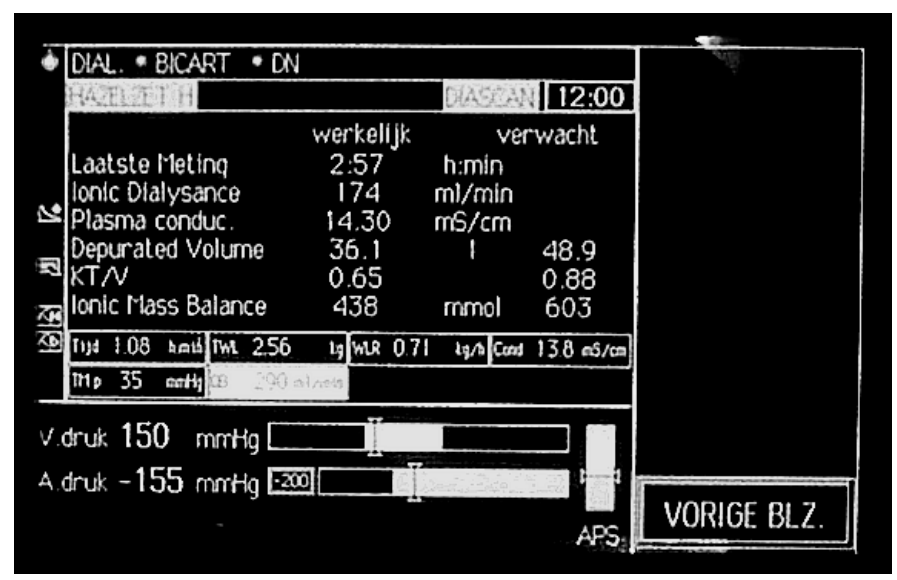

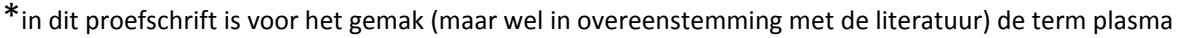
geleidbaarheid gebruikt, terwijl Diascan ${ }^{\circledR}$ eigenlijk de geleidbaarheid in plasma water berekent
} 
Zoals in de Introductie uitgebreid beschreven is, is de geleidbaarheid van een oplossing gelijk aan het vermogen om elektrische stroom te geleiden. Plasma geleidbaarheid wordt beoordeeld aan de hand van een eenvoudige wiskundige formule, welke rekening houdt met ionische klaring en veranderingen in de geleidbaarheid van de dialysaatuitgang na een tijdelijke verhoging van de geleidbaarheid aan de dialysaatingang tijdens de dialysebehandeling:

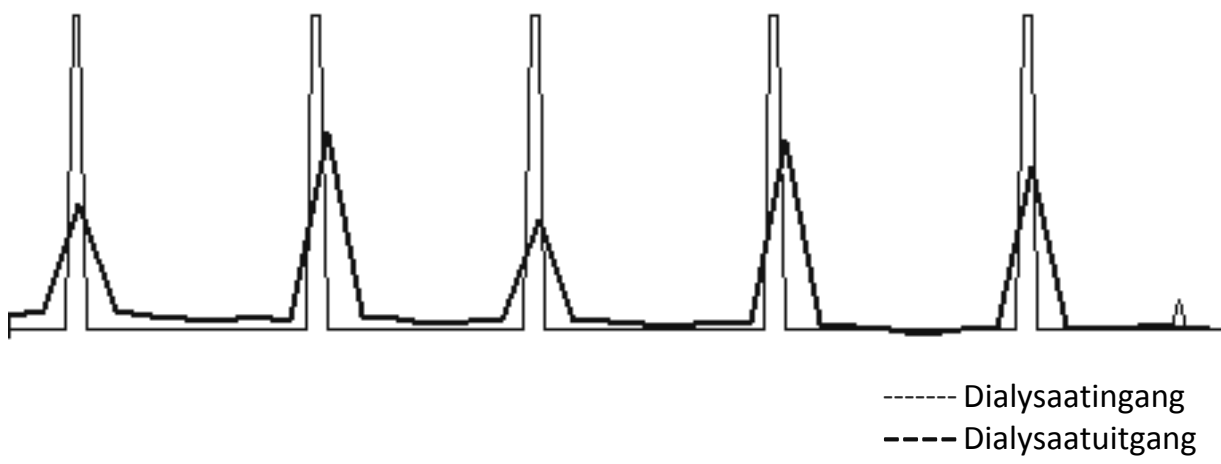

Eerdere onderzoeken hebben al een bijna lineaire relatie aangetoond tussen plasma natrium en plasma geleidbaarheid op basis van onderstaande formule:

Plasma natrium $=($ Plasma geleidbaarheid $\times 10.4)-9.57^{1}$. Gebaseerd op resultaten van verschillende studies mag aangenomen worden dat plasma geleidbaarheid voldoende is gevalideerd om deze als surrogaat voor plasma natrium te mogen gebruiken. Echter dient wel in aanmerking genomen te worden dat andere ionen ook, in geringere mate, de plasma geleidbaarheid kunnen beïnvloeden.

Ditzelfde geldt voor de relatie tussen dialysaat geleidbaarheid en dialysaat natrium, omdat de totale geleidbaarheid ook beïnvloed wordt door andere ionen zoals chloride en bicarbonaat, die kunnen veranderen door de dialysebehandeling. In hoofdstuk 3 en 4 wordt wel ingegaan op de verschillende methoden van natriumbepalingen, maar worden deze niet gedetailleerd beschreven. $\mathrm{Bij}$ een ingestelde dialysaat geleidbaarheid van $14.0 \mathrm{mS} / \mathrm{cm}$, waren dialysaat natrium bepalingen door middel van vlamfotometrie en indirecte ionemetrie vergelijkbaar $(140.4 \pm 1.5$ en $139.9 \pm 0.7$ $\mathrm{mmol} / \mathrm{l})$, maar weken af indien ze bepaald werden met behulp van directe ionemetrie $(135.4 \pm 1.1 \mathrm{mmol} / \mathrm{l})$. Zoals in de Introductie al beschreven, komt dit waarschijnlijk door complexvorming van natrium met andere ionen in het dialysaat, wat niet gemeten wordt door directe ionemetrie. Daarom, zoals la Milla ook al concludeerde ${ }^{3}$, is de bepaling van natrium uit verzameld dialysaat afhankelijk van de gebruikte methode en verdienen bepalingen door middel van indirecte ionemetrie en vlamfotometrie de voorkeur. 
Voor de ionische massa balans (IMB) als surrogaat voor natriumbalans tijdens de dialysebehandeling zijn er minder gegevens beschikbaar in de literatuur. Lambie zag een significante relatie tussen deze twee methoden door gebruik te maken van een formule die gebaseerd is op veranderingen in plasma natrium tijdens de dialysebehandeling en ultrafiltratievolume ${ }^{2}$. In hoofdstuk 4 werd de ionische massa balans gevalideerd ten opzichte van de natriumbalans door dialysaat te verzamelen tijdens de dialysebehandeling, waaruit natrium werd bepaald door middel van vlamfotometrie, en te vergelijken met de getelde ionen door de dialysemachine $\left(\right.$ Diascan $\left.^{\circledR}\right)$. Ook in dit onderzoek werd een sterke relatie gevonden tussen natrium balans en ionische massa balans $\left[r^{2}=0.95\right]$, hoewel er binnen de individuele patiëntmetingen wel discrepanties gezien werden tussen de beide methoden. Of deze verschillen met name verklaard worden door de inherente variatie van de natriumbepalingen, of mede door veranderingen in andere ionen in het dialysaat kan niet worden afgeleid worden uit dit onderzoek. In hoofdstuk 5, bleken ionische massa balans-metingen door Diascan $^{\circledR}$ significant te correleren met handmatige geleidbaarheids-metingen van het dialysaat.

Samenvattend, met de bovenstaande beperkingen in het achterhoofd houdend, zijn in dit proefschrift

ionische massa balans als surrogaat voor natrium balans, plasma geleidbaarheid als surrogaat voor plasma natrium en dialysaat geleidbaarheid als surrogaat voor dialysaat natrium gebruikt.

\section{Relatie tussen plasma geleidbaarheid en ionische massa balans}

Verwijdering van natrium tijdens dialyse wordt vooral veroorzaakt door convectie. Daarentegen zou ook diffusie, veroorzaakt door verschil in plasma en dialysaat natriumconcentratie, een belangrijke rol kunnen spelen. Dit werd beschreven in hoofdstuk 3 en 4, waarin een zeer sterke relatie tussen predialyse plasma geleidbaarheid en diffusieve ionische massa balans werd gezien. Dit werd aangetoond door middel van gerandomiseerd onderzoek tijdens isovolemische dialyse en door middel van retrospectief onderzoek, waar vanuit de database van een dialysecentrum gegevens van alle patiënten gedurende een half jaar werden geanalyseerd.

In het onderzoek met de isovolemische dialyse van hoofdstuk 3, waarin 13 patiënten geïncludeerd werden, werd ionisch massa transport van dialysaat naar patiënt gezien vanaf het moment dat de plasma geleidbaarheid $0.2-0.3 \mathrm{~ms} / \mathrm{cm}$ lager was dan de dialysaat geleidbaarheid, of vanaf het moment dat het plasma natrium 4-5 mmol lager was dan het dialysaat natrium. In de databasestudie in hoofdstuk 4, werd opgemerkt dat diffusief ionisch massa transport van dialysaat naar patiënt optrad als de plasma geleidbaarheid lager was dan $14.25 \mathrm{mS} / \mathrm{cm}$ (of plasma natrium lager dan $139 \mathrm{mmol} / \mathrm{l}$ ) bij een ingestelde dialysaat geleidbaarheid van $14 \mathrm{mS} / \mathrm{cm}$ (dialysaat natrium 140 $\mathrm{mmol} / \mathrm{l}$ ). De mogelijke verklaring van de discrepantie tussen deze studies zou kunnen 
zijn dat door ultrafiltratie, eiwit coating van de kunstnier optreedt, waardoor het Donnan effect beïnvloed wordt en daardoor de diffusieve ionische massa balans. Daarnaast zouden $\mathrm{pH}$ veranderingen tijdens de dialysebehandeling het Donnan effect ook kunnen beïnvloeden ${ }^{4,5}$.

In het onderzoek, beschreven in hoofdstuk 4, bleek dat diffusieve ionische massa balans voor gemiddeld $18.3 \pm 16.7 \%$ deel uit maakte van de totale ionische massa balans. Maar, uit de grote range [0.4 - 75.3\%] bleek dat binnen de individuele patiënten, diffusieve ionische massa balans soms een groot onderdeel is van de totale ionische massa balans.

Verschillende andere studies hebben ook het effect van dialysaat natrium op natriumbalans tijdens dialyse bestudeerd. In het onderzoek van Song, trad diffusieve natriuminflux op bij een dialysaat natrium vanaf $137.8 \mathrm{mmol} / \mathrm{l}^{6}$, terwijl Flanigan bij een groot aantal patiënten interdialytische plasma natrium stijging zag tijdens een dialysaat natrium instelling van $140 \mathrm{mmol} / \mathrm{l}^{7}$. Of het kleine verschil tussen deze studies toegeschreven kan worden aan verschillen in kunstniereigenschappen (b.v. door eiwit adsorptie) of ultrafiltratiesnelheid is niet verder uitgezocht.

Conclusie: er is een sterke relatie tussen pre-dialytisch plasma natrium, dialysaat natrium en ionische massa balans. Volgens de beschreven resultaten van hoofdstuk 4, wordt er geen belangrijke diffusieve natriuminflux van dialysaat naar patiënt verwacht wanneer de dialysaat natriumconcentratie lager of gelijk is aan de pre-dialytische plasma natriumconcentratie.

Een belangrijke extrapolatie van hoofdstuk 3 en 4, en van studies van anderen, is dat er bij gebruik van dialysaat natrium van $140 \mathrm{mmol} / \mathrm{l}$, diffusief natriumtransport van dialysaat naar patiënt kan optreden bij patiënten met een laag pre-dialytisch plasma natrium. Dit is van belang, omdat het pre-dialytische plasma natrium bij een aanzienlijk deel van de patiënten lager ligt dan $140 \mathrm{mmol} / \mathrm{l}$. Bij 33\% van de patiënten uit hoofdstuk 4, werd diffusieve natriuminflux en verhoging van de plasma conductiviteit gezien, alhoewel bij bijna alle patiënten totaal ionisch massaverlies van patiënt naar dialysaat werd gezien door convectieve verwijdering. Volgens de literatuur wordt in het algemeen aangenomen, dat bij gebruik van dialysaat natriumconcentratie van ongeveer $137-138 \mathrm{mmol} / \mathrm{l}$ een redelijke balans wordt bereikt tussen, aan de ene kant het voorkomen van natriuminflux tijdens de dialyse en aan de andere kant effecten van een te lage natriumconcentratie op bloedvolumepreservatie $^{8,9}$. Bijvoorbeeld, leverde het verlagen van dialysaat natrium van 141 naar $138 \mathrm{mmol} /$ op een dialyse afdeling een kleine verbetering in bloeddruk op, terwijl de hypotensieve periodes tijdens de dialysebehandeling niet toenamen ${ }^{8}$. Tijdens een audit van 2187 patiënten, werd gebruik van dialysaat natriumconcentratie van 140 $\mathrm{mmol} / \mathrm{l}$ of hoger geassocieerd met meer interdialytische gewichtstoename, hogere polsdruk, en zelfs met een hogere incidentie van intradialytische hypotensieve 
episodes vergeleken met patiënten waarbij een dialysaat natrium van 136 of 137 $\mathrm{mmol} / \mathrm{I}^{9}$ werd gebruikt.

Of vooral patiënten met een laag pre-dialytisch plasma natrium en patiënten met moeilijk te behandelen hypertensie zouden kunnen profiteren van het verder verlagen van het dialysaat natrium (b.v. tot $136 \mathrm{mmol} / \mathrm{l}$ ) is een interessant onderwerp voor toekomstig onderzoek. In een recente studie van Lambie et al., werd bij sommige patiënten een verlaging van dialysaat geleidbaarheid tot $13.0 \mathrm{mS} / \mathrm{cm}$ bereikt, met bijkomende voordelen zoals bloeddrukverlaging en verlaging van interdialytische gewichtstoename. Patiënten, die regelmatig intradialytische hypotensieve periodes hadden, werden echter niet geïncludeerd in het onderzoek ${ }^{2}$.

\section{Effecten van alternatieve hemodialysebehandelingen op natriumbalans en plasma geleidbaarheid}

Alhoewel een dialysaat natrium van 137-138 mmol/l bij de meerderheid van de patiënten adequaat lijkt, worden hogere dialysaat natriumconcentraties en/of natriumprofielen regelmatig op dialyseafdelingen gebruikt om intradialytische hypotensie te voorkomen. De verbetering van refill van bloedvolume vanuit het interstitium tijdens ultrafiltratie, opgewekt door de natriumgradiënt, ligt aan dit gebruik ten grondslag. Echter, zijn de effecten hiervan op de natriumbalans niet onderzocht.

Gebaseerd op de resultaten van hoofdstuk 3, is ionische massabalans een acceptabel instrument om de verschillen in natriumbalans tussen de verscheidene behandelingen te vergelijken. Ionisch massa transport van patiënt naar dialysaat (als surrogaat voor natriumverlies) was significant lager bij dialysebehandelingen die uitgevoerd werden met een (hypertone) dialysaat natriumconcentratie van $144 \mathrm{mmol} / \mathrm{l}$ [80 mmol] vergeleken met een dialysaat natriumconcentratie van $140 \mathrm{mmol} / \mathrm{l}$. In het onderzoek beschreven in hoofdstuk 5, waarbij verschillende technieken werden uitgevoerd (gedurende 11 opeenvolgende behandelingen) om intradialytische hypotensie te voorkomen, (inclusief natriumprofiel) werd een verschil in ionische massa balans alleen gezien tijdens de eerste behandeling met een natriumprofiel, terwijl bij de volgende behandeling de predialytische plasma conductiviteit duidelijk verhoogd was tijdens de beginsituatie. Waarschijnlijk is de afwezigheid van verschil in ionische massabalans na de eerste behandeling het gevolg van de sterke relatie tussen de ionische massabalans en de predialytische plasma conductiviteit. Tijdens de behandelingen met natriumprofiel, waarbij de pre-dialytische plasma geleidbaarheid steeg, bleef de ratio tussen de predialytische plasma geleidbaarheid en dialysaat geleidbaarheid hetzelfde, waardoor de ionische massabalans hetzelfde bleef. Deze resultaten komen overeen met die van Lambie et al, waarbij een geleidelijke verlaging van de dialysaat geleidbaarheid alleen tijdens de eerste behandeling met de nieuwe dialysaatinstelling resulteerde in een verandering van de ionische massa balans ${ }^{2}$. 
Stijging van de plasma geleidbaarheid door de dialysebehandeling is in strijd met het model van een stabiel individueel plasmanatrium ${ }^{4,7,11,12}$. Dit model gaat ervan uit dat natriuminflux tijdens de dialysebehandeling tot gevolg heeft dat de patiënt meer dorst krijgt en meer gaat drinken, waardoor de plasma natriumconcentratie niet verandert. In overeenkomst met resultaten van Thein ${ }^{8}$, maar in tegenstelling tot resultaten van anderen ${ }^{2,6,12}$, veroorzaakten veranderingen in dialysaat natriuminstellingen veranderingen in plasma geleidbaarheid, maar niet in meer vochtintake. Of in onze studie de patiënten wel meer dorst hadden, door stijging van de plasma geleidbaarheid, maar niet meer interdialytische gewichtstoename lieten zien (door b.v een stabiele vochtcompliance), is niet onderzocht.

Literatuur toont aan, dat natrium profielen de oorzaak kunnen zijn van verhoogde interdialytische gewichtstoename, hypertensie en effecten op de plasma geleidbaarheid zoals die in hoofdstuk 5 beschreven zijn, waardoor gebruik van hypertone natriumprofielen wordt afgeraden om intra-dialytische symptomen te voorkomen. Interessant genoeg, ook al was het aantal geïncludeerde patiënten laag, bleek in hoofdstuk $\mathbf{5}$ bloedvolume-gecontroleerde feedback een effectieve techniek om intra-dialytische hypotensie te voorkomen, zonder nadelige effecten op de zoutbalans. Bloedvolume-gecontroleerde feedback is een technologie waarbij op basis van metingen van bloedvolume-refill continu met ultrafiltratiesnelheid wordt gevarieerd, om zo een te snelle bloedvolumedaling (met als gevolg evt. hypotensie) te voorkomen. De effectiviteit van deze biofeedback technologie komt overeen met andere studies, ook van onze dialyse afdeling ${ }^{13,14}$.

Ook werd er geen verschil van zoutbalans gevonden tijdens het gebruik van plasma geleidbaarheid-gecontroleerde feedback vergeleken met standaard hemodialyse. Plasma geleidbaarheid-gecontroleerde feedback is een technologie, waarbij op basis van online gemeten plasma conductiviteit de dialysaat conductiviteit zodanig varieert, zodat een vooraf ingestelde einddialyse plasma conductiviteit wordt behaald. In deze studie werd, in overeenstemming met de beschikbare literatuur op dat moment, gekozen voor een doel plasma natriumconcentratie van $14.0 \mathrm{mS} / \mathrm{cm}$ (of plasma natrium van $\pm 138 \mathrm{mmol} / \mathrm{l}$ ). Echter bij deze instelling, zou bij een aantal patiënten met een laag predialytisch plasma natrium, diffusieve natrium influx opgetreden kunnen hebben. Daarom, zou vooral voor deze patiëntengroep individualisatie van dialysaat natrium een goede optie kunnen zijn.

\section{Individualisatie van dialysaat natrium}

Er zijn weinig gegevens over individualisatie van dialysaat natrium beschikbaar in de literatuur. In het onderzoek, beschreven in hoofdstuk 3, resulteerde individualisatie van dialysaat natrium in een verhoging van natriumverwijdering tijdens dialyse bij patiënten met een laag pre-dialytisch plasma natrium, maar in een vermindering van natriumverwijdering bij patiënten met een hoger pre-dialytisch plasma natrium ten 
opzichte van een dialysebehandeling met de standaardinstelling. Om die reden, in ieder geval vanuit theoretisch oogpunt, wordt verwacht dat vooral patiënten met een laag pre-dialytisch plasma natrium zouden kunnen profiteren van een geïndividualiseerd dialysaat natrium. In het onderzoek van de Paula ${ }^{18}$, werd dialysaat natrium geïndividualiseerd, door handmatig het dialysaat natrium aan te passen aan het pre-dialytisch plasmawater natrium met een correctiefactor voor het Donnan effect. Dit resulteerde in vermindering van de hypertensie en vermindering van de inter-dialytische gewichtstoename. Tegelijkertijd verminderde de incidentie van intradialytische hypotensie vergeleken met dialysebehandelingen met een vast dialysaat natrium van $138 \mathrm{mmol} / \mathrm{l}$. In dit onderzoek behaalden vooral patiënten met moeilijk te behandelen hypertensie voordeel van het verlagen van het dialysaat natrium. Predialytisch plasma natrium was voor de start van het onderzoek al vrij laag $(134.0 \pm 1.4$ $\mathrm{mmol} / \mathrm{l})$, wat veroorzaakt werd doordat patiënten met hogere plasma natriums geëxcludeerd werden. Vergelijkbaar onderzoek werd gedaan door Sayarlioglu ${ }^{19}$, waarbij de predialytische bloeddruk en interdialytische gewichtstoename afnamen op het moment dat het dialysaat natrium geïndividualiseerd werd bij patiënten met predialytische plasma natrium waarden die lager waren dan de standaard gebruikte dialysaat natriumconcentratie. In deze studies werden alleen stabiele patiënten geïncludeerd, zonder frequente hypotensieve episodes.

Al met al, hoewel er meer onderzoek nodig is, lijkt het individualiseren van dialysaat natriumconcentratie een veelbelovend instrument, vooral bij patiënten met lage predialytische plasma natriumwaarden, hoge interdialytische gewichtstoenames en ongecontroleerde hypertensie. Daarentegen, zou meer informatie over variaties in pre-dialytisch plasma natrium (of geleidbaarheid) zinvol zijn, omdat tegenstrijdige informatie uit de literatuur de zin van een vast individueel dialysaat natrium bestrijdt.

\section{Variaties in pre-dialytische plasma geleidbaarheid}

Om de individuele variaties in pre-dialytische plasma geleidbaarheid te onderzoeken, is er een retrospectieve analyse uitgevoerd, beschreven in hoofdstuk 4, van alle dialysebehandelingen op een dialyse afdeling gedurende 6 maanden, waarbij plasma geleidbaarheid werd gebruikt als surrogaat voor plasma natrium. In dit onderzoek, was de gemiddelde variatie-coëfficiënt van pre-dialytische plasma geleidbaarheid $1.3 \%$. Opvallend was het gemiddelde intra-individuele verschil van $\pm 0.9 \mathrm{mS} / \mathrm{cm}$ [ plasma natrium $9 \mathrm{mmol} / \mathrm{l}$ ] tussen de hoogste en de laagste plasma geleidbaarheid tijdens de follow up van zes maanden. Opmerkelijk is, dat inter- en intradialytische verschillen in pre-dialytische plasma geleidbaarheid correleerden met variaties in predialytische bloeddruk, wat een bijkomstig bewijs zou kunnen zijn voor volumeonafhankelijke effecten van natrium op bloeddruk. Natuurlijk is hierin veel meer onderzoek nodig.

Ondanks het feit dat de intrapatiënt variaties vrij gering waren, trekken de resultaten van hoofdstuk $\mathbf{4}$ en $\mathbf{5}$ het bestaan van een gefixeerde dialysaat natriumconcentratie 
per patiënt in twijfel. Indien individualisering van de behandeling strategie wordt, zal plasma natrium of plasma geleidbaarheid regelmatig bepaald moeten worden. De online beschikbaarheid op de dialysemachine van plasma geleidbaarheid lijkt een zeer handig instrument om individualisatie van dialysaat natrium te bereiken, zonder dat daar bloedafnames voor nodig zijn. Meer onderzoek zou zich hierop moeten concentreren.

\section{Deel 2}

\section{Beoordeling van dialyse adequaatheid door middel van ureum kinetiek: is er een voorkeur methode?}

$\mathrm{Kt} / \mathrm{V}_{\text {ureum }}$ is de meest gebruikte parameter ter beoordeling van de adequaatheid van de dialysebehandeling. De uitkomst van deze parameter is een getal, wat aangeeft hoe vaak de V (berekend ureumdistributievolume per individuele patiënt) geklaard is van ureum (en andere kleinmoleculair stoffen) tijdens de totale tijd van de dialysebehandeling. Binnen de meest invloedrijke richtlijnen over dit onderwerp, bijvoorbeeld de European Best Practice Guidelines (EBPG) and Kidney Disease Outcomes Quality Initiative (K-DOQI) is er echter enige discrepantie met betrekking tot de methodiek van de Kt/V bepalingen. Aan de ene kant, adviseert K-DOQI het gebruik van single-pool Kt/V (spKt/V) metingen, terwijl EBPG het gebruik van doublepool of equillibrated $\mathrm{Kt} / \mathrm{V}$ (eKt/V) onderschrijft, omdat deze voor ureum rebound corrigeert $^{20,21}$. Uiteindelijk is eKt/V alleen een wiskundige correctie op de formule van spKt/V waarvoor geen extra bloedmonster nodig is. Beide richtlijnen adviseren het gebruik van de ureum reductie rate (URR) alleen als aanvulling bij het beoordelen van dialyse adequaatheid.

Het is niet bekend tot welke hoogte er discrepantie zou kunne bestaan tussen de verschillende formules in de beoordeling van de adequaatheid van de dialysebehandeling. In hoofdstuk 7 is deze vraag onderzocht bij 830 patiënten van de NECOSAD database. eKt/V boven 1.2, spKt/V boven 1.4 en URR boven $70 \%$ werden gebruikt als adequaatheids doelen, en respectievelijk 1.0, 1.2 en 65\% als adequaatheids minimum.

Alleen $5 \%$ van de patiënten met een spKt/V boven 1.4 had een eKt/ $\mathrm{V}$ onder 1.2 . Bij deze "gemisclassificeerde" patiënten was de gemiddelde eKt/V 1.19, dus erg dicht bij het adequaatheids doel. Het percentage "gemisclassificeerde" patiënten was hoger als URR was gebruikt als formule voor adequaatheid. Min of meer dezelfde percentages "gemisclassificeerde" patiënten werden gevonden als de minimum adequaatheid werd vergeleken. Bij mortaliteitsanalyse werden eKt/ $\mathrm{V}$, spKt/V en URR die onder het minimum adequaatheidsniveau werden beoordeeld geassocieerd met 
een hoger risico op overlijden, wat het klinisch nut van deze formules bij dialysebehandelingen aantoont.

Vanuit de resultaten van hoofdstuk 7 kan geconcludeerd worden, dat gebruik van eKt/V of spKt/V niet zoveel uitmaakt voor het beoordelen van de dialyse adequaatheid, onder voorwaarde dat er goede afkappunten worden aangehouden. Het risico van "misclassificatie" wordt wat groter bij gebruik van URR, maar of dit ook invloed heeft op andere patiëntuitkomsten kan niet uit dit onderzoek herleid worden.

\section{Beoordeling van dialyse adequaatheid door middel van ionische dialysance}

Voor Kt/ $\mathrm{V}$ bepalingen zijn bloedafnames nodig. Zoals in de introductie van dit proefschrift beschreven is, is Kt/V bepaling door middel van ionische dialysance een non-invasieve methode die het mogelijk maakt om tijdens elke dialysebehandeling dialysaat adequaatheid te beoordelen zonder bloed af te nemen. Dit kan erg belangrijk zijn gezien de variatie in bereikte $\mathrm{Kt} / \mathrm{V}$ tussen verschillende behandelingen bij dezelfde patiënt, welke niet opgemerkt wordt wanneer de Kt/V alleen maandelijks bepaald wordt met behulp van bloedafnames. Deze variaties in $\mathrm{Kt} / \mathrm{V}$ werd gerapporteerd in hoofdstuk 8 , als bevestiging van eerder onderzoek ${ }^{22}$. Ook al zijn dialysance (diffusief transport van een oplossing door een semipermeabel membraan) en klaring (verwijdering van een oplossing uit een substantie) een heel ander concept, toch kan ionische dialysance gebruikt worden om ureumklaring tijdens hemodialyse te beoordelen ${ }^{23}$.

Kort samengevat, kan ionische dialysance gebruikt worden als surrogaat voor ureumklaring, omdat deze én dezelfde eigenschappen van transport door een kunstnier hebben én dezelfde osmotische distributievolumes in het bloed. Zoals te zien op de figuur op pagina 152, wordt ionische dialysance (door Diascan ${ }^{\circledR}$ ) gemeten door veranderingen bij de dialysaatuitgang te beoordelen aan de hand van veranderingen in de dialysaatingang tijdens de dialysebehandeling. De veranderingen van deze dialysaatuitgang worden meegenomen om de ionische dialysance te berekenen, ervan uitgaand dat de plasma geleidbaarheid tijdens die meting niet verandert $^{24}$. Een zeer sterke relatie tussen ionische dialysance en ureumklaring werd gesignaleerd. Echter lijkt ionische dialysance de ureumklaring iets te onderschatten, hetgeen ook de relatie tussen $\mathrm{Kt} / \mathrm{V}$ met behulp van ureumkinetiek en met behulp van ionische dialysance zou kunnen beinvloeden ${ }^{24,25}$. 


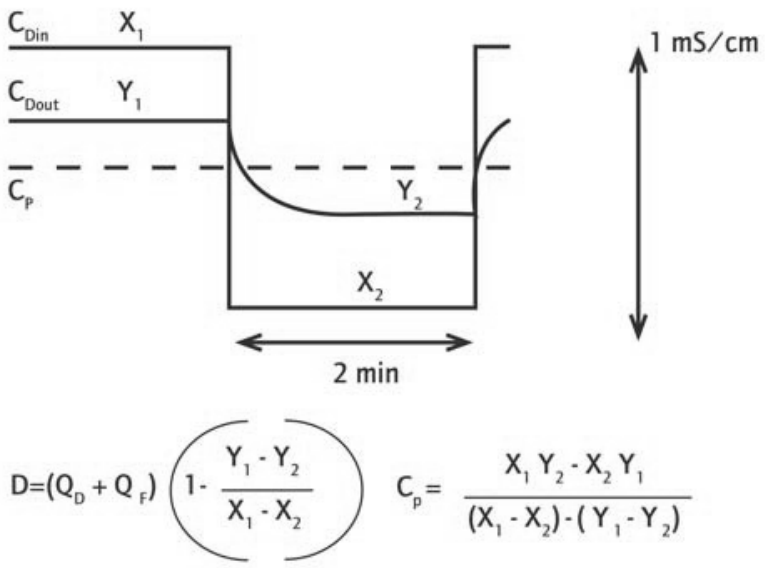

Figuur 9.1 Schema van de ingang- en uitgangdialysaat geleidbaarheid tijdens een meting van de ionische dialysance (D), waarbij $X_{1}$ en $X_{2}$ twee waarden zijn van ingang dialysaatgeleidbaarheid, $Y_{1}$ en $Y_{2}$ de twee gemeten waarden van de uitgang dialysaatgeleidbaarheid en $C_{p}$ de geschatte plasma geleidbaarheid van de patiënt. $Q_{D}$ is dialysaatflow, $Q_{F}$ ultrafiltratiesnelheid

\section{Overeenkomst tussen ionische dialysance en ureumkinetiek bij het beoordelen van $\mathrm{Kt} / \mathrm{V}$}

Ook al is Kt/V met behulp van ionische dialysance een single pool methode, toch valt deze berekening lager uit dan wanneer die berekend is volgens spKt/V met ureumkinetiek, blijkt uit de resultaten beschreven in hoofdstuk 8 en in andere studies uit de literatuur ${ }^{24}$.

Naast de (geringe) onderschatting van de ureumklaring door ionische dialysance komt dit onder andere ook door de methode waarmee het ureum distributie volume (V) berekend wordt, zoals in de volgende paragraaf uitgebreider wordt besproken. Deze dient in de formule Kt/V bij gebruik van ionische dialysance (K) ingevoerd te worden, waardoor de $\mathrm{V}$ een aanmerkelijke invloed krijgt op de daadwerkelijke uitkomst.

De Watson formule wordt, als bekendste antropometrische formule, meestal gebruikt om deze $\mathrm{V}$ te berekenen, maar deze formule heeft de neiging om het ureum distributie volume bij dialysepatiënten te overschatten, waardoor de uiteindelijke $\mathrm{Kt} / \mathrm{V}$ te laag uitvalt. Echter, zelfs wanneer $\mathrm{V}$ wordt berekend met een exactere formule volgnes het ureumkinetiek model, laat Kt/V gemeten door Diascan ${ }^{\circledR}$ (een single pool methode), meer overeenkomst zien met eKt/V dan met spKt/V (hoofdstuk 8). Deze goede correlatie tussen eKt/V en $\mathrm{Kt} / \mathrm{V}$ met behulp van ionische dialysance komt overeen met de resultaten van McIntyre et al. ${ }^{26}$. 
Een andere factor die de oorzaak zou kunnen zijn, van het lager uitvallen van de Kt/V door middel van ionische dialysance vergeleken met de $\mathrm{Kt} / \mathrm{V}$ door middel van ureumkinetiek, is het cardiopulmonale recirculatie effect. Cardiopulmonale recirculatie bestaat uit het effect dat een gedeelte van het gezuiverde bloed dat via de arterioveneuze shunt terug gaat naar het lichaam, direct via het hart weer de arteriële aansluiting van de arterioveneuze shunt bereikt, zonder eerst weer via lichaamsweefsels afvalstoffen op te nemen. Dit fenomeen is per definitie altijd aanwezig tijdens hemodialyse, waarbij gebruik wordt gemaakt van een arterioveneuze shunt en nooit aanwezig tijdens hemodialyses via een centraal veneuze catheter.

Een andere reden, die de onderschatting van $\mathrm{Kt} / \mathrm{V}$ door middel van ionische dialysance zou kunnen verklaren, zou het effect van de geleidbaarheids-pulsen op de plasma geleidbaarheid kunnen zijn. Bij de berekening van de ionische dialysance, wordt ervan uitgegaan dat de plasma geleidbaarheid constant blijft, ondanks de geleidbaarheids-pulsen tijdens die meting. Het constant blijven van de plasma geleidbaarheid tijdens de ionische dialysance meting is in twijfel getrokken door Gotch, die beweerde dat de geleidbaarheids-pulsen voor extra natriumbelasting zorgden en vervolgens voor verhoging van de plasma geleidbaarheid ${ }^{28}$. In hoofdstuk 6, is het effect van deze geleidbaarheids-pulsen op de ionische massabalans onderzocht. Geen verschil werd gezien tussen behandelingen met of zonder Diascan ${ }^{\circledR}$ metingen in ionische massa balans. Op zich is dit geen definitief argument voor het niet optreden van tijdelijke natriumbelasting door geleidbaarheids-pulsen, maar het lijkt vooralsnog, dat vooral de bevinding van Marcadel over aan- of afwezig zijn van de pulmonale recirculatie (die hierboven beschreven is) van groter belang lijkt voor het verschil tussen ureumklaring en ionische dialysance ${ }^{27}$.

In Nederland zijn verschillende merken dialysemachines beschikbaar met allen vergelijkbare technische opties om $\mathrm{Kt} / \mathrm{V}^{29}$ te meten. Interessant is wel, dat bijvoorbeeld de $\mathrm{OCM}^{\circledR}$-monitor (online clearance monitor) van Fresenius en de Diascan ${ }^{\circledR}$ van Gambro een andere manier toepassen om de geleidbaarheids-pulsen te doseren. Diascan ${ }^{\circledR}$ verhoogt de geleidbaarheid gedurende korte tijd tijdens de puls met $1 \mathrm{mS} / \mathrm{cm}$, terwijl $\mathrm{OCM}^{\circledR}$ gebruikt maakt van een drie fase geleidbaarheids-puls met een langere stabilisatietijd ${ }^{24}$. Of deze methodologische verschillen resulteren in verschillen tussen de beide methodes dient verder onderzocht te worden.

\section{Ureum distributie volume}

Verschillen tussen ionische dialysance en de standaard ureumkinetiek voor het bepalen van de dialyse-effectiviteit, zijn ook afhankelijk van de methode die gebruikt wordt om het ureum distributie volume (V) te bepalen. Hiervoor is het effect van de cardio pulmonale recirculatie op de berekening van de ionische dialysance al besproken. Daarnaast is het effect van de meest gebruikte antropometrische formules 
(b.v. Watson) om $\mathrm{V}$ te berekenen een andere reden voor het verschil, omdat deze formules het ureum distributie volume overschatten.

Deze overschatting kan verklaard worden, omdat antropometrische formules uitgaan van een standaard lichaamsverdeling, terwijl bij dialysepatiënten vaker het spierweefsel afneemt en het vetweefsel relatief toeneemt ${ }^{30}$. Anderzijds zal de redistributie van het ureum naar centrale lichaamscompartimenten (door verminderde perfusiedruk in de perifere compartimenten), als gevolg van de dialysebehandeling, bijdragen aan een overschatting van het ureum distributie volume bij gebruik van de ureumkinetische methode.

In hoofdstuk 8 werd aangetoond, dat indien gebruik gemaakt wordt van de kinetische formule om het ureum distributie volume te berekenen, de relatie tussen ionische dialysance en ureumkinetiek (door middel van bloedafnames) sterker werd. Dit komt overeen met de resultaten van di Filippo ${ }^{31}$. Helaas is deze vorm van berekenen ingewikkeld voor de dagelijkse praktijk en zijn er ook weer bloedafnames nodig om deze te kunnen berekenen. Indien gebruik gemaakt werd van de ionische dialysance formule om het ureum distributie volume te bepalen was er tevens een goede correlatie, maar deze formule bleek niet betrouwbaar bij patiënten met restnierfunctie. Beide formules blijken niet betrouwbaar indien recirculatie van de shunt aanwezig is.

Daarom, blijft de vraag, of er andere methodes mogelijk zijn om het ureum distributie volume te berekenen, die makkelijk uitvoerbaar zijn in de dagelijkse praktijk. Bioimpedantie meting, waarbij het totale lichaamswater wordt geschat, door elektrische geleiding van een wisselstroom door het lichaam, is makkelijk uitvoerbaar en non-invasief. Uit recent onderzoek van Lindley et al. bleek (vergelijkbaar met de resultaten uit hoofdstuk 8 ) een onderschatting van de dialyse-effectiviteit indien antropometrische formules (b.v. Watson) werden gebruikt, terwijl het gebruik van bioimpedantie resulteerde in vergelijkbare $\mathrm{Kt} / \mathrm{V}$ uitkomsten als met behulp van de kinetiek formule om het ureum distributie volume te berekenen ${ }^{32}$. Uit een vooronderzoek van onze dialyse afdeling bleek ook, dat het ureum distributie volume, indien het gemeten werd door de bioimpedantie methode BCM $^{\circledR}$ (Fresenius), significant lager was dan wanneer deze gemeten werd door de Watson formule (32.4 liters \pm 7.2 versus 34.9 liters \pm 6.1 ). Het effect van het gebruik van deze nieuwe methode bij de vergelijking van Kt/V tussen ureumkinetiek en ionische dialysance is een belangrijk onderwerp voor vervolgonderzoek.

Geconcludeerd kan worden, dat ionische dialysance de bepaling van Kt/V een stuk makkelijker maakt, en lijkt ook steeds meer gebruikt te worden in Europese dialysecentra $^{33}$. Toch zijn er nog steeds discrepanties tussen ionische dialysance en ureumkinetiek, veroorzaakt door onder andere de methode van bepaling van ionische dialysance, de methode van laboratoriumbepaling en de methode om het ureum distributie volume te bepalen. In het algemeen kan wel gesteld worden, dat een 
onderschatting van de spKt/V door Diascan ${ }^{\circledR}$ minder schadelijke gevolgen zal hebben dan indien dit een overschatting zou zijn.

Met in acht neming van bovenstaande bezwaren, zou ionische dialysance een goed middel kunnen zijn om de dialyse effectiviteit te bewaken. Als tijdens elke dialysebehandeling de ionische dialysance wordt gecontroleerd kan, door deze trend te bewaken, geanticipeerd worden op elke verandering in dialyse adequaatheid, b.v. door shuntrecirculatie, regelmatige onderbrekingen van de behandeling, verkeerd aansluiten van dialyselijnen of dialysaatkoppelingen en het niet behalen van de voorgeschreven bloedflow. Dit zou normaal pas opgemerkt worden op het moment dat de dialyse adequaatheid door middel van ureumkinetiek (bloedafnames) gemeten wordt (1 keer per maand), of helemaal niet. 


\section{References}

1. Locatelli F, Di Filippo S, Manzoni C, Corti M, Andrulli S, Pontoriero G. Monitoring sodium removal and delivered dialysis by conductivity.Int J Artif Organs. 1995;18:716-21

2. Lambie SH, Taal MW, Fluck RJ, Mclntyre CW. Online conductivity monitoring: validation and usefulness in a clinical trial of reduced dialysate conductivity. ASAIO J 2005;51:70-6

3. La Milia V, Di Filippo S, Crepaldi M, Andrulli S, Del Vecchio L, Scaravilli P, Virga G, Locatelli F. Sodium removal and sodium concentration during peritoneal dialysis: effects of three methods of sodium measurement. Nephrol Dial Transplant. 2004;19:1849-55

4. Flanigan MJ. Sodium flux and dialysate sodium in hemodialysis. Semin Dialysis 1998; 11:298-304

5. Vaussenat F, Bosc JY, LeBlanc M, Canaud B. Data acquisition system for dialysis machines. A model for membrane hydraulic permeability. ASAIO J. 1997 Nov-Dec;43(6):910-5

6. Song JH, Lee SW, Suh CK, Kim MJ. Time-averaged concentration of dialysate sodium relates with sodium load and interdialytic weight gain during sodium-profiling hemodialysis. Am J Kidney Dis. 2002;40:291-301.

7. Flanigan MJ. Role of sodium in hemodialysis. Kidney Int 2000; 76(Suppl):S72-S78

8. Thein H, Haloob I, Marshall MR. Associations of a facility level decrease in dialysate sodium concentration with blood pressure and interdialytic weight gain. Nephrol Dial Transplant 2007;22:2630-2639

9. Davenport A, Cox C, Thuraisingham R; PanThames Renal Audit Group.The importance of dialysate sodium concentration in determining interdialytic weight gains in chronic hemodialysis patients: the Pan Thames Renal Audit. Int J Artif Organs. 2008;31:411-7

10. Song JH, Park GH, Lee SY, Lee SW, Lee SW, Kim MJ. Effect of sodium balance and the combination of ultrafiltration profile during sodium profiling hemodialysis on the maintenance of the quality of dialysis and sodium and fluid balances. J Am Soc Nephrol 2005;16:237-246

11. Santos SF, Peixoto AJ. Revisiting the dialysate sodium prescription as a tool for better blood pressure and interdialytic weight gain management in hemodialysis patients. Clin J Am Soc Nephrol 2008;3:522-30

12. Keen ML, Gotch FA. The association of the sodium "setpoint" to interdialytic weight gain and blood pressure in hemodialysis patients. Int J Artif Organs. 2007;30:971-9.

13. Wolkotte C, Hassell DR, Moret K, Gerlag PG, van den Wall Bake AW, van der Sande FM, Kooman JP. Blood volume control by biofeedback and dialysis-induced symptomatology. A short-term clinical study. Nephron. 2002;92:605-9.

14. Santoro A, Mancini E, Paolini F, Cavicchioli G, Bosetto A, Zucchelli P: Blood volume regulation during hemodialysis. Am J Kidney Dis 1998;32:739-748.

15. Hernández-Jaras J, García-Pérez H, Torregrosa E, Calvo C, Cerrillo V. Usefulness of the Biofeedback Diacontrol module in the automatic programming of plasmatic conductivity and ionic mass transfer. Nefrologia. 2003;23:62-70

16. Petitclerc T, Hamani, Jacobs C. Optimization of sodium balance during hemodialysis by routine implementation of kinetic modeling. Blood Purif 1992; 309-

17. Jacobs C, Kjellstrand CM, Koch KM, eds. Replacement of renal function by dialysis. Winchester JF. 4th edition,1996

18. de Paula FM, Peixoto AJ, Pinto LV, Dorigo D, Patricio PJ, Santos SF. Clinical consequences of an individualized dialysate sodium prescription in hemodialysis patients. Kidney Int 2004;66:1232-1238

19. Sayarlioglu H, Erkoc R, Tuncer M, Soyoral Y, Esen R, Gumrukcuoglu HA, Dogan E, Sayarlioglu M: Effects of low sodium dialysate in chronic hemodialysis patients: an echocardiographic study. Ren Fail 29: 143-146, 2007

20. Tattersall J, Martin-Malo A, Pedrini L, Basci A, Canaud B, Fouque D, Haage P, Konner K, Kooman J, Pizzarelli F, Tordoir J, Vennegoor M, Wanner C, ter Wee P, Vanholder R. EBPG guideline on dialysis strategies. Nephrol Dial Transplant. 2007;22 Suppl 2:ii5-21

21. NKF-K/DOQI Clinical Practice Guidelines for Hemodialysis Adequacy: update 2000. Am J Kidney Dis 2001; 37:S7-S64.

22. Lambie SH, Taal MW, Fluck RJ, Mclntyre CW. Analysis of factors associated with variability in haemodialysis adequacy. Nephrol Dial Transplant 2004; 19:406-12 
23. Petitclerc T. Do dialysate conductivity measurements provide conductivity clearance or ionic dialysance? Kidney Int 2006;70:1682-1686.

24. Mercadal L, Ridel C, Petitclerc T. Ionic dialysance: principle and review of its clinical relevance for quantification of hemodialysis efficiency. Hemodial Int (2005) 9:111-9

25. Di Filippo S, Manzoni C, Andrulli S, Pontoriero G, Dell'Oro C, La Milia V, Bacchini G, Crepaldi M, Bigi MC, Locatelli F.How to determine ionic dialysance for the online assessment of delivered dialysis dose. Kidney Int. 2001;59:774-82.

26. Mclntyre CW, Lambie SH, Taal MW, Fluck RJ. Assessment of haemodialysis adequacy by ionic dialysance: intra-patient variability of delivered treatment. Nephrol Dial Transplant 2003; 18:559-63

27. Mercadal L, Du Montcel ST, Jaudon MC, Hamani A, Izzedine H, Deray G, Béné B, Petitclerc T. Ionic dialysance vs. urea clearance in the absence of cardiopulmonary recirculation. Nephrol Dialysis Transplant 2002; 17:106-11

28. Gotch FA, Panlilio FM, Buyaki RA, Wang EX, Folden TI, Levin NW. Mechanisms determining the ratio of conductivity clearance to urea clearance. Kidney Int Suppl. 2004:S3-S24

29. Maduell F, Vera M, Arias M, Serra N, Blasco M, Bergadá E, Fontsere N, Cases A, Campistol JM. Influence of the ionic dialysance monitor on Kt measurement in hemodialysis. Am J Kidney Dis. 2008;52:85-92

30. Woodrow G, Oldroyd B, Turney JH, Tompkins L, Brownjohn AM, Smith MA. Whole body and regional body composition in patients with chronic renal failure. Nephrol Dial Transplant 1996; 11: 1613-8

31. Di Filippo S, Manzoni C, Andrulli S, Pontoriero G, Dell'Oro C, La Milia V, Tentori F, Crepaldi M, Bigi MC, Locatelli $F$. Ionic dialysance allows an adequate estimate of urea distribution volume in hemodialysis patients. Kidney Int 2004; 66:786-91

32. Lindley EJ, Chamney PW, Wuepper A, Ingles H, Tattersall JE, Will EJ. A comparison of methods for determining urea distribution volume for routine use in on-line monitoring of haemodialysis adequacy. Nephrol Dial Transplant. 2009;24:211-6

33. Couchoud C, Jager KJ, Tomson C, Cabanne JF, Collart F, Finne P, de Francisco A, Frimat L, Garneata L, Leivestad T, Lemaitre V, Limido A, Ots $M$, Resic $H$, Stojceva-Taneva O, Kooman J; QUEST working group on dialysis adequacy. Assessment of urea removal in haemodialysis and the impact of the European Best Practice Guidelines. Nephrol Dial Transplant 2009;24:1267-74 

Dankwoord

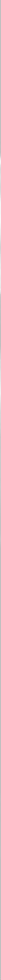




\section{Dankwoord}

Sinds 1999 werk ik met veel plezier als (deeltijd) researchverpleegkundige op de dialyse afdeling. Een leuke en interessante tijd heb ik beleefd in de periode waarin we onderzochten in hoeverre de technische opties die beschikbaar waren op onze dialysemachine meerwaarde hadden voor de patiënten. Samen met het Maastrichts Universitair Medisch Centrum gingen we op onderzoek uit om te kijken of deze opties op een wetenschappelijke wijze verantwoord konden worden. Kort daarna kwam de vraag van Maastricht bij dr. PGG Gerlag en dr. AWL van den Wall Bake of zij het zagen zitten om de resultaten van de onderzoeken te bundelen in een proefschrift, waarbij het MUMC mij wilde begeleiden. Onderzoek doen in Veldhoven, promotor en copromotor in Maastricht en een tweede co-promotor in Veldhoven. Dankjewel Paul en Warmold, voor jullie vertrouwen en de kans die jullie mij gegeven hebben.

Met veel enthousiasme heb ik de afgelopen jaren gewerkt aan het onderzoek wat in dit proefschrift beschreven staat. Veel heb ik geleerd in die tijd waarin ik van verschillende professionals uit allerlei vakgroepen hulp heb gekregen bij het organiseren, meedenken over, uitvoeren, beschrijven en evalueren van onderzoek.

Mijn co-promotor dr. JP Kooman heeft dit allemaal mogelijk gemaakt. Beste Jeroen, zonder jou was dit proefschrift er nooit geweest, zelfs het idee om een proefschrift te schrijven is van jou, dit zou nooit in me zijn opgekomen. Dankjewel voor je blind vertrouwen in mij en voor je bedrevenheid om mij te stimuleren en te inspireren, zodat ik altijd op de terugweg van Maastricht naar Veldhoven overliep van enthousiasme om verder te gaan op de ingeslagen weg. Jij was de onvermoeibare, stuwende kracht achter dit hele traject. Jouw wijsheid, kritische blik, nooit aflatende enthousiasme en positieve inslag hebben ervoor gezorgd dat ik met veel plezier terug kijk op de afgelopen periode en trots kan zijn op het eindresultaat, dankjewel daarvoor!

Vanaf 2005, werd dr. CH Beerenhout mijn tweede co-promotor, om mij te begeleiden met het onderzoek in een perifeer ziekenhuis. Beste Charles, omdat je zelf net gepromoveerd was kon je mij goed voorbereiden op wat mij te wachten stond. Dankjewel voor je hulp. Ondanks je drukke werkzaamheden kon ik altijd bij je terecht als ik vragen had.

Mijn promotor, prof. dr. KML Leunissen wil ik bedanken. Beste Karel, voor alle moeite die je voor mij genomen hebt om ervoor te zorgen dat ik de kans kreeg te promoveren aan jullie universiteit, hartelijk dank.

De leden van de beoordelingscommissie, prof. dr. APG Hoeks, dr. PJ Blankestijn, prof. dr. JP van Hooff, prof. dr. RP Koopmans, wil ik danken voor hun kritische beoordeling 
van het proefschrift. Also thank you dr. Peter Kotanko for your participation in the thesis committee, and for willing to review my manuscript.

Dr. FM van der Sande, beste Frank, hartelijk bedankt voor je kritische blik bij het nakijken van onze artikelen en voor de geweldige ervaring van de onderzoekstrip naar het Renal Research Institute in New York.

Mijn collega's van de dialyse afdeling ben ik erg dankbaar voor de jaren waarin ik mij dagen mocht terugtrekken op mijn kamer om aan de onderzoeksvoorbereidingen en resultaten te werken. Doordat jullie patiëntenzorg van mij overnamen kon ik ongestoord $(;)$ andere werkzaamheden verrichten. Hartelijk bedankt voor alles, voor jullie begrip, interesse en vertrouwen in mijn vreemde werktijden. De hartelijkheid en collegialiteit zijn mij dierbaar. Ik heb me altijd op mijn gemak gevoeld op de afdeling ook al was ik een vreemde eend in de bijt. Met name de "oude" Integra werkgroep wil ik natuurlijk extra bedanken voor de hulp bij het uitvoeren van mijn onderzoek. Al die vreemde behandelingen met zoutprofielen, ultrafiltratieprofielen, Hemocontrol, Diacontrol, waarbij jullie altijd met veel interesse en enthousiasme hielpen met bedenken, plannen, uitvoeren en uitleggen. Jullie zijn altijd een super werkgroep geweest met veel technische interesse en kennis, kritische blik en motivatie om te ontwikkelen. Toon, Lianne, Gerda, Saskia en Sandra dank jullie wel voor alle hulp.

Daarnaast moet ik natuurlijk ook de medisch technische dienst noemen, die mij in de afgelopen jaren vaak bij heeft gestaan met advies en ideeën. Vooral naar Jarno gaat mijn grote dank uit, die altijd geïnteresseerd was, zich betrokken voelde en meedacht over nieuwe werkwijzen, problemen en alarmen. Ik denk nog vaak terug aan de $\mathbf{3 0 0}$ liter tank die jij midden op de dialysezaal had gezet om daar al het uitgaande (stinkende) dialysaat in op te vangen, waarna we met een grote lepel roerden voordat we er monsters uit af konden nemen..... Of de geleidbaarheidsmetingen die jij voor mij uitvoerde op het laboratorium. Hartstikke bedankt voor al je hulp!

Dr. M Scheltinga wil ik speciaal bedanken voor zijn persoonlijke belangstelling. Beste Marc, fijn dat je altijd zo geïnteresseerd was in mijn onderzoek. Jouw onderzoekslust was voor mij altijd stimulerend en je bereidheid om te helpen verwarmend. Dankjewel daarvoor, hopelijk komen we samen nog tot interessante studies in de toekomst.

Dat ik tijdens mijn werkzaamheden als dialyseverpleegkundige de mogelijkheid heb gekregen om onderzoek te doen, en dat ik daarbij zo vaak als verantwoord mogelijk was werd onttrokken van de patiëntenzorg om dit promotietraject te mogen volbrengen, heb ik te danken aan de organisatie van het Máxima Medisch Centrum. Geweldig dat ik deze mogelijkheid heb gekregen in een voor het ziekenhuis niet altijd gemakkelijke periode. Dankjewel Frans Dreessen, jij hebt dit mede voor elkaar gekregen. Math Vankan, ook door jou kon ik mijn onderzoek voortzetten, en 
dankjewel Linda, Mariette, Irena en Mary voor het altijd proberen rekening te houden met me en mij zo regelmatig mogelijk uit te plannen van de patiëntenzorg.

Saskia Houterman, als manager van het wetenschapsbureau was je altijd geïnteresseerd en heb je mij regelmatig met raad en daad bijgestaan bij het interpreteren van onderzoeksresultaten. Daarnaast heb ik heel veel profijt gehad van de door jou gegeven statistiek- en SPSS-cursus. Dankjewel daarvoor.

Bij Carola van Pul kon ik altijd terecht met vragen over figuren, Excel spreadsheets en ingewikkelde formules. Dankjewel voor je tijd en inspanningen.

De klinische laboratoriumafdeling van het Máxima Medisch Centrum wil ik heel hartelijk bedanken voor de continue bereidwilligheid om mee te werken aan wetenschappelijk onderzoek. Ik kon altijd met vragen bij jullie terecht. Met name Gerard Coppens dank voor de fijne samenwerking bij de geleidbaarheids en natriumbepalingen en Anita Groos dank voor je administratieve werkzaamheden en up-to-date houden van de gegevens.

Tiny Wouters wil ik bedanken voor de mooie lay out van dit proefschrift. Fijn Tiny, dat je ondanks je drukke werkzaamheden nog tijd kon vrij maken om je te buigen over de finishing touch van mijn proefschrift, het ziet er weer geweldig uit.

Tijdens mijn onderzoek heb ik gebruik mogen maken van de database van NECOSAD. Dank jullie allen voor het kijkje dat ik mocht nemen in jullie professionele onderzoekssetting. Vooral Els Boeschoten, Friedo Dekker en Diana Grootendorst wil ik heel hartelijk bedanken voor de mogelijkheid om in een academisch ziekenhuis onderzoek te mogen doen. De hulp die ik daarbij van jullie heb gekregen is erg waardevol geweest voor mij.

En natuurlijk Magda van Loon. Lieve Magda, wat was het fijn regelmatig met jou van gedachten te wisselen over onderzoek doen, tegenslagen, opleidingen, frustraties en motivaties. Ik vond onze gesprekken heel waardevol, vooral bij jou thuis, met een heerlijk glaasje wijn was ik weer helemaal opgeladen als ik naar huis reed. Dankjewel voor je luisterend oor en adviezen (ook van Hein natuurlijk).

Dank wil ik uitspreken aan de hemodialysepatiënten van het Máxima Medisch Centrum die belangeloos hebben meegedaan aan de verschillende studies. Ik wil jullie met name bedanken voor de bereidwilligheid en het gestelde vertrouwen. Daarnaast wil ik ook nog een woord van dank richten aan de patiënten die altijd geïnteresseerd waren in de fase waarin ik was met mijn onderzoek. Vooral meneer Kouwenhoven, meneer Roes en meneer Ferrero toonden altijd oprechte belangstelling. Dat jullie 
ondanks jullie vaak zorgelijke gezondheidstoestand toch nog energie op konden brengen om naar mijn voortgang te vragen heeft mij erg geraakt.

Lieve René en Mirjam, bedankt dat jullie mij willen steunen als paranimfen. René, mijn steun en toeverlaat toen we op de afdelingen begonnen met ons onderzoek naar Hemocontrol. Mede door jouw enthousiasme en inzet heeft mijn onderzoeksdrive zich toen ontplooid. Mirjam, jij hebt altijd al bewezen dat je door gewoon hard te werken zonder te klagen alles kunt bereiken. Ik heb altijd veel bewondering gehad voor je doorzettingsvermogen, hopelijk ben je nu ook een beetje trots op je oudere zus. :)

Lieve vrienden, dank jullie wel voor jullie vriendschap en belangstelling de afgelopen jaren. Jullie waren en blijven altijd een welkome afwisseling.

Lieve Claas, mam en Ton, dit is het dan, het is eindelijk af. Dank jullie voor jullie niet aflatende warme belangstelling en steun. Claas, dank ook voor je geweldige relativeringsvermogen.

Lieve papa, dit proefschrift draag ik aan jou op. Wat vind ik het jammer dat je dit niet meer kan meemaken. Ik weet dat je ontzettend trots zou zijn geweest en er niet over uitgepraat zou raken. Een verpleegster die gaat promoveren, hoe bestaat het! 
Curriculum Vitae

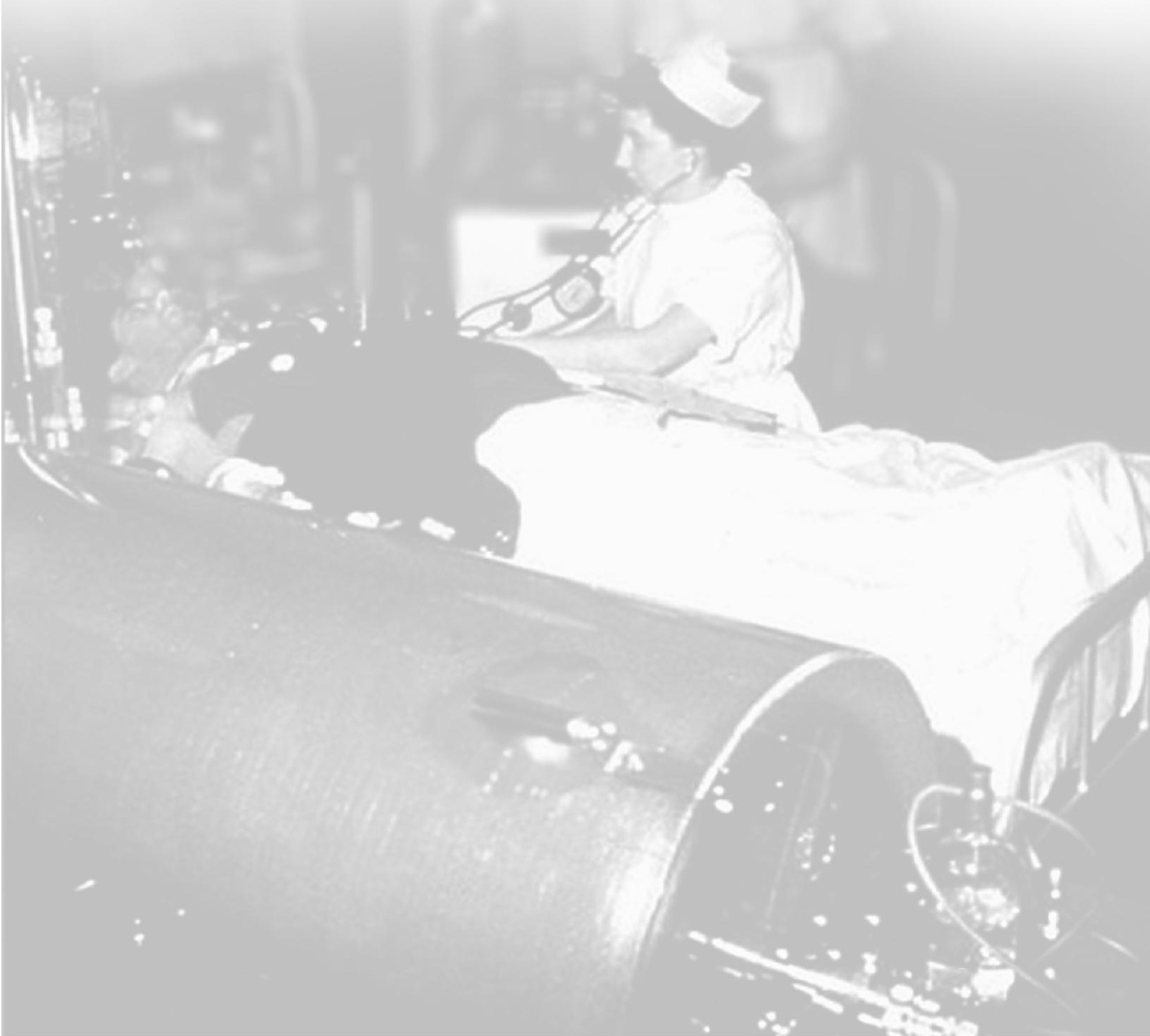




\section{Curriculum Vitae}

Karin Moret werd op 21 april 1968 geboren in Eindhoven. Zij voltooide in 1988 het atheneum aan het Bisschoppelijk College te Weert. In datzelfde jaar begon zij de inservice opleiding voor A-verpleegkundige van het (destijds nog) st Joseph Ziekenhuis in Eindhoven en rondde deze in 1992 af. Na een jaar als invalkracht op verschillende verpleegafdelingen van het Máxima Medisch Centrum in Veldhoven gewerkt te hebben, begon zij in 1993 op de dialyse afdeling, waar zij in 1994 de opleiding voor dialyseverpleegkundige afrondde. Vanaf 1999 hield zij zich daar onder andere bezig met onderzoek, waarvoor zij in 2000 de post-HBO opleiding researchcoördinator bij de Transfergroep in Rotterdam volgde. Daarnaast was zij tot 2004 werkzaam als kwaliteitsmedewerker en was zij bestuurslid van de L.V.D.T. Na een aantal jaren actief te zijn geweest als onderzoeksverpleegkundige voor diverse externe studies, startte zij in 2001 met eigen onderzoek in samenwerking met het Maastrichts Universitair Medisch Centrum. Gestart werd met onderzoek naar de meerwaarde van bloedvolume gestuurde ultrafiltratie met de dialysemachine (Hemocontrol). Daarna werd dit uitgebreid naar andere opties van deze machine. Een deel van dit onderzoek is beschreven in dit proefschrift. 
